\title{
AUTO-ETHNOGRAPHY
}

\section{IN A KABYLE LANDSCAPE}

By

\section{Si Belkacem TAIEB}

\author{
A thesis \\ submitted to the Victoria University of Wellington \\ in fulfillment of the requirements for the degree of \\ Doctor of Philosophy \\ in Education
}

Te Kura Maori, Faculty of Education,

Victoria University of Wellington, Wellington, New Zealand

November 2012 


\begin{abstract}
In this auto-ethnography, as an indigenous man in a Kabyle landscape, I take into account the relational experience that involves the development of a Kabyle identity. The indigenous cultures in North of Africa all come from the same family called the Imazighen (free men). Kabyle live in the North East of Algeria but there are other Imazighen living in the diaspora all over North Africa, from Morocco to Egypt, like Touaregs or Mozabites. My inquiry narrates my personal experience as a Kabyle man born of Kabyle parents in France. In this auto-ethnography I return to my father's village to understand and access my heritage. I hope that this narrative helps my readers to reflect on the effects of globalization on the transmission of indigenous cultures. I portray Algeria, a North African Muslim country in 2010. I draw on critical pedagogy, socio-constructivism and indigenous knowledge and experiences. Looking to Algeria with the perspective of an indigenous person, I explore the social organization in my village and the way values and relationship shape the traditional education of a Kabyle man. My experiences and research in my ancestral village show that the war Kabyle people have fought against France has not resulted in independence. Rather, in my case, decolonization made me twice stranger to myself as Kabyle in an Arabic dominated country but also as an immigrant in France, the old colonial country, and Canada. However, my spiritual and sacred heritage is still alive in me, shaped by both my own experiences and the teachings of other members of my culture, and I have expressed this heritage throughout this narrative.
\end{abstract}




\section{ACKNOWLEDGMENTS}

Taking the decision to write a $\mathrm{PhD}$ from a personal narrative has been a challenge in many ways. During this whole experience I have been supported, by my former Master's degree supervisor Dr. Ann Beer. Thank you.

At the same time I have been blessed with amazing support and incredible commitment from Professor Dr. Mary Maguire, my secondary supervisor from McGill University. Taking from her personal time she promised to support me along the way, until the end of my project, and she did. I would have never been able to accomplish this without her. Thank you.

Professor Dr. Wally Penetito is my first $\mathrm{PhD}$ supervisor. Wally's commitment to Indigenous education and culture is true and strong. Wally Penetito gave me his words that he would support this journey of cultural recovery. Wally has been true to his words and wonderful in understanding the purpose of my journey. His personal involvement with his community while working within academia is an exceptional example. I thank you Wally Penetito, for everything. Thank you for believing in me in the most challenging times of this experience.

My first day in Wellington was 7 years ago; I stepped into Te Herenga Waka Marae of Victoria University in Wellington. Te Ripowai Higgins, the head of the Marae, sent me to a Powhiri (welcoming) ceremony. I found family and friends in Te Herenga Waka Marae. Every time I would come back to the Island I would spend my first night in the Marae to reconnect with my family before engaging with the land. I cannot thank you enough, my whanau (family) 
for this nurturing home you shared with me. I am proud to have received your love and blessings.

The Kabyle Landscape has seen many life stories and has provided support to my community for thousands of years. Coming back to my village I was wondering what I would find. In every house I found hospitality and support. Even if talking about the past is a very difficult thing in Algeria and especially in Kabylia, I found in the Djur Djura Mountains a community honouring its heritage. In times of peace or of adversity Kabyle people stand there strong with open hearts. I have so much pride and a great respect for all the Berber people. Thank you for these lessons you taught me. You teach me pride, honour and respect, hospitality, humility. I found these values in my family, inherited from my parents, but I now connect to you all, my relatives. Thank you so much for the strength you give me.

I found in France a beautiful Kabyle and/or Berber Diaspora. Kabyles/Berbers taught me the diversity of our identity. While living as real participatory citizens in France, Kabyle showed me with their support during my inquiry how much we have to contribute to the world. Thank you very much for welcoming me in your homes, associations, cultural and social events. Thank you so much for presenting me to all these people and making my research possible in Algeria as well as in France.

But this whole cultural journey is also an administrative experience in New Zealand. The places that Victoria gave me, the interest that its staff found in my indigenous inquiry, have led me to receive a PhD research scholarship. I am most grateful for this. This whole project would have never come to life without this exceptional academic environment. 
I must thank especially Luanna Meyer, Dean of Research for the Faculty of Education, and Pania Te Maro, Head of Te Kura Maori, for allowing me to do this research under their Leadership. I am most grateful to Pine Southon for the coordination of my file within Te Kura Maori.

Finally I have a very special thank to Sheila Law, our postgraduate coordinator. Sheila Law has been wonderful; her door is always open for us students. She provides us with constructive advice and solutions, making this experience much less stressful for all of us. Sheila welcomed me into my office and answered my queries via email from the other side of the world. She showed flexibility and understanding throughout the time of my studies. Thank you very much, Sheila Law.

It is difficult to be exhaustive when it is time to acknowledge everyone involved in this inquiry. However I would like to extend my gratitude to each and every one of my friends all over the world from every culture, country and beliefs. You have all been part of this journey.

Blessings and love to all of you. 


\section{TABLE OF CONTENTS}

Abstract

Acknowledgements

Lexicon $\quad$ xvii

$\begin{array}{ll}\text { Prologue: My story begins } & 1\end{array}$

$\begin{array}{ll}\text { Introduction } & 1\end{array}$

Major reflective understandings and implications of my inquiry 4

I begin with the story in narrative episode 1

A Kabyle Indigenous Life Story Narrative Inquiry 6

$\begin{array}{lr}\text { After my mother's death } & 8\end{array}$

Entering indigenous land- Moving from Outsider to Insider of my

$\begin{array}{ll}\text { community } & 10\end{array}$

$\begin{array}{ll}\text { From being a deviant } & 10\end{array}$

The Canadian Native Friendship Centre in Edmonton $\quad 11$

$\begin{array}{ll}\text { My arrival on the land and in the culture } & 13\end{array}$

$\begin{array}{ll}\text { Self Awareness } & 14\end{array}$

The importance of bringing the self to the surface 15

Self-reflexivity means understanding stories from a researcher's perspective $\quad 18$ 
Horizontal development of Identity

Chapter One: Journey into my PhD inquiry

From Native American Education in Canada

To my Kabyle identity in my village

Narrative thread of my inquiry

The form and movement of this inquiry

Chapter Two: Theoretical framework

Introduction

In Western academia 
Like an eagle opening up his wings

Overcoming fragmentation and strengthening the self

Path of decolonization of the Berber intellectual in the work of auto-ethnography 62

A movement into the Heart of the inquiry

Part 1: Writing an Auto- ethnography 
Part 3: Positivist and post-positivist assumptions on qualitative research 
My father

My Ojibwe Father

My Maternal Grandfather

Getting into the circle

Shaping the partnership from culture

"You see, my son. Even the trees grow straight in France."

"A dog does not make cats"

A panel of Kabyle participants as part of my inquiry in France

"Awal dh'Awal", "Words said are words given"

Summary

Chapter 5: My experience in Kabylia

Introduction

Learning the communication protocol

Understanding the silence 
Introduction

Evangelist Church in Kabylia

Muslims

The Constantine Archive Library

A woman and government perspective on Kabyle women's rights in Algeria 208

Indigenous and Muslim feminism

Summary

The Kanun, Fire place of the house, speaks in the Qanun: Rules and 
Tamusni: From knowledge to Power

The fig tree symbol of life and fecundity

The Olive tree: Symbol of wisdom of the past generations

Reflexions

Chapter 8: The founder and foundation of my village

Introduction

Who was my Ancestor? (History, teachings and gifts)

Epistemology of the word Marabout in Kabylia

A Muslim leader from the Saquiet El Hamra (the Red source)

Baraka (supernatural gifts)

The gift of healing

The Marabout heritage under criticism 
General outline on Marabout identity

Politics of culture

Conclusion

Reference list 


\section{LIST OF NARRATIVES}

Narrative episode 1: Drawing the structural metaphor of the inquiry, June 2010. 5

Narrative episode 2: From being a deviant, October 2000

Narrative episode 3: Eating with Red Buffalo, November 2000

Narrative episode 4: Connecting with a Medicine Man, November 2002

Narrative episode 5: Arrival in Te Herenga Waka Marae in Poneke (Wellington, Aotearoa/New Zealand), April 2007

Narrative episode 6: Simply Home, summer 2009

Narrative episode 7: Looking at the village from the tree of my grandfather, summer 2009.

Narrative episode 8: The light shining in the middle of a tree that gives the branches the form of a circle.

Narrative episode 9: Like ants on a piece of sugar

Narrative episode 10: Algeria dropped us in the Sea

Narrative Episode 11: During the time of terrorism

Narrative episode 12: Using the drum to talk to the mountains

Narrative episode 13: My Father arrived in France to do his army training

Narrative episode 14: My adoption by an elder of the Ojibwa nation

Narrative episode 15: The sounds Pfeee reminds me of my grandfather 
Narrative episode 17: "In Algeria we entered into Capitalism with the mind of socialists".

Narrative episode 20: Threatened with aggressive tactics by the Algerian gendarmerie

Narrative episode 21: Followed in the streets of Tizi Ouzou

Narrative episode 22: Entertaining conversation with the younger generation.

Narrative episode 23: Conversation with the head of family on ownership of the land

Narrative episode 27: A perspective on my family experience from an external informant.

Narrative episode 28: Long term grief passed on to the children 
Narrative episode 32: Archives in Constantine.

Narrative episode 33: My mother is an example

Narrative episode 34: From the bottom of the Olive trees.

Narrative Episode 35: Harvesting the Olives.

Narrative Episode 36: The Imam and My Ancestor have different opinions

toward women's place in everyday life.

Narrative episode 37: My informant from the House of Culture tells me about Marabout

\section{LIST OF INTERVIEWS}

Interview 1: The Catholic Priest.

Interview 2: An official point of view

\section{LIST OF FIGURES}

Figure 1: Medicine Wheel from Grandfather William Commanda 


\section{LEXICON}

Agguram: Spiritual guide and healer.

Awhal: Word, verbal engagement.

Avidayel: Hand drum.

Baraka: Supra natural gifts.

Bou Nyia: Individual with excessive generosity

Marabout: Murrabit, Descendant of Holy Ancestor man, Saint.

Mawali: New convert to Islam.

Niff: Honour, Pride, self esteem, cultural strength.

Nyia: Generosity, humility, innocence, honesty.

Ouada: Donation.

Tafsa: Pregnant woman.

Tafsut: Spring

Tadjamait: Gathering house.

Tamusni: Knowledge, wisdom, (contemporaneous interpretation: contact and network).

Tiwizi: Act of sharing. 


\section{PROLOGUE:}

\section{MY STORY BEGINS}

\section{INTRODUCTION}

With this prologue I aim to describe how I have become aware of the effect oppression has had on me personally. Because of painful childhood experiences and the early break up of my family, I have spent my life in many places. I became, for a time, a nomad, with lengthy stays in Canada, in Quebec, Newfoundland, North West Territories and British Columbia, France and Algeria, and New Zealand, as well as travelling widely in South and East Asia. These nomadic periods in my life, times of stable residence in one place and the period of research in my ancestral village in Algeria, are all contributing factors in the development of this narrative of my Kabyle (Berber) Identity. I deliberately include narrative scenarios in non-linear patterns; these scenarios are cameos, like miniature paintings, that contribute to some part of my deepening understanding of Self and Spirit that this journey allowed. I believe this non-traditional style of writing is essential and unavoidable, in order to present the narrative with integrity and in a way that is respectful of indigenous methodologies, (Smith 1999). Rather than adopting a more reductionist approach characteristic of more positivistic objective inquiries (Denzin, 2010). I offer narratives and discussions of them that convey meanings that allow each reader to form impressions and draw conclusions based not only on my narrated experiences but also on their own world-view, identity and culture.

The support of indigenous communities helped me to engage in a cultural recovery and value my traditions, Kabyle language and Berber culture that I thought I had lost. I chose to do this inquiry in New Zealand because it was a "culture friendly" environment. Even though I do not quote Maori scholars in depth, being in an academic location and intellectual space where 
questions of indigenous cultural recovery and social justice are important helped me find a great support for my inquiry. I met with Dr. Wally Penetito, my supervisor, when he was in Montreal. He read my Master's degree thesis, Education as a healing process. We engaged in extended conversations about issues of culture, indigenous education and cultural revitalization. Much of what has happened in Maori education over the last 30 years he saw as a potential endorsement of what I was setting out to understand and achieve with my own indigenous people. Clearly, I was seeking out a kindred spirit and intellectual guidance.

At the same time, my renewed cultural strength was something I was able to develop with the help of Native people on the North American continent, I have found, in this narrative, the energy and motivation to share my experiences of cultural recovery. Narrative inquiry enables me to write and bridge the two worlds, both academic and indigenous, and bring them into a coherent sense of self (Geertz 1986). With my auto-ethnography of cultural recovery, I discover and share the channels that irrigate my Amazigh, "Free man", the name of the Indigenous group I am a part of, through identity. In the northeast of Algeria a part of the Amazigh people are also called the Kabyle, an Arabic word for tribal man. This dissertation is an Auto-ethnography in a Kabyle landscape, my story of cultural recovery of a Kabyle man in his natural environment. Ellis and Bochner (2011) explain that: "Auto-ethnography is an approach to research and writing that seeks to describe and systematically analyze (graphy) personal experience (auto) in order to understand cultural experience (ethno) (Ellis, 2004; Holman Jones, 2005)" (p.1). Ellis and Bochner (2011) present different sorts of ethnographies that are all related in my inquiry:

- "Indigenous/native ethnographies, for example, develop from colonized or economically subordinated people, and are used to address and disrupt power in research, particularly a (outside) researcher's right and authority to study (exotic) others... 
- Narrative ethnography refers to texts presented in the form of stories that incorporate the ethnographer's experiences into the ethnographic descriptions and analysis of others...

- Reflexive, dyadic interviews focus on the interactively produced meanings and emotional dynamics of the interview itself...

- Reflexive ethnographies document ways a researcher changes as a result of doing fieldwork...

- Layered accounts often focus on the author's experience alongside data, abstract analysis, and relevant literature...

- Community auto-ethnographies use the personal experience of researchers-in-collaboration to illustrate how a community manifests particular social/cultural issues (e.g., Toyosaki, Pensoneau-Conway, Wendt \& Leathers, 2009)...

- Co-constructed narratives illustrate the meanings of relational experiences, particularly how people collaboratively cope with the ambiguities, uncertainties, and contradictions of being friends, family, and/or intimate partners...

- Personal narratives are stories about authors who view themselves as the phenomenon and write evocative narratives specifically focused on their academic, research, and personal lives (e.g., Berry, 2007; Goodall, 2006; Poulos, 2008; Tillmann, 2009)” (p.5-6).

In my auto-ethnography, I share my experiences at the same time that I learn from other people's experience. My process of meaning making is reflexive. This process shows how I change and adapt as I learn in the field. My reflexive narrative gives a different focus on the journey that creates different layers of understandings where my personal experience is in relation with the experience of my community. My narrative illustrates my community socio- 
cultural knowledge. This Kabyle indigenous life story narrative is the academic inquiry that I present here.

\section{Major reflective understandings and implications of my inquiry}

I aim to write my Kabyle life story narrative in the sense that I explain hereafter and that I develop in chapter Three. As a Kabyle, I am experiencing a journey back to the place of origins of my family from my father's side. I write about my indigenous journey of cultural and social recovery. I undertook this journey to reconnect with my community and my culture. In the future, I aim to participate more in the life of my community. I also want to be able, after this journey, to take my responsibility in the heritage that will be left for me after my father passes. My narrative then is not a traditional ethnography of a Kabyle society as Bourdieu did, for example, in Esquisse d'un théorie de la pratique (Outline of a theory of practice, 1972). Rather I envision my text as an auto-ethnography of my cultural journey back to my Kabyle society. Thus, I highlight more of my route to the center of my village than the village. I present my ethnography with different lenses as Geertz explains:

"Confinement to experience-near concepts leaves an ethnographer awash in immediacies as well as entangled in vernacular. Confinement to experience-distant ones leaves him stranded in abstractions and smothered in jargon” (p.29).

Although this narrative is more a text written from the perspective of a man who grew up in a diaspora, a community with members of the same cultural origin regrouped outside of the country, than of a man born and raised in the village, I present my perspective as well as an insider because I am part of the culture I experience. 


\section{I begin with the story in narrative episode 1}

With this following narrative I aim to present my purpose and shape of the inquiry:

Narrative episode 1: Drawing the structural metaphor of the inquiry, June 2010

“Walking along a street in Sainte Anne de Bellevue, Quebec, my Master's Degree supervisor, Ann Beer, now retired from university teaching, and I were talking about the possible shape of my PhD dissertation. We considered motivation, methodology and other delights that we needed to order to complete the menu of a good evening in extraordinary early summer weather in April.

We decided to go to a Thai restaurant. In a cozy little house, there was one table left in the corner. It seemed to be the best place for us to sit. We stood there waiting for the waiter to clean up the table and then we moved closer. A woman came over with a big piece of paper that she put on the table to be our tablecloth... Ann and I looked at each other with a smile, touching the material and laughing again at what it was going to become: our working and drawing sheet. We asked the waiter and he said yes. I took out my pencils and, after ordering some wonderful food, Ann asked me: "Tell me, what is your PhD about? How can I help you?"

To answer Ann's question I drew a big tree on the table and explained that the purpose of my research was to reopen the channels within the body of the tree that isolated the Berber culture and diaspora from its roots. So began my journey into doctoral studies. 
I wanted to understand the context of Berber people in a dynamic movement of culture-recovery. Instead of drawing a two-dimensioned diagram that described a situation where people are isolated in their post-colonial locations, I thought about the geopolitical dimensions to return to an organic conception of culture. By organic I mean a genetic and spiritual heritage. I thought about the interconnectedness of things. Instead of staying at the borders and locating myself in a space of friction, I hoped to transcend political borders in my indigenous culture, re-establishing an idea of harmony rather than struggle. "I want to have a family of my own and I want to know how to raise my kids! I want to write about peace and harmony rather than colonization, assimilation and acculturation.”

Given the tensions in which indigenous people live today in an increasing climate of globalization, how can we who have indigenous families raise our children in indigenous cultures? Building a nest from peace and harmony, how can we overcome the colonizing situation, assimilation and acculturation present in the actual systems of education today?

\section{A Kabyle Indigenous Life Story Narrative Inquiry}

This inquiry is a Kabyle Indigenous Life Story Narrative Inquiry. My text is Kabyle from the beginning because I write as a Kabyle to understand from two main indigenous concepts that shape my inquiry: Niff and Nyia. Niff refers to the pride, sense of connection and honor that I show about my heritage. Nyia is the principle of respect, generosity and humility that I use in my everyday life. They are both developed in depth in the methodology but they are the life values that speak throughout this inquiry. I present them here to explain who I am when I start my journey. My father and my mother transmitted these values to me. Niff and Nyia are the expression of the education of these two strong individuals that I wish to honor here with this life journey. When one asks me where I was born, I respond, "In the womb of a 
Kabyle woman." This is where my journey as a Kabyle man started. This is also what makes this journey a Kabyle journey.

I view my task as an indigenous academic experience similar to that described by Linda Smith in Decolonizing methodologies (1999), because of its transformative, decolonizing, empowering agenda.

"The implications for indigenous research which have been derived from the imperatives inside the struggles of the 1970's seem to be clear and straightforward: the survival of peoples, cultures and languages; the struggle to become self-determining, the need to take back control of our destinies. The act of reclaiming, reformulating and reconstituting indigenous cultures and languages has required the mounting of an ambitious research program, one that is very strategic in its purpose and activities and relentless in its pursuit of social justice"(p.142)

My inquiry is indigenous because it is written by myself, an indigenous man, in order to recover my culture and honor my indigenous heritage. This inquiry is a personal life story narrative auto-ethnography as described by Ellis and Bochner (2011): "When researchers do auto-ethnography, they retrospectively and selectively write about epiphanies that stem from, or are made possible by, being part of a culture and/or by possessing a particular cultural identity" (p.3). Being a Kabyle is a key requirement for the writing of a Kabyle autoethnography, as I understand here. However, at the same time, I view my inquiry as an act of experiencing and/or being in/from the culture and also an act of sharing my culture with others. "Auto-ethnographers must not only use their methodological tools and research literature to analyze experience, but also must consider ways others may experience similar epiphanies; they must use personal experience to illustrate facets of cultural experience, and, in so doing, 
make characteristics of a culture familiar for insiders and outsiders" (Ellis and Bochner, 2011. p.6).

The acts of sharing can be divided in two different acts that are the telling that is the more reflective part of the experience and the showing that is less directed to the explanation of a subject matter but more to an holistic presentation of my experiences. Combining these two approaches enable me to position myself as an insider outsider and engage in selfreflectivity. ""Telling" is a writing strategy that works with "showing" in that it provides readers some distance from the events described so that they might think about the events in a more abstract way" (Ellis and Bochner 2011. p.5).

Auto-ethnography is an act of writing in relation to social contexts in a particular place and time; it is artistic and scientific. "Auto-ethnography, as method, attempts to disrupt the binary of science and Art. Auto-ethnographers believe research can be rigorous, theoretical, and analytical and emotional, therapeutic, and inclusive of personal and social phenomena" (Ellis and Bochner, 2011, p.16). My Kabyle indigenous narrative life story aims to create emancipating inquiry in the continuity of my family life's story that I undertake and share within western academia. My inquiry is written in relation with my family and my community.

\section{After my mother's death}

It is difficult to find where or when my auto-ethnography actually started. I have always been a Berber, a Kabyle. With this inquiry, am I discovering a culture or recovering it? I am learning about my culture, that is sure. I could have lost my culture, since I was raised in France in a context that was culturally threatening to my heritage. My mother's untimely departure from this life set in motion a journey of loss and discovery. I realized how important her presence was in our family. My mother passed away when I was twenty-three years old. 
When this happened, I realized that I had lost much more than I had even thought. She died after five years of fighting cancer at the age of forty-three. None of us were ready to let her go. As she used to say when she was alive: "When I die, you will understand what I am telling you today." I have now realized the importance of her words. She brought the culture into our home and kept the Kabyle community that is our family, together. She not only taught us how to be Berber or what it meant to be a family, she was also working all the time at home and as a full-time worker fighting in an environment totally hostile towards us. France, after the war of independence in 1962, was a very difficult place for new Algerian Nationals. Even if France had many wonderful aspects, the interrelationships between two peoples of different cultures and countries were limited. The French cultural education I experienced in France was organized like an uprooting and assimilationist school system where one needed to move away from the cultural background of one's origins. This distance was the only starting place for an exile to fulfil his or her duty of becoming French by embracing responsibilities as a foreign citizen in France. Even though I was born in France and even though my mother was a descendant of one of the heroes that freed France from the Nazi occupation of the Second World War, I was still called an immigrant and my mother did not have her place in French society.

Moving from an oppressive outside world to my interior world I found that reaching the place supposed to be providing me with inner peace was a rough transition. Our families, village of origins, language and culture became a battlefield for our new ambiguous selves. The children, who were kept silent within them, had to deal with a lot of acculturation too; they were witnesses to their own destruction at the same time that they were, as well, actors in the acquired and internalized destructive neo-colonial behaviors. Today, my family is scattered throughout different countries and family meetings are almost impossible. Thus, my 
need for healing was important and I realized it more when I came to North America and was exposed to the cultures of the Native American Nations of the Innu, the Cree, the Algonquin, the Ojibwe, the Cherokee and the Lakota. In September 1998, I entered Canada via Quebec and I realized that I had much to learn. My first challenge was to let go on the need to control the outcomes in my life and to engage in my learning experiences.

\section{ENTERING INDIGENOUS LAND - MOVING FROM OUTSIDER TO INSIDER OF MY COMMUNITY}

I now explain how I ended up connecting education and culture and how I entered the Innu Nation, an indigenous Nation in Northern Quebec. In these next episodes I connect the different narratives that brought me into this field of indigenous study and to the precise aims of this inquiry -- that is to understand the main goal of Indigenous Education and transform it to a personal inquiry about my cultural recovery. These three narrative episodes offer understandings of the social location I was in. They show what helped me end my cultural alienation and find a location that reconnected me to my deepest roots.

\section{From being a deviant}

Narrative 2 takes place in Edmonton, Alberta, in the Library of the Faculte Saint Jean where I did my Bachelor degree in Elementary Education.

Narrative Episode 2: From being a deviant, October 2000

"I was standing at the counter of the library trying to sort out some nebulous administrative issues when one of my new friends there came to me. He was standing there with a book in his hand and told me that I was different from the others-- outside 
of the norm. I was happy with that but as he kept on going with a description of my inappropriateness I started feeling uneasy. I was fine with the idea of being different but something was bothering me and I went closer to him and asked him what was wrong. He laughed and said: "You are a deviant. It is not me saying it but the dictionary." And he showed me the cover of the book he was reading. He saw I was upset and he said: "Don't worry, I am deviant too." We had a good laugh and started a chat. I said: "Do you want to go for a drink?" His face changed. I said: "What?" He said: "I don't drink." I said: "Of course you do." He said: "I mean alcohol." I said: "Me neither. I am Muslim. I didn't say we were going to drink alcohol. You can choose what is in your glass, no?" He looked at me with eyes wide open and said yes."

My friendship with him has led to many wonderful experiences and a rich journey into the Native American world. The next time we spent together, we went to the Native American Friendship Center in Edmonton.

\section{The Canadian Native Friendship Centre in Edmonton}

When I was in Alberta, I had no social time outside of my courses. The local culture was so foreign to me that I did not seem to find a way to connect to it. Luckily, my new friend brought me to a place where I found an echo of myself in the depth of the Native American culture in a Canadian Native Friendship Center in Edmonton, which I describe in narrative episode 3. 
The Innu man and I became good friends. We would walk together on the trail that surrounds the faculty. He would show me rabbit tracks; bring me to a beaver house and other things I would have probably not noticed without him. One day he invited me to a drum dance at the Canadian Native Friendship Centre and only asked me to bring tobacco. I said ok. We laughed a lot. He was joyful but never explained much about the place... He just brought me there and he left me do what I wanted. I would not do much because I was too timid but I never felt judged, looked at or something else. The ceremony started with a prayer on the first floor that we would not see and then the feast, sharing food. I remember going once, thinking that it was time to eat. An elder called Red Buffalo I think, was serving plates. I went there. I was sure that they were asking me to go there. I took a plate and a young man came to me asking me to wait. I was not sure about it but I was starving. The old man asked him to let me go. He asked my name, I told him, we shook hands and I went back to my place. I felt terrible after I realized that I had served myself at the same time as the elders but the old man was totally comfortable with that, I thought. So I guess it was the right thing to do. Or at least this is what I told myself but I excused myself to the elder and to my Innu friend who invited me there."

The time in Edmonton led me to go to Northern Quebec where I learned more about the traditional and contemporary lifestyle in the Innu Nation. The next narrative is about my arrival in the woods somewhere in Labrador where my friend would go to hunt geese every year. 
My arrival on the land and in the culture

With this next short narrative episode 4, I explain that access to native spirituality is made with a sincere offering of tobacco. I show how that spirituality happens any time and everywhere; it is not only a question of programmed and routine rituals, but at the same time it is not a closed circle but rather a place where all can find a space at any time as long as one respects the culture.

\section{Narrative episode 4: Connecting with a Medicine Man, November 2002}

"In November 2002, I was on Innu land in the reservation, with a bag of tobacco. I wanted to ask a medicine man for his help after I had a major burnout. I needed a place to rest and a home to rebuild my energy and to come back to life. I was walking in the streets of the reservation with my friend $D$. and he brought me to a place where a man was working on a house with two young men. He said: "Go give him your tobacco and tell him what you want." I entered and went to the man... He was looking at me surprised and I could feel the eyes of the other man in the room on me as well. I gave him tobacco and asked for his help. He took the tobacco and said: "I will have a prayer for you." Then he excused himself and went back to work after saying something to D... I said thank you and we left... This is how I met my good friend and a man that became like a father and definitely a spiritual teacher for me..."

This bag of tobacco brought me more than I could have expected. I owe those two men a lot for the strength and wisdom they gave me that helped me complete this journey I am sharing here. It provided me with the motivation for this Doctor of Philosophy inquiry based on the understanding of the issues of culture in education, the pride of being an indigenous 
person and the duty to protect and nurture it in forms, shapes and context appropriate to us. Feeling strong with my experience of Native American culture, I regained enough strength to rebuild my "Self" and begin to move towards the Algerian village of my Ancestor. Because this inquiry is a part of my journey of recovery, this inquiry brings me more self-awareness.

\section{SELF-AWARENESS}

Polanyi (1961) explains that: "Focal and subsidiary awareness are definitely not two degrees of attention but two kinds of attention given to the same particulars."_Knowing my "focal and subsidiary awareness", I mean different degrees and proximity of focus on the "Self," is important for the writing of a peaceful and balanced inner "home" (Attarian 2009).

"Understanding my story by actually retelling it made sense for me. The act of narrating, telling and re-telling the stories of our life experiences carries a deep interpretative stance. I believe that we consciously refine and redefine our identities through telling our stories, since it is an essential way of understanding ourselves, our actions and reactions within a historical and social context." (p.14)

Attarian presents the idea of writing home as the construction of the self. I give my interpretation of Attarian's conception of "home" more in detail chapter 3. Attarian (2009) explains that the act of writing is an act of creating as well. When one writes his dreams he is conceptualizing the walls of his house; it is then only a little step before being able to move in. Conceptualizing home in writing supports the reconstruction of my Self in this inquiry, a part of my "home". I am not aiming to reproduce a romantic perception of Kabyle identity but I instead write and create my Self in the narratives of a Kabyle, a man from the tribes of Algeria, in a globalizing world and contextualize my Self in my present. The house I refer to here is my "Self," a member of a culture, a village, a community and a society. Retelling the story of my 
cultural recovery I redefine my identity while bringing this silent self to the surface and focal awareness in Polanyi's sense.

\section{The importance of bringing the self to the surface}

In Polanyi's (1961) definition of focal and subsidiary awareness, he goes on to make the following point: In the case of visual attention we may speak of looking at the particulars in themselves, as distinct from seeing them while looking at the context of which they form part. But " seeing " and " looking at " cannot be generally used instead of subsidiary and focal noticing" (p. 463).

Looking at my experiences, I can see them as isolated and separated from each other by time differences. However, if I rewrite them back into the context of my life then I start to make sense of them and understand more about what Polanyi (1961) explains as the meaning of focal and subsidiary awareness

"We can formulate the difference in term of meaning. When we focus on a set of particulars uncomprehendingly, they are relatively meaningless, compared with their significance when noticed subsidiarily within the comprehensive entity to which they contribute. As a result we have two kinds of meaning: one exemplified by the particulars of a physiognomy, where the uncomprehended particulars are inside our body or at its surface, and what they mean extends into space outside" (p. 463).

I focus on an indigenous culture, the Kabyle culture into which I was born. My aim is to bring this culture to focal awareness for others and myself. Although my family is Kabyle, I was born and raised in France.

I want to contribute to the ongoing creation of knowledge in education and to add to the critique of certain received ideas about the relationship between education and identity. I 
want to retell my own story to fix in my heart, mind, and body and spirit the experiences that I have been gathering until now in my life and what I have learned of the past generations. However, I am anxious about the idea of opening a file that feels closed and sealed by an "Omerta", a rule of silence, motivated by the necessity to move forward without learning from the past. Because of all that my people have endured at the hands of colonizers, there is some kind of a conjectural and systemic tacit interdiction against opening our eyes to the real landscape and unfolding the ugly stories of the past. There are accounts of family wars, conflicts and other stories I experienced, witnessed or that I have been told, but that I was supposed to protect in silence, silence because of at least two main reasons. The first reason is the habit of not speaking about anything that is from back home, a habit that I fell into in France because of the reciprocal attitude of denial of the "different" that I grew up with. I just didn't find anybody to speak truth to. My parents didn't want to hear about France at home because they were silencing what we were becoming or could become in the undergoing process of assimilation and France didn't want to hear about us as we were only what it considered we should be. It was a reciprocal rejection or maybe a dog chasing its own tail. This political status quo caused enormous damage to me psychologically, emotionally and economically; reflecting on my sociopolitical context even today makes me aware of the choices we all have to make if we want to bring our own children into a better world.

The second reason for silencing this story is the possibility that it may provide materials for another invasion of our country. This silence could be due to the sacredness of our family life. We cover the family stories with silence, but we also silence what is related to rituals that connect us and help us to protect what is treasured and vulnerable from outsiders.

However, in 2012, I feel much different. I am opening the gates and I am bringing some fresh air into this secluded society. I know from my experience that travelling brings 
good energy to those fortunate enough to experience it. I know from my experience that I can be a Berber in the world and share who I am because there are always friendly, honest and welcoming places and people to connect with and who will share blessings in a reciprocal exchange. In narrative episode 5, I retell the story of my arrival in Victoria University in Wellington, New Zealand and how I entered in the Maori family of Te Herenga Waka Marae (the Maori sacred house).

Narrative episode 5: Arrival in Te Herenga Waka Marae in Poneke (Wellington, Aotearoa/New Zealand), April 2007

"This is what happened to me when I arrived at Te Herenga Waka Marae in Poneke (Wellington) for the first time. I stepped in and a friendly woman immediately asked me to go around the building to the main gate. I didn't know anything about Maori culture back then. At the other entrance, I found a group of three people from the USA waiting and I asked them what they were doing there. They said that we were going to be in a welcoming ceremony and that I had probably been asked to be a part of it. The women who asked me to leave was standing at the doorstep of the Marae and she started chanting. And we went together to the powhiri "welcome ceremony." It is only later that I discovered that she was the head of the Marae. The one we all call Whaea (Mum). It has been a few years now and we are still a whanau (family). I have found support, advice, and strength and love in that place and from the first moment I was welcomed as I am, a Kabyle man from the Djur Djura Mountains of Algeria."

This opportunity of wider dialogue motivated me to bring this work into existence, and to address the issues that we face as indigenous people who work for the preservation, 
celebration and onward movement of our living cultures. In February 2010, writing this dissertation, I felt very emotional and my back started to ache. I started dancing on my chair. I felt stressed and excited at the same time. The idea of breaking free was so energizing. I needed to bring this situation to an end. For so many years I had been trying to settle down and so many times. I had destroyed everything I was building, refusing to commit because of the idea of sacrificing this connection to my home land, the home I am made to go back to.

\section{Self-reflexivity means understanding stories from a researcher's perspective}

I discuss my place as a researcher and give a sense of the debate that is taking place in our mountains. I am present in Kabylia in different ways. I was a Kabyle man, a member of a family. Thus I experienced going up the mountain with two members of the family. Simultaneously, I was a helper and I helped them on their journey, selling goods in the remote villages of the mountains and I was also a student, learning the places, the social codes, cultural backgrounds and stories of the villages. It hit me how lucky I was to be a part of this land. I became conscious of the privilege of being Berber. The other way I am present as Kabylia is as this young man born in France who has come back to the village to do research for a western institution. During my work I needed to constantly be aware of this multidimensionality.

My awareness of this multiple positioning is made possible with the use of a reflective approach. Hourig Attarian (2009) explains, "Self reflexivity, a rigorous perception, is a key to explore researcher subjectivity. It is a process of meaning making that is focused on an understanding of a dynamic, transformative "becoming" rather than a static "being" (p.14). During my fieldwork I play with different lenses. I am in Algeria as a participant but also as an inquirer. Attarian (2009) explains: 
"This is a conscious methodological and epistemological decision in the design of both the form and the content of this text. I delve deep into the narratives to use them as a reflexive and interpretive tool to explore the historicity of the self and its actions, and to reflect on constructions of identity and agency"(p. 14).

In my text, I intend to help readers develop a reflective understanding drawn from their experience of my experience that I am describing and sharing. In the position of an insider and outsider I am sometimes the reader and sometimes the writer. This dual participating dimension of my work leads me to embed actions and experiences within my general narrative about my experience of cultural recovery in the story of my village as a place for analysis and interpretation. Reflecting on the experience allows me now to step aside from an emotional space to reflect upon my experiences as a researcher.

Narrative inquiry allows an external reader to develop proximity to the situation being narrated. This proximity hopefully can lead a reader to an insider perspective even though the reader has no background in Berber territory. I hope readers move into an emotional zone, gain familiarity that connects them to an organic understanding of the Berber culture, and become involved in the building of the Berber society with a deep personal understanding of Berber history. I hope that readers can become part of this society and gain a new perspective about Kabyle culture and the Algerian society. My vision and hope is to construct perspectives of the self and bring knowledge of the world the reader lives in. Global knowledge, in that sense, is not general and external to the individual but broad and rooted in the place of inquiry. By developing relationships with the Berber people and western academics, I am hoping nonacademic readers can develop an intimacy with us that will express this sense of welcoming that is inherent and so important in our tradition. 
I experienced my research in different ways. As an insider, I had to follow the rules of the land, but as an outsider I could step back and move away from the social pressures, a fact, that, in a social and political situation like Algeria, is very important to take into account. As described in this Chapter One of this dissertation, the global political and economic situation in Algeria is very difficult and complicated. So stepping back or even out of the country is a good way for me to look at my village, and the knowledge that emerged and to appreciate it, maybe, with greater potential. Of course I came back from this theoretical aside to say that this step is only possible as one develops a deep understanding and involvement in the society being studied. Understanding Berber society in an inquiry like this one is realizing that Berber identity is not contained within Algerian political borders. It is much more than that. Algeria only became on official country in 1962 while Berber Identity goes back at least 5000 years. Most Kabyle, however, claim to be Algerian since Algeria is the symbol of the victory against French colonial power. Yet, most Kabyle often refuse to be Arab when Algeria is described as an entirely Arab and Muslim country. Berbers are before everything Berbers. I aim to help readers and myself understand with this auto-ethnography.

So my place as a researcher and a participant is as a family member; I deal with issues common to many like my place in the family, for example. I am in the middle of a family of eight children from three different marriages. Twice, my father married women from his village and once, he married a woman from another village, my mother, whom he met in France. He divorced his first wife, then my mother passed away and he remarried again. These differences among the village origins of the wives are important because of the culture of the family. Different villages have different identities. I was dealing with two little republics with specific cultures, my father's village and my mother's village. In our culture, while we acknowledge the mother's family, officially a child always becomes a member of the 
father's village. I remember looking at my mother. We were in France with all the family sitting at the table. The main rule of the house was we all had to be sitting at the table together before anyone could eat. My mother was portioning out a chicken amongst us. She would give the wings to the girls and the legs to the boys but split the white meat between us all. Then my parents would eat the body. I was really surprised, but then she explained to me that this ritual meant that the girls were supposed to fly away from the nest when the boys were going to stay close to help the family. This example of sharing and the expression of our culture in France, a foreign country, I hope conveys a lot about my philosophy of this research, the duty and location of a Berber man as a participant and researcher in his own village and the cultural foundations of this inquiry.

Returning to the argument on the place of the researcher as a participant, I looked at the epistemological standpoint of my researcher/participant role. I reflect on a frame of mind that is appropriate not only to enter the village but also to stay there. It was important to be seen as someone who was part of the village and who was going to stay there. My objective of reconnecting to the tradition by being in the place of tradition means expressing my voice as an insider and building a narrative project that was made in agreement with the village and for the village. This positioning pushed me away from positivist claims of objectivity, as I would never be able to be free of influences from my upraising in other countries as well from the requirement of western academia. However, as previously stated, being an insider does not mean not being able to take an outsider perspective. It was in this movement of travelling forward and backward that I understood the depth of the vision of the researcher. The different layers of culture that shape the message's meanings, interpretations and actions and their interconnectedness give the body and soul of the narrative I start presenting here. 


\section{WRITING HOME FROM ABROAD: CANADA}

I am in Canada, engaged in the writing of a $\mathrm{PhD}$ with the support of two present supervisors; one is an incredibly bright, honest and visionary female academic from McGill University and the other is a wise, supportive Maori supervisor from Aotearoa in Victoria University of Wellington. I am dismembering myself and I feel totally stretched between the three or four geopolitical locations that this research is involving. Like in the old time when the Roman Empire was dislocating the limbs of the barbarians in their circus, I seem to be dislocating myself in an inquiry that brings me to four directions, and places: France, Algeria, Canada and Aotearoa. This feeling I am experiencing illustrates the pattern of self-destruction that seems to be common amongst Indigenous people. Often we indigenous people have to leave our cultures, lands and family to go and get what we need for our survival and we end up being torn apart from wanting to go back home but needing to stay away for socioeconomic reasons. This at least is what one reader might see from an ethnocentric idea of education. From an ethnocentric perspective of education this would be an insane and impossible or suicidal project to work on but from an indigenous perspective this is my one and unique self. With this narrative, I am not losing any limbs, and this socio-cultural representation in which I am being an actor is an inquiry that allows knowledge to travel through time and space like spirits that hold together memories.

Spirits connect me with the different layers of my "self" in the multiple dimensions I am in. I am not being torn apart but instead I make sense of my diversity within a narrative. I feel privileged that, as an indigenous man, I can still express a free Berber spirit. The movement of my inquiry springs from the roots of the tree that connects me back to the land of my ancestors and takes shape back home in the village that I will describe here. My inquiry flows within the trunk, the valley where all the rivers of our different mountains bring their 
pure water to the first gatherings and exchanges of the selves. Then it travels all the way to the fruitful branches of those rivers that carry the rich alluvia of our culture; I go all the way to the ocean that is so terrifying for the people who decided to change into fertile sediment on the side of the streams but who stay connected to the millions of leaves and the wonderful fruits that bring their full potential to the land that they enriched with the sweet and rich culture that they hold. I write that journey to explain the place of my indigenous culture in this world today.

\section{HORIZONTAL DEVELOPMENT OF IDENTITY}

I went to Algeria with the goal of rebuilding a family tree and finding the connection between the different missing parts. With this first structural approach, I looked at ways to draw the idea of chronological linearity of the generations in order to recreate the picture of my family heritage. I understood my mistake when I went to a community meeting in a village in the Djur Djura. I presented my theory to two members of the association and of course they challenged me. The first one asked me: "If we are a tree, how can we move all around the world like we do?" The second one answered: "Because a little bird comes and swallows this olive to bring it all the way to its places of migration and then gets rid of the seed at the end of its natural process, the tree grows up on another land but stays a part of that first tree."

More questions came to me and I asked: "Is that tree still Berber? Is that new tree the man individually moving or is the bird the actual metaphor of the migrant person? What is actually travelling in/with the bird?" We realized that it was the culture. The person, the bird or the seed all carry something that is our culture. 
This life that we carry around the world connects us to our ancestors and grounds us to the planet. The older the roots, the larger the tree and the more life force it carries. Then the metaphor for culture is no more the tree itself but more the water that runs into it and that gives it its density and strength. This water is the life force of our culture. For Kabyle people:

“...Human existence was not separate from the natural world, since it followed the same cyclical patterns. It was believed to emanate from the same invisible source that belonged to the eternal cycle of death and rebirth. Kabyle spirituality united the physical world of their surrounding with the invisible non-concrete world, which for them, was just as real..." (Makilam, 2007, p. 231)

I explain here how water takes a special place in my culture. Understanding who is in charge of carrying the water, I will also give a better understanding about the actual irrigation systems, and connections that shape my family tree and village into what it is today. This is in line with the belief that: "The human is a passenger on earth and his duty is to prolong the cycle of life he carries within him by transmitting it to his children. Ancestor-worship is linked to family belief and thus heavily dependent on the cult of maternity" (Makilam, 2007, p.231).

I make sense of who I am today in the contexts of where I evolved. These different contexts are my starting point for the writing of the journey back home and their influence on my decision to engage in this inquiry will be explained. In next chapter I present the narrative structure and shape of my inquiry. 


\section{CHAPTER ONE:}

\section{JOURNEY INTO MY PHD INQUIRY}

In this chapter, I explain how I came to design the shape of my inquiry starting with my motivation to write my auto-ethnography of a Kabyle cultural recovery. I present the organization and an overview of the content of my dissertation.

\section{CONSTRUCTING THE JOURNEY INTO MY PHD STUDY}

\section{From Native American Education in Canada}

I was trained to be a teacher in Edmonton, Alberta, Canada. I worked in Francophone schools outside of Quebec, where I taught French to English speaking children in immersion classes. I returned to Quebec to teach in the outskirts of Montreal in a non-privileged, economically deprived location, in Montreal Nord. I was hired by a band council in the North of Quebec and taught in native schools. That educational experience contributed to my own schooling experience in France. My experience of the education systems in these different locations and especially in the Innu schools brought to an end my wish to leave the field. It had nothing to do with the people but more with the educational agenda for native students. I took a year off to travel in Asia. I wanted to leave for one year but the little money I saved teaching allowed me only a six-month trip with a very limited budget per month. I had to bargain for every piece of bread during all my trips; luckily it was culturally appropriate to do so there. 
That journey was probably one of my most important life experiences. I decided to let go of my need to control my future but also my insecurity toward money and career. I was just going to enjoy the hazards and blessings of the road, meeting new people, eating new types of food and probably, before everything, taking time to distance myself from my previous experiences. I then decided to do a Master's degree in education at McGill University. After all the experience I had as a teacher, I needed to find a way to protect native culture from assimilation. I wanted to support the work of the elders and the families working hard to protect their heritage. First Nation elders in Canada told me to take care of myself as a piece of the heritage of this world and work to help my own people. I felt rejected at first but then I understood. The medicine wheel is what most of the North American First Nations recognize as the mental, spiritual, emotional, and physical interconnected and holistic system of reference. The medicine wheel places us all in an interconnected system of sharing where all of us can be ourselves and bring our full participation to the world.

I learned about the medicine wheel from Grand-father William Commanda, the spiritual chief of the Algonquin nation. Grandfather William was the teacher of the Innu family I lived with, in the North of Quebec. Grandfather William Commanda represents the medicine wheel in this figure 


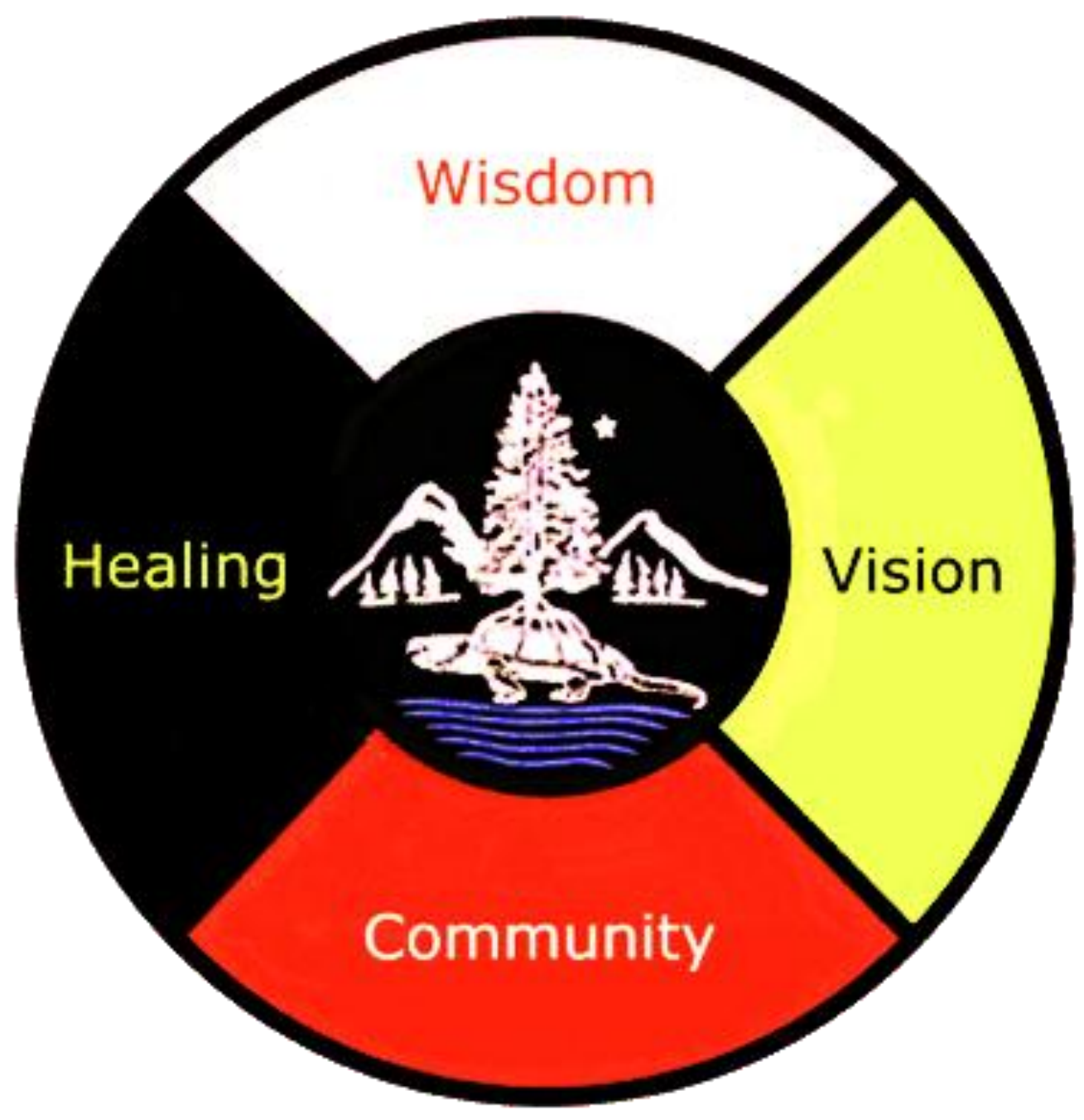

(Retrieved from http://www.angelfire.com/ns/circleofallnations/page2.html)

The teachings of the medicine wheel that we see here, Healing, Community, Wisdom and Vision, represent the 4 directions as well: East, South, West and North. From each of our cultural locations of the world, we can bring healing to the planet. It is mainly with that advice that I decided to seriously work on an auto-ethnography called Education as a Healing process. My Master's degree thesis was probably one of the most difficult tasks I had to accomplish. My personal education, looked at from the eyes of an indigenous man, was an ugly story of assimilation and enculturation surrounded by the sweet coat of the so-called positive intentions to develop Berber people as this education integrated us into the so-called beautiful and welcoming French society! 


\section{To my Kabyle identity in my village}

Every Northern hemispher's summer, I go back to Algeria to my village. I just enjoy the simplicity of a cultural retreat. I take care of my house, meet my family and walk up the mountain to go to my ancestor's grave and have a drink at one of our springs. The village is a geographic construction developed around the physical needs of the body with gardens and rivers, but the spirit of the people today travels far away from that place. I am explaining that the spirit is stronger than the physical arrangement of the space and reaches each and every one of the descendants of the Ancestor wherever we are in the world. The community used to meet in the village on regular basis but often nowadays a trustee carries the messages from one family to another one. Often today, in the village, decisions are made with no consensus and problems arise that are not being dealt with because of lack of interest or communication. Most of the people have left the village and just a few still care about the place. The meetings in Tadjmaith (Tadjmait is a building where the man of the village gather) are being replaced by the sermons in the mosque on Friday; a sermon is given by an Imam hired by a government who still denies us our culture. It is not the people speaking anymore, but the government dictating its agenda. An Arab population of Islamic believers is replacing the Berber villagerepublics, an Islam shaped more by the religious and political tensions in the world than the actual culture of the people. Ait Menguelet sings: "Avlid I tsou meden" (the forgotten road). In that song, he says that on the trails that people don't take anymore, the grass keeps growing. Quickly the road is disappearing and people are getting lost. Our villages are becoming lost memories.

Situated between the pressures for a secular state modelled after France, the other Western images of success and an Arab religious state with an Islamic image that looks like Saudi Arabia, Berbers feel their desire for cultural expression torn apart, shaped and reshaped. 
Like trees from which we remove the bark and fruits, our culture sees its men going away. This leaves the trunk exposed to the air and the circle interrupted. The men leave their families to look for work elsewhere.

The western world pulls us in its direction of capitalism and the Algerian government pulls us toward an assimilation of Berbers into an Arabic Islamic state. During the independence war, the French army took the women out of their houses, undressed them in front of the village and took pictures of them naked to dishonour the whole family. Today, the constant call for more human resources from other countries undresses our culture from its shields, exposing our land, and culture to any abuse. The capitalist system of production takes away the protective bark of our culture and abuses its heart in a never-ending system of consumerism. To make more money, the population of the village migrated to foreign countries and abandoned the crop sharing and a culture of local subsistence for more profit and consumerist power. I had a conversation with one of my informant regarding the teeth of his daughter and I said that she might be lacking certain vitamins. He has a grocery shops with vegetable and fruits, which is why I was surprised. He said the fruit in the shop were for selling and he was making so little money that he and his family could not eat his products.

During Tafsut Imazighen in 1980 (Berber spring), there were strikes in Kabylia and in the city of Algiers. The objectives were to ask the government for cultural equity for the Berber people and the recognition of Tamazight, the Berber language. The first consequence was the arrest of twenty-four Berber men and the repression of Berber cultural initiatives organized by Berber cultural associations in Universities.

The pressures against the Berber youth remained important and on April 18, 2001, a young Kabyle Massinissa Guermah was killed inside of the gendarmerie of Beni Douala, a Kabyle town not far from my village. This marked the beginning of riots opposing the Kabyle 
movement against the security services. 132 Berbers were killed and 5000 were injured. The country was headed for devastation and the government, after sending the gendarmerie to shoot at the protesters, decided to take calming measures.

Tamazight has been implemented in the education curriculum and is now a national language. A commissariat of Amazighity has been created in Algeria.

\section{Travelling in direction of the cherry tree in front of my grandfather's house}

Every time I return home, I enjoy going back to the mountain to drink from the same source next to my village.

\section{Narrative episode 6: Simply home, summer 2009}

"I sat in the shade and had a little sleep at the bottom of the mountain. The Shepherds used to bring their sheep there for the night and they found refuge in one of those little holes left by the erosion of the limestone. After the sleep I met my uncle in his little house, an old, one room house where he kept some of the food he needed for the supply of the small number of the villagers left in the area."

The village used to be shared by four clans all coming from descendants of one of the four sons of the ancestor. Located on the Djur Djura (Atlas) Mountains of Algeria, my village is a Marabout village, like many other villages, which means that it was founded by a Marabout, a Saint. Saints can be man or woman but in my case it is a man. The descendants of the Saints are also called Marabout. To respect the anonymity of my participants, again I withhold the name of the village and the names of the different children and clan descending 
from the Ancestor even though naming them would not be a problem for our safety. Close to the top of the mountain, the village is hidden between the fig trees and the mountains.

During my fieldwork I would take a ride up the mountain with my informant, Malick (Pseudonym). He would stop on the way up and I would keep going by the trail to my village. I usually went back with my informant who brought me up all the way to the first stop of his selling journey; I then walked up to the village with his father, a man probably seventy years old.

My informant knows the history of this mountain and knows what games are being played and have to be played there in order to survive. Sometimes, it felt like I was talking to a wolf and sometimes to a sheep. In both cases, I learned a lot and never felt in danger. He showed me the plants and places telling me all their names in Kabyle and their use in our culture. He had lots of very interesting and amusing stories attached to some of them. Usually he decided from which way we would enter the village. There is the official road, the traditional path and the little trails left by the shepherds and their sheep. We sometimes went straight to the mountains and enjoyed refreshing water and some other times; we would go to the grave of the Ancestor directly to leave an Ouada, a donation. I usually stayed there alone for a bit and then joined my uncle in the cemetery where we would sit and exchange a few words.

Inside the building where my Ancestor is buried, there were a lot of books and information left behind by our Ancestor, but the French army destroyed them during the occupation. The books were supposed to tell the story of his journey from Sequya el Hamara, a city in the Sahara desert, as well as probably some ethnographical work on our village and some Muslim treaties. 
After a little time my informant would go to my grandfather's house. It was a little house built by my father for his father when he was a child. Very basic, it had two floors and two rooms. There were two doors. One door was facing a little area where we could see the remains of a stable and the other door in the back leads out to the mountain. The downstairs room had one small window, probably for security purposes. It used to be the kitchen. It had a little hole in the floor called Kanoun (fire place). The walls were still painted the colour my aunt painted them a long time ago. We have a cherry tree just in front of my grandfather's house. That tree turned into a kind of a symbol for me as I describe in narrative 7.

Narrative episode 7: Looking at the village from the tree of my grandfather, summer 2009

"I sat outside and in the actual front of the house. There was a little bench made out of rocks. There was very little land between the house and the ditch. But on the slope, going down to an improvised parking lot, my grandfather's cherry tree stood. I imagined that it must have been a great pleasure sitting under that tree during the warm season. That tree had looked pretty much dead for a while. For a long time people thought it was actually dead but then a little branch started to come out the last couple of years and started growing again. It has not given any fruit yet but I liked seeing the tree as getting back to being stronger and stronger. It was a funny thing that this is happening because that branch seems to be giving life back to the whole tree. I became worried about what could happen to that only branch."

Supporting that tree in its growth became the rationale and a key metaphor for my inquiry. The tree expressed the roots that sustain my cultural heritage. It also represented the 
relationships between the people of the diaspora and their villages. Kabyle are spread all over the world. However, one commonality with all the people of my village is the attachment to our land and our cultural heritage. Different identities politics blurred the heritage but still claimed our place in the village via our sacred explain meaning of sacred heritage. The word sacred means to be treated with respect but it does not mean secret.

\section{SHAPING MY INQUIRY}

\section{Narrative thread of my inquiry}

In Chapter One, I present the location, rational, shape, energy and movement of my personal narrative. As I expressed earlier in the prologue, we follow the rivers of culture in the veins of the Berber tree of knowledge and/or experience to tell the journey as a reflection on Berber education today in relation to the context in which it happens.

In Chapter Two, I present the theoretical framework that frames my narrative experience and some of the encounters I had and continue to have with scholars like Fanon (1963, 1986), Bourdieu (1961, 1972, 1978), Linda T. Smith (1999), Battiste (2009), Grande (1964); also with Berber writers like Mammeri (1984, 1990, 1996). In this chapter, I show how these people helped me to find a place in academia and helped me understand the experience of Berber/indigenous people in education today.

In Chapter Three, I describe my methodology and methods: my ontological and epistemological frame for constructing a culturally appropriate narrative in a Kabyle Marabout community. I explain the methods I used to conduct my inquiry. I aim to write a Kabyle indigenous life story narrative. I examine what I learned from my experiences back home in a story form after having informal conversations with informants. 
In Chapter Four I describe the dynamics of my inquiry moving form from the outside to the inside of the fieldwork. I present a part of my genealogy with my father, my Ojibwe adoptive father and my grandfathers. I explain my connection to Kabyle and Indigenous identity genealogy to explain my Mana, the Maori word for authority and/or legitimacy, in this cultural inquiry. Then I present three important informants who are members of Berber associations in France and who understand the politics of Algeria.

In Chapter Five, I am located in Kabylia. In Tizi Ouzou, one of the biggest cities in the Kabyle province. I describe the ambiance that animates everyday's' life from my experience. I introduce that city's House of Culture. Once I have passed the gates of anonymity on the streets of the big city and made my transition to the Kabyle culture via the House of Culture, I get closer to the Inner circle of the village that enable me to develop a partnership with my community in the field. I share the sounds, stories and personal narratives gathered and recorded in my journal. These sounds are shaped by communication with my informants. I show the complexity of the debate about Kabyle culture. I conclude with a conversation with a 20-year-old Kabyle man. I continue to listen in to the Berbers' messages today, looking more closely at the different influences that I see are shaping the Kabyle mental landscape: religious discourse with the Evangelists Church, Catholic Church, the Muslim religion. I conclude with a conversation on women rights.

In Chapter Seven, I describe the organization of the Kabyle traditional society. Understanding the traditional society while reflecting on the modern one helps me make sense of the ambiguity of the Algerian society evoked before. I try to make sense of my previous social experiences. This reflection provides me with a vision that highlights how my indigenous culture organizes itself around the heart of our culture, the kanun name for the fireplace of the house, kept together in a value system called qanoun 
In Chapter Eight, I discuss the organization of my community today from its history but also using Gellner's theory of segmentarity. The organization is visible when I replace the values represented with the grave on the Ancestor and located at the core of the village. Going to the heart of the community in this Chapter, I become aware of the socio-cultural organic and spiritual essence of my identity. I describe how I make a step forward to learn more about the Marabout people. This work designed as a parallel experience in academia and Berber culture has today the possibility to root me back in my village. It was challenging to find the right methodology. The cultural difference between university and Kabyle society as well as the fact that I was raised in France, made it complicated to find the right tools for the inquiry as I explained in the Methodology and ethics discussion.

Moving away from the place of my birth does not mean cutting connections with the place of birth but extending the reach to reconnect with an earthly identity leaving behind conflicting ideas of property over a land from which we are only the keepers. In the last chapter, Chapter Eight, I revisit indigenous social organization. I describe how the previous metaphor of the indigenous tree illustrates a human ecological integrity, the start of a natural metaphor. In this last chapter, I try to make sense of all the fragments collected in the field, understanding the interconnectedness between people and explaining the social behaviours today to recompose my narrative of my re-creation of the village.

\section{The form and movement of this inquiry}

I reiterate intentionally that the purpose of my study is to contribute to the field of indigenous education as I make sense of all my experiences in the recovery of my personal story as a Kabyle man. The image of a Kabyle coherent society today is still best represented by the image of a tree. 
The Berber tree keeps growing in a culture that never abandoned its kind wherever they are in the world. After two generations, the children born in the village or the ones born in lands of immigration are still the children of the village, unified in a metaphor of the relationship between the grandfather and the land. The children of the expatriate redevelop roots that they extend again. The roots are reconnecting the trunk to the branches and to the heart of the culture illustrating our never-ending call for life. Fragile, but full of life, they support the weight, pressures and windstorms that menace to pull the tree down. They bridge the past and present of our culture. If we were a village-republic in the past, today we have become an individual republic carrying seeds of culture that we keep undeveloped and leave silent for many reasons that we will look upon in this inquiry.

Throughout this whole journey, a wonderful experience, I have reflected on the voices of Kabyle people and my other participants and learned the teachings. My metaphor for the structure of the whole inquiry is the spiral (Attarian, 2009). It can be best illustrated by the following story in narrative episode 8. Often my Innu friend, whom I met in Alberta, comes from somewhere in the world and appears in my life carrying all kind of reflections and images that he expresses through his Innu culture. That day he came over to me with a wonderful teaching again.

Narrative episode 8: The light shining in the middle of a tree that gives the branches the form of a circle

"My Innu friend D. and I had couscous in a Berber restaurant. I had invited him there on a previous occasion. The owner recognized him and said. "Oh, we have a great visit from our brothers from the North!" With his arms wide open he said: "Welcome in your home!" He was playing with the concepts of land and indigenous identity, a 
quick reminder of his insider understanding of the native situation in Canada. Later, we were walking in the Park Jeanne Mance in Montreal. We stopped in front of a tree and D. said: "Look. What do you see?" I looked at the branches going in all directions and he said: "Come here." He asked me to face the street lights and said: "If you look up at a tree, putting a light at the back you will see branches forming circles around the light." I was amazed to see that he was right. We tried with many different trees playing like kids with what seemed like a miracle. In the daylight, those branches seemed to develop in complete disorder but in the night they form a circle around the light."

Designed as a spiral (Attarian, 2009), the shape of the inquiry shows that we are moving around the heart of the village and move toward its centre. It is organized the same way as I envision society that I explain later in this dissertation. It is a spiral that moves up and down from the place of values, the grave of the Ancestor that unifies our village with a common heritage, to the outside world. It shows that we address the world from our value system, the root of our society, but we enrich our society with the interactions with the outside world. The inquiry moves in and out of the story of the founder of the village. I hope that the movement gives the pulse and rhythm of the story and the direction this inquiry is taking. Understanding the society's movement means for me that I move to a better understanding of the story of the village. I reintegrate my heritage without excluding "me" from the actual story of the culture. I believe I have built a coherent and healthy "self" from my cultural heritage in its extended society. This dissertation is written in the direction of the core of my village. Every chapter brings me a step closer to the story of my Ancestor. As I move closer to my Ancestor I rebuild my whole landscape as a Marabout Kabyle man today. However, before 
moving to the third chapter, my methodology chapter, and describing my preparation for the fieldwork and analysis, it is essential to situate these arguments within a theoretical framework. Chapter Two is therefore a detailed description of my reading and relationship with the theories and theorists that inform my understanding of the Berber situation. This part is a theoretical journey into academia. 


\section{CHAPTER TWO:}

\section{THEORETICAL FRAMEWORK}

\section{INTRODUCTION}

The task of writing a theoretical framework for this inquiry was a journey into academia that brought me back to my cultural heritage. I begin this chapter in Western Academia and first reflect on the politics of writing a theoretical framework, and then move towards my expression of an indigenous inquiry. With my sensitivity to the suppression of knowledge, I provide a reflection on my positioning as a researcher. My upbringing in France pushed me to first look into the concept of diaspora. Reflecting on diaspora brought me to the consideration of displacement that I connect to the concept of fragmentation. Once I understood both displacement and fragmentation I was able to move to the explanation of my reasons for selecting a relational approach in this inquiry. This theoretical framework gave me the theoretical foundations for the building of my methodology and methods.

\section{IN WESTERN ACADEMIA}

\section{The politics of writing a theoretical framework}

My first goal seemed to be self-evident: it was to go to Algeria and to actually be with the people. However, this was easier said than done. The path back home was no longer an obvious one. My memory of my father was blurred for many reasons; my mother had passed on to the other world many years ago now. The different political and cultural systems involved in such a trip required that I seek out the support of academia, scholars who used an 
ethnographic approach. I looked in detail at Samia Costandi's (2007) and Hourig Attarian's (2009) work, as well as others' ethnographies.

I was aware that my research could become more an adaptation of the research according to the literature available, than a real ethnography of a Berber culture today. Therefore, I looked at theories through the lenses of my experience in actually "doing" the research. I was conscious of the politics of academia and the movement and activities of the market of knowledge as a commodity. Understanding the research market meant understanding the location of the research and being able to anticipate how the knowledge could be used. Keeping the discourse related to Berber culture, I constructed my inquiry from the work of academics that had deconstructed the systems of control and colonial exploitation, Freire (1987), L. Smith (1999), Grande (1964), Fanon (1963). Then, once I felt the tensions were removed, I expressed the Berber culture in a story that I hope finds its anchor within academia and the field of Indigenous research. The story I am relating is not only physically located on Berber land but also in places that are inhabited by other indigenous people. One issue was then to find a way to talk about Berber culture and other indigenous cultures in a framework that was respectful, harmonious and nurturing for all.

\section{Moving away from the reductionist approach}

The process of writing a theoretical framework was an exercise that, somehow, pushed me to align with what has been said. I did not shake the conventions too much. I spent my time not only reading papers but also extracting parts of them that served my purpose. Academic papers, at least many of the ones I came across, were mainly focused on showing the conceptualized idea of life in a linear and fragmented way. I often found it difficult to understand history when it was presented as a succession of events placed in a linear notion of time. For example, according to history, French aristocracy disappeared after the beheading of 
King Louis XVI. However, when I look at French society today, I still find elitist behavior, aristocrats and privileges. While looking at the work of Levi Strauss I find, in France, an archive of relics and anthropological "data" and material collected from the field and kept in Paris museums. Academia feels like a scary museum where societies have been put on shelves during "the enlightened period;" the aborted embryos of social emancipating projects that have been put in glass containers.

\section{FOR INDIGENOUS ACADEMIA}

\section{Indigenous methodology: A theoretical framework for an Indigenous man}

Fortunately academia is changing, and this is what we are going to see here. I looked at the actual experience of writing a theoretical framework and drew from the insights of theorists like Foucault (1980, 1994), Said $(2000,2002)$ and Fanon (1967, 1986). I also connected to the field of Indigenous and Kabyle perspectives in sociology and education through the work of Bourdieu \& Sayad (1980), and quoted as well in Bourdieu (1964), Pierre Bourdieu (1978, 1980), Makilam (2000), Mammeri (1990), and Melhenni (2004). These authors helped me in this journey. With their research, they showed me the path for my cultural recovery.

\section{Framing the theories including history and future}

I needed to connect literary and scholarly worlds together: one relating to indigenous identity and the other relating to the traditional academic literature on immigration. It was important to look at the internal and external motivations that have pushed, and continue to push, Berber people to leave their place of origin, to understand how they appreciate their places of relocation, but also how Berbers relate to each other and the world today. Thus, I 
needed to work in the different times and spaces of Berber life. I could argue, like Fanon, that the divisions today could have found their source in the colonization and neo-colonization periods in Algeria and have expressed themselves in the fragmented society created during the decolonization period in the middle of the 1900 until today.

In the past, France was at the origin of the Berber migration from Algeria. After the Second World War, France was rebuilding itself and needed people to work in its factories. To satisfy its economic needs, France was scavenging its colonies to build a labor force. Entire villages were deported to work in France and in the other colonies, just as the Berber people from Algeria were deported to New Caledonia in the 1870s. Today immigration is different. The tensions in Algeria between Arabs, Kabyles, Muslim fundamentalists and secular people, have added to tribal tensions. Before our independence in 1962, expatriation was motivated by social solidarities. The expatriate was leaving to support his (they were only men in the beginning) family in the village. The departure was a result of the pressure from the colonial power. Today it is justified because of the tensions presented before. These tensions are a result of the internalized colonial fragmenting pressures. Initially the colonial origins of displacement generated a counter movement that brought people together into diaspora in reaction to the oppressor. Now, it seems, individual Berbers avoid association with their kind. It feels as if all of us are running away from each other to avoid self-destruction. However, the connection to the motherland, our culture and our identity are still there. The theories I examine here follow the movement of the people as well as the culture.

I constructed this theoretical framework by following the movement between the different theories that brought me to this inquiry and guided me through it. To bring clarity to the Western reader, I present the theoretical framework in a linear way. 
I have divided the theoretical background into four main parts. I present here the work of each of the academics previously listed in this chapter, who provided material to help me understand and prepare me for my journey back home, those academics who contributed to the global discourse around this auto-ethnographic journey. Like on those numerous times when I packed my bags to leave on a journey, I had to choose the appropriate items to take. However, I already knew that I would probably be taking too much and that most of it would have to be dropped somewhere along the road. It was important to consider these materials as an evolving frame of mind rather than a cemented theoretical framework. I did not want my experience to be contained within the limits of my bags and I needed to keep my spirit free enough to learn during this journey of gathering knowledge. I now present an illustration of my theoretical location in this ethnography of an indigenous man in a Kabyle Landscape.

\section{CONTEXT OF INQUIRY AND RESEARCHER: WHERE IS MY IDENTITY}

Edward Said, in Power, Culture, and Politics (1996), helped me in analyzing the ways in which the identity and the language of the colonized have been shaped by the work of the colonizer. I referred to Said's use of metaphor as he discusses his feeling of being dislocated in Out of Place: A Memoir (1999). Stuart Hall (2003) and Hourig Attarian (2009) guided my reflection on identity with their experiences of a Diaspora and postmodern identity.

\section{Like an eagle opening up his wings}

In my childhood, we were very sheltered and I did not really know what was happening in the world. So even if I was born and raised in France, I was still a Kabyle in some ways. I was conceived inside of a Berber body, my mother. The first education I received was from within her. One's identity in the Western world is connected to the place of 
birth, the naming of a political administration called a country. In Kabyle culture, the woman is like the earth. For this reason, I can say that my mother was my place of birth. Makilam (2007) explained this analogy in our culture. She said:

"The analogy between the fertile earth and the fecund woman is clearly seen in Kabylia in the interdicts that surround them and that are identical for both of them. The cultivation of the earth is, furthermore, accompanied throughout the gardening cycle by ritual gesture similar to those that are addressed to the woman and her child. As we have seen, the woman's body is merged with her exterior garden as it blooms." (p.52)

In the same book Symbols and Magic in the Arts of Kabyle Women (2007), Makilam explained the connection between the earth mother and the mother earth:

"The first rite of passage of the cycle of life of all humans occurs at birth. The mother has formed and nourished the child with her blood. As the giver of life she must expel it in a bloody sacrifice from her dark depths. It is in the cutting of the cord that links the child to its maternal earth that it will pass from the aquatic world of darkness to life on earth in the daylight." (p. 62)

It was after my birth that I ended up in what was supposed to be the political/cultural context of France but again it was a Kabyle diaspora reorganized in France, adapting to this new context, but still connected to our mountains back home. Six years ago, in 2005, I was with my father and we were doing something that we hadn't done for a long time. We were going to the early Saturday Market. The market was an important place for the Kabyle because it was a place where men would get together. For my father, however, it had acquired an unsettling atmosphere. At an earlier time every Saturday my father would run into the man who tortured him during the Algerian War of Independence. Every week the man would say: 
"It was war" and my father would answer "... and if I had to do it again I would." I never met this man. He died not long ago. His death left my father with a silence in his heart, like a place left empty.

The next narrative episode number is a metaphor as well as a practical example of the dynamics of our community. I describe how the differences that spread us across the world come to an end when the road to the village is threatened. Like ants on a piece of sugar we come together and destroy adversity before going back to the unknown diversity of our destinies.

\section{Narrative episode 9: Like ants on a piece of sugar.}

"A week after we went to the market, my father and I were driving up the mountain in our little green car. We got stopped on the road because of a huge rock that had fallen from the mountain, completely blocking the way up to the village. The villagers were working like ants on a piece of sugar. They came from all over the mountain and started to fight this new enemy, attacking the block until nothing was left. They brought tires to burn under the rocks until the block cracked open. A man came over to us appearing from down the cliff. I recognized him. It was the man I had seen at the market except that with his smile and arms wide open, he looked much brighter and twice the size. He looked like an eagle opening his wings. A big surge of energy came out of him as if a powerful force connected the mountains and him. He said: "So you are his son! Welcome home, brother. This is our land." I said: "What are you doing here?" He replied: "I take care of my sheep. It feels good to be here." We smiled at each other and I left as the road reopened." 
This episode was important to me as it illustrated my relationship to my mountain through my father with the energy of the land. I described the aura of the man in his natural context, rather than economic context, as it describes how I felt when I returned to Algeria. That feeling could be called love. It is that unconditional love that I have for my land that is the bond of our diaspora.

\section{Learning about my "Diasporic" self}

My challenge was to understand the dynamics of the diaspora, with its relationships to my country of origin, in order to shape my inquiry about the idea of cultural recovery. Stuart Hall, (2003) in his article Cultural Identity and Diaspora, explained the diaspora situation very well.

"The Diaspora experience as I intend it here is defined, not by essence or purity, but by the recognition of a necessary heterogeneity and diversity; by a conception of 'identity', which lives with and through, not despite, difference; by hybridity. Diaspora identities are those which are constantly producing and reproducing themselves anew, through transformation and difference". (p. 235)

I connected with this definition of Diaspora as it contained the idea of a flexible, alive and evolving culture, as Hall (2003) said:

"Cultural identity, in this second sense, is a matter of "becoming" as well as of "being" It is not something which already exists, transcending place, time, history and culture. Cultural identities come from somewhere, they have histories. But like everything which is historical, they undergo constant transformation" (p. 225).

I connected even more to this concept of cultural identity because it conveys that the roots of a culture are strong and expressed in the ever-developing self and not an identity 
condemned to die, or a culture built in vitro in some new post-colonial country. Cultural identity is the recognition of the connection to our origins and the acceptance of one's cultural location. As well, it is a way of embracing the changes and welcoming new influences into a system. Until now, culture seems to have been described in a very static manner, enslaving the destiny in a description or a definition of what it was to be part of a Berber diaspora. Such static descriptions create an image of differences focused on opposition rather than diversity lived as an equitable exchange. That perspective is at the root of a never-ending acculturation process, a permanent struggle for expression within systems that are externally generated. This meant, as Stuart Hall (2003) explained:

"Use this term (diaspora) here metaphorically, not literally: diaspora does not refer us to those scattered tribes whose identity can only be secured in relation to some sacred homeland to which they must at all costs return, even if it means pushing other people into the sea. This is the old, the imperializing, the hegemonizing, form of 'ethnicity'." (p.235)

We can move with Hall from an imperializing perception of cultural identity to a fluid energy that seems to be freeing culture and connects with an indigenous vision of identity, something that connected us all together as people engaged in a similar process. "The first position defines 'cultural identity' in terms of one, shared culture, a sort of collective 'one true self', hiding inside the many other, more superficial or artificially imposed 'selves', which people with a shared history and ancestry hold in common". (p. 223)

I go back to Hall's second perception of cultural identity. He seemed to be defining displacement as the actual displacement from his land, which for Berber people is not the case as we were born in foreign countries, such as France, Germany, Italy. I connected to the global cultural identity of being Berber today. I did not claim those countries as mine, nor did I create 
a new conceptual country from the hybridity of the newly created population. In my situation identity is an abstract construction.

Being a Berber is already a dynamic culture as it has developed from constant contact with other cultures, Jewish, Christian and Muslim. Some of us are now developing a new identity created from the misunderstood and opposing concepts of secularism, tradition and religion, combined with the forces of Islam, the West and the Algerian government. Secularism is presented as a default religion. The effect of such politics in the country has a direct impact on the relocation of the people. Plus, the concept of indigenous identity as a relationship with the land, binds Berber people to their land of origin and denies them the plight that Hall seems to put forward of a disconnected Self that grows from rupture. Instead the Self grows from a unifying source that reaffirms the idea of interconnectedness so important to indigenous cultures. It creates the place where the streams come together to generate an ocean in which all of us find our place in unity and diversity. So I think Stuart Hall is right about a perspective of culture that is organic and alive, but other influences need to be included in the actual heritage to shape and renew the strength of the culture of origin. Individuals are always connected to their place of origin, their ancestors and families. Berber culture does not value one's individualism. We, the Berber people, believe that if someone decides to move away, and sever the relationship to the land, they will always be haunted by spirits of the past.

As I explained in the prologue, developing the metaphor of the tree, even when there is displacement, a clean cut from the homeland is totally impossible; there cannot then be any complete break in the chain of tradition. The Berber blood cannot dry out because it is created from a spiritual connection with the other generations. Culture is composed of different parts, aspects working together in a holistic system of interconnectedness. I see the different aspects 
of the Self as being spiritual, physical, emotional and mental. It seems to me that this framework, taken from Native American people, coincides with Hall's views, but also shows that Hall ignores a big dimension of what creates cultural identity. Stuart Hall's wonderful explanation of the identity of a Caribbean African descendant seems to be more a claim for a land, a discourse that locates him in a new place he claims as "home". "The 'New World' presence - America, Terra Incognita - is therefore itself the beginning of Diaspora, of diversity, of hybridity and difference, what makes Afro-Caribbean people already people of a Diaspora"(p. 225). Hall's discourse is also a wonderful vision as it shows the birth of what my elder William Commanda calls the Rainbow Child, someone who bridges the world as they reach for their roots. This rainbow creates a place where harmony and peace develop. Hall describes a place where the rainbow takes shape and voices speak in a discourse of diversity and hybridity, which encourages me to turn to the voice of my elders. Thus, the borders and places of struggle are not initially the place of peace but allow us to construct that peace. "In turn, it is this negotiation of identity which makes us, vis-à-vis other Latin American people, with a very similar history, different - Caribbean, les Antilliennes ('islanders' to their mainland)" Hall (p. 227). I come back to the idea of a spiral that takes us from the centre, to that famous point where we seem to all be going and coming, as Attarian (2009) writes:

"Could it not be then that going through each of these layers, reflective selfconsciousness, active construction, and reconstruction of personal experience, is what affords the distancing and the detachment necessary in doing autobiographical research? The emerging metaphor is that of a spiral. In the hub, revolves the axis of involvement, and with each layer of reflection superimposed, the spiral moves outward and above, providing the distance needed in the interpretive phases."(p.28) 
The unavoidable destination from where we come and where we are going is brought to life in the continuous movement of our interrelated stories. However, I would slightly refine this image to that of the circle of life as a movement that keeps the medicine wheel rolling and that places us in positions of humility, as contributors rather than creators. The philosophy of the medicine wheel is a humbling perspective that places us in a global and interrelated system, one where each and every one of us has gifts and responsibilities. We contribute to the creation of what and who we are. Even if we can put ourselves in the middle of a circle, we are still only a part of a whole and as such we can only be humble contributors. We are always reminded that we are impermanent and as such, the place we take in the creation is limited. This idea of continuity and continuance of the spiral is missing from Stuart Hall's work. He describes history as linear. The present is made of the past but the past is gone. The second point that Stuart Hall makes is that hybridity is a new identity, inspired by the past but independent from it. He explains that this identity has developed on a new land and that the descendants of the First Comers are now removed of their roots and can grow without the past. What Indigenous people believe is that the past is always in the present and the cycle of life keeps reproducing itself. Indigenous people also believe that individual culture and land are connected. They describe a wheel that spirals toward to the core of its origin. That center is always fed from the lives of its descendants.

After re-establishing the relationship between the different directions that form identity we create a phenomenon that supports Hall's argument. Once I bring together the two directions and I look in a circular way at what he describes with linearity, I agree with him that identity is indeed alive and changes according to events and human encounters. Cultural identity seen as involved and interconnected in the world, helps support the "being" as well as "becoming" as well also the notion that is important to me as a Berber man, the "coming 
from." Circularity enriched with the movement of the spiral is then a representation that allows for harmony of cultural identity in time and space. Cultural identity keeps growing but stays connected to its land of origin. This growth can be seen as emancipation in interconnection. It is this movement of independence from and to the center of the culture that generates the strengthening of the Self.

\section{BERBER IN THE BOX: STRUCTURALIST DESCRIPTION OF BERBER IDENTITY}

Starting from where I was born and where my journey began, I returned to France with Abdelmalek Sayad (1991). He describes in Immigration or the Paradox of Alterity a dislocated self that generates the situation and the feeling that he calls The Uprooting. In the same line of thought, Bourdieu's ethnographic essays of Kabyle identity (1972) give us wonderful insights into the Kabyle culture as well as into the consequences of a structuralist approach to describe that culture. Bourdieu argues that:

“... a deeper study of real weddings, and in particular cases of misalliances, in Kabylia as much as in Béarne (region of France), led me slowly to doubt of the structuralist vision. That structuralist vision could have had a part of its seduction from the fact that it tends to reduce the social operation to a kind of clock industry and makes the ethnographer, who carried to light the mechanism, into some kind of a god of the clock and watch maker, outside and superior to its creation.” (personal translation, p.4)

I was not an omnipotent and outside "watch maker." I was the researcher as well as the participant. As such, I broke the rules of objectivity and further describe here my location in this inquiry. 


\section{Where do I start and who am I when I start?}

I was born in France and as such I became an immigrant before being a Berber, or at least that is how France explained it to me. Being an immigrant meant being an economic entity, someone whose identity is connected to the need for a labour force. Abdelmalek Sayad (1991) explains in Immigration or the Paradox of Alterity, how immigrants' conditions are connected to the need for immigrant workers, which is the reason they have been brought to France. Immigrants are not coming to the developed countries for the beauty of the culture and these countries do not open their doors for the beauty of being called welcoming. There is an economic need for countries to keep a controlled but constant immigration. The hypocrisy is to exploit this situation, by commercializing the image of welcoming the "wannabe" French, suggesting that France is beautiful and therefore that is the reason why people go to France. Many expatriates do not get involved with the mainstream culture outside of places like schools or in other institutions of public administration. We stay in the suburbs, or in social projects like the housing project for low-income families in France, built to "welcome" us into developed structures.

In my father's time, the immigrants were shipped to France and stocked in dormitories. I remember my father telling me that he used to have only one day off a week and it was the day he would wash his clothes and clean himself up. Now our people are lodged in suburbs, also called Zones of Educational (geographical area within a city where resources in education are invested to "help" the immigrant to integrate into the society), Priority or Prioritized Zones for Urbanization (ZUP). A ZUP is focused on answering to the shortage of accommodation. It is a policy that took place in France between 1959 and 1967. A ZEP refers to cities or regions that received, in 1981, extra funding for the building of supplementary schools where education was an emphasis. My upbringing and my education were a bit different as I grew up among 
the French in the "European" part of town. The town was divided into two main sectors. The first was the European part with the factory that provided some of its employees with decent accommodation. This area was also made up of new housing from earlier Italian and Portuguese employees. The second part was located on the outskirt of town, just on the border of Luxembourg and Belgium, and was separated from the rest of the city by a big Boulevard. The apartments were big buildings of up to twenty floors with thin walls and broken elevators. My father bought a house in the first part of the town and fortunately we didn't grow up in the ZUP. But after I turned 13, my father decided to go back to Algeria, which was when life changed drastically, as illustrated here in narrative episode 10.

\section{Algeria dropped us in the sea}

\section{Narrative episode 10: Algeria dropped us in the Sea}

"We, the children, didn't decide to go back to Algeria. My parents decided and to be honest, I don't think we would have been able to decide anything for ourselves. It felt like the longest summer of my childhood. We went to Algeria after school finished that year in June. We took the ferry and arrived in a very short time with a loaded car. I remember the summer stretching inexorably to September and then into early October.

We stayed home most of the time because we didn't know anybody. My mother tried to push us out to go play with the kids of the neighborhood. She was hoping we would adapt to this new life. We didn't know we were there to stay and that Algeria was going to be our country from now on. I did have a couple of friends by the end of the summer but they disappeared as soon as school started. We didn't know what to do. My father was never home and my mother was busy with some other things. We kept on asking her when we were going back to France but she never replied. Today I 
understand that she wasn't sure either. It was the year the government decided to turn the whole school system into Arabic. From one moment to next, the whole system was in Arabic. I was supposed to enter grade 6 but that change meant that either I start school all over or to stay home uneducated. No choice was given for us because we are Kabyle and did not know any Arabic. Algeria dropped us into the sea. Stripped of his hope and dignity my father had to bring us back to France, a shame that we kids had to face every time we were getting in trouble, a shame thrown at us in the word "bastards", as they used to call us. We had no other choice than to go back to France. That year, I remember sitting at my desk in school watching the students in my classroom. It felt strange, different from the movement and excitement of life in Algeria. I went back to a classroom where I now was a stranger. It was so quiet and structured. It is funny how this feeling is still with me. We were all sitting at our desks in silence facing the board. I can still feel the spirit of my youth in the sun, of the fall season in the northeast of France drumming little comforting rhythms of Kabylia with my fingers on my desk. I was silently sharing with my new friends my summer back in Algeria. Slowly and slowly the rhythm disappeared again and left me in complete silence."

My youth felt like the writing of a partition in which my family was trying to find a harmony in this departure from our origins to our new home. The beating of the heart is the beat that reconnects me to the land back in Algeria. This Algerian cultural identity that we, expatriates, experience together in different socio-political contexts is described in the work of Foucault and Fanon that I present here. 


\section{GETTING OUT OF THE FRAME}

\section{Overcoming fragmentation and strengthening the self}

Foucault $(1980,1994)$ and Fanon $(1963,1986)$ take a critical stand against oppression and describe the dynamics of colonial power. Foucault objectively studies the discursive methods that shape power into a discourse and Fanon explains the fragmentation of identity. Both lead to an understanding of the mechanism of subjugation of cultures, knowledge and people. It is where we start in order to get out of the colonial framework.

I use Foucault's references to illustrate what indigenous and colonized people experience and explain how one's knowledge can be subjugated by institutional racism. Together with the work of Fanon, I understand the concept of fragmentation and the need for a decolonizing methodology that will act as a more holistic methodology for the recovery of a Kabyle indigenous self. I am also influenced by the amazing work of Paulo Freire who explains that consciousness is the first step to freedom. Freire (1971) teaches, with a Pedagogy of the Oppressed in action, a Cultural Work for Emancipatory Projects.

"Not infrequently, training course participants call attention to "the danger of "conscientization" in a way which reveals their own fear of freedom. Critical consciousness, they say, is anarchic; others add that critical consciousness may lead to disorder. But some confess: Why deny it? I was afraid of freedom. I am no longer afraid!" (preface, no page number).

While I was writing this theoretical chapter, I had a conversation with the main organizer of the Berber Festival in Algeria. He told me that he went to Pierre Bourdieu's paper to look for Kabyle culture. I was amazed to hear that from him. He was born in Algeria 
and grew up in Kabylia. How is it possible to look through the lenses of a colonizer to find the roots of our culture? Bourdieu's (1978) position in his earlier work was that:

"Sociologists have only a chance to succeed in his work of objectification if, as an observed observer, they submit themselves to objectification, not only of all they are, their own social conditions of production and from that the limits of their brain, but also their own work of objectification, with its hidden interests that are invested, in the profits that they promise" (p.68).

However, Nadia Mohia-Navet (2008) has constructed her vision of the "participant objectification" from Bourdieu (1978).

"It is about perfecting the objectification as much as of the social reality studied as of the subject who studies it. In other terms, to make it seem that one and the other appear as external realities directly accessible, this, even to their most subjective dimensions. However, doing so aren't we continuing to ignore the nature itself of subjectivity that is precisely everything but a directly perceptible "external reality" (p.9).

Reflecting on structuralist perspectives means endorsing support of Foucault's analysis of knowledge construction and its exploiting process. Foucault (1980) provides a great understanding on the discursive methods that creates "subjugated knowledge." Indeed knowledge is subjugated in the sense that populations are being silenced by systems of oppression, control and exploitation. Knowledge is subjugated because it is enslaved to the system of knowledge management developed by the so-called developed societies. There is a hierarchy of knowledge in which indigenous knowledge takes last place. It always intrigues me to see how one can talk about the need to fight fragmentation, cutting down stories and experiences into isolated units like phonemes of knowledge. The reader must then have a 
translator to change the whole thing back into a life story. It is a reanimation of what Whitehead (1929) calls in The Aims of Education "inert knowledge," so much so that the writer makes a non-significative participation, unable to bring that dead matter back to life. Controlled by a few, knowledge becomes an elitist tool that can be used to manipulate a story into a system of control, reproducing the situation of alienation and power. This leads to the creation of a vortex in which every meaningful experience is swallowed and classified for academic enzymes to breakdown.

I reflected on the process of gathering information in indigenous locations. I wanted to avoid an outcome in which Indigenous people's stories were displaced, vulgarized and taken away by anthropologists to be put in Western museum and libraries. Gathering knowledge with or without the authorization or understanding of the researched and in a way that ignores empathy in the process of gathering and constructing knowledge would be using colonial authority to expropriate indigenous people from their heritage. It was for that reason that I reflected on my positioning as a researcher in this inquiry. The crisis of representation in research raised the issue of whether researchers should be involved with the population or not. Denzin and Lincoln (2008) explain:

"In North America, qualitative research operates in a complex historical field that crosscuts at least eight historical moments (...). These moments overlap and simultaneously operate in the present. We define them as the traditional (1900-1950); the modernist, or golden age (1950-1970); blurred genres (1970-1986); the crisis of representation (1986-1990)... The blurred genres phase produced the next stage, the crisis of representation. Here researchers struggled with how to locate themselves in reflexive texts. A kind of methodological diaspora took place, a two-way exodus. Humanists migrated to the social sciences, searching for new social theory, new ways 
to study popular culture and its local ethnographic contexts" (p.3-4).

I questioned the idea of power between researchers and subjects in the knowledge gathering process. This crisis did not go to the extremity of questioning why we needed to gather so much knowledge and how we could have organized an equitable redistribution of the knowledge on a global scale. Anthropologists tend to make available knowledge that is supposed to stay connected to the place of discovery in order to stay active. Unfortunately, the relationship between people is not always concerned with equity but more with issues of competition, dominance and power among anthropologists. In such systems, the knowledgeable become the leader and leaders want to keep their supremacy by gathering more knowledge, a never-ending race for wealth and power. This system is designed as a pyramid that aims to condition everyone to want to climb. By doing so, the energy of the struggle to succeed is strengthening the people on top.

However, knowledge is not totally subjugated for everybody and I believe in human agency. Knowledge is also shared in some very intimate circles and in laboratory like environments. The old pattern of positivist norms for experimentation wants to keep knowledge for an elite. Pierre Bourdieu and Abdelmalek Sayad (1964), in Paysans déracinés (Uprooted peasants), described knowledge, once "decontaminated" in processes that we can call uprooting:

"Most frequently, the uprooting creates a field favourable to the cultural contagion, weakening the collective defences that the group was opposing to borrowing and to innovation. Uprooted from his land and his house, dispossessed from his birth word that he owned, the peasant dies as a peasant: It is the end of the old thafellah'th, the peasantry, the total and intangible art of life that falls apart in one shot in its totality. 
The last descendants of the servants of a revered land are now one's slaves chained to their heritage in a hateful condition" (p.56).

I learn about fragmentation from Franz Fanon (1986), displacement and fragmentation are experienced by many of us, indigenous people, who were socialized in specific frameworks with chosen people, whose minds have been framed as well. Access to higher education means having access to a lot of knowledge and possibly powers but to access a level where power can be changed into decisions means following the rules in the marketing of knowledge. A hierarchy is present at every level of the educational processes to protect the rules. The knowledge is actually gathered in places and languages that are supporting it, building walls around it. Said explains the relationship between knowledge and power in Politics, Power, and Culture (2002).

"In the West, for instance, in certain fields, such as anthropology, history, cultural studies, feminist studies, it (knowledge) has influenced people to think about problems of power relationships between cultures and people, where dominance includes the power to represent and create, to control and to manipulate. In other words, it makes the argument for the connection between the production of knowledge and power. And specifically, because it was a historical work, it really looks at all of this in the age of empire" (p.372).

Later Said, in the same book (2002), insists on the connection between power and knowledge referring to the United States of America's example:

"...In the last chapter (of Orientalism, 1979) I look at the role of the United States after classical empires were dismantled in World War II, to see, since the extraordinary role that the United States played as the last remaining imperial power, and the influence of 
that role upon knowledge and the production of knowledge" (p.373).

And Said (1979) introduces the idea of control in this quest for power: "Once again, knowledge of subject races or Orientals is what makes their management easy and profitable, knowledge gives power, more power requires more knowledge, and so on in an increasingly profitable dialectic of information and control" (p.36). Having knowledge means gaining control. Having the knowledge is having the power to manage populations and use their foundations to build up a system that will sow the seeds of acculturation and domesticate the population, turning it into a usable crowd. The power to control also comes in the capacity to manage the distribution services. Universities are now pushing for more and more productivity. The more one does the more wealth one brings to the system. Wealth is often measured in research dollars. Said explains in Politics, Power, and Culture (2002):

"As a systematic discourse Orientalism is written knowledge, but because it is in the world and directly about the world it is more than knowledge: it is power since, so far as the Oriental is concerned, Orientalism is the operative and effective knowledge by which he was delivered textually to the West, occupied by the West, milked by the West for his resources, humanly quashed by the West" (p.26).

This idea of capitalizing knowledge to gain power leads me to compare schools to banks. The new bank customer has to go to a bank with his money. The customer opens an account and people are very friendly, trying to see what type of person he is, to see who to refer this new investor to. Then the customer meets a representative that will offer him/her a chair, or not, according to the amount this newcomer brings or could bring in. After that he or she is sold a package that "helps" manage their money, a package that includes a number of possible transactions (number of deposits are unlimited but withdrawals are limited to a certain amount per day, internet banking, credit cards etc.). Once one is in the bank, they try to 
secure the client's loyalty to assure that they will come back and ask for more products. That is when one becomes part of the system. In the future every transaction that he or she will do will have to be done via the bank. They will decide where one can live and how one will live. Now it is even more interesting because the employer is actually in partnership with banks and "helps the new customer" choose the bank to which he or she will have his or her salary sent. It is also what Freire (1971) calls "banking education":

"Education thus becomes an act of depositing, in which the students are the depositories and the teacher is the depositor. Instead of communicating, the teacher issues communiqués and makes deposits, which the students patiently receive memorize, and repeat. This is the banking concept of education, in which the scope of action allowed to the student extends as far as receiving filing, and storing the deposits" (p.45-46).

After describing the student as a passive and a submissive receptor engaged in a nonequitable relationship, Freire (1971) continues his metaphor describing the exchange transaction of knowledge in such a banking system. In Freire's theory (1971), the student is the bank where the teacher puts money (received and oppressive knowledge that the student is not supposed to interfere with and does not really own).

"In the banking concept of education, knowledge is a gift bestowed by those who consider themselves knowledgeable upon those whom they consider to know nothing. Projecting an absolute ignorance onto others, a characteristic of the ideology of oppression, negates education and knowledge as processes of inquiry. The teacher presents himself to his students as their necessary opposite; by considering their ignorance absolute, he justifies his own existence" (p.46). 
You are from any part of the world and you carry so much knowledge. That knowledge is bought packaged and achieves maturity in boxes that get traded on a market according to the dominant pressures of the day. Societal pressure shapes it to fit into defined boxes. This neoliberal perspective of education turns the world into a battlefield for intellectual survival. Turned more and more into a research-intensive orientation, universities have to answer to the law of a market that still fights to know the truth, if it is fair to everyone or not. Actually we do know, as it is clear that only a very small part of the population of the earth profits from the benefits that the market generates. Placed in banks and exchanged on the market, indigenous cultures become a good for which indigenous people have to fight to get access. We, indigenous people are trapped in a system from which we need to emancipate ourselves, replacing the colonialist system; we now have to deal with cultural imperialism. It is for that reason that I return to the book The Wretched of the Earth written by Franz Fanon (1963). He explains the path to independence, as he sees it, with the example of Algeria during the War of Independence. That war still has an influence on what Berber people are going through today.

\section{Path of decolonization of the Berber intellectual in the work of auto-ethnography}

Sartre (1963), in the preface of The Wretched of the Earth, written by Fanon, illustrates the portrait of the starting point of my journey. He describes colonial violence and puts words to my thoughts. He says:

"Colonial violence not only aims at keeping these enslaved men at a respectful distance, it also seeks to dehumanize them. No effort is spared to demolish their traditions, to substitute our language for theirs, and to destroy their culture without giving them ours. We exhaust them into a mindless state. Ill fed and sick, if they resist, fear will finish the job: guns are pointed at the peasants; civilians come and settle on their land and force them to work for them under the whip" (p.53). 
I experienced Sarte's powerful statement, extracted from the preface of Fanon's "The Wretched of the Earth" (1963, p.1) during my education in France. "Destroy their culture without giving them ours..." An education based on expropriation and instrumentalization is what I see in these words. Raised in France, I received an education that never gave me room to develop my personal cultural identity. At the same time that this education was aspiring to make my culture disappear, I was sowing the seeds of my culture on French land. I was provided with tools to work on a land that was not mine, and a soul that was removed from its source to be exploited on international markets. I was going to school with French people in France and I was serving in a colonial society without being conscious of it. I was learning through my education to whiten the world. In the book "The Wounded Storyteller: Body, Illness, and Ethics," Arthur W. Frank (1995) explains the phenomenon of reverse of leadership and expropriation with the example of medicine.

"Both the divide that was crossed from the pre-modern to the modern and that from modern to postmodern involves issues of voice. The woman reported by Bourdieu seems to perceive that medicine has taken away her voice: medicine assails her with words, she does not want to know and let her not knowing more about her sickness" (p.7).

The Voice here is the powerful expression of the true Self, meaning the one of heritage from the position of personal consciousness. The voice Frank refers to is the one threatened by an authoritarian system of knowledge, as explained previously, as well in the Freire statement on banking education. Frank then makes reference to Pierre Bourdieu's work in Algeria and quotes a Berber woman: "In the old days folk didn't know what illness was. They went to bed and they died. It is only nowadays that we've learned words like liver, lung, stomach and I don't know what!” (p.5) 
We understand here that the colonized who went to western schools use a langage foreign to his kind and learned social reproduction of situations of oppression. Deepened in theoretical contexts, dominated by colonial discourses, the colonized learned the methods from the colonizer. They encouraged the domestication of the Imazighen, placing then into the cages of the colonizer's methods. Fanon (1963) says that:

"In order to assimilate the culture of the oppressor and venture into his fold, the colonized subject has had to pawn off his intellectual possessions. For instance, one of the things he has to assimilate is the way the colonialist bourgeoisie thinks" (p.79).

The colonized wants to decolonize. Artist or intellectual, he goes back to the traditional tools to communicate. He tries to go back to a time when he was independent and could innovate and look to the future from an independent perspective. He does not understand that his nation has changed. If the colonized wants to emancipate from his colonizing jail he needs to be in the present and find the tools to address the present situation. The colonized has a vision that is blurred by the will to rediscover what he had lost or changed.

"When he decided to return to the routine of daily life, after having been roused to fever pitch by rubbing shoulders with his people, whoever they were and whoever they may be, all he brings back from his adventures are terribly sterile clichés. He places emphasis on customs, traditions, and costumes, and his painful, forced search seems but a banal quest for the exotic" (Fanon, 1963, p.225).

As a colonized intellectual myself, having grown up in France, I felt touched by what Fanon says when he describes the three steps of the work of the colonized. When I obtained my bachelor degree in France, I had successfully "assimilated the colonizer's culture" (Fanon, 1963, p.227). I made a name for myself and I proved that I was capable. At the same time, I 
answered my social anxieties and accepted the game of socialization in the context of colonization. I accepted the pressure. But as time went on, experiences grew and inequalities multiplied, leaving me no other choice than the one of reflecting critically on my experience and committing to the journey of healing. I had to go back to my roots. I distinguished myself from this machine that tried to shape me since I had roots in a foreign civilization. I refused injustice or the schizophrenic split Self as a solution to my situation. I refused to live this life of an "angel" (see next paragraph, Fanon) and I had to inscribe myself on the earth, to leave my imprint on it. Fanon describes so well the situation of the colonized in these words: "This painful and harrowing wrench is, however a necessity. Otherwise we will be faced with extremely serious psycho affective mutilations...” (p.223)

I am a part of the nation, "...individuals without an anchorage, without borders, colorless, stateless, rootless, a body of angels" (p.223). But I chose to not let that be my destiny. I threw myself into a master's degree that looked a lot like what Fanon describes as "an outsider relationship" with "my" people because I had not lived, or only in a fragmented way, with them. Wanting to come back to my origins is a "task of memory" (Fanon, 1963, p.227). At the start of this $\mathrm{PhD}$ work, I was delving into my memory for stories, connectors, receptors, and transmitters to my Kabyle culture. I was socially acceptable because, in some way, I was exoticizing myself, looking for an identity in a tradition and of going back home to Algeria. It was for this reason that I did not threaten the system that raised me and I was, in fact, even an exotic experience. Fanon (1963) explains that:

"No colonialism draws its justification from the fact that the territories it occupies are culturally nonexistent. Colonialism will never be put to shame by exhibiting unknown cultural treasures under its noses. The colonized intellectual, at the very moment when he undertakes a work of art, fails to realize he is using techniques and a language 
borrowed from the occupier. He is content to cloak the instruments in a style that is meant to be national but which is strangely reminiscent of exoticism" (p.227-228).

Even if I did wish to produce a work that could be undermined by the colonizer, it was necessary for me to become aware of my motivation for this inquiry, to understand my context and to emancipate me. I could then finally arrive at what Fanon describes as a "combat stage" where the colonized "after having - tried to lose himself among the people, with the people, will rouse the people.” (Fanon, 1963, p.227). By adopting a critical and participative approach to the Berber condition, I shook the social structures, dusted up the cultural conceptions and pushed for an actualization of my culture. My work was an inquiry that I wished to leave to my close and extended family. It was possible that through this work only a trace of me would remain after a definitive departure from a land of the forgotten. Often I thought that this research would be my last attempt to bring my contribution to Algeria, a land that is mine, but about which I know so little. I saw my work as a way of accepting a reality, but paradoxically, this reality then became the corner stone for a liberating creation. Fanon (1963) explains that:

"This creator, who decides to portray national truth, turns, paradoxically enough, to the past, and so looks at what is irrelevant to the present. What he aims for in this inner intentionality is the detritus of social thought, external appearances, relics, and knowledge frozen in time. The colonial intellectual however, who strives for cultural authenticity, must recognize that national truth is first and foremost the national reality. He must press until he reaches that place of bubbling trepidation from which knowledge will emerge" (p.230).

The independent nation was born from what she accepts, as she is now embracing her history, pain and happiness, while shame and pride to keep her going on the journey. The Amazigh nation is a nation representing humanity. This work of the colonized intellectual, 
described by Fanon as the unavoidable road, a road used many times, is in fact for me a personal experience of liberation. For Fanon, the colonized intellectual cannot be on the right trajectory unless he leaves his bourgeois cloth behind, to take back his place with the people.

“... We must first and foremost rid ourselves of the very Western, very bourgeois, and hence very disparaging, idea that the masses are incapable of governing themselves. Experience has proven in fact that the masses fully understand the most complex issues. One of the greatest services the Algerian revolution had rendered to Algerian intellectuals was to put them in touch with the masses, to allow them to see the extreme, unspeakable poverty of the people and at the same time witness the awakening of their intelligence and the development of their consciousness." (Fanon, 1963, p.198).

Even if liberation has already been explained, maybe in psychoanalytical words, liberation does not exist as long as it is not lived. It is this need to live liberation that is the source and the reason for this work. I was not only looking for the result of an experience. This experience was the result and it belonged to me. It distinguished itself by the fact that it was my personal life journey. I went back to Algeria to connect with the Algerian Berber people and through an auto-ethnographic research I found answers to my cultural needs. The nation that I wished to live in is not the one of decolonization but the one of my indigenous culture. It was not an identity that separated us from the rest of the world but, on the contrary, unified us. As Fanon explains, I was cutting up the wings that made me an angel to return to what made me a Kabyle man, an indigenous person. I went back to my land. "For the colonized people, the most essential value, because it is the most meaningful is first the land: the land, which must provide bread and, naturally, dignity" (Fanon, 1963, p.9). 
However the dignity of the Berber man is built of the pride to share and not to possess. It is not a pride of having power but a pride of having wisdom and values. What I dislike in colonial movements is that they have defined too fast the geopolitical identities that have fossilized the colonial divisions. Even if I wish to support social justice with my work and the rights of people for self-determination, which I have in common with Fanon, I do not wish to create a society based on the idea of domination and class struggle. The sovereign nation is the one that lives in a world of brotherhood, conscious of its human dimension. If Fanon's discourse is strong and firm and shows that independence is the only solution, it shows, as well, that the colonized man, peasant or not, is before everything isolated from himself, instrumentalized by his colonizer using his quest for freedom. I find my way, not through fighting, but by the positive and pacific expression of cultural resilience, as my culture embraces the future of this planet.

Frank (1995) explains that to come back is to take back possession of one's history. It is a phenomenon that, according to him, characterizes postcolonial society. He introduces the concept of voice in his story. To whom does this history belong? To whom does this voice belong? Frank (1995) also explains:

"Voices tell stories. Stories are pre modern; Bourdieu's informant suggests that the coming of modern medicine took away a capacity for experiencing illness in her folk's traditional stories. In the modern period the medical story has pride of place. Other stories become, as non-medical stories are called, "alternative" meaning secondary. The postmodern divide is crossed when people's own stories are no longer told as secondary but have their own primary importance... Postmodern illness is an experience, a reflection on body, self, and the destination that life's map leads to" (p. 7). 
With colonization, and decolonization, the colonized took a second place in his personal history and culture. The anthropological work that aimed to make him better known made him become an "other" to himself. Dispossessed of his own image, he would see himself only in the words of his colonizer. He would lose control of his representation system and give up the power to move in time and space, to become the object that could be moved. In the anthropology for neo-colonization, the colonized could either move from the hands of the colonizer, or move himself as the colonizer would move him. He was changed into a subject. However, through Paulo Freire I get a sense of what it is to be empowered in education and what it is to engage in reflection. Freire says that "to study is not to consume ideas but to create and re-create them" (The Politics of Education, Culture, Power and Liberation, 1985), while also reminding us that:

"The act of study assumes a dialectical relationship between reader and author, whose reflections are found within the themes he treats. This dialectic involves the author's historical-sociological and ideological conditioning, which is usually not the same as that of the reader" (p.4).

From that perspective of emancipatory projects on education I move to the next part of this theoretical chapter: a reflection on relationships and anthropological research. Nadia Mohia-Navet (2008) illustrates the dynamic between relationship and knowledge. Put in a context of cultural recovery we will see that it has the potential for the holistic rebuilding of an identity. 


\section{A MOVEMENT INTO THE HEART OF THE INQUIRY}

When we introduce ourselves as indigenous people, we always say the names of our ancestors and elders. Those names are often introduced in stories, connecting them in the context that has developed. In the same way that when we enter a sweat lodge saying "All my relations," Nadia Mohia-Navet (2008) presents her understanding of relationships in L'expérience de terrain, Pour une approche relationnelle dans les sciences socials (Field Experience: For a Relational Approach in Social Sciences). She helps us move from the anthropological work "on" the object to "with" the participant, which in my case means "within" the participant. The relationship of the researcher to his/her community is a crucial bond. The re-composition of the Self occurs when individuals are reconnected to their families and the land. They become one with the past generation and the universe.

The organization of the transmission of heritage illustrates the importance of genealogy in indigenous culture and how knowledge is embedded in these relationships. When I was drawing the tree on the tablecloth in that little Thai restaurant, as the plan of my $\mathrm{PhD}$ thesis, with my former Master's degree supervisor Ann Beer, we both realized that a part was missing. It was this connection, between the trunk to the branches and the branches to the leaves and fruit. This missing part was a result of the time spent in the educational system, the time during which I was being packaged to fit into the boxes of the society. This tree that was supposed to represent my lineage had been cut during this experience of education. I understood why my grandfather's tree back home had lost so many branches after we all left for school in France.

I referred to Abdelmalek Sayad (1964, 1981), Attarian (2009) and Fanon (1963, 1983) to talk about knowledge but in fact they focus on individuals. When discussing people, we 
talk about human resources. How can one manage human resources on the international free market? Attarian (2002) talks about the displacement of Armenian refugees:

\begin{abstract}
"Growing up with their stories of pain and suffering, of robbed childhoods and torn lives, I learned firsthand what the power of memory can signify; how it can inhabit our dreams and inhibit our realities" (p. 64).
\end{abstract}

This long root that stretches all the way to the deep heart of our identity, of our knowledge, must be kept in touch with its origin to keep the individual alive. If education is not a place for active cultural practices it becomes an instrument of cultural genocide. Fanon provides a solution to the goal of achieving the work of decolonizing and healing the world:

"The Third World must start a new history of Man, a history which takes into account not only the occasional prodigious theses maintained by Europe but also its crimes, the most heinous of which have been committed at the very heart of man, the pathological dismembering of his functions and the erosion of his unity, and in the context of the community, the fracture, the stratification and the bloody tensions of his unity, and scale of humanity, the racial hatred, slavery, exploitation and above all, the bloodless genocide whereby one and a half billion men have been written off' (Fanon, 1963, p.238).

Grande (2006) explains the story of Native American people in her chapter on indigenous methodology in her book Red Pedagogy. Grande points out that democracy and equity are not new to indigenous people but are, in fact, part of their traditions. As well we need to understand that the people of the land connect to their land via their ancestors. That connection is expressed in the stories indigenous scholars share: 
"But where revolutionary scholars ground their vision in Western conceptions of democracy and justice they presume a "liberated" self; indigenous scholars ground their vision in conceptions of sovereignty that presume a profound connection to place and land" (p. 240).

This connection between freedom and land is at the very root of the indigenous debate. It is the right to have an education that values the history and culture of its students. Such a claim could mean that everybody should live on their own land but unfortunately the map is not as clear it used to be. As I illustrate later in this dissertation, Berbers are an amalgam of identities. However, for Berber people, migration is one that is, in actuality, a continuing situation of colonization, as discussed in the analysis of Franz Fanon in "The Wretched of the Earth". Nadia Mohia-Navet (2008), a Kabyle women raised in Algeria, is a psychiatrist. She argues that:

"If we consider objectivism as a block to sociological and ethnographical knowledge, then we cannot emancipate from it only by admitting that objectification cannot be the unique approach possible to the social reality. This reality cannot be, by definition, completely exterior, neither for the researcher nor for the one who lives it" (p.9).

She worked with indigenous people from Guyana and Canada, as well in Kabylia. Her work shows the importance of the relationship between the participant and the researcher. I think, as well, that a real scientific praxis exists in the expression of the Self in Science. For me, to be a Berber scientist means speaking as a Berber in science. I want to express my identity with my thoughts, my history, and my language. 
I was my first participant in this inquiry because I decided and reflected on what I was doing. Nadia Mohia-Navet (2008) explains self-reflexivity here when she examines Levi Strauss's work. She states:

"At the risk of repeating myself, I would like to insist on this: his (Levi Strauss) situation is, from the beginning, comparable to the one of a subject dreaming, inventing a reality from himself, everything becoming an "other" one, gift of an “other" thought, meaning stranger to its self” (p.191).

She shows how his research is colored by his despair of being away from a France that he believed had abandoned him. The turn towards socialism in France, a movement he had wanted to be part of, excluded him and his work, and so inspired Tristes tropiques (Sad Tropics). But his tropics were in fact the celebration of life, but a life that kept him aside because he was not marrying into the right culture. He would only look through the empty eyes of the exiled. Strauss communicates the epistemological position of the ethnologist in his work Tristes Tropiques and his vision is analyzed by Mohia-Navet (2008) to arrive at her conclusion that:

"An alternative in front of which Strauss found himself conducted him to close himself down in a system of thought. He will formulate it at the end of "Mythologiques" (Mythologics): the "being" or the "non being", to be an anthropologist in that way (entering a "civilization", incarnating the "us" and adopting the conformist walk implicating the negation of the self - "the hateable self" - assuming an appearance, and playing the role of a character) or "nothing", so failing, and even not existing at all, to "self destroy"” (p. 257). 
I have been travelling for 15 years through various realities, each more beautiful than the last, marvelous in their differences and their diversity. When I travel, I often cross paths with people on the same journey. There is one nation of travelers. They enter everywhere, participate in everything, and then one day disappear. Like spirits invited into houses, they enter and nourish themselves from the lives of other. They give birth to a life of sharing. This sharing raises questions all over the world, offering a different lens through which people's perceptions are changed. The presence of a stranger in a community is not without consequences. One cannot talk about experiences without acknowledging that they are lived with others, at least to a certain degree, When travelling with guide books I always miss something. Reading the Rough Guides books forced me to live the guide rather than the country. Often it was my unplanned meetings that were the most valuable, chance encounters that were the result of the decisions made as I moved through the world I understood that the best way for me to really know a place was to go there. Guides cannot convey the obsessive noise of the streets of Calcutta, the headache of the negotiation with a Tuk Tuk driver in Thailand, or the emotions of experiencing all at the same time. These travels have shaped my understanding of India and Thailand, and they also have a direct impact on how I see the world

My experiences have given me a voice to express this knowledge and have brought a human element to my writing. My voice in this inquiry is the expression of my emancipation through the process of writing. I needed to pay attention to the feelings, personality and desires of the people who shared their story. I maintained an awareness of the subjectivity that was colouring my experience. Personality and desires cannot be overlooked as they are also the expression of the man or woman, and as such need to be considered. If I placed myself in the Berber culture, it was with academic honesty, so that I could accomplish my objective of 
producing this auto-ethnography. I put forward the idea of Nadia Mohia-Navet's lens, to get out of the relationship between subjects in the study and to come back to the idea of the reflection, the "mirror game of the soul", as Sartre calls it. This mirror I turned to relocate myself in my humanity. I acknowledged the depth of the being, going deeper into the different dimensions of my humanity, sending me back to my lineage and engaging this knowledge in the development of the methodology of this inquiry. Paulo Freire (1971) says:

"We simply cannot go to the workers- urban or peasant (The latter, usually submerged in a colonial context, are almost umbilically linked to the world of nature, in relation to which they feel themselves to be component parts rather than shapers) in the style to give them "knowledge" or to impose upon them the model of the "good man" contained in a program whose content we have ourselves organized. Many political and educational plans have failed because their authors designed them according to their own personal views of reality, never once taking into account (except as mere objects of their action) the men-in a situation towards whom their program was ostensibly directed"(p.66).

With indigenous methodology we ground our theory in cultural landscapes. Instead of telling people what to do, we actually listen to what they have to say and learn from what they do. Lalmi Nedjma (2004) explains the complexity of trying to know who the Berbers in history are.

"Trapped by the effects of the "Kabyle Myth" that divide the readers of Kabylia in two categories, the one who over evaluates and the one who under evaluates, we have a lot of trouble in objectifying the most elementary of our interrogations and not developing contradictory expectations towards that region, expectations conforming to positives or negative, derogatory representations...” (p.523) 
In this chapter I have understood that being an indigenous in academia necessitates a consciousness of the politics of knowledge, as well as an engagement in emancipating actions. This theoretical framework allows for the expression of an independent voice in a culturally sensitive and respectful inquiry. We will see in the next chapter how Makilam establishes the Kabyle society in Magic of Kabyle Woman and Unity of the Traditional Society (2000), showing how Berber culture is a culture of unity rather than one of hierarchy and opposition, with the ontological concept that represents the value system of this inquiry. Tassadit Yacine illustrates this point, expressing the distortions in the Berber woman's voice today; these Kabyle women who have helped me shape a research methodology respectful of my home. 


\section{CHAPTER THREE:}

\section{METHODOLOGY AND METHODS}

\section{INTRODUCTION}

In writing this chapter for the thesis, I reflected on the reasons that brought me into Western academia looking for answers and support in the search for my cultural identity. I realized that I had mixed motivations. The school Te Kura Maori, in the Education Faculty at Victoria University in Wellington that welcomed me, was culturally different from my life in Algeria, the source of my identity. While this difference was sometimes challenging, this academic space provided me with a safe place for reflection. It was a peaceful, nonthreatening environment for the realization of the Self. I view academia as a place to explore freedom of thought and speech, where I can engage in the sharing of and reflection on Berber community, history and heritage.

In this chapter, I describe my methodology, which is an auto-ethnography of my Kabyle indigenous life story narrative. I first define auto-ethnography. I then explain my Indigenous and Kabyle methodology. I discuss positivist and post-positivist assumptions of auto-ethnography as a methodology and critique these assumptions. I discuss the ethical challenges of doing and writing my Kabyle indigenous life story narrative. I discuss my data collection and methods. 


\section{PART 1: WRITING AN AUTO-ETHNOGRAPHY}

\section{Understanding auto-ethnography}

In the prologue of this inquiry I introduced the methodology of Kabyle indigenous life story narrative. From Ellis and Bochner (2010), I explained that auto-ethnography is the writing (graphy) of the "auto", the Self, and the "ethno", the culture. My Auto-ethnography deals with these three dimensions. I also inspire myself from Ellis and Bochner's (2010) presented list of ethnographies to write my inquiry. My inquiry is a Kabyle, indigenous life story narrative that is written with my community as a co-generated reflective narrative ethnography. In the prologue, I explained that: "Narrative ethnographies refer to texts presented in the form of stories that incorporate the ethnographer's experiences into the ethnographic descriptions and analysis of others" (p.6). I understand and present here the realization that to be included into in community has multiple methodological significations. I choose to write a life story narrative because this methodology allows me to reconnect to my village in the holistic sense of connecting. Holistic means for me physically to go back to my village and later mentally reflect on the experience and produce a written text. It also means emotionally living the relationships and spiritually embedding the Kabyle beliefs and connecting with my Ancestor. This life story narrative aims to answer to my duty as a member of my village to take my place and claim my responsibilities in my heritage. Self reflexivity is an important aspect of this process.

\section{Life is action: A reflective ethnography}

"Reflexive ethnographies" (Ellis and Bochner 2010) illustrate the changes ethnographers experience during the field work It is that praxis, of reconnection to my village, that I am looking for when I start my inquiry. Praxis for me means to change when I go back 
to Algeria. I see myself changing and I reflect on those changes. Denzin (2003) states that: “... performance auto-ethnography contributes to a conception of education and democracy as pedagogies of freedom. As praxis, performance ethnography is a way of acting on the world in order to change it" (p. 262). Praxis is viewed here as the coming together of theory and action. One most important motivation of writing a life story is to work for social change. I am not only describing my community but I include myself in it.

\section{Writing home: "community auto-ethnography"}

Since the purpose of my inquiry is the recovery of my identity, it is crucial that I reconnect with my community in a way that is sensitive to my Berber culture. I hope that my inquiry has the potential to build my community by sharing Kabyle cultural practices. Ellis and Bochner (2010) state that, "Community auto-ethnographies thus not only facilitate community-building research practices but also make opportunities for cultural and social intervention possible" (p.59). Narrative inquiry allows me to integrate my story into the stories of my people. I built a home, a Self, where I integrate my community and myself. Writing a story is already an analysis as this genre organizes the events according to the researcher's choices and aims.

"Narrative is a conventional form, transmitted culturally and constrained by each individual's level of mastery and by his conglomerate of prosthetic devices, colleagues, and mentors. Unlike the constructions generated by logical and scientific procedures that can be weeded out by falsification, narrative constructions can only achieve "verisimilitude" (Bruner J. 1991, p.4).

My narrative is a form of writing that includes the individual in its socio-cultural context, inscribing me in the continuum of my community life cycle. 


\section{Continuity and continuance: "co-constructed narratives"}

As a member and active citizen of my community in Algeria, I participate in the protection of our traditions by telling the story of the wisdom of my whakapapa (genealogy) within my village. With this inquiry, I aim to bring the spirit of my Ancestor back to the village. I share narratives that my family, my community, and I co-construct when sharing that experience. I try to restore the story of the Ancestor to the people and myself as a part of them. In that sense, I reconnect to the past to bring a new beginning to our traditions, a beginning that Shirinian (2000) describes as follows:

"Beginning implies both return and repetition and not a linear development to some ultimate moment... Beginning a quest, departure from what is known, sets up a connection between continuance and continuity" (p. 145).

Narrative inquiry brings the idea of interconnectedness to the forefront, supporting a holistic approach to research. Polkinghorne (1988) explains in "Change from "beginning" to "end" that:

"Narrative explanation derives from the whole. We noted that narrative inquiry was driven by a sense of the whole and it is this sense, which needs to drive the writing (and reading) of narrative. Narratives are not adequately written according to a model of cause and effect but according to the explanations gleaned from the overall narrative..." (p.116).

\section{Interconnectedness}

The interconnectedness of my story is rendered by the holistic characteristic of my methodology. The connection happens on multiple levels, between me as researcher and the participants, but also between me as researcher and the readers. Ellis and Bochner (2010) 
present interconnectedness as layered accounts that "use vignettes, reflexivity, multiple voices, and introspection (Ellis, 1991) to "invoke" readers to enter into the "emergent experience" of doing and writing research (Ronai, 1992)"(p.6). I write a narrative that respects my personal agency. The socio-cultural and political environment is an important teacher during my journey in self agency. Arthur Frank (2010) explains that:

"What begins as a disruption is then a reconstruction into continuity - perhaps a contingent continuity, but nevertheless a single narrative trajectory that holds different aspects of a life together as a whole. Life as a whole, bound by causal connections, is the artful accomplishment of the self-story" (p.115).

This interconnectedness between us all, the concept of the cycle and the transmission of heritage and continuity are at the root of our identity. It means that we are all connected. The land where our Ancestor comes from is a part of that cycle and a part of us. Makilam (2007) explains here that for Kabyle people:

"Human existence was not separate from the natural world, since it followed the same cyclical patterns. It was believed to emanate from the same invisible source that belonged to the eternal cycle of death and rebirth. Kabyle spirituality united the physical world of their surrounding with the invisible non-concrete world, which for them, was just as real [...] According to this belief, the human was a passenger on earth and his duty was to prolong the cycle of life he carried within him by transmitting it to his children. Ancestors-worship was linked to family belief and thus heavily dependent on the cult of maternity" (p.231).

Interconnectedness in this auto-ethnography is shown explicitly with the presentation of my genealogy in the next chapter and with the story of my Ancestor. In the last chapter, my 
auto-ethnography does not make me feel like I am an isolated individual but instead reestablishes me in the journey of my people and my land. I take the place of participant as well as researcher. This position makes me reject the claim of objectivity and instead accept subjectivity as my epistemological stance. Auto-ethnography is a process within which I can position myself in my Kabyle socio-cultural landscape. By positioning myself in that specific landscape I support the building of my identity as a Kabyle man. I share the words of Tami Spry (2011) who says that:

"Performing auto-ethnography has allowed me to position myself as active agent with narrative authority over many hegemonizing dominant cultural myths that restricted my social freedom and personal development...”(p.711).

This auto-ethnography is also an indigenous ethnography in the sense that Denzin and Lincoln (2008) define in Critical Methodologies and Indigenous Inquiry, introduction to the Handbook of Critical and Indigenous Methodologies:

"Such inquiry should meet multiple criteria. It must be ethical, performative, healing, transformative, decolonizing, and participatory. It must be committed to dialogue, community, self determination and cultural autonomy" (p.2).

My inquiry is the recovery of a dialogue between my community and myself. It is located in the different places where we Kabyle live today, as well as in relation to the place where we all come from, our villages. The conversation that follows explains in more detail the methodology of this Kabyle inquiry. I make clear the strong Kabyle/indigenous voice in this auto-ethnography. I divide this part of my methodology chapter into four. I first explain the politically transformative agenda of my auto-ethnography. From this perspective, I explain the interconnectedness of the methodology. In the third part, I explain as well that storytelling is a 
holistic method respecting the indigenous epistemology in the larger sense of the word indigenous. I conclude by presenting my cultural standpoint with the two main Kabyle values of Nyia and Niff. I then explain how Niff and Nyia rule my auto-ethnographic experience.

\section{PART 2: INDIGENOUS AND KABYLE METHODOLOGY}

Narrative inquiry and auto-ethnography are significant tools for this personal journey of cultural recovery because they allow me to integrate my story into the ones of my people. Since my purpose is the recovery of my identity, I need to reconnect with my culture in ways that are culturally sensitive. I need to achieve self-determination with a Kabyle indigenous methodology. Linda Tuhiwai Smith (1999) explains:

"Self determination in a research agenda becomes something more than a political goal. It becomes a goal of social justice, which is expressed through and across a wide range

of psychological, social, cultural and economic terrains. It necessarily involves the processes of transformation, decolonization, of healing and of mobilization of people. The processes, approaches and methodologies -while dynamic and open to different influences and possibilities -are critical elements of a strategic research agenda" ( $p$. 116)

My experiences and personal narrative also interacts with Native American people. I recount in many places in this inquiry the teachings that I received from indigenous elders during on my journey.

\section{A decolonizing agenda}

Grande's (1964) Native American academic work is a major influence as I discussed in Chapter Two. She shares insights about her peoples' story: 
"Indian education was never simply about the desire to "civilize" or even "deculturize" a people, but rather, from its very inception, it was a project designed to colonize Indian minds as means of gaining access to Indian Labor, land and resources; therefore, unless educational reform happens concurrently with the analyses of the forces of colonialism, it can only serve as a deeply insufficient (if not negligent) BandAid over the incessant wounds of imperialism" (p.19).

I connect to this story of colonization since my inquiry addresses the issues of my colonized mind by supporting the development of my Kabyle self. I discuss the active colonial powers shaping the Kabyle landscape. They are very similar to the ones that Grande (1964) presents:

"With the regard of American Indians, this means understanding that "the Indian problem" is not a problem of children and families but rather, first and foremost, a problem that has been consciously historically produced by and through the system of colonization: a multidimensional force underwritten by Western Christianity, defined by white supremacy, and fueled by global capitalism"(p.19)

We, Algerians, have been in a war against France for our independence from the first time the French arrived on our land with a conquering agenda, in the early 1800. I aim for a decolonizing methodology that helps me to reintegrate into my community and brings back the integrity of my family endangered by the colonizing forces. Bishops (2005) explains the risks of colonization in ethnographical narratives:

“... The process of self-critique, sometimes termed paradigm shifting, that is used by Western scholars as a means of "cleansing" thought and attaining what becomes their version of "truth". Indigenous scholars challenge this process because it maintains 
control over the research agenda within the cultural domain of the researchers or their institutions”. (Bishop, 2005, p.115)

I avoid this trap of positioning myself within the representation system of the colonizer by staying deeply rooted in my cultural landscape and by writing with an awareness of the politics of indigenous research. My auto-ethnography inscribes itself in Lester-Irabinna Rigney's vision:

"I understand Indigenist research to be informed by three fundamental and interrelated principles:

- Resistance as the emancipatory imperative in Indigenist research

- Political integrity in Indigenous research

- Privileging Indigenous voices in Indigenist research” (Lester-Irabinna Rigney, p116).

Accepting this as a decolonizing experience, I become conscious of the culture that I have always carried but that I had not seen clearly. In doing so, I distance myself from the French culture within me; that French culture was until recently fighting for a position of leadership in the development of my identity. Thus I can become an active agent of decolonization. The closer I get to the core of my culture, the stronger my voice as a Kabyle is heard within me and in my village.

\section{Shared with the community}

In this respect, Denzin (1997) argues that:

"The living body/subjective self of the researcher is recognized as a salient part of the research process, and socio-historical implications of the researcher are reflected upon "to study the social world from the perspective of the interacting individual" (p.xv). 
I try to ensure that my story, my Kabyle auto-ethnography, is never isolated from my family, community and nation, but in fact works on bridging us together, just as Bishop envisions Kabyle identity:

“...just as identity to Maori people is tied up with being a part of the whânau, a hapu, and iwi. In the research relationship, membership in a metaphorical whânau of interest also provides its members with identity and hence the ability to participate. Furthermore to step aside from participation in these terms is to promote colonization, albeit participation in ways defined by indigenous peoples may well pose difficulties for them.” (Bishop, 2005, p.129)

As I work on my decolonizing self, I bring with me my community. However, I realize that my community is much bigger than I had imagined. Maori people of Aotearoa/New Zealand are working toward self-determination as well.

\section{Story telling: a holistic approach}

Storytelling is an indigenous and Kabyle methodology. Makilam maintains that the transcription of the imaginary and the oral tradition is a common practice within Kabyle people's culture. Makilam says that:

“The study of Magic arts of the Kabyle woman's oral tradition involves transcribing and definitely writing down something that is invisible. Capturing formulaic speech exposes several issues, which are also determined by the lived experience of the ritual life of Kabyle practice.” (p.15)

Battiste (2009) explains that indigenous epistemologies are asking for methodologies adapted to the indigenous cultures. Because of the nature of indigenous epistemologies, there are protocols to respect to keep the holistic integrity of these epistemologies. 
"Indigenous people's epistemologies are derived from the immediate ecology; from people's experiences, perceptions, thoughts, and memory, including experiences shared with others; and from the spiritual world discovered in dreams, visions, inspirations and signs interpreted with the guidance of healers or elders. Most indigenous peoples hold various forms of literacies in holistic ideographic systems, which act as partial knowledge meant to interact with the oral tradition" (p.499).

For Linda Tuhiwai Smith (1999) the stories told to create community are at the same time talking about the one that exists. They reinforce the connection between the people. She refers to each individual story as a powerful catharsis of the community. All stories inscribe themselves on the global narrative of the tribe. They are conversations in and between us. My auto-ethnography is first a conversation with myself, an element of my community, but also with my community at large. My story is part of the story of my village.

"Story telling, oral histories; the perspectives of elders and of woman have become an integral part of all indigenous research. Each individual story is powerful. But the point about the stories is not that they simply tell a story, or tell a story simply. These new stories contribute to a collective story in which every indigenous person has a place. The story and the story teller both serve to connect the past with the future, one generation with the other, and the land with the people and the people with the story. Intrinsic in story telling is a focus on dialogue and conversations amongst us as indigenous peoples, to ourselves and for ourselves. Such approaches fit well with the oral traditions that are still a reality in day to day indigenous lives. Importantly, story telling is also about humor and gossip and creativity. Stories tell of love and sexual encounters, of war and creativity. Stories tell about our cultures..." (Linda Tuhiwai Smith, 1999, p.144, 145) 
Auto-ethnography is a Kabyle and indigenous methodology when it respects the agenda enunciated by indigenous research and methodologies. My Kabyle auto-ethnography is expressed within an indigenous value system and epistemologies using the Kabyle values of Nyia and Niff that I present later in this chapter.

My story is written with two perspectives: the Kabyle participant's perspective and my own, which are woven together. I have a double consciousness and two narrative threads throughout my inquiry. The story respects the connectedness and coherence of an identity that has moved through centuries with flexibility, adaptation and coherence, without becoming the linear description of a fragmented self, a collection of identities with no connection between themselves. Battiste (2009) explains that:

"Through analogies and personal style, each person in tribal society modeled the harmony among humans and the environment in their stories, through art and design of their craft, and on their personal objects and clothing” (p.499).

In my narrative I participate in the enrichment of the body of knowledge of my community by working as a participant in this story of cultural recovery. I share on a different level with my community, to whom I explain my inquiry and with whom I look for the story of my Ancestor, and with my indigenous community at large, with whom I engage in cultural dialogue, sharing my culture and talking about the cultural challenges of writing such an inquiry in an academic environment. I now explain the Kabyle culture of this methodology.

\section{Kabyle epistemology and perspectives}

Becoming aware of my heritage, I realized that what kept me walking were my Kabyle teachings. I wrote inspired by the love of a woman, my mother, my land, who has taught and still teaches me that pride is not in power but in generosity, that self-esteem and honour are not 
in superiority but in humility, and that dignity is not a flag that we shake in the storms but a strength that helps carry family in the blinding blizzards of life. In the shapes and voices that my mother takes, she has taught me that forgiveness is the gateway to a healing relationship with the world and trust is not a granted gift but a responsibility towards others; it is not a burden but a gift that makes the journey easier.

In Kabyle culture, respect is given to an individual of great value, that is an individual who shares and listens, an individual who is available to his family and community, not to an individual guided by ego, power or financial success. We listen to the poor as well as to the rich but give resonance to the words in our life; that is why a poor man can be more respected than a rich one. Mana is given to people of Niff, meaning people involved with the community as well as people who show dignity and pride in their identity. People of Nyia also have a special place in my community; they have humility and extreme generosity (Bourdieu, 1972). The two concepts here of Nyia and Niff could be the main concept for a Berber philosophy of education. I approached my inquiry with a Berber ontology: respect, humility, generosity and honour.

Thus, when I am asked about my methodology I answer that values are tools but tools are not values. I wish to be with my people, to create a healthy relationship that can sustain my community so that my Ancestor stays alive in our hearts, bodies, minds and spirits. I use the word healthy to explain that it is by working in and with our culture that we will bring healing to the community. Inspired by a Berber value system, I aim to write the story of my self-cultural recovery, interacting with people in my village. I keep the name of the villages fictitious and the location stays vague for ethical reasons. My aim is not to teach the Western knowledge to my people, and my ancestors through them, but more to bring these experiences 
as an offering in exchange for this identity I have for so long silenced in order to fit into the Western country I was living in.

Josselson (2007) argues that while writing one's life story narrative the question of respecting moral behavior is important. The author explains that there is no guidebook to moral behavior. However, if ethics in narration is not a matter of abstractly correct behavior, it is a responsibility in human relationships (p.538). I see the responsibilities evoked in this quotation that are encoded in my value system. As much as I intend to interact with my people back home, I want to share the knowledge gathered here with a wider public. For Josselson, "Narrative research consists of obtaining and then reflecting on people's lived experience and, unlike objectifying and aggregating forms of research, is inherently a relational endeavor." (p.537) Infusing academia with indigenous knowledge is an ambitious agenda if one wants to carry this task alone. Yet, it is possible when it means walking with our Western brother on a journey that brings a better understanding of each other. Those values I am living by in my village I will live with in academia, respecting Kabyle principles of ethics and commitment to the wellbeing of my brothers and sisters.

\section{Key sensitizing concepts: Nyia and Nif}

In order to understand my methodology, it is important to clarify the principle of Nyia and how it applies to the Kabyle society. Although Nyia is difficult to translate, it relates to generosity. This concept can then lead to methods that I used to collect the data with the community. The presence of the concept of Nyia in our culture shows that generosity is superior in value to wealth. Kabyle culture is not about adapting society to economic needs but growing a culture from the land and changing it to become an economy. There is a dynamic of growth from the bottom to the top, but the community bonds create a horizontal movement 
between members of the community; the act of sharing doesn't fit into a pyramid. Generosity is a horizontal force. It is one of the Earth's forces that speak in the Kabyle concept of Nyia.

\section{Researcher profile}

The Bou Nyia (generous man) is the model we traditionally start with and from which we build our society. It connects us back to the earth and keeps the organic dimension of our culture. When one talks about Kabyle culture, one has to see it as it has developed and as it wants to be, not only in a pragmatic and idealistic way. The participant/researcher must be considered Bou Nyia, honest and trustworthy. Not respecting that principle might lead to a rejection of the researcher from the group and stamp the negative label of "selfishly interested" on the research. The whole inquiry can be considered individualistic and thus threatening to the social order.

Silverstein (2003) describes the Kabyle society from the principle of Nyia but he looks at it from a different perspective.

"...It comes back to say that the stability of the economy of Kabyle good faith lies directly on the capacity of Bou Niya to misunderstand its own practices, seen as simple repetitions of social norms in the form of natural cycles. The rooting of social rhythm in the natural cycles has the effect of changing the cultural forms to natural forms. The reproduction, in other words, generates more reproduction". (Personal translation, p.29)

The meaning of Nyia is to share without expecting anything in return. With this type of sharing a man becomes a Bou Nyia.

\section{The gift of Nyia}

It is indeed a self-regenerating process as generosity brings more generosity, even more so because the law of honour in the Kabyle community keeps one from taking advantage of someone else's generosity. Furthermore, Kabyle culture does have a material form, as it is 
generated from a natural order, not a simple reproduction of rites and customs. Nyia, for an honorable man, is like breathing. We know we are doing it but we won't stop because our life depends on it. Looking for individual profit in a context like this one becomes then like having a smoke, a short release of pleasure that in the long term kills you and your family. Nyia or the principle of generosity comes from the natural need to help each other. If there is one thing that Nature teaches us it is humility, and one big fact that we learn is that we are small and that is why we need to help each other. We are born from the Earth and go back to the Earth.

Indigenous people grow societies from the land. It is a much different dynamic that raises questions regarding the legitimacy of other societies and their ecological and philosophical foundations. We have societies of harmony rather than control. I mean to say here that we do not create societies from the need to control the people but to live with them. Economic imperialism generates a culture that is mentally constructed around principles of domination and competition, which is an inappropriate standpoint to talk about in Berber culture. We live according to the land. If today the situation has changed it does not mean that those changes are definitive; they are just more unfortunate. One aim of my inquiry is to look for a solution to that situation. Bourdieu (1972) and Silverstein (2003) seem to describe culture as an intellectual organization of social space according to economic determinism. I agree that economy influences cultures but a culture as old as the Kabyle one has not been developed from capitalist philosophy and cannot be described by it.

Nyia is a gift as well as a burden. A person with Nyia gives away what they consider most important. That person is considered as overly naive by some people but respected because such a heart is thought to have the protection of God. Nyia is also the destiny of all because it is said that nothing belongs to us but is only shared with us. I share the story of my ancestors even if it is sacred for my family. By sacred I mean, that has to be treated with respect by that is not secret. It is offered with the intention of supporting brotherhood. This 
relationship nourishes the work I am engaging in. It works with the trust and respect of my community; it gives me access to knowledge. This sharing experience creates a relationship between the participants of my inquiry and myself. Josselson (2007) says:

"The greater the degree of rapport and trust, the greater the degree of self-revealing and, with this, the greater degree of trust that the researcher will treat the material thus obtained with respect and compassion. What constitutes respect and compassion in the minds of this researcher/participant pair is the nature of the implicit contract between them" (p. 539).

Narrative and Auto-ethnographic methodologies however face challenges from positivist scholars who view research as unethical. In the next part I discuss the positivist assumptions on qualitative research and auto-ethnography.

\section{PART 3: POSITIVIST AND POST-POSITIVIST ASSUMPTIONS ON QUALITATIVE RESEARCH}

The critique of auto-ethnography and narrative inquiry focuses on three main arguments: auto-ethnography is considered (a) self indulgent, (b) narcissistic and (c) individualistic. The methodological dialogue that I undertake here is a non-exhaustive presentation of the positions of auto-ethnography. Atkinson (1997 and 2001) presents the positivist and post-positivist assumptions on qualitative research. I then discuss Atkinson's ethical concerns. 


\section{Individualistic/ethno-less research}

Auto-ethnographic research methodology can result in the creation of an individualistic self. By such practice there is a "danger of recreating a new, individualized homunculus that escapes sociological or anthropological comprehension" (Atkinson, 1997, p. 335). As I want to describe the journey to the centre of my village, I need to share the context of study. Atkinson is worried that it might not be possible for auto-ethnography to present the world in which the researcher is evolving. He is concerned that:

"We may have abandoned forever (though others have not) the model social actor driven solely by self-interest or the rational actor of classical economics. We should not reintroduce a new variant - the isolated actor who experiences and narrates as a matter of private and privileged experience" (p. 335).

I share Atkinson's concerns because I have decided to use auto-ethnography as a methodology of social recovery and decolonization from within my community. This means that the place of the society is important for my inquiry. If I ignore the political and sociocultural context necessary for the creation of my indigenous identity, I might forget about the colonizing construction of the self that lead me into this experience. Atkinson (1997) explains that:

"It (auto-ethnography) starts to transcend the realm of analytic methodology and becomes a surrogate of liberal humanism and a romantic celebration of the individual subject..." (p. 335).

He states that auto-ethnography is the description of the self by the self, isolating the individual from his environment. Atkinson (1997) critiques Kleinman (1988) saying that: 
"In the hand of Kleinman (1988) it seems to me, we do not find a commitment to understanding the forms of social life or even the forms of narrative... Moreover, his analysis dissolves the social"' (p. 335).

If auto-ethnography does not describe the society, as well as if the discourse in the auto-ethnography is not informed by judicious narrative choices (in that regard), this methodology might end up in misrepresentations of the self or the society as well. However, Atkinson (1997) says that: "The assumption of authenticity uncritically reflects dominant beliefs about the self and its revelation. It endorses a romantic image of the interior self- a self that is also anterior to the realm of social action" (p. 342). Dauphinee (2010) is confronted in her ethnographic research with the lack of social context in the planning of her ethnography. She goes to Bosnia with a set of outcomes that she tries to prove in the field, but soon enough she realizes the limits of this methodology:

"So the knowledge that emerges explicitly in auto-ethnographical accounts is already there- it is present because all of us who arrived in someone else's country with solid research agendas and eager questions have encountered aspects of these communities (or individuals within them) that do not fit with the overall account. These people ask something else of us; something that our profession is not prepared to give" (p. 805).

This story illustrates the limit of a post positivistic methodology that creates a world apart from the world, with an individualizing consequence such as a therapy based on the assumptions of the healing power of the mind and independent of the community. Atkinson (1997) warns against the narcissistic aspect of ethno-less methodology and explains that in auto-ethnographical inquiries: 
"We need to pay attention to their construction in use: how actors improvise their personal narratives of work accomplished. We need to attend to how socially shared resources of rhetoric and narrative are deployed to generate recognizable, plausible, and culturally well-formed accounts" (p. 341).

\section{Narcissistic and self-indulgent research}

Doloriert and Sambrook's (2009) present a fictive auto-ethnographer, creating a fictional character that they "use" to describe the limits of auto-ethnography. In their presentation Josie, their fictional character, shares with her reader some of her personal psychological "issues". She confesses that she is going to a psychologist. "She thought about how much her cognitive behavior therapy had helped her manage these attacks and highlight to her the power of the mind" (Atkinson, 1997, p.31). In this case study Josie addresses her personal inner life with a rationalizing therapy. At the end she is happy with what she has done and celebrates her own successes. Doloriert and Sambrook (2009) present a very selfindulgent behavior. Josie seems only motivated by herself and her wellbeing. Even though she shows empathy, that empathy is turned towards a more selfish wellbeing. Knowing that she has empathy helps her feel better about herself. Josie "feels comforted by the interconnectedness, empathizing with the pain of others, being touched by their narrative, affected by their reflexivity and in sheer admiration for their wonderful story telling" (p.7). Doloriert and Sambrook (2009) are presenting Josie's auto-ethnography as self-indulgent, and patronizing toward the participants of her life story. Her participants are being objectified. They become instruments for her wellbeing.

Self-indulgence or narcissism can be associated with subjectivity. Subjectivity in autoethnography implies editorial choices in the narrative that might be pushing the auto- 
ethnographer to silence the truth for the profit of a friendlier narrative of the Self, removed from the influence of the Other. Roth (2009) explains:

"Authors write about their being conflicted by something, about their upheaval, about their selves, about their self-consciousness, completely failing to address not only the ethno in their method but also the very constitutional Other prerequisite to the existence of the Self."'(p.5)

Clearly stated here is the importance to move away from a self-centered attitude. Roth (2009) explains that auto-ethnography can be a succession of personal facts presented independently from each other and from the context of inquiry. As such, auto-ethnography risks being a story about the "auto".

\section{Positivist and post-positivist ethical concerns for qualitative research}

In his work on auto-ethnography, Atkinson (2001) constructs his argumentation from Beauchamp et al:

"These Dual concerns with outcomes and rights are often translated by ethicists into a set of principles to guide research practice. The following list, from Beauchamp et al. (1982:18-19) is typical:

. Non-malfeasance: that researcher should avoid harming participants.

. Beneficence: that research on human subjects should produce some positive and identifiable benefit rather than simply be carried out for its own sake.

- Autonomy or self-determination: that the values and decisions of research participants should be respected. 
. Justice: that people who are equal in relevant respects should be treated equally.

The first two principles are consequentialist while the latter are primarily deontological”' (p. 3).

These principles enunciated by Beauchamp find echoes in different methodological dimensions of an inquiry: autonomy/ownership, objectivity/clarity, outcome/purpose, fieldwork/laboratory and finally beneficence/profit. They resonate in ethical concerns such as issues with safety, duty of protection of the researched, problem of objectivity as well as the question of autonomy and ownership.

\section{Precise outcome for safety}

In the whole discussion on the "validity" of ethnographic research the main obstacle is always the philosophical as well as political standpoint of the interlocutor. Atkinson seems to embrace a positivist perspective. Indeed, the writer tries to define, control and manage the outcome of research and presents positivist research as an ethically appropriate research method. "However careful researchers may be in their own writing, they cannot guarantee it will not be used to produce offensive characterizations of participants or setting" (p. 7). For Atkinson (2001) in "good" qualitative research the participant is aware of all the consequences of the research. The ethics of research create a context, a conceptual laboratory, in which the participant, the object of study, can evolve safely. "The rights of research subjects in ethnographic work will not be respected simply because consent forms have been signed: indeed, as in much biomedical research, these forms may offer more protection to the researcher than the subject in the event of litigation" (p. 9). The emphasis is then put on the outcome, which Atkinson wants to protect with an ethical research method. Atkinson 
expresses his concern for participants who might lose autonomy that can be "at odds with the exercise of self-interest" (p. 3).

\section{Authority of the researcher for protection of the researched}

Atkinson suggested here that his conventional methods can be judged by other methods that are coming from a different perspective. This issue of legitimacy implies a standpoint already critical of the qualitative methodologies being questioned. With his discourse Atkinson puts the qualitative ethnographer in front of the jury and becomes the prosecutor. Qualitative researcher becomes the offender and the research the threat for the participant's self-interest. For Atkinson (1997), "the value of memory and the value of narrative are closely correlated, of course, and are clearly demarcated by the hierarchy of professional position and authority" (p.329). Atkinson (1997) places himself in a position of protector of the interest of the participants. I find that Atkinson's position brings the reader to consider positivist research as the best alternative to the "other" research methods. He says: "Unlike experimental researchers, ethnographers typically have limited control over who enters their field of observation. All research lies on a continuum between overtness and covertness" (p. 9). Atkinson (1997) separates the concepts of autonomy and selfdetermination and creates opposition between self-determination and self-interest, placing himself as the referee. He explains that the subject studied might not be aware of the result of the research and that this might be a threat. Not being able to control the direction the researcher is taking might create an imbalance in the social situation of the subject. This imbalance might turn into a loss of autonomy for the participants, as it is setting the researched in a place where he or she does not have any control. 


\section{Objectivity for transparency}

In the positivist paradigm that Atkinson defends, the research participant is considered an object for the benefit of science and for the participant's own sake. For Atkinson (1997), "the publication of accounts may expose individuals to other versions of reality held by those close to them, breaking down protective silences" (p. 8). The research agenda should be predetermined in order to allow the researcher to manage the consequences of the research: "Consequentialist approaches focus on the outcomes of research" (p. 2). The researched has to agree to give up for a while his or her "mana" (ownership, honor, dignity) so that the researcher can do his job as "scientifically" as possible. Of course the word "science" here is seen from a positivist standpoint and presented as the white horse on which Western society rides to save the world. What I wish to explain here is that a "positive" research is to show concern for the interests of the researched. It is a reality that every researcher has to face as Atkinson (1997) says:

"At the level of presentation, there can be little disagreement that ethnographers are, at least potentially, able to exploit their authorial position by imposing interpretations on their data. Nor is there any doubt that, in doing so, he may disempower and abuse research participants" (p.16).

Scientists might be able to have a clean conscience about the research. What is good is what the researcher can find for the community. If a scientist decides to run a battery of exams on you to test your resistance to some viruses and explains to you the possible consequences of that experiment, and you decide to sign off your rights, then it means that the experiment is ethical. This method is also justified by the "higher" outcome of scientific progress; the scientific universal dimension and the value for the whole of humanity that positivist scientists 
give to themselves. In the example previously mentioned the researcher respected the ethical guidelines.

\section{Autonomy/ ownership}

The participant experience is not disappointed because he or she has no expectation other than the compensation agreed upon with the researcher, and that could be money and/or moral acknowledgment of his or her participation. Roth (2009) introduces another aspect of betrayal of the participant. He presents Eminem's songs as auto-ethnography. Eminem is a hip hop singer from the USA. From the songs he draws a reflection on the ethical aspect of autoethnography, most precisely on the safety issues for the researcher or participant, "because he raps about his own life, he also exposes those surrounding or involved with him. Their pain is no longer something private, but something that is made public, perhaps without their consent.”(p.3) Atkinson supports the same critique:

"Auto-ethnography typically presents the actions and interactions of others from others perspectives. What is the basis of the auto-ethnographer's authority to represent those others in this way? Should the consent of other players in the auto-ethnography not be obtained before publication?"

Tolich (2010) supports the idea that prior agreement cannot be given by the ethnographers because of the nature of the inquiry. By not taking control of the research and accepting to expose an ongoing process, the ethnographer is at the same time exposing his or her "subjects". The ethnographer creates new situations that could not be considered previously by the ethics agreement. The ethnographer is then forced to proceed to a post research agreement that can be challenged as not ethical because it is not really genuine as it is based on the need to make use of the research. In this respect Tolich (2010) argues: 
"I question whether genuine consent can be gained retrospectively without creating a conflict of interest weighted in favor of the author rather than the research subject. Seeking informed consent after writing an article is problematic and potentially coercive, placing undue obligation on research "subjects" to volunteer" (p.2).

It is important for these authors to discuss whether the "subject" of an emancipatory research wants to, or is ready to, be installed in a new life paradigm where the newly acquired empowerment can have consequences for which the researchers, as well as the "subject", are not prepared. Tolich (2010) shows that "some of the leading auto-ethnographers, often held up as experts in their craft, did not appear to anticipate ethical issues or recognize boundaries within their collection of ideas" (p.4). In auto-ethnographical research the author is taken into reconstructing a reflection of the Self that challenges the situation or status quo of his or her life. Auto-ethnography brings new insights that the "researcher-researched" has to live with. Moreover, to live with the knowledge, the auto-ethnographer sees no other possibility than to address it in challenging his/her personal life. The consequences can be difficult to deal with for him, her or the environment. Can this new consciousness result in an alienation of the researched- researcher, myself here, from my community? Is this new consciousness a possible threat for the balance of the inner Self of the researcher-researched?

\section{PART 4: CRITIQUE OF THE POSITIVIST STANDPOINT}

Atkinson's (1997-2002) arguments translate into ethical questions about values. What if it is better for the participant to give up on his self-determination for his own interest? What if it is better for a participant to be fed so he will not have to think of looking for food? Denzin explains that: 
"The three main interpretive communities (post-structural, mixed methods, science-

based research) must learn how to cooperate and work with one another... Fruitful dialogue is not only a possibility; it is a requirement if a democratic community is to flourish in the academy and within the qualitative inquiry community" (p.42).

The first important step in developing a friendly Kabyle indigenous methodology is to move away to from Cartesian thinking, which I discuss next.

\section{Necessity to move away from Cartesian thinking}

Important to the task of defining a Kabyle methodology is that it needs to integrate culture and spirituality in their philosophy of education. In the old paradigm of research in Cartesian or Newtonian perspectives, a reductionist and instrumental knowledge has been implemented to the detriment of mysticism and spirituality. Postmodernism seems to acknowledge culture and spirituality of human life in bringing more humanism into the field of science and research. A fundamental epistemological assumption of postmodernism is that no method is privileged. That tendency allows us to address new avenues in human inquiry, avenues that were unfortunately ignored for a long time in our relationship with our students. Educators tend to lament the disappearance of education for the profit of simple training which in turn leads to a disengagement of the individual in the society in which they live. Ultimately, they exchange active citizenship for passive consumerism. Ross (1993) expressed his opinion in contrast with an older version of research in a social paradigm that shows the desuetude of Cartesian and Newtonian perceptions: "I hold to a more open, hopeful view of the world as still creative and promising, a view that may yet break in upon us as we move out of an older world of Cartesian dualism and Newtonian science" (p.308). My aim to reconnect with my community is a creative experience in education. I share it in my Kabyle Indigenous life story narrative. Having raised the positivist questions, I engage with them in this following section. 


\section{For a dialogue}

I do experience tensions, if not frustration, when I read Atkinson $(1997,2002)$ from my indigenous academic perspective, but I acknowledged his position in order to reflect on it from my personal standpoint. From my experience as an indigenous person and my life within indigenous communities, I believe that Atkinson's position is very disrespectful. How can an outsider decide to come and "study" my family and me, and then pretend to protect us? How can he know what is good for us before he actually knows us and becomes part of us? What gives him or her right to tell me what is good for me? There is a patronizing agenda here that really makes me feel uncomfortable. A community can take ownership of their responsibilities when participating in an inquiry especially when it comes from within their community, through a member of that community, serves the story of the community and has been decided by the community. The fact that the community decided for itself to engage in a research project is already a "positive outcome". Denzin (2010) explains:

"The ethical agenda"

The qualitative inquiry community needs an empowerment code of ethics that crosscuts disciplines, honors indigenous voices, implements the values of love, care, compassion, community, spirituality, praxis, and social justice"(p.40)

As an indigenous researcher I cannot agree to place myself completely outside of my community. Roth (2009) introduces the concept of co-generative research.

"Co-generative dialogue as we have developed in the context of inner-city schools, involves all stakeholders in the process of making sense of their life worlds... Because each person gets to speak and each person provides space for others to speak, the understandings (about what happened) are not conflated into homogenizing one 
(usually the researcher's) voice but retain the multiplicity arising from co-presence of all participants voices" (p.3).

Coming from an indigenous perspective, it is clear that the land is part of our culture and identity and as such cannot be ignored in the research process. Describing the land and the participants separately would be dismissing the cultural contexts of the research. Controlling

the interactions of participants for the sake of clean and accurate knowledge runs the risk of distorting the culture. This distortion would be totally contrary to the agenda of social science and indigenous studies.

\section{Empowerment}

According to Atkinson (1997), "exploitation only occurs when ethnographers use their superior power to achieve their objectives at real cost to those they are studying" (p.11). Autoethnography and indigenous studies have a different agenda than positivist research. Autoethnography aims to empower the people in and through their stories. Empowerment can result in the realization of the Self, within a life that is designed by the Self, within the "natural community" to which one belongs. I use the word natural community here in contrast to postcolonial or colonial geopolitical community. I refer to culture as an organic heritage coming from the interaction between the land and the creatures that inhabit it. Maguire (2006) described this interconnectedness as ethical because:

"This concept of authoring views a self that is answerable not only to the social environment but also a self that is answerable for the authoring of its responses. From this perspective dialogue is a socially embedded meaning-making process, human and actions are synonymous and as self is answerable and responsive to both self and other" (p.4). 
Culture is the expression of life in action. As such, a narrative inquiry like the one I am writing, one becomes the language of a land. An auto-ethnography in a Kabyle landscape is not a political document that promotes the supremacy of universal academic techniques of inquiry but rather one that requires the respect of the author and his participants who places himself in the landscape that nourished his culture and his family.

\section{Sustainable reconnection}

Maguire (2006) explains:

"This conscious positioning of authors within their texts opens up possibilities for evocative, innovative ways in which researchers may represent realities, themselves and their research participants in their texts. Auto ethnography, a genre of writing that involves personalized accounts in which authors draw on their own lived experiences, connects the personal to the culture and places the self and others within a social context (Reed-Danahay, 1997)”.

A research paradigm that aims to protect the outcome also protects the place of the researcher. By wanting to build a safe and clear environment for the researched and the researcher, the researcher creates a world inside a world. This context is philosophical and geographical. It leads to the creation of the concept of fieldwork but an indigenous researcher cannot use the lexicon of fieldwork when he or she talks about his or her family or indigenous culture. It is not an expedition to a foreign country, but an embodied experience that supports the building and transformation of the Self. The word "embodied" here is important because it means to take inside, to welcome and be a part of. Atkinson explains that "the conventional approach is also troubled by the problem of "false consciousness": What if the exercise of autonomy and self-determination by research subjects is at odds with the exercise of autonomy and self- 
interest?” (p.3). It is a much deeper research process than simply trying to bring to the surface a knowledge that will be available for all as a commodity after surrendering to the ritual accumulation and regurgitation of knowledge in classical Western education. Indigenous education is an inclusive and transformative process. The only outcome is that of opening the world to an individual by supporting him or her with the strength and love of the community that welcomes him or her. In return, an ethical approach would require honoring that community and sharing with them the blessings and fruits of their love and work. As such, a methodology that only creates limited and temporary outcomes would be unethical in indigenous locations. Family bonds are supposed to last forever and are not tools or instruments of research; otherwise it would mean that one abuses the trust, love and hospitality of "participants".

\section{PART 5: ETHICS OF MY INQUIRY}

\section{Niff and Nyia applied to auto-ethnography methodology}

The two values of Nyia and Niff have been discussed in Bourdieu's (1972 and 1980) works. However, I believe it is necessary to remember that these values are Kabyle concepts and that it is a Kabyle man, myself here, who is sharing his culture. For this reason the reference to Pierre Bourdieu is only here to honour his contribution but cannot replace the expertise of my people and my experience in the field. I aim to show the connection between my indigenous identity and the auto-ethnographic research methodology that I am using to write my narrative inquiry. I present two crucial aspects of a "good "Kabyle auto-ethnography: Niff and Nyia.

I need to clarify that writing an auto-ethnography is not writing a dislocated description of the Self from the context of inquiry. On the contrary, writing a Kabyle auto- 
ethnography is an act of reflecting and critical thinking. It helps me to come closer, with the reflection on my experience, to the teachings that are embedded in the experience of my culture. The two cultural values guiding the building of a Kabyle methodology are Niff and Nyia. My village is open to outsiders who need support, or to outsiders who come for cultural reasons. We are always happy to welcome them for that purpose. However, if it is an outsider coming to assert authority or an outsider's taking ownership of our knowledge in our village, then the person is asked to leave. Presenting my inquiry as a gathering of data for the purpose of a scientific analysis in a Western university would be disrespectful and definitely not indigenous. However, writing an auto-ethnography of cultural recovery means reconnecting with my history and community in a culturally respectful manner. At the same time, it is important to remember that foreigners coming for a specific culturally appropriate reason, such as to come and honour the memory of the Ancestor or to pray on his grave are given hospitality. This principle is called Lahnaya. It engages the whole village in the protection of their guest and at the same time it is a contract that brings the duty to the guest to honor the community, or family that welcomes the guest. Foreigners are fed, honored and respected for their faith in the respect of our heritage.

To write an interconnected story is to be able to articulate the experience with respect. Geertz (1974) expresses very well my challenge when he says:

"The difficulty lies in articulating that experience, making it available to common view. Impressionism, invocations of camels and minarets, rice terraces and shadow puppets, produces a travel poster view of things. Empiricism, magpie amassment of cultural detail, produces an ethnographical telephone book. And thematicism, grand sentiment and large ideas, produces historical opera... (It) begins when one starts to think about 
where one is, and then, after the fact, works to replace them with something a little less summary, a little less external, and a little less charged." (p.23)

In the case of my indigenous auto-ethnography and educational experience, I am both not part and part of the village from the beginning. However, I am not considered an outsider. My experience of going back to the community shows the importance of their values and also teaches me what the values are. I learn more about them and the role they play in keeping my village together as I interact with my community

As I described previously, to be culturally appropriate and at the same time write an inquiry that is a Kabyle life story narrative, I have to write with the concepts of Niff and Nyia. The first value then is Niff. It means self-esteem, pride, sense of belonging and cultural strength. With the pride that I show in presenting myself as a Kabyle man and I honor my family. In my culture, a man is supposed to go out and be visible in public. By expressing yourself in public you show your strength, you contribute to the community and learn from it. In the past, these exchanges happened during the market. The men would come once a week from all the villages around for their weekly shopping. My father always insisted that I come with him to the market, where people would see me and associate me with him. It is also when fathers were shopping for a potential husband for their daughters. When I write my autoethnography I show respect for my father and my genealogy. These give to my autoethnography the Kabyle values expected of a man of dignity and pride. An example may be helpful here. I am in this big meeting place that is academia and I introduce myself to the world as a Kabyle Marabout man. For that reason my project is welcomed in my community. This honour that I give to my family comes back to my village, my family and me. My autoethnography becomes an act of honoring my traditions, my Ancestor and as such it is a much respected methodology. 
As I previously mentionned, Nyia is the second value that I am implicitly asked to have or learn here during my inquiry. It means generosity, honesty and humility. The people of my village were initially puzzled about the reasons for my inquiry. They have been very supportive since they saw that I was sincere and that my goal of sharing with the world was an act of Nyia. Welcoming me in the community was also an act of reciprocal love to my father and the possibility for them to show their gratefulness and respect to my father.

Thus, my auto-ethnography is a Kabyle methodology because it respects the two main values of Niff and Nyia. These values are the roots for the building of the Kabyle ethics for the inquiry.

\section{Challenges I faced}

I am not "new" in my village, as I have been going to Algeria regularly since I was a child. The longest period that I did not go back lasted four years. When I turned 18 I had to go to the army in Algeria like all the individuals of my age, but because I was studying I had authorization to go later. I finished university in France at the same time that my mother passed away. I did not go to her burial because of the Army. I stayed four years outside of the country until I received the official paper of my military exemption. Since then I have been going alone or with my father three times per year. However, I did not get very involved in the life of my village because I spent most of the time in our house on the outskirts of a big city at the feet of the mountain. During all my time in Algeria I developed a good relationship with my family. I was always welcomed. My relatives took me to the mountains, taught me about the roads, plants, food, and traditions, and brought me to their houses in the village. During these times I was not a village resident. Even though I was learning all these beautiful things I was still in some ways an outsider. I was only here on vacation and had no project that would be of any support to the family or the village. It was during my fieldwork that I finally 
engaged more with the people. It was time for me to engage in the dialogue with the members of my village. It was time for me to learn the life ethics of my community.

The ethical protocol of our culture asks to respect the relationship among individuals. In my culture, trying to take knowledge from an elder is appropriate when the elder agrees with the subject of the inquiry. It might take time before he decides to participate as the elder does not want to expose himself too much if he is not sure of the situation. If it is an important subject, such as the story of my Ancestor, then it might take time. In my case the village members engaged in informal conversations that I overheard. They decide whether it is respectful to our qanun (a value system that I explain later in my inquiry). The answer came with the participation of different elders.

I had to speak to my father who is the first entry to my genealogical story and the official representative of our family. My mother passed away and could not be a support in this task. To be able to have my father's approval I needed to make myself clear to other members of my community who had more knowledge of the traditional protocol. These individuals had to be members of my clan. They could not be from another clan, because going to another clan to ask for support could have been understood negatively by my father. The consequence could have been a major argument. But knowing that I did not grow up in Algeria my hesitations became a learning experience.

The access to knowledge was not easy. It meant engaging in the discursive activities of the community, putting myself for the first time on the spot in my community and taking my place in the writing of the history of the village. When my father understood that my intention was to take my place in the village, understand Algeria and the Kabyle society, and do that with respect for our heritage, he became supportive. He called people for me, told me stories, asked me to record some of our conversations and even went back to the village with me to 
introduce me to the permanent residents and ask them not to forget me and my family when he, my father, passes away.

My relatives played an important role in helping him to accept my inquiry. He could not, anyway, make that decision alone. This discussion and thoughts are all informal and I was amazed to see how the system of interconnectedness in the decision making process was so deeply embedded in my Algerian family. I was, in fact, far away from even imagining it, but this inquiry has been the chance for me to learn the decision making process.

Once in Algeria, my duty was to work on the building of my house. I hired a man and started the construction work. At the same time, I was going to the libraries. The members of my clan understood my journey and helped me get approval for the inquiry from the elders of my family clan, because honouring my father's life by pursuing his life work inscribes my family into the continuity of our village.

At the early stage of my PhD inquiry, I had to understand the protocol of the village. I made mistakes by asking direct questions and presenting my research according to the ethics application that I had written. I talked about anonymity and other condition that the ethics committee had asked (see ethics application I annex). The member of my village did not see the value of this ethics proposal. They went to our qanun (village rules and regulations) and came back to me when they were ready. It was in an informal conversation and I started receiving bits and pieces of information, until one day, going to the market; I spoke to an elder of my village. He had heard about my inquiry. He asked me what I was doing in Algeria. I said building my house and learning about my family. He looked at his son and said: "What he does is good and honorable. He is honoring his origins." Then he gave me some information about the Ancestor. During our conversation, we met some other members of the village who were also going to the market. They insisted on telling me more about the story 
that I present later in chapter 8 . They were from another clan. Their voices went up and the conversation became passionate but not aggressive. The elders were all talking together. In the beginning I thought that I had brought trouble into their gathering. When I saw my first interlocutor sitting back on his seat I called his son and asked him to stand behind his father. The man smiled and stood up. The other members of the village lowered their voices. We finished the conversation by greeting everyone and the members of the other clan insisted that I come and meet them. Obviously, something positive happened. However, I realized in the conversation that I could not retell the story associating specific members of the clans with the information given. Therefore in my inquiry, I cross-referenced between the stories told and I present the history from the history books that I have found in Algerian libraries, keeping the names, places and content of the interviews with participants anonymous.

As we see in this example, my place as an individual is never separate from the place I take in my clan. Even in a project of auto-ethnography, if I want to engage in the life story of my village, I need to be in harmony with the value system of the village.

The ownership of the knowledge is not a problem of course. First, because it is my life story that I am sharing; second, because it is knowledge that is public; and third, because sharing this inquiry shows pride in my heritage. The experience was presented to me like a good and honorable learning experience for all of us. With my participation, the village has developed a relationship with the House of Culture in Tizi Ouzou, which has promised to send them new books on a regular basis to support the building of a village library. The president of the village association signed a document with the official stamp of the association allowing me to do the research and write the story of the Ancestor if I so desired. In the letter it is explained that it is my heritage and that I was entitled to it. I do not add the document because it has the name of the village and the participants. However, they totally agree to have their name cited 
if necessary. After my "fieldwork", I kept receiving emails from the responsible members of the village association to thank me for the books and the research.

The members of the association asked me for my bibliography as they are always looking for book suggestions. Since our life story and educational background are very different, they are interested in what I read and know. However, academic language can be very elitist and may exclude the members of the village from the conversation about our heritage. They did not ask for my thesis but I am writing my inquiry in a language that aims to be accessible to all. Not only is English an international language but it is also understood in my village.

\section{Summary of the cultural ethical requirements for my inquiry}

Respect for the elders

Respect for the reputation and honor of the participants

Respect for the community bonds and social organization

Respect for the values

Respect for the knowledge transmission protocol

Respect for the communication protocol

Respect for the sites and places of inquiry

Respect for the medium of transmission.

In this part of the chapter, I have presented a conversation on methodology and ethical requirement for auto-ethnographic research; I also have summarized the ethical requirement based on the qanun of my village. Now I will move to this next part of the methodology that 
gives the details of the data collection process. It is important to remember that before going to my village I had to fill out an ethics application. The ethic application did fulfill the requirement of the ethics committee. I have been authorized to continue with my inquiry. I now turn to a discussion of the ethics application that was accepted by the ethic committee of Victoria University in Wellington.

\section{PART 6: DATA COLLECTION AND DATA SOURCES}

In this section I describe how I gained access to the site, collected data and my data sources.

\section{Context: negotiating access to the site}

It was not difficult to access the site because I go back to Algeria a couple of times every year. I have an Algerian passport, which means that I don't need a visa to be in Algeria and I can stay as long as I want. The fieldwork specifically took place over seven month, two months in France and five in Algeria. On my way to Algeria I often do that same journey. I stop in France to meet with my relatives and then go to Algeria. I always spend more time in Algeria than in France. What is new is the focus for my journey this time. The site is the multiple places of my inquiry. In France, I was introduced to cultural associations from my personal network and family relatives. Members of the association as well as some relatives referred me to other informants in France and Algeria. This helped me develop a network around the topic of my inquiry. In Algeria, I lived in one of my family houses, which is not in my village. I met with informants when they came to visit me, or when I would meet them at the market, in the village or even in the streets of the city near the village. 
On arrival, I hired a taxi following the advice of one of my informants. It is safer to know the driver, as going to the airport and coming back is an expedition in itself. Along the road there are army checkpoints that are built pretty much every ten kilometers on the national roads. I arrived during the day, as recommended by my informants. The advice is "No fast moves during controls." Sometimes we get stopped and asked for papers and sometimes we don't. The political and police repression in Algeria is directly connected to the terrorism of the 1990's. At the same time, terrorism gave the government more authority to keep the pressure on the population. The government took advantage of the climate of fear to develop a bigger police state. The next narrative illustrates the climate of fear as I remember it in the 1990's.

\section{Narrative Episode 11: During the time of terrorism}

"I remember a couple of year ago when I went back to Algeria, during a period of high political tensions, to visit my mother's grave. When my mother passed away I didn't have my army papers and for that reason I was not able to go to her funeral in Algeria. Four years after her death, I was working for the Royal Bank of Canada in Montreal and I was given two weeks vacation. At the same time my army card arrived. The army card is given to you if you have done your army service or if you have been exempted. In my case I was exempted. During the most intense times of terrorism the army was not taking nationals who lived outside the country; it was too dangerous.

This actually created a business of army cards. An exemption would go around 30000 francs (6000 Canadian dollars) depending if you were going to present yourself to the officials or if you wanted to avoid the whole process. I flew pretty much the same day to Algeria. When I arrived, my father had arranged for a friend of the family who was working at the airport to pick me up. I didn't know him. When he called me, I didn't 
answer. He called me with my name but then called me again adding "Si". This particle is given to members of my village and is a mark of respect for my ancestor. I said "yes".

He took my passport, asked me to stay on the side of the queue and left. I didn't know him but I had no choice. I was in the hands of the army. After a few minutes, he came back and brought me through the customs to leave me again with a group of customs agents who looked in my bag to find only clothes. After a little game that they played with me, they let me pass. The man was waiting on the other side. Only when we left the airport did he introduce himself and take me to his car. On the floor of the car there was a handbag. He asked me to open it and to give him what was in there. I did. I opened the bag and found a gun. He said "Give it to me". I did. He turned the gun to my face with no expression on his face, looked at me and after a minute said "This is our insurance". He cranked the gun and slipped it under his right leg where I could see it. I kept my hand on the door handle a good part of the trip."

Today the blockades are not as dangerous as they were in the past. During the time of my inquiry, there were no such risks. However, in order to address this political and historical contextual sensitivity, I decided to collect data using various notebooks. I would write in French and in English. I kept them in separate places and I did not travel with them to protect the sensitive work I was doing.

\section{Methods of data collection}

My data collection started after obtaining the consent of my participants in my inquiry. I explained to them that I wanted to reconnect to my village to take my place in the history of 
my community and learn my heritage. The data collection happened in France and Algeria. I choose my first participants "among" or "within the group of" my Kabyle friends and relatives. The Fieldwork happened from September to January 2010. I became involved in the everyday life of the people, shopping for myself, helping in a convenience store, working on construction in my house, going to public libraries, visiting other cities. I was present in the places described before without asking direct questions. I collected information from public archives where I was looking for books on Kabyle culture and specifically on my geographical area of the country. I also collected data during street experiences, waiting with members of my village at the very busy regional bus stop. Sometimes I would also get more data by going to the market. I collected mainly informal conversations that I would have with my informant when I would meet at the different places I presented earlier. I would then write some personal reflections that helped me make sense of my experiences of the day. I did not keep account of the number of inquiry moments that I experienced. The actual auto-ethnographic aspect of this inquiry is a set of writings of my own experiences within the context of my culture. The data collection happened in everyday life, not during traditional rituals or religious gatherings.

\section{Research questions}

My next goal was to explore the knowledge and experiences of my family and community. I wanted to work with one male elder from each of the four families that represent the village. Some of the questions that formed the basis of the interviews were:

What do you know about your ancestor?

What values from your inherited family story are still important for you?

Living in cities today how did tradition change or adapt?

How important is your heritage for you today? 
What do you wish to pass on?

How do you wish to pass it on to the coming generations?

What do you think of the place of your heritage in the world today?

These questions are examples of what I asked my participants. However, for different cultural as well as political reasons the questions cannot be asked directly. I looked for the answers in the stories being told. Asking direct questions, taking a position of authority, would not be seen as respectful of the elders, and might alter the relationship and level of trust and openness with the researcher.

I kept coming back to the process, the knowledge and the relationships, taking different perspectives in a reflective approach to the experiences. The reflective approach distances me from my experiences, helping me understand them from different angles. I move within the experience with the effect of a close up that shows me the details of the experience, and then zooming out to shed light on the context, time and space of the lived experience. This recursive approach to research can be accomplished through the careful use of both computer and paper based records, keeping notes on my computer, in note books, a field and reflective $\log$, careful organization of the material and respect for the confidentiality of the knowledge gathered. The relationships and bonds created with the community are also crucial.

I conducted this research with culturally appropriate consent and with respect for the village's social structure and qanun. To maintain respect for their culture, I respected the elder's position in the transmission of information, and I asked questions at the appropriate time by not asking questions during prayers, and mainly following my sensitivity about the appropriateness of the moment. I did not enter spaces where I was not welcome or where I would create an awkward situation with my presence. I had informal conversations rather than 
conducting formal interviews with participants. I collected data such as video recording with a little pocket camera, and audiotapes with a voice recorder. These data were conversations about Algerian society, Kabyle culture, and organization of the village, general personal comments on conversations and reflective notes on experiences. I kept my data mainly in the form of a personal journal, ethnographical notes kept in notebooks, visual data such as photos, and other cultural data sources such as songs.

I also audio and videotaped specific moments such as public meetings and informal conversations; I followed the consent requirements explained. I collected data in everyday places such as my home, small shops, the cemetery, which is a gathering place for us. I also collected data orally as I travelled by car up and down the mountain. The conversations with the participants helped me understand my culture. However, I did not quote any of the participants if they did not give their consent. I obtained consent before ? including a participant in my inquiry. All the consents were obtained during informal conversation in French and/or Kabyle. I explained to my participants that I would try to keep the material anonymous and would use fictitious names. Moreover, I explained to all the participants that I could not guarantee anonymity, so that they could make informed decisions about their participation. Given the sensitivity described earlier, my participants still agreed to share their stories, for the survival of our culture. They shared with generosity (Nyia) and pride (Niff) as I explained previously talking about ethics. My participants would sing songs, take me places, introduce me to people and even offer me books to read.

\section{Ownership and use of data}

Although this data collection includes places and people, I never share their names. In my village it is not always appropriate to share stories that are part of our heritage; I do not share any such stories in my inquiry. The only family story I share is the one of my father 
being tortured during the war for independence. He had no problem with that and the torture that happened in Algeria is well documented. It is not shared for its factual content, even though some readers might hear about it for the first time, but it is shared to show the climate of the inquiry. Some stories might have helped me to have a better global understanding but they have not been communicated here. There are no sensitive political stories in my inquiry.

Like the Maori people, "traditionally certain knowledge was not universally available. Rather it was entrusted to chosen individuals who then ensured its accurate transmission and appropriate use for the good of the people." (Makareti. 1986, Mead 2003, Smith, 1999). It is not that we have the same type of secret, but for us it is more an insider knowledge, that is the property of the village, that links its keeper with the trust of the community. I did not have access to that knowledge. Sharing it anyway would have removed me from the first purpose of my inquiry, connecting me back to my community.

A challenging facet of the relationship with my participants is the language and protocol of communication. In Algeria, I communicate with people in Kabyle and French. I do not speak any Arabic. In my village some people went to school in Arabic, but we still spoke French or Kabyle. Most of my relatives never pursued an education. When I started my inquiry, my family did not really grasp what a $\mathrm{PhD}$ would be. I explained to them in detail what it is. Indirectly a member of the community supported me because that individual is an insider who has a PhD. There was also another member of the village who went to school with one of my main informants who lives in Europe. That informant has a $\mathrm{PhD}$ and grew up in Algeria. Another friend of mine from another community came for a visit; he has a PhD and grew up in Algeria. I first experienced some resistance from my community because I was conducting this inquiry, but my inquiry actually became a source of pride. At the beginning I thought that my participants were looking at it as if it was something that would shine a light 
on them at a time when it seemed better to be silent and discreet. The climate initially felt like one of a certain level of mistrust and even social paranoia, that I associated with the colonial and postcolonial traumas, the memories of war, terrorism, military dictatorship and political oppression. Realizing the resistance, I took time and left my participants to reflect on my project. I understood later that it was the nature of my involvement that was the question. Some participants did not understand what a PhD meant. I got supported by those academic relatives and friends I have just mentioned, who grew up in Algeria in contact with my village members. These people with doctorates explained in the language and culture to my participants what it is to do academic research. The inquiry got accepted after that and I started getting positive feedback. Eventually this attitude changed with greater understanding; it was just that people needed time to fully understand the inquiry I was conducting

I kept a journal but I also recorded my own personal reflections, and some conversations with participants, with the permission of the interviewee. I had, for example, recorded one informant telling me the story of my Ancestor. We would have meals together and I would ask him if I could record him. He always agreed and started telling the stories of our village. Every night I would type them the stories into my computer in English, in an office that I organized in my house nearby. I was able to tape some conversations directly from my friend's computer that he had set up for his son in the back of the shop. There I used Skype to call my supervisor for feedback. I also accessed libraries online and had more privacy than in a coffee shop. I did not have the Internet at home and the length of time it took to get hooked up to the network was often very long. It was still a dial tone communication, which meant a very long time to download files, but for heavy documents I could go to the city, a half hour walk away. The coffee shops had Internet via satellite. 
The result of this inquiry, I knew, could be a source of information about the origins of the village and the real story of the Ancestor. It could, in the long run, be given back to the participants as a seminar or conference organized by the village association. I have the minutes of meetings and notes on conferences or seminars throughout the year that are kept by a trustee, chosen by the community. I shared my thoughts during seminars in the Faculty of Education at Victoria University of Wellington. I participated in informal moments in the everyday life and exchanges in the Marae and the School of Maori Studies. When we had a meal together or when I stayed overnight at the Marae to participate in events, we talked about our studies. In Algeria, was sharing by facilitating the meeting of all the different participants within the inquiry. The participants and myself would talk about the story of the village and we would share our knowledge. Each and every one of us always left with more knowledge than when we arrived, as they were involved in all the dimensions of the study. I was happy to break the isolation of my family and bring a new vision of the world to my community, but in fact I soon understood that they knew more than I realized and that the society that I thought was secluded was much more open. The situation continues to develop as more members of my community want to know more about Maori and other indigenous people. The Kabyle have started to think outside of their oppressive context.

\section{Method of recruitment}

My method of recruitment is directly connected to my access to the site and my methodology. I built from my community in France where I have friends and family from Algeria. They suggested two cultural associations and introduced me to four friends and relatives members of these associations. These members of association referred me to four more informants in France but also in Algeria. In Algeria, this inquiry takes place on the path to my own ancestor's village. The key participants are members of my close family, who 
agreed to be part of my inquiry. I shared our everyday life activities as well as special gathering moments. I worked with the people according to their connection to our main sacred Ancestor, and with respect to the role they play in my education. My recruitment was also influenced by the role people play in keeping the traditions alive in the village. I looked for the paticipants in village meetings. Further interviews resulted from the initial ones, like a snowball effect. I worked with people I knew from my previous participation in community work, like the building of a cemetery, bringing water into the houses, etc. I contacted them by word of mouth, on the mountain, by phone or through personal invitation; sometimes I simply ran into them in town or in the village. Overall, I mainly worked with the people who are still involved and living the Kabyle culture.

\section{Importance of an informed consent}

This research is anonymous for reasons I explained. However, participants are aware that I cannot totally protect their anonymity and they agreed with that. I just don't share anything that they would have not wanted to communicate to the public and in fact I did not hear anything that could cause any harm to them. I conducted my inquiry in my own family and community. However, I took the greatest care to ensure that information received from one participant could not be connected to that same participant during and after the inquiry process. I did not divulge the names of any participants in the inquiry. The informed consent was obtained from participants in culturally appropriate forms, with respect of the social organization. Some of the agreements are on audio tape recordings. I agreed to give no real names and explained to the participants that in order to avoid difference in treatment between participants I did not want to give any name, unless specifically asked by the participants which however never happened. None of my participants insisted on having had their names shown. 


\section{Talking with key informants}

The village is built around the grave of my Ancestor, a spiritual leader. This is where I started and finished my story. From there I moved to the first circle of people who are directly related to him but who are part of my clan. They are my close relatives and I am part of that first circle, all descendants of one of his four sons. Even if the village seems physically empty at certain times of the year, we are still connected and it is from that connection that I learn. Then I moved on to the next circle, which includes the mountains and the people living there. Though most of them are not related to the same ancestor they share the same language and culture. Going all the way down the mountain I moved to the valley and got involved with another group of people and also with more public administration, such as government, public libraries, foreign scholars etc. In my village I dealt specifically with four families, starting with mine, with my father and my closer relatives, who are both directly involved in my education. In France, I was also involved with active members of Berber associations and researchers from different backgrounds and countries, mainly in France and Algeria. My participants were aged from 21 to 80 years old.

\section{Myself, my father and my family as participants}

The community I belong to is my father's community. I don't name the community to help keep the anonymity of the participants and the material presented here are totally safe for the participants. The participants are never quoted directly here unless they were officials, for example the Catholic priest or the member of the woman and children's human right centre, who agreed to be interviewed in a more formal manner. My village is very small like most villages in the mountains. My father is my anchor to my village and according to tradition I connect to him in order to connect to my Ancestor. My father had difficult experiences with colonizers during the War of Independence; as a result he is sensitive to questions regarding 
our village. Any direct questioning can be viewed as a threat, but he quickly understood that I was not colonizing the village but instead going back home, something that he always wanted me to do. It took some time before I could even get him to go back with me to the village. This inquiry was new for him and he wanted to make sure that it was respectful before agreeing to share with me what was appropriate for that precise inquiry. Later (still today after the fieldwork), he was always happy to share stories about the land, the Ancestor and the village but did not want to engage in any political conversations. I therefore avoided talking about politics.

Trust of authority, and even between members of a family, is difficult today. It was important for me to work on my relationship with my father, because reconnecting with him meant connecting to the community in my village and doing what I should do as a Kabyle son. In fact, this is the heritage process. My choice of the father rather than the mother is obvious, as my mother passed away a couple of years ago so she is not there to share her stories. Likewise, in our culture a man has to look more to his father to learn about his heritage. Focusing on the father's ancestry did not disrespect my mother's side, but instead completed it, as my mother raised her children during their childhood and teenage years. She has passed on to us her heritage, stories and beliefs.

The organization of the fieldwork in Algeria was a collaborative process. Since I started designing the research, I communicated with my family regularly and looked into the different resources available to me for this project. The first place of inquiry immediately became my own family. In fact, even an external researcher employed by the government could probably gain access to the sites with the authority given to him or an outsider anthropologist would be able to also develop a research project with the support of the population, but it remains a delicate operation to get to the village and access personal stories 
like mine. Marabout villages are located on the outskirts of Kabyle society. The personal dimension of this story is important in two aspects: the first one is the positioning of the researcher's discourse, and the second one is the interpretive understandings that emerged. Being an indigenous person myself, I chose to do research on indigenous education. This means getting firsthand knowledge as well as being a firsthand learner but more than that, it means for me to be Kabyle. The possible contribution of this inquiry is the recovery of my culture and the witnessing of an indigenous system of transmission.

The village is a very tight society, where family stories are supposed to be kept inside and not revealed to the outsider. For that reason, there was an ethical tension and balance that needed to be kept in order to respect the culture of the place, while developing and communicating an educational experience. To access the site, I have had to take many detours and I had to learn the qanun, adapt many times to the participant's opinions, the political situation, the age of the participants, as well as their gender. This whole experience is a Kabyle learning experience itself. When I started my research inquiry I first had to find the right methodology for the fieldwork. I had to identify and communicate with the first informants.

Sometimes, I have been asked why I decided to leave a "paradise-like" Canada to come back to Algeria, but my family understood my attachment to the country and it is a tradition for us to come back after a long time away. There are many songs about the subject of migration. Silmane Azem sings in Algeria my beautiful country:

"Algeria my beautiful country

I will love until death comes

Far from you I am getting older 
Nothing can keep me from loving you..." (Personal translation from French version of the song, 1982)

Most of them are sad songs. I actually do not know any that celebrate the departure from home, from the motherland, as it is a sad affair. Even when one is born outside of the country we are still connected to it and missed by our relatives. They keep count of the community members including the ones that are not present in person. That tradition keeps me as an insider and, with a short period of adaptation, allowed me access to my culture as it is lived by the people today.

Writing my Kabyle life story narrative has been a community experience. It is more than writing a descriptive document about culture. It is a cultural act in itself and as such inscribes itself in the qanun of my village.

\section{SUMMARY}

In this chapter, I have explained my methodology and data collection methods. I used a Kabyle indigenous life story narrative and I selected a methodology that allows me to reconnect to my community. Describing my ontological and epistemological stances, I designed a process to respectfully access the knowledge available to me in the village. I explained how I went back to the village to collect the data as well as the types of data I collected. I introduced as well the positivist arguments about auto-ethnography in order to acknowledge a different perspective on my methodology. I then critiqued them and presented different arguments supporting the use of my Kabyle, indigenous life story narrative and my epistemological stance. 
In the next chapter, I provide explanations of the roots that connect me to the land and the field of indigenous research. I then present my genealogy, with my father, my adopted Ojibwe father, my grandfather from my mother's side, but also some of my informants who provided me with great support during my inquiry. I decided to separate this chapter from the presentation of my participants because they were more than just participants, they were also the genealogy I was looking for and the personal lineage that I reconnected with as I went back to the land. Thus, they were part of the key in the interpretative understandings of the inquiry, honored as real human beings and thus more than just data in the method and methodology. 


\section{CHAPTER FOUR:}

\section{LEARNING MY GENEALOGY; GAINING ACCESS TO THE LAND}

\section{INTRODUCTION}

Narrative methodology has helped me conceptualize my home as a coherent place and space, allowing me to reflect and make sense of my experiences within my community in Algeria. I entered the field with the goal of engaging with my family and untying the many confusing experiences I had in Algeria, experiences that kept me from feeling comfortable in my homeland. Gaining knowledge about my community as a researcher and as a participant provided me with insights into the community's psyche. In this chapter, I explain how I needed to move away from the field of inquiry to be able to reflect on it. I share a part of my genealogy by presenting three men who are key cultural references for me. Through their life stories they taught me pride and gave me the strength to be an Indigenous person and a Kabyle man. I consider them to be part of me. They are narrators within my own story because of the place they have in my voice. These men anchored me to the world of Indigenous people and Algeria. To gain access to the land, I asked for the support of three members of Berber associations in France, who grew up in Algeria and who shared their local contacts with me. In this chapter I aim to honour them by distancing myself from the village in order to talk about the inside of it.

It is February 2011 and I am in New Zealand. I have just returned from Algeria with the goal of writing my paper, but as I turn on the TV, I see Algeria is in the news. Arabic countries are on the brink of a major revolution. The French media described the Arabic revolutions as a step towards democracy, but what I noticed that Berber people were not 
acknowledged in these reports, silencing the voice of a large part of the population. There are over 30 million individuals who are not Arabic on those lands and they have been fighting for centuries to protect their heritage. Yet again, we were being silenced in our own revolution. Back in the library of Victoria University in Wellington, in a small, well-lit room on the fifth floor of the building, I looked at the harbor. I asked the horizon to send me some inspiration and help me find the words to share my experiences from back home. I felt that words were gone and silence had invaded me. I looked around me for souls to hold on to and to help bring my voice back to the surface so it could speak again.

I faced the challenge of having to explain my experiences and myself again and again. What seemed obvious to me was not to others. I turned and turned and turned again trying to find the words to express what it meant to go back home. Every meeting with a new person in the context of my inquiry helped me better understand my culture. I explain here the idea of interconnectedness, in which we all support the learning experience of Others. I aim to illustrate that my guides and parents are part of my life story and they are essential to the building of my identity.

When I started my inquiry, people who seemed to be scattered on the path suddenly became the lighthouses that brought me back to the shores of my conscious self. Like a track left by angels, they lit up the journey for me. Every time I asked myself a question, I met the right person to guide me in my quest for an answer. In Alberta, I met my friend D. searching for a way to live my indigeneity in Alberta. My Innu friend D. brought me to his community in northern Quebec and shared his experience of the Western culture on his lands. From the hunting lands to the reservation, he showed me his experience of development and civilization. He gave me a different perspective of academia and Canada, that of an Indigenous man. He helped me see through the clouds of the culture at the Faculte Saint Jean at the University of 
Alberta. My father told me many times: "Tell me who you associate with and I will tell you who you are..." What used to be annoying had now become a source of pride, "He was right!!!"

I believe that excluding relationships from research or using relationships as a means of access to data are actions that do not respect participants. Excluding participants' perspectives is characteristic of a positivist standpoint that I challenged earlier in this dissertation. My family members were my participants, but getting to know them was also my goal.

I aim to write, in this chapter, about my fieldwork in Algeria and come back to the concept of fieldwork in an auto-ethnography. Talking about fieldwork in an auto-ethnography is difficult because I am always myself. I carry Algeria with me wherever I go. I may be changing external cultural and political locations, but I am always myself. My inquiry does not happen in a set time, but is the continuity of my life journey. I present pieces of it while attempting not to separate those pieces from the realities in which they are located. Therefore, "the field" is my auto-ethnography of cultural recovery, but it is important to note that this is a culture that started long before the arrival of the French in our country. My motivation in going to Algeria this time was to learn intensively about my culture, but I also knew that I would keep learning about it after my "field work" was done. In fact, my learning began many generations ago.

Looking at culture from the perspective of gathering knowledge on a topic is not appropriate for me. My culture, like all cultures, is ever-evolving, changing every minute of every day. Thus, I chose to use a dynamic data collection process. My idea was not to stop time and allow people to create a cliché of my life, but rather to unleash the water of my 
indigenous identity into the circuits of academia by telling my story and reconnecting to my genealogy and my village.

\section{MY IDENTITY DOES NOT START WTH MY PLACE OF BIRTH}

I was born and raised in France. I lived in an area of Longwy, a city in the northeast of France that was mainly populated by Europeans. I considered the neighbors on that street to be my family. They fed me with attention and sometimes even with treats. They welcomed me into their homes, and sometimes complained about my over-expressive happiness. I thought we were all a large family. As I grew up, I became conscious of my identity in France. Writing a national exam, I recall how I would have to put my identity card (ID) on the table. To this day, I do not know what the consequence would have been if I had put an Algerian passport on the table instead of a French one. Every time I had to write my national identity, I would have to mark an "x" in the box for "double": I was Algerian and French. It wasn't until very recently that I realized that there was another layer of identity that I had to take into account. I am a Kabyle. But where do I put this on an administrative paper? There was no place for it on the French ID papers and even less so on the Algerian ones. I found that place for the first time on Canadian immigration papers as a landed immigrant. The box for ethnicity was a great discovery! I actually found a place to put my real identity. The box called "ethnicity" felt more accurate even if it was still just a box. Yes, this is the language I used (or tried to use) at home;

the food I ate at home, such as our traditional bread; the songs of singers, such as Ait Menguellet, that I listened to and sang at home; in this cultural ensemble is where I deeply consider myself at home. Furthermore, this identity is what my grandparents, all the generations before me, and hopefully those who follow, spoke and will continue to speak. It is not only who I am, but also who I want to be. 
What does going home mean to me? What does it mean to recover my culture, my language and my peace? When the spirits of my ancestors want to celebrate and dance, my duty is to find a place for them to celebrate. I look for a space to organize the gathering and I find that the only one actually available is in my heart, body, soul and mind. Narrative 12 shows the reconnection of the four corners of my being (heart, mind, body, and soul) in the experience of the land. My soul finds its echo in the beating of the traditional Berber drum.

\section{Narrative episode 12: Using the drum to talk to the mountains}

"I walked up the trail home and I found a beautiful village hidden in the mountains; it seemed totally deserted. But as I went up, songs were starting and stories appeared from everywhere, like spirits released from the stones. All I had to do is to heat up the avindayel (hand drum) and start singing. The mountains answered my call."

It is not difficult to understand that the best way to go somewhere is to actually start going. The easiest way for me to have missed my goal would have been to be afraid or stay trapped in "the quicksand of the colonized mind" (McCabe, 2009, September 23). . A colonized mind can be fragmented; it is a mind where the concept of the self is distant from the self itself. The representation system of the colonized person is manipulated and the individual is reprogrammed to self-destruct. The colonized person does not emancipate or take the initiative; he or she is trapped in power relationships that turn him or her into a passive instrument or even worse, into an active agent of neo-colonization. After many years in Canada, I had the chance to meet members of Native American families from the Innu Nation, Ojibwe, Cree, Algonquin, Cherokee, Delaware, Lakota, Mig'Maw as well as many other nations. I met these individuals during their gatherings, when we were learning about native 
spirituality from the elders. These gatherings were open to non-native people because the elders believed that sharing and welcoming were the only way to overcome mutual ignorance and bridge nations divided by the demagogy and lies of the history of colonization.

\section{AN INDIGENOUS GENEALOGY}

Genealogy is commonly considered as a list of names in a linear organization through time that leads from one individual to another individual following a genetic heritage. In Indigenous traditions, genealogy is also the transmission of spiritual bonds from the ancestors. These bonds become evident in the affinity between people and can be consecrated with ceremonies. I use this understanding of the concept of genealogy to describe my own genealogy. I start by presenting my father in narrative 13, then my various grandfathers, and then my participants, who are now part of my identity.

\section{My father}

\section{Narrative episode 13: My Father arrives in France to do his army training}

"My father turned 80 in July, 2011. He left Algeria when he was about eighteen to enter the Army. It was compulsory for every man back then. Algeria was under French colonization. Even though he hadn't wanted to go, he says today that those times were probably some of the best times of his life. He was young and had to leave Algeria, where he was working very hard to help feed his family. That was the first time he left the country. He told me that when he was recruited to the army he didn't even own a proper pair of pants, and of course he didn't have any shoes. Luckily one of his family members owned a pair of jockey pants. He put them on and went to see the army 
recruiter. When the man saw him he said: "I see you have experience with horses. Well, I will send you to the French cavalry." That was how my father ended up taking care of horses in France. He loved it. They gave him the Arab horses, saying that he was like them and would probably understand those horses well. My father laughed remembering that story. He told me that he was offered the chance to go riding, but he preferred taking care of the animals. For him, the toughest part of the whole experience was being away from his family. He was not given enough time to go back home, but he continued to send all his money to them - to the extent that when he finished his military service he was left alone with no food at a Paris train station. He had no ticket back home and no money to buy food. After a couple of difficult days, being chased away by the police, he finally decided to jump on a train heading to the east of France, where he hoped to find a job. Talking about this experience again, he looked at me and said, "I was wearing their uniform one day and the next day it was people in uniform insulting me for being in the street." He repeated, "Four days with no food." Finally he ended up in Longwy and went to a bar to ask for his friend. Unfortunately, he didn't find him. The man was at work. My father was going to go for another day of fasting, but a French man offered him a coffee and a croissant. He said "I will remember him for the rest of my life. My first meal in France outside of the army I got from a French man. This man is probably dead now, but I am still grateful.'

This was a wonderful moment to see my father reminiscing and having so many emotions still resonating as he recalled that story. My father finally met his friend later that 
day and was able to get a good meal. A few days later he got a job and he started for the next part of his journey.

My father's arrival in France was in answer to the call for military service. My father turned into an immigrant in France, the country he had come to defend. The colonizers were happy to have him fulfill his military duties, but were not willing to accept him as one of their own. My father suffered in that situation for many years. It was abusive to treat him like a burden on society, and as an outsider, after 50 years of living in France. It is time for us to break through that wall of silence that society has built and reclaim our stories, our histories. I shared my story when I participated in sacred teaching and healing lodges in the Innu nation of Canada. This is where I met the elder of the Ojibwa nation who adopted me, as I explain in the next section.

\section{My Ojibwe father}

Grandfather R. was a hero. He enjoyed telling me about his trips all over the world and all the good times he had experienced. However, at a certain point he decided it was time to come back to his community to work on traditional healing and cultural recovery. To say that he was very disappointed with all the Canadian politics regarding indigenous people is an understatement. He considered colonization responsible for a lot of the sickness in his community and, I must say, that I agree with him. But that opinion never kept him from listening to everyone and including everyone in his prayers. White, Black, Yellow or Red, everyone was welcome in his teaching lodges.

Often during Native American ceremonies, I walked with him, following him around. Members of the Innu nation who were organizing traditional gatherings asked me to be the Elder's translator and helper. The participants in the ceremonies found in him an incredible 
strength and a love that made us all feel unique, loved and protected. This man could carry the whole nation in his heart. Despite his broken voice and his difficulty walking, he was always there with us in some way. Many times during ceremonies, I told him that I was happy to be there but that I needed to be back home in Algeria or France with my family. His answer was always "soon enough". I owe my spiritual awakening to him and his wife. He is a spiritual father and I have grown a lot because of him and his wife. In the next narrative I share the very privileged moment of my adoption ceremony by this Ojibwe elder.

\section{Narrative episode 14: My adoption by an Elder of the Ojibwe nation}

"I was sitting on the top of a waterfall on a blanket. The place was called Manitou Falls, outside of Sept Iles, Quebec on Innu land. The Elder was just sitting beside me. He was smoking his sacred pipe. He was asking me to focus on my prayers and I was talking and talking and talking, but I finally fell silent, seeing that he had gone deeply into his prayers. He asked me to stand up and to sprinkle my tobacco to two places... He seemed puzzled. I asked him, "So, what is my name?" He made a sign and didn't say anything... We packed up and left to return to the forest. As we passed a curve, the water went silent. I said something and he turned to me with his eyes wide open and he said, "Can you repeat that?" I repeated. He asked me to repeat it a couple of times. "This is your name," he said. "I could not find the right way to say it. It was in my head but I could not say it. You just gave me the words. This is your spiritual name. You will use it to introduce yourself to the spirit during ceremonies." I felt happy. I sat in front of him. He looked happy and was smiling. He said, "I am adopting you as my step-son." I said, “Thank you...” He said, "For us Ojibwa, adoption is something serious. We do not do it just like that. It is rare. Unlike some people I haven't adopted a lot of people, but I am adopting you as my step-son. Now all my brothers are your 
uncles and your teachers. I will teach you as well. Remember that there are many ways to learn and teach." He was speaking in English and I had to ask him what he meant by step-father. I asked, "Who is my father then?" I meant spiritually, "Of course I know who my father is..." I said: "but spiritual teacher I mean." He smiled and did not comment. It is now; as I write this PhD that I realize the importance of the gift he gave me, as well as the responsibilities. I am confident that I am on the right path and that I am honouring him with my life.

I was in New Zealand when he died of cancer in 2009. I received an email from my native family back in Canada and took the first flight I could, to be with him and to pray with everyone as he was on his journey to the other world. When I received the email, I was in Te Kawa a Maui's office; I went to the Marae next door and found all the Whanau (family) there at a table. I sat with them and asked them what they thought of my decision to leave again. I needed that last push. Their answer was, "When we Maori people have a death in the family we all go back home to be together. That is what we are supposed to do." I said thank you, and went back on the internet to find a seat sale with Air Canada. A few moments later, my bags were packed."

Unfortunately, when I lost my maternal grandfather I could not be there for the funeral. My maternal grandfather was a quiet man and it was not until after his death that I learned more about him, as I share in the following section.

\section{My maternal grandfather}

I never met my paternal grandfather but I knew my maternal grandfather more. He used to live in France. My father and mother insisted that we go visit them every week end. 
My maternal grandfather had this funny habit of making the sound "Pfeee". All of us in my family wondered what he was trying to say. This sound acted as a discrete reminder of his presence with us as we understand in narrative 15.

\section{Narrative episode 15: The sound Pfeee reminds me of my grandfather}

"My maternal grandfather had a very funny habit. He would make a special sound with his mouth. It sounded like the sound of despair or sometimes of disgust. "PFEEE..." He would let it slip from his mouth as he walked alone in the house. Sometimes you would hear it coming from the corner of the living room. Seated next to the fireplace, he would spend most of his retired days playing with the ashes. We used to go see my grandparents every Sunday. Their visit always began with a welcoming "hello", but after an hour it would deteriorate into a nonsensical argument, doors would be slammed and there would be loud voices. But as soon as the voices went silent, we would hear a PFEEE coming from the corner of the room and that would remind us of the fireplace's comforting heat.

The sound "PFEEE" woke me up that day in Betiamite, an Innu community. I woke up from a nap after the funeral of my Innu elder. I don't remember crying like that before in my life, except when my mother passed away. The channels opened up and my emotions exploded into a river of tears for the first time in my life. I was deeply asleep and I heard "PFEEE". I woke up in the warm room looking for my grandfather. I didn't know where I was. I looked at the man who was standing there in the room and it was an Innu Elder, an ex-chief of the Mashteuishash community from the Innu nation in Northern Quebec. I looked at him and asked him to do that again. He said, 
"What?", but I was sure it came from him. Since then I have considered him my grandfather. He is another great healer."

Every time I saw the Innu Elder I was reminded that I could not return to Algeria to bury my mother's father, nor was I there for my mother's funeral. However, their spirits have visited me many times as I describe in Narrative 16.

\section{Narrative episode 16: The spiritual visit of my maternal grandfather}

"The last time I was in Belgium was in January 2011. I was visiting my uncle, on my mother's side. I heard PFEE coming from the room. I looked at my uncle with eyes wide open and fell silent. I felt him again and I looked at my uncle, and said: "It is weird but grandpa is in the room; I can feel him." He said, "I was about to say the same thing." We looked at each other, trying to keep our hearts connected to that little bit of him that we could feel in the room. We miss him a lot and I am really sad that I was not there for his funeral. He was another great hero."

In the book Le silence tiraillé (Stretched Silence, personal translation, p.156), Rachid Bouamara quotes my oldest uncle, the first son on my mother's side, telling his father's story. Enrolled in the French army in 1938 , he joined the $13^{\text {th }}$ regiment of the African Infantry. A prisoner of the German army, he escaped and went back to join the French army in Marseille. However, seeing that they would not give him permission to go back to Algeria, he chose to leave the army. He then married my grandmother. Taken back by the French, he was sent with the 19th African Corps to the shores of Corsica, where he saw his friend Slimane dying, 
leaving behind a family. It was with the idea of winning back his freedom that he fought the Germans all the way to Zerbrugge. In 1945, he finally was set free. He lived, carrying the weight of the death he saw. After his escape from a German military prison camp, he ran away to go back to Algeria because he was refused permission to go see his family. He was caught. The Cross of Honor that he received for killing so many Germans soldiers was taken away because of his escape. My grandfather was very proud that it was De Gaulle himself who took his decoration away. After the war, he had to wait until 1976 to receive the first trimester pension of 50 Francs $(11.5 \mathrm{Nzd})$. Pfeee. He carried these injustices, silently endured, to his death. Looking at his mountain for the last time, he closed his eyes a free man, Amazigh again and forever.

As I retrace and present my genealogy I start to understand the silent moments of my father's and grand-fathers' lives. It is a difficult journey, through the clouds of silence, to find my cultural heritage high in the Djur Djura Mountains.

\section{GETTING INTO THE CIRCLE}

It was a long and exhausting journey to reconnect with my family back home. I looked for ways to communicate with them in a constructive manner. Family relationships are no longer based on the gathering of the extended family, organized like a fortress, where people were co-dependent, while at the same time independent. Family members were co-dependent because they helped each other and participated in community life, but they were also independent because each and every one had the choice to express their participation in the way that best suited them. The people back home in Algeria made me feel that information was being withheld at the source - this source being my father, of course. I remember the time 
that I tried to have an official interview with my nephew about a scholarship I gave him in 2007. The conversation was difficult and left me with the impression that he was holding back. As he left, my father was standing at the door, wondering if my nephew had been reticent. My father's reaction reminded me of the old family coalition resisting the colonizer. They were holding onto the knowledge, resisting my inquiry. It seemed clear that the direct method of questioning seemed familiar to the people in my house as reminiscent of unhappy times. I understood that my method of inquiry was not appropriate culturally. I had to go back to respect the clan organization of my village. I needed to place my questions within my community and accept the challenges coming back from the community. These challenges would be teachings of the knowledge production system. Encounters often in my village turned into a rhetorical game in which the person being asked became the keeper of the knowledge. I felt that silence was used to remind me of my place in the village. Silence became the expression of the importance and respect given to the story of our community. Above all, I understood that talking about our culture is not our culture. Our culture is not something we talk about but something that we are and do. This point of view explains the difficulties I experienced to direct type of questioning regarding our cultural heritage.

It was really difficult for me to accept this "the rule of silence". I felt a terrible sense of injustice, of being ostracized by my people and family, when all I wanted was my place in the story. I understood much later that it was my understanding that was wrong because in fact I was being taught my place and explained how to defend it. Often at the beginning my father expressed his concerns regarding my potential selfishness. I knew that the story of my village was an intrinsic part of our heritage, a link between the members of our community. It was important for me to make sure that the village approved of the inquiry and had access to my interpretations. 


\section{Shaping the partnership from culture}

Even if there were challenges along the way, I gradually found support in my community. I constantly had to be careful not be an instrument of anyone's personal propaganda or politics. One rhetoric of certain Kabyles who claim to be secular, is to say that Islam is responsible for the assimilation of the Berber people in North of Africa into the Arab world. I was often subject to these political influences and that is why it was always important for me to withdraw from the field and reflect on my experience from a distance. This journey in and out is through the portraits of my main participants.

I have worked with Mr. Ahmed a lot (M. Ahmed is a pseudonym). His story is common to many of us living overseas. M. Ahmed and I agree to disagree, but even though we disagree he has been very supportive of my inquiry. He has been trying to get me back to France many times and get me involved in an association, but every time I go back, I am disappointed and frustrated with the discrimination in France. Born in France, of two Kabyle parents, he is married to a European woman and has two children. He wants to pass his culture on to them, but it is difficult to do so in France. His wife, who is very supportive, is participating in his cultural projects and enjoys having their children learning their language and going to Algeria on a regular basis. M. Ahmed supports the entry of young Berbers into the French system. When I was listening to him, I could hear the message of a cultural and political association in France, one that I have been involved with in France. In mainstream French culture, education tries to transform the student from his origins, integrating him into the mainstream French culture, an education policy based on assimilation and acculturation. M. Ahmed considers himself to be secular, promoting a Kabylia without religion. However, he forgets about the spiritual dimension of the Kabyle identity and places Kabyle culture into a Cartesian demonstration of difference between the French and the Arabs. He would make a 
list of "We are like this and they are like that", in an incomplete version of history that expresses a Western viewpoint on Kabyle history rather than an independent Kabyle voice. He said that Islam is foreign to Berber people, when in actual fact, for centuries they have accepted Islam as theirs and fought to keep it. He also refers to the Roman Saint Augustin, born of a Berber mother, to talk about Christianity as an important religion with Kabyle people. However Saint Augustin never lived like a Kabyle and was totally Roman in his everyday life, language and beliefs. Therefore, he cannot represent independent Kabyle people but rather the assimilated Kabyles.

I understood that I was dealing more with a cultural mediation of Kabyle into French that, more than once, seemed to me like the implementation of a neo-colonial view. The cultural mediation in France, as I experienced it, is more an undertaking of assimilation. You are asked to describe your culture in a linear way and then the classic model of deconstruction enters and point by point your culture is dismissed until there is only no culture left. French cultural policies encourage an individual to negotiate his identity until he is dispossessed of it, and assumes the negotiator's culture. Even if empowered for a specific function, my key informant is on a journey of cultural recovery as well, and this is what we share. Like me, he is taking on the responsibility of conveying his culture to the next generation. After his father and mother had passed away he assumed the role of leadership in his family, embracing his Kabyle heritage. He is the person who helped me gain the most support from the community; however his view of a French Berber community often conflicted with my concept of Berber identity. I could not see myself supporting an Indigenous identity based on political origins and postcolonial administrative legitimacy. Berber identity is rooted in ancestral land. A simple administrative document like a National ID card, as respectful as this political and administrative identity can be, does not represent Kabyle heritage. Kabyle heritage is mental, 
physical, spiritual and emotional, and connected to the land of the Imazighen. For me, it goes back to the Djur Djura Mountains in Algeria. As such, claiming to be Indigenous in another country while silencing the culture of origin is not coherent with Indigenous identity construction. It is not in the nature of Indigenous identity to be a post-colonial product. I am not saying that Indigenous people are not political, but I am saying that demagogy and politics do not make up the Indigenous identity. Indigenous politics are the fight for the respect of an Indigenous identity, one that is sovereign and inalienable. Indigenous politics do not create an identity, but rather, they defend it.

I also experienced ethical issues in working with him. I always kept a very open and clear form of communication, sharing my opinions and making sure that my position was clear. Eventhough Mr. Ahmed and myself were from different point of view regarding traditional culture, he has been very supportive of my inquiry. He provided me with contacts and descriptions of the Berber cultural association in France. He helped me find informants in France and Algeria, sent me book references, like the one I refer to in previous chapters from Nadia Mohia-Navet, and other invaluable support. His personal position is motivated by two main factors: the first one is his very critical attitude toward traditional culture and the second, the will to break what he considers as the "archaic" power structures to built a society based on the French system. Mr. Ahmed considers the traditional society to be nonsensical and ridden with taboos, and sexual repression, blaming an oppressive Islam regime. He is of Marabout heritage but does not call himself Muslim and accuses the Arabs of having brought religion to the Berbers. He always dismisses the accusation of French colonization and strongly criticizes the Arab Islamic policies in Algeria. He is also from another village that is not always on good terms with mine. In the next section I understand more about my father's perception of Kabyle Algerian people today. 
"You see my son. Even the trees grow straight in France."

I told my father about writing an inquiry in a Western institution. He did not initially appear to understand why I would write an inquiry about our culture for a Western university. He said that culture is a way of life not a topic of study. As well, his experience with Western institutions was not supportive of his identity, so why would a Western institution want to support him today? The whole political landscape of imperialism - cultural and economic - is very familiar to him. He often makes interesting prognostications on the outcomes of the news he watches carefully on TV, such as the future of Arabic countries in the Gulf, and the result of elections in France. These are his favorite programs. I am always surprised with his comments. His positioning and his views are never motivated by hatred or revenge. He always chooses the difficult path of rightfulness, justice and wisdom. During my brother's wedding, in France, my father and I took a little break from the crowd and the music. We took a walk in a park and he was looking at the trees. He lifted up his head, looked at the tree and said: "You see, my son, even the trees grow straight in France." I laughed. Again he was sharing his thoughts with a simple sentence. When I was surprised with his patience during this wedding, but then realized that he was having this whole internal conversation while chewing on his tobacco in silence.

He never said he was against my work but he was giving me a glimpse into the community attitude and showing me the path to my Ancestors in his own way. Every path is a learning experience. He understood that the important thing was for me to learn my culture and made me understand his position. 
"A dog does not make cats"

Even if my father has a very critical philosophical view regarding our culture, he is very deeply and organically connected to his heritage and ancestral story. He knows my informant M. Ahmed and does not agree with him. My father would say: "A dog does not make cats." His father was an Independence warrior and his mother a leader of a women's group in the Mountains. Like most of the immigrant families, his father worked in factories while his mother took care of the family. They had many children; all of them have stable professional positions in France and all go back to the village at least once a year, during summer vacation. Raising the children was difficult, and they were often left on their own in France while their parents went back to Algeria. Like many families, they had trouble seeing their children taken away by this French education while they had to provide for the village to justify their departure. Often, the village was getting more than the children in France.

Today, Mr. Ahmed works on rebuilding his story as well, but with the tools left to him by French society: the Cartesian thought process and a linear perception of history and heritage. French education is an accumulation of knowledge, without developing the self and independence from authority and hierarchy. Mr. Ahmed is learning to forgive both sides that turned his psyche into a battlefield. But forgiveness is not easy and he is now withdrawing from both sides, his association with France and his village. He sold his house in France and moved away, keeping a place in the village in Algeria.

\section{A panel of Kabyle participants as part of my inquiry in France}

I worked with two interesting participants who definitely made this work easier for me. One was a Kabyle activist newly arrived in France, Mr. Mulud, and the other a Kabyle cultural worker also newly arrived in France, Mr. Slimane, (these names are pseudonyms). The two of 
them shared their contacts and sent me to different places in Algeria: to their villages in Kabylia, Algiers and Constantine. They did not consult each other but helped me in the same way. They opened their doors and hearts, and shared with honesty their experiences in Algeria. Despite their different backgrounds, they were both activists in a way, because of their involvement in the promotion of Kabyle and/or Berber culture in its different contexts, Again, the two of them decided to present a context rather than telling me what to think. Mr. Mulud was much more directive; he was a young man, militant for the independence of Kabylia. His discourse was very political and very controversial. It was difficult to have a conversation with him and I often felt patronized. He was also very provocative. However, he introduced me to very interesting people and these people helped me get a picture of Kabyle public opinion today. Through him and his referrals, I was introduced to the political situation in Algeria. Highly politicized, he helped me understand with his words or simply with the effect he had on people, the different political issues concerning Kabyle in Algeria today. He explained that the evangelist church in Algeria was increasingly gaining influence because Evangelists were translating their books and were performing their ceremonies in Kabyle. He told me that the son of Ferhat Melhenni, a poet, singer and intellectual, was killed in Algeria after he started calling for the recognition of the Tamazight language. However, today, Melhenni is the leader of the Kabyle government that he created in 2010. He explained to me that the "Commissariat de l'Amazighité" (Observatory of the Amazigh culture in Algeria) was not efficient and was only a figurehead organization used to calm the people while assimilation was taking place.

The second young man did not talk about politics but shared his culture. He was always sharing stories with me, using proverbs, and all kinds of sayings, referring to his life in the village and his experience in a cultural association. One of my friends there made a very interesting remark to me one day. He was not talking about being Kabyle, he was Kabyle. We 
had a lot of things in common and it is for that reason that a member of my family introduced him to me. This member of my family also knew about the situation with my father and had insider knowledge of my village. It is for this reason that he was able to help me get over the problems initially set in front of me by members of my village. He introduced me to this other informant, Mr. Mohamed, and made sure that the members of his village would be there in case I had difficulties.

The two men are the same age, but they did not seem to get along. They respected each other and kept a reasonable distance, but they were divided by a main argument. The first one wanted an independent Kabylia; the second one wanted to stay Algerian and claimed that the country is made up of, and populated by, Berber people and it made no sense to divide the two. We have been fighting for this country and we do not want to destroy it today, he argued, but instead work on building it up.

\section{"Awal dh'Awal", "Words said are words given"}

The current political situation in Algeria is confusing. The relationships between people are extremely complicated. The Kabyle people are expressing themselves and showing a presence, while knowing that there is little space left for opinion and free speech in the Kabyle part of the country. Historically the art of rhetoric was an important part of the Kabyle culture. This art was based on facing the other with strong arguments in order to find the best solution for a problem or simply to enrich the rhetorical skills of the group. Today the rhetorical art is becoming a game of hide and seek, where the players use honourable words to achieve negative actions. Nobody is held to his or her word, and it seems that there are no consequences for not respecting a word given. We used to say "Awal dh'Awal", meaning, "Words said are words given." Rhetoric used to be used in an act of respect, courage, honour and strengthening of the community bonds but becomes today an act of self-destruction and 
assimilation into a mainstream competitive and individualistic society. The people are divided by their use of the culture, pushing each other into the corners of a silent but terribly efficient alienation. A rhetorical process that was supposed to gather people around a common goal, honorably leading to a decision, has become a poison. A poison, sprayed through these relationships, it dissolves the foundation of the culture. The communication between people that support the common work for survival as a group, in a society managed by cultural practices, like sharing and supporting each other, is disapearing. We have moved from a community, where people actually sit at the same table and exchange ideas to improve the situation for all, to a society where it is about taking from the other to help oneself

In the country, the philosophy of capitalist profit is still considered dirty by the people but is increasingly taking hold. Where people used to go and gather for the community, they now play the running game for success, where one tries to beat the other one in the accumulation of wealth and goods. Recently, I spoke to my uncle on the phone in Algeria who was telling me how happy he was when the 47 members of his family were living in the same house and how it has changed since everyone has left. He described happiness as the presence of everyone, as the warmth and life of their old crowded house, as opposed to the cold and empty house of single families isolated in the various cities of Kabylia, scattered across the world.

\section{SUMMARY}

I have presented my key partners in this inquiry. With their personal stories and views we understand the influences that have shaped my understanding of Algeria and my experience in the field. Each is a part of my personal landscape and the social construction of my identity as a Kabyle today. Similarly, they express the variety of voices and opinions that are present in Kabyle society today. We understand the geopolitical landscape of our culture 
today, located in France and Algeria. I relate to the key partners as a part of my heritage, and, as well they express the face of postcolonial Kabyle identity today. In the next chapter, I describe my fieldwork in Algeria and what I have learned from my relationships with my participants in the country. I share my journal to show my internal thought process and my reflections at different moments of the fieldwork, concluding with a conversation with a young man that reveals much about education in Kabylia and Algeria. 


\section{CHAPTER FIVE:}

\section{MY EXPERIENCE IN KABYLIA}

\section{INTRODUCTION}

Since my childhood, I have returned to Algeria twice a year since for extended visits. My family and I would return to build our family home. This last time however, I went back alone, in a context that was totally foreign to my family there. They had difficulty understanding what it was that I was doing. The first weeks, I worked on the house so I could get acclimatized. While I was doing that, I explained the purpose of my journey there. I did not feel understood at the beginning. It was very frustrating; I often felt discouraged and I thought I would never be able to do my work. Even though I had been working on this project for over three years and I shared the topic of my inquiry with my village on many occasions, the doors to my family story remained closed to me. Something was missing. I could not go on my own and ask questions. Every time I tried, I found silence and people disappeared. But the news of my arrival was being passed around and it took quite some time before I started feeling as though something was moving in the direction of my inquiry.

In this chapter, I reflect on my experience by retelling moments of my inquiry in which I visited the House of Culture in Tizi Ouzou, one of the biggest cities in Kabylia. During that time, I learned about the sharing protocol and the city's socio-political disorder. The House of Culture was where I went to distance myself from my village and my family while remaining in my culture, and was a place of great learning for me. In the second part of the chapter, I enter into one of my informant's house and I share the conversations with youngsters, my informant and an Elder from the village. Later, however, my breaching of the conversation 
cultural protocols would generate tensions that demonstrate the sensitive nature and instability of my relationship with the country. I conclude this chapter with the experience of a young clandestine immigrant in the Algiers airport.

I share my field experience by using my personal journal to describe how I felt and to communicate my understanding of my culture in the context of my inquiry. I write about a moment here when I came to a consciousness in my thinking. In the first part I explain the sharing protocol and how it affects my inquiry.

I was in Algeria in November 2010. I was trying to make sense of what was happening around me. In the following narrative encounters, I learned about the Kabyle society today and share my personal reflections on it. This chapter helped me see the need for me to understand the Kabyle social organization in order to make sense of my experience. As such, it was a step toward describing the villages' social organization. Tizi Ouzou seemed like a chaotic place. There was a strong government presence in the form of repression, which manifested itself as a lack of maintenance, and infrastructure in the city. At the opposite end of the spectrum, the family organization expressed in the relationship and exchanges demonstrated an important concern for social order and human values. I made a parallel between the Algerian contemporary society and the Kabyle traditional society to show that this traditional society was very structured, with strong expectations towards its members. Even with the history of this new country, the traditional culture continues to keep the Kabyle population together. In the first section of the chapter, I share some of my understandings and the tensions I experienced. I end this chapter with a long conversation with a young man of my village about education, culture, employment and relationships. I aim to show in the following chapters of the dissertation, the active influences on the Kabyle society by presenting the main 
actors involved in religion: Roman Catholic and Muslim, as well as activists for women and children's rights. However, here I aim to help readers understand how Kabyle communicates.

\section{LEARNING THE COMMUNICATION PROTOCOL}

I begin with a narrative that helped me make sense of an exchange I had with the bookstore owner in Tizi Ouzou, in November 2010. From this simple encounter with the man, I reflected on my experience with him to understand one of the rules of the protocol of exchange in my part of Algeria.

Narrative episode 17: "In Algeria, we entered into capitalism with the mind of socialists" (Stated by the owner of a bookstore in the city near my house)

"I had an interesting experience in town. I was invited to give a talk at a cultural association in a village of the Djur Djura Mountain in Kabylia. I needed to prepare a little something for that and I was looking at methods to explain my argument and a simple black marker and a classic piece of paper appeared to be the most accessible tool. I went to a bookstore and asked the man, whom I found working there, for a paper conference pad. He went in the back of the building, brought me a piece of paper that he took out of his photocopier and gave it to me. He said that he knew what

I wanted, but that was all he had. When I went into my pocket to reach for some money, he stopped me and gave me a menacing look. I asked what was happening and he told me that it was insulting to offer to pay for that. I excused myself trying to explain why I was doing that and he said: "Don't worry. In Algeria we entered into capitalism with the mind of socialists..." I tried to explain myself, saying that I wanted to contribute to their business. He didn't reply. I thanked him and walked toward the 
door. The owner walked me (back) out of the shop and very politely wished me a good day. As I left, I felt like I was being watched."

I had difficulty understanding my social interactions in Kabylia. It took me a few days before I could make sense of what happened in that shop that day. This narrative highlighted my need to develop a better understanding of relationships and social exchanges as a step toward my adaptation in Algeria.

\section{Understanding the silence}

I tried to understand the communication process so as to understand what my relations were trying to tell me, but I remained puzzled. Something in the way of communicating was making my comprehension difficult. The whole communication process left me thinking for a while. I spent long hours trying to analyze my interactions with the people back home in Algeria. In this shop, what made me think were not the words but the silence. The silence was rich in significance. It reminded me that I was supposed to know my place and culture and expected to behave as such. I was considered as an insider in the cultural location of this exchange. Silence is also a polite way to say, "We do not need your compassion," and a diplomatic way to remind the other person of his place without picking a fight, while showing readiness for it anyway. During a service exchange, there is a risk of imbalance because the initiator of the support gets the leadership. In this communication, the receptor is not passive and defends his "mana" (honor, dignity, leadership) by refusing help. Trying to pay for a gift

was breaching the discourse code of honor with the belittling words of generosity. Even if done unconsciously by the shopkeeper, my attempt to pay was taken as that. If I had accepted the gift with humility I would have shown strength by accepting the honor. 
This episode was important because it helped me understand why I initially had trouble getting a participation to my inquiry from my village. It was natural for them to be cautious until I demonstrated enough humility to explain that I considered it a reciprocal exchange and that in the exchange they were also giving back. This narrative is very important because it explains the tension that I experienced with my fellow villagers. In the next parts of this chapter, I enter the home of my informant and have a conversation with the youngsters first, then with my informant, a middle aged man, and finally with an Elder and his wife. These conversations were examples of the sense of pride and the perpetual demonstration of honor. I felt like I could never let my guard down and always had to be ready for what might to come next. Demonstrations of happiness, for example, never seemed to happen openly with a stranger. Was that another way of hiding pleasure? Was it Muslim or a humble expression of pride? Was it another way of hiding an expression of the self or was it an expression of insecurity? This dilemma between pride and insecurity reminded me of a Berber saying: "The burnous (traditional woollen coat) is as light as a feather." The coat is what keeps you from being exposed. It represents burnous honor. The burnous is an image that not only demonstrates how easy it is to be honorable, but also how easy it is to lose your honor. Because it is as light as a feather, your honor is something you have to struggle to protect from being taken away by the winds of life.

More and more often, members of my village agreed to share stories, but the stories they were comfortable sharing were the ones denouncing France. The story of the Ancestor was a difficult subject for them to talk about. This difficulty could be attributed to the village politics where knowledge, and therefore power, should be kept through silence, in order to avoid confrontation with Kabyle or the fundamentalist Muslims who considered it a nonMuslim practice; and probably the fear of losing face by not knowing, or knowing less than 
the other. This made it difficult to gather any stories. The discursive practices in my village were often a means for rhetorical argument; a set up for a demonstration of skills more than power. These rhetorical moments could happen at any time in any situation. I always had to be aware and ready.

These previous thoughts are multifaceted. They show the confusion I was experiencing, in trying to understand signs and looking at my experiences through an academic lens in order to analyze an Indigenous reality. I also realized that sociological and ethnographic work by Bourdieu (1963) that I had read not only helped me to discover some cultural patterns but also led me to analyze them through his work. It was not what I wanted to do. I wanted to understand from my own experience and reflect with the help of Bourdieu's research. As a Berber, I was reticent to give a French sociologist, even with such an esteemed reputation, authority over my culture. He actually refused to have such authority as I have shown in a previous chapter. However, Berber society has changed a lot with French colonization taking place from the early 1800s through to 1962. The decolonization acted as another type of colonization. The fragmentation of the society with the forces listed here below shows more neo-colonization than independence. In this inquiry, I had to ask: "What is colonization and what is Kabyle culture?" A society that was unique in its cohesion was now scattered around the world, divided and broken apart, for the multiple reasons mentioned earlier, such as military dictatorship, religious fundamentalism, outsiders' imperialism, and the intimate internalized mode of neo-colonialism all occurring within a tribal culture, This was what I was trying to understand a little better. Often in my communication with my relatives or participants, I had trouble finding what was making it so challenging. This next narrative gives an example of how randomly a social exchange can turn into an argument. 
Narrative episode 18: What is colonization and what is culture?

"During my field work, one of my informants was an electrician. He came over to my house and offered to help fix the electricity installation in my house. Another of my participants was with us. Both were very multi-skilled and they were talking about the modification on the installation I had in my living room. They didn't know each other. However, I had a privileged relationship with them and they were meeting for the first time. When the electrician was working, the other came over and started to meddle in the conversation, throwing in some counter arguments. The electrician offered to put in a lower capacity switch, a 20-ampere, whereas the other participant would have installed a 25-ampere. If the electrician had agreed, he would have asked him why he initially wanted to put in a 20, and the conversation would have gone on without anything getting done. The conversation became very complicated and began to deviate from the electrical problem. When I saw the electrician putting his screwdriver down to talk, I entered strongly into the conversation and asked the other participant to let the electrician do his work. I not only had to steer the conversation back to the task, but also towards finding a solution. They both looked at me with a friendly smile for me losing patience. They stopped the argument and in no time we had the electrical problem solved. I really wondered if what happened here was a demonstration of culture skills or the expression of the division in a society, or some kind of manipulative behavior from one of my informants to take control over the global relationship and develop influence with my new friend in my house. I was confused. However, I understand that the point of such arguments is never to put someone down but instead, to show superiority with the use of rhetorical skills and cultural awareness. 
The complexity of Kabilya's communication system made it difficult for me to talk about the Ancestor, the founders of our village. My upbringing in France often made me an outsider. I was showing humility but I could not show ignorance and I had to handle those rhetorical games. Because I was raised outside but was present as a member of the village, I was not expected to know the story, which likely also turned me into a second-class citizen in the village. I needed to be careful on that slippery slope. Before I started my research it seemed that the whole story was far away. Suddenly bits and pieces started to come together. Elders started to speak and I started to collect a story. It took me a lot of time to get to a point where people would feel comfortable sharing with me, and it was definitely thanks to the respect that they had for my father that made it possible. When I listened to one person, he seemed to consider himself better than the other person. I was always surprised to see how my village was torn apart internally and yet be so supportive to one another.

Everyone I spoke to had undermine his own brother in one way or another, saying that he was not respecting the customs, showing high expectations for the respect of the qanun. If I could not keep myself from thinking that it was a very negative way to encourage our people to love and respect our heritage however, I can still see this old man saying all kinds of wonderful things about my father.

In Kabylia, we say "The one the closest to you is the one who will hurt you the most." But I learned a lot from my family and my mistakes. Every Kabyle person I met for this inquiry who was not closely related to me, they were welcoming and supportive. They offered me help in time, knowledge, contacts and many other ways as we se in the next part of this chapter. I now tell the story of my experience of Tizi Ouzou, as I went to the House of Culture, which I describe at the end of this section and share everyday life in Tizi Ouzou. Tizi Ouzou, 
was considered the capital of the Kabylia region for a long time. Today it is a place where many tensions reside.

\section{TIZI OUZOU IN NOVEMBER 2010}

\section{Street views}

\section{Narrative episode 19: Ambiance at the taxi stand.}

"During the time I spent collecting data, I had to deal with times of insecurity, like when I was waiting for transportation from Tizi Ouzou to my home town. The road between the two cities was known to be very dangerous; it was the theater of many horrible stories. A minivan driver told me that he found the head of a man on a rock on the side of the road. It could have been left there by fundamentalist Muslims or by members of the army, according to some people's opinions. Every day after five in the afternoon there was no transportation because the drivers, who travelled back and forth in their private minibus, often with no official license, refused to drive at night.

The bus stand gets crowded and thieves like to empty pockets. They take advantage of the chaos that takes place while people are getting on and off the minibuses, to pick people's pockets. This bus station also hosts all kinds of merchants. Some are like the ones that I have been watching, filling out with care the little bags of salted and roasted peanuts, that they sell for 10 dinars a bag, (0,153 New Zealand dollars) the

DivX (Compressed recording format) dealer selling one disk with 7 movies for 100 dinars, a little less than 1,52 New Zealand dollars, or the restaurants selling sandwiches for 250 dinars, 3.7 New Zealand dollars, which is a little more than one fourth the salary of a labourer, or small salesmen who sell coffee maker parts of 
coffee, cell phones and other things that made me wonder what they could be for... The place is a very lively area. Men, women, children, students, professionals, all of them wait together patiently and end up fighting over a place in the last bus. They have to negotiate their dignity for a seat in an overcrowded minivan. Hotel rooms in Tizi Ouzou are so expensive that most employees prefer travelling back and forth to their village and going home to their family rather than being left alone with no money for their food in a big city.

Thursday night was probably the most chaotic night. No taxis, no minivan, all of them had stopped very early. There was a time when the weekend used to go from Thursday to Friday but has now changed from Friday to Saturday like most Muslim countries. Friday is the day for prayers. Many people were waiting at the station for all the directions of Great Kabylia as opposed to the small Kabylia, another part of the province. That day, I was waiting there at the station. The chances to find transportation were very low as it was very crowded. Suddenly police came from all the corners of the place and in less than one minute had circled the whole area and arrested a couple of people. The police kept arriving from everywhere with sticks in their hands. I remember wondering if they had a good excuse to arrest anyone. Simply suspecting some one was a thief was enough. We saw cars leaving with young people in the back. I found the demonstration a little excessive just to arrest a couple of young thieves and I still wonder what could have happened there. Nobody wanted to comment on that. They were all stepping aside, watching the police do their job. I recall feeling trapped at some point when I felt someone behind me and three men, two in uniform and one without, were walking towards me. I didn't move and let them come to me. I knew I didn't have anything to be afraid of and in fact would have nowhere to run 
anyway if they were here for me. I just tried to keep up my conversation with my companion trying to avoid eye contact but at the same time not showing any fears or discomfort.

The government's repression is very harsh and the population is kept under strict control with this demonstration of authoritative power. Sometimes arresting thieves is justified, but sometimes it is simply an abusive demonstration of power, as I explain in this next narrative.

Narrative episode 20: Threatened with aggressive tactics by the Algerian gendarmerie

"Last year, a friend of mine's uncle was put in jail and beaten by the police or the gendarmerie with no other reason than the fact that he was suspected of being a terrorist. He was stopped on the road in the taxi he hired to go get his niece at the airport. Five men dressed as civilians jumped from a car, held him down, beating him up with no reasons, putting his head under the wheel of the taxi and asking the taxi to drive over it. The taxi driver refused and got taken to jail as well. After a couple of hours of mistreatment, once the gendarmerie was convinced that the two men were not terrorists, they were set free with no other form of judgment. It is in this climate that the population must live." 
I was told the story a year before I went to Algeria to do my fieldwork. It served as a warning. It illustrated the social climate of the country and brings me to this next narrative of my personal experience in the city of Tizi Ouzou.

\section{Narrative episode 21: Followed in the streets of Tizi Ouzou}

"The level of suspicion and fear is very high. Control over the population is extremely tight. Every day when I would walk in Tizi-Ouzou, I would notice a man following me very closely. He was a civilian dressed with old clothes. He would follow me everywhere, to the point that I had to stop a few times to actually let him go first. Once I stopped and faced him; another time I turned myself around and he ran into a shop. I entered after him and followed this man dressed with very dirty clothes. He was pretending to take note of the prices of very elegant, expensive shoes. Another time I went to a shop to look for a gift for some children in my family. The shop was well furnished with all kinds of sportswear for kids from 2 months to 12 years old, little shoes, sweatshirts etc. The prices were extremely high. As I turned around, I saw the shop owner leaving. I looked into the window, which was the size of a wall and saw the man that was following me with his head stuck to the window. I stopped right in front of him and looked at him in the eyes. He stayed there a minute, a little surprised by my reaction and then left. I left the shop to enter another one and as I left the small shopping mall I had company again.”

Khalil (another pseudonym), my informant from the House of Culture, whom I met in the city for lunch, said that it might have been a thief following me because of my computer sticking out of my bag a little bit. I thought my informant was probably trying to dismiss my 
worries to help me feel better. I didn't comment and went with him to the House of Culture where I found a place to recharge my energy and refocus on my inquiry. Even though our culture is rich, the House of Culture in Kabylia is not used for the support of this culture alone, but for a variety of purposes.

\section{The House of Culture in Tizi Ouzou}

The House of Culture had a very diluted influence on the Kabyle cultural life stream. However, I was able to find in the House of Culture some good and diverse Kabyle resources, such as academic research or interpersonal informal exchanges. My experience of academia in Algeria was very much located in the positivist and Cartesian philosophy I spoke about earlier. Conversation around Kabyle culture stayed descriptive and referred to the past. However, there was a lot of cultural awareness developing in Kabylia. The province is extremely rich on that level but it seemed that the location was limited to the micro society of cultural associations in the villages. Most of the original creative Kabyle expression I encountered was because of my personal network and not from official communication. This shows again that Kabyle identity, culture and society are located in the villages and are an interrelated experience. In the House of Culture in Tizi Ouzou, the majority of books about Berber culture were descriptive history books or scientific linguistic analysis of the language. Poetry and novels are in short supply and movies were totally absent. Medical students mainly used the library and the resources generally fit that public. This situation seemed to be in disagreement with what Tassadit Yacine (1988) wants for Kabyle culture. She says:

"Kabylia is one of the regions that offer much literature, oral or written. Homogenous from an "ethnic" and linguistic point of view, this region represents a particular kind of cultural diversity. This diversity is considered from its positive richness and the 
multiplicity of the variables unaccepting of an eventual reduction, implying isolation or fragmentation.” (p. 9)

The House of Culture was still considered a place for Berber culture in the city. Mouloud Mammeri, the great Kabyle poet, academic and writer who died in a suspicious car accident, as well as the singer Matoub Lounes, who was assassinated, used to go there. One employee of the House of Culture told me one day that when Matoub crossed the gardens of the House of Culture, just to go from one side to the other one, as the House of Culture was located between two main avenues, there was always a group of policemen coming to make sure that he would not go there to create some political mischief. It was obvious that the place was under great surveillance and I made sure that my conversation there stayed within the limit of what I would consider a non-political ethnographic study describing Kabylia and its culture and everyday life without supporting a specific political point of view.

My motivation to go to the House of Culture was more to look for Berber resources and to share time and conversations with other intellectuals, men and women, who could help me get access to more insider knowledge. However, I knew that doing such an inquiry could be interpreted as political. I believed that it was politicized, not political. It was not the purpose of my writing that was the political act but the political context of writing that politicized my dissertation. Mouloud Mammeri says in his preface to Tassadit Yacine's book Poésie berbère et identité, Qasi Udifella, hérault des Sidi Braham (Qasi Udifella is a name):

"When one is a Berber speaker, meaning a member of a group which legitimacy makes a problem, when one is a woman in a Muslim society, when one has left the ancestral village when one was a child, its values and habits to go to university, when far from denying the sources, one assumes them with strength, even with passion, when, if because of that, a long use of discursive reasoning makes one not give into the 
amazement of nostalgic love that one gives enough enthusiasm to penetrate its essence, but also to be careful to see them like they are rather than what one feels of it, what could have been a cold research becomes fascinating for its truth.” (1988, p.14)

The story of Kabylia is indeed fascinating and it had been my experience to continue to uncover more and more wonderful treasures hidden behind the mental bars of the French education I received. How funny it was to discover that the House of Culture was located in an old French jail. It had been rehabilitated after the independence.

The House of Culture was divided into three main buildings, a theater hosting music groups and movie projections, another one with different offices and classrooms and the last one with the library on the first floor and a couple of study rooms. The two main buildings, office and library, had a guardian and metal detectors at the entrance though most of the time the guardians were elsewhere and the metal detectors did not work. The theatre was kept secure by guards and by police also during main events and was only open to the public during those events. Visual exhibits took place in the hall of the administration but during my time there I saw an exhibit in the theatre hall as well. Most of my conversations there took place in the library office or in the little courtyard in front of it. That courtyard was only open to authorized members of the place, most of them being university students.

I had exceptional authorization to use the resources there without requiring a membership. Everybody was extremely welcoming as my informant introduced me. I had wonderful support the entire time and was always treated with respect and patience. The person responsible for the House of Culture came over while the technician was showing me around. She introduced herself and asked the man who was leading me inside to give me everything I needed for my work. I was really happy to be welcomed like that. While I was usually met with mistrust by other institutions like the research centre and the Diocese 
archives in Algiers, I had openness and support in the House of Culture. That support was extended by invitations into villages and families to share the life of Berber people today. I was worried about getting a cold and distant welcome, but got the opposite. When I arrived, I saw many books on the floor as they were repainting the shelves. Two main librarians worked there full-time. They explained to me that the house was under reconstruction and they were reorganizing the resources. Upon entering the library, the end of the first row on the right hand side was reserved for Berber literature. One of the writers represented was Mouloud Mammeri, an anthropologist as well as a linguist. From 1969 to 1980, he was the manager of the CRAPE (Centre de Recherches Anthropologiques, Préhistoriques et Ethnographiques, Centre for Anthropological, Prehistoric and Ethnographical Research) of Algiers. Mouloud Mammeri is now a major cultural Icon for the Berber people of Algeria. I found in the House of Culture a little bit of Mulud Mammeri's work consistent with what the House of Culture was to some extent dedicated to. There were also books from Tassadit Yacine, Hanotaux and Letourneau and some parts of the Fichiers Berber. I found it pretty poorly resourced in written Berber materials for an institute of culture in the heart of the Kabyle country. But what I found there was more than books; I found access to the land and the life of Kabyle people. Books were only a detail in the Kabyle culture I was witnessing. I had no real expectations when I went to the House of Culture. My first time there I had no project and had not made it further than the general entrance. This time I found more than a simple documentation centre. From feeling as thought I was being spied on during my time there to the pleasures of being spoken to with respect and encouragement by the employees, as well as the sharing of Berber pastries made by my friend's sister a baker in Tizi Ouzou, I had a full range of experience of the Kabyle life today. I really liked my time in the House of Culture. The House of Culture was a positive, supportive, constructive, and non-judgmental environment. I am very grateful for that. 
My time in the House of Culture was blessed in the sense that I felt understood in regards to my inquiry. It gave me a place and a community in which to share my topic of cultural research. However, the purpose of my work was not to only exchange with Berber/Kabyle intellectuals but also to get to know my family and take my place with them with the story of my Ancestor. I will share in the next section what happened and how I understood my time in the family house.

\section{LIFE IN MY INFORMANT'S FAMILY}

My informant's house had two floors and gave shelter to three families. All were living in small rooms. Every space freed was being looked at as a potential extra room for the youngster getting older and needing more space. During my time in Algeria a question was raised about one room left empty after the departure of one of the members of the family house. The young girl was about to leave for University and two young men were ready to take her place in the bedroom. It seemed that there was a shortage of room but in fact this unification of the society was a strength. The budget for the whole house came from each and every member of the family and it is what helped them survive. Every married couple had their own space. If in reality it was shared with everybody, there was a level of intimacy and ownership at night that made it their own home within the house. I entered the living room and landlord's official bedroom to use the Internet because my system was not yet connected. I met a couple of young members of my family - two young men followed by three young women. The landlord came in after they left. On my way out, I met an elder and his wife and we exchanged a few words. I present here the conversations I had with all of them. 


\section{Narrative episode 22: Entertaining conversation with the younger generation}

“ This episode happened in the beginning of my field work in early November; my Internet did not always work and sometimes I would have to go to my informant's house to read and send messages. The ADSL Internet connection went via an external modem and was connected through the phone line, making it quite slow. This system had been abandoned years before, as the country moved on to Wifi and cable broadband. I did not actually understand the system itself but I knew I had a cable to hook to my laptop. It took a couple of passwords to enter but after a couple of attempts I was successful. I heard that there was a password business happening and people were buying wireless codes on the black market so they could access the internet on their phone for free. I had the surprise myself of receiving the occasional message saying that my IP address was being used by someone else. The connection was slow. I received my emails but I could not do things like chat with people overseas. First, the connecting process and secondly the presence of the family in the background made some of my conversations very difficult. There were just too many differences between the members of the household and my interlocutor in Canada. It would take me a lot of time to be able to explain and share these talks. I actually did not want to share. I was happy to be in Algeria and I did not feel capable of bridging the two worlds. The moment of the conversation, the culture, the different languages, all that made a very complex situation. Having to communicate in two cultures at the same time with two interlocutors was difficult. So I had to finish my first conversation online and then go back to talking with the family and exchanging observations on football games. One young man was a strong supporter of the English National team while the other one supported what he called the Czech team. There was a good spirit and we all laughed. 
The Czech supporter asked me about New Zealand. I told him that it is a wonderful country. I told him about the beach in Wellington but was silent on the notorious winds of the city. Then I told stories of spear fishing in the outskirts of the city. Of course I told him about the movie the Lord of the Rings but he confessed not to have seen it yet. He smiled and told me about the All Blacks, the Rugby team; he even knew the Haka. I got online and I found two different Hakas. He knew one of them and he was even capable of giving the scores of the game. I was amazed. It was the final game against France a couple of years ago. During that Haka, the French national rugby team came closer to the NZ rugby players while they were performing the Haka. I tried to comment on the French behaviour and I said that they did not respect the Haka, entering into the space of the players. I told him that I found that disrespectful. He ignored it and said that the French did not get intimidated and even won the game. I tried to explain the Haka, including the welcome dance performed by the women, at the same time as two women entered the room. The two men put their heads down as I talked about the dance of the women, trying to avoid making the two girls feel uncomfortable, but in fact, they were probably more comfortable than me and I finished my little story. Later, we arrived at experiences with sharks, and other fantastic adventures and I witnessed the culture of my interlocutors. I showed my admiration and my respect for their knowledge but I was careful to not go in the other direction because I did not want them to think that I was patronizing. I could have told stories of great achievement but this would have looked as though I was showing off. Respect in Kabylia is an implicit value of life, not a imposition of superiority. 
In this narrative, I explained that Algerians are not cut off from the rest of the world.

We live all around the world and we can also look at the world and make our opinions using the technology at our disposal. Even though most of my family does not have a high level of education, they are still very aware of the world's affairs. We come from a tradition of culture and education and our history nourished us with many of insights into the world. However, we do not interfere into other countries' businesses and try to recognize the values in each and every one of them. The short section talked about the issues with the Internet access shows the real problem of Algeria. It is corruption, a negative method for survival used to work around the government's authority. The internet provider employees sell the Wi-Fi access numbers to other people on the black market and often the network is overcrowded with undesired guests. My Internet was not running at that point and I had to use my informant's Internet. The next narrative happens in the same room after my young family members left me alone to give me some privacy to write my emails. My uncle as informant is between 40 and 50 years old; he is in charge of a group of families. I was using the family computer when he came in. We talked about the politics of the culture and the issues on ownership of the resources of the land.

Narrative episode 23: Conversation with the head of family on ownership of the land

" The group left me when I asked for time to write my emails. Later the landlord, the official occupant of the room, arrived in the room while I was writing to my supervisor Mary Maguire in Canada. I was alone at that time but I heard him coming in. I welcomed him. We started by talking about the situation in our village. I observed that we were going through a process of assimilation. I talked about the religious situation and the imposing of a different form of Islam upon our people and I said that these pressures wanted to make us forget our history. He seemed to agree but his only 
comment was that we would have to do something to keep our history and our knowledge; that we could put into place a project but we could not do anything unless we did it on a small scale, otherwise the village politics would get in the way and we would lose a lot of time in useless conversations. I avoided being too pushy with him.

He told me that he thought that the government works to get people out of their villages, taking them away from the source of their culture. But on another point when I told him that the government wanted to get rid of the Kabyle, he said that it was not true and that the government was sending us back to the villages. He told me that the government was even working on getting the water back to the people in the mountains (unfortunately not very well as there are water shortages in many places). I understood from my informant that the water used to belong to the people of the villages but now it was the property of the State and government control was now imposed on this natural resource. The same government that had dried out the rivers was now sending back the water to the same villages that this water came from. However, I was advised not to drink the water from the tap in my home. I was to drink from the water from the village. A member of my family who lives permanently in the village went to get water for us. My uncle explained to me as well that the cultures had disappeared everywhere in the mountains and we who used to eat the fruits of our harvests, cannot pretend to do so anymore. When the rivers dried up, so did the local subsistence economy. Today, the government has changed its mind and reopened the gates to let the water flow back in, which will allow the peasants to have their small parcels of fertile land again. We finished with a short talk about the responsibility of passing on the heritage to the next generations. We insisted on the fact that no one is actually trying to do research to find out about our heritage and that it is a shame. He tells me about an Imam that he met. The Imam told him that we were "Chorfa," that is, "respectable 
between the respectable," descendants of the prophet. He has doubts about the Imam's versions but he is clear on one simple point and it is the fact that he does not want our language to disappear. That is his first prime motivation."

It is on that note that we finished the conversation and on my way out, I met the elder of the house. In the next narrative, an elderly couple shows me their interests and motivation for an inquiry that would help to bring back the story of the Ancestor.

\section{Narrative episode 24: Words from the Elder}

"The old man told me about giving away his stories. He was insecure with the idea of letting our knowledge get out of the village but was supportive of the idea of taping them, writing them down to leave them to the young people of the village as a heritage. He wanted it to be done in Kabyle. I asked him to ask about it in one of the community meetings and I explained to him that he could find it difficult to do it because of the local politics. He answered that the story of the village is one and unique and as such there is no other version possible. Everybody respects the story of our Ancestor and the young people should sit and listen to it. I totally agreed with him. He told me that all the countries of the world learned their stories except us who are staying ignorant. Emptied of all substance we become subject to outside influence.

I was definitely surprised and showed him how happy I was to hear that he felt that way. I told him that if the people of the village decide to do so I would even buy a video or sound recording device to keep those oral archives and to bring back the archives and memories burned by France during the colonization. He told me that he 
is proud to have lived and seen so much. I sat down and listened. He stood straight with great pride and told me that if his father were here, he would have been able to tell us the story. I told him that he was there and that I would be more than happy to listen and record him. His wife was in her bedroom; she heard us and came closer. She understood the outcomes and displayed a very strong conviction towards conserving our family's heritage. The man told me how Kabyle were servants of our Ancestor; he talked about abuses from Marabout families and justified with it the behaviour of the Kabyle population against Marabout people today. We will see later in the dissertation as we enter my Marabout village, who exactly Marabout are in connection to Berber people and Islam. The Elder told me that today Marabout people feel pretty low. He explained to me as well where I could find the missing books that retrace the story of our village. He knew where to go and even gave me the names of places inhabited by descendants of our Ancestor. I felt very happy about the way things were going. There was real motivation to transmit our heritage and not much was missing before it would turn into a collective task. I had to see to which point this surprising motivation would go."

Even if my uncle and informant here showed support for the work I was doing, I had to show cultural awareness in order to have good communication. The complexity of the postcolonial society, mixed with the traditional heritage, created different levels of communication that I needed to recognize in order to communicate efficiently. It was not always easy. I now explain some of the communication breaches I encountered during my time in Kabylia. 


\section{A BREACH OF COMMUNICATION BECOMES A LEARNING EXPERIENCE}

\section{Breach of communication}

The relationship with my family was not easy. Sometimes it was just not possible to explain the necessity of writing my journal and my field notes. The old couple living with me could not always understand my inquiry. The old man wanted to take my father's place and raise me like he did with his children. However, I needed to do something else. The more focus I had on my work the more uncomfortable the old man was. He could not understand what I was doing on my computer. It was frustrating for him to see me sitting and reading instead of working on the house. He expressed this concern many times. If I listened to him, I would have spent three months breaking rocks and painting the walls of my house. For him, my inquiry was only something one does during free time. His son was 49 years old. He wanted to help me but he explained to me later that he was waiting for his father to leave for his pilgrimage to Mecca before being able to help me more actively. After a while, the situation became difficult and sometimes I experienced tension and breaches of communication. Algeria, with the political repression, the terrorism and all the conflicts around Kabyle culture versus Arabic, is very unstable. Everyday life was experienced with tension that took place in different spaces of life. I am sharing here some of these tensions.

My neighbors did not really understand what I was doing there. I would pass by their house, greet them and walk to town to get a minivan to Tizi Ouzou or to go shopping but one day they came closer. Here I tell the narrative of my encounter with my neighbors. 


\section{Narrative episode 25: Tension with my neighbours}

"Walking back home two days ago a man yelled in Kabyle: "Do you have electricity?" I answered yes. Maybe he was not talking to me. But then he started saying nonsense sentences to set me up in a meaningless conversation and made me pass in front of the neighbors who are not friendly with my father and with whom I am not supposed to have a relationship because of that. He spoke in French then and threw a bit of English to me. I answered him in English and slowly left, not really caring about his answer... I heard him saying behind my back: "He is French, he doesn't understand our language..." The situation was obviously designed to make me pass for an idiot and lose face in front of everybody; a first step into my personal sphere and a first step to develop a relationship based on abuse. The next step would probably be to get closer and go all the way to physical contact. It could become a fight but here having the last word in a conversation can be more important that getting into a fight.

I pass by the house. Nobody is there. I have 'flip flops' on my feet and I remember thinking if I have to get into a fight I will not be comfortable with them. I walk to town slowly enjoying listening to music, a Kabyle singer, Matoub Lounes. Everyone seems to be working and I make my way peacefully to town. I find it very difficult to deal with tension at home and outside; at the same time I have to manage a relationship with my informants that would help me in my inquiry. Luckily, I have a young cousin from my village visiting me often, and we have interesting conversations."

This complication added to my struggle to understand the cultural language of my participants. I experienced a disagreement between the old man I was living with and myself. 
This disagreement translated itself into a misunderstanding that could have been terrible for my family.

\section{Narrative episode 26: Tension with my family}

"The old man and his son came back home after the Friday prayers. The older man gave me all kinds of blessings, telling me that my father was happy. His son told me he had spoken to my father for more than 45 minutes. I had a good laugh with him. He told me he spoke with my young sisters there as well. I had a very difficult relationship with my father but my father got along very well with the old man's son because they were talking the Marabout cultural language that my father understood. The son would get everything he wanted from my father, as long as my father felt respected in his beliefs and not threatened in his dignity as "man of the village". I know my father was conscious of what he did and I know he has probably processed his relations with my informant around in his head many times. However, I was not feeling comfortable and I felt that my informant was using that relationship with my father as a means of intimidation and an excuse to claim the authority of my father. The son knew I did not have a good relationship with my dad. He tried to settle the tensions between my father and me but the situation got worse. Algerian society is patriarchal. The relation with the father is essential for the success of any project. Support of the group is given according to the father's decision. My father never went to school and always made projects for his whole family. He stood for us all during times of hardship but then stayed in control even after. I could not take that any more and started to push that relational pattern away when I was eleven years old. But removing myself from that relationship is not as easy in Algeria. I reacted very strongly and for two days I was really upset after the intrusion in the relationship between my father and me. 
Challenging the patriarchal system meant developing new rules and regulations. It made the old man feel uncomfortable. The old man started interpreting everything I was saying in an inappropriate way and felt a little bit overloaded with my negativity.

He started thinking I wanted to get everybody out of the house and he interpreted almost everything as a threat. I spoke to his son who did not understand it that way and told me that his dad and I had trouble with communication. He even was about to say that our families were going to separate and that he would never give me any support anymore. He said that very calmly and with a low and hesitant voice. We were in the car going to town to get the Internet connection to my house.

Later at home, the oldest man told me the story of these two brothers. One had a little bit of money and did not want to share with the poorer but the poorer one day got more money and ended up having more than the other one who was experiencing bankruptcy. The man explained to me the rules here and how we needed to keep together "as a family". I was not sure that I wanted to have this is the type of relationship. Especially that the needs here are huge and that it is very difficult to know how to participate in the family business and with whom."

I decided to choose this narrative to illustrate my misunderstanding at the beginning of this experience. The narrative illustrates a moment when we set up a relationship and prepared the transmission of heritage after my father. The inquiry was articulated around the relationship in my family that led me to learn about my Ancestor's heritage. With this last narrative I come closer to the story of the village founder as I learn to respect my family 


\section{Accepting the rules, I learn about my Ancestor}

The old man's son got to be known and respected not only because of his roots and his education but also because of his work. He was happy to say that people were adding "Si" in front of his name. Si is a sign that shows Marabout lineage. He told me that this research that I was doing had created a shock wave that awakened people of our village to think of the story of the Ancestor. Everybody was related to this Ancestor. It was an unconditional thing in our village. This heritage gave my people a special status that made them different. They had pretty much no Western education but they had a lot of knowledge, values and an established social structure. It was a huge heritage that the village did not seem to be able to transfer into this new society. My village was silenced in Algeria in both its Marabout lineage and its Kabyle heritage. The non-Marabout people were not happy with the acquired privileges of the Marabout and the government was not happy with the social authority that the Marabout used to represent. Inherited from colonization, these social disruptions were carried in our society and they split the traditional organization into different clans according to individual interests. We went through the colonial era, military dictatorship after the war of independence, fundamentalism and so on, but we kept our attachment and respect to our roots, a respect that stayed connected to the idea of genetic transmission. "My grandfather was sacred and therefore I am." But this history or this genetic heritage must be activated with an act of consciousness. There is some work that must be done in order to set the soul free. There is no cultural activation because there is no more traditional education. So when I arrived there asking questions, I made people uncomfortable. I was challenging the social status quo. We looked for someone who could have kept the archives. We asked questions to each other, we looked at our genealogy. Understanding the importance of the information, people started to hide it. We realized that there was a family that had the story but hid it because letting go of 
the story meant letting go what gave them an advantage over the others. That advantage was there to balance with the fact that they are considered less honorable because of their specific family story. My uncle explained to me that their family history was apparently not respectable and staying more knowledgeable about the Ancestor and Islam helped them compensate for it. In their family story there were memories of lies and thievery. They were also related to the Ancestor but their grandmother, first wife of the Ancestor, was not Marabout. She did not come from my village but from another village where the Ancestor had lived but that he left because he did not find it a safe location for his teachings. This decision by the Ancestor was imposed upon that family line today. The second wife was from our village and she was my great grandmother. My clan then has the superiority in honor for two reasons. Our village had been able to keep the grandfather with us and we are direct descendants from a double Marabout union.

Bourdieu's positions on Kabyle marriage shows that:

"In fact the ethnologist is the only one who gives himself to research purely and is not interested in all the itineraries possible between two points of a genealogical space; in practice, the choice of one or another progression, masculine or feminine, that orients the marriage to one or another lineage, depends on the power relations inside the domestic unity and tends to double the power relation, legitimating what makes it possible." (1972, p.125)

In that situation, the precedent family clan had supplementary points of honor and did not want to let go. This advantage allowed them to say that they were equal to my clan. One of my informants, a girl from the first family in my village who was living in France, made me understand that she knew the story but never wanted to reveal its source. When I was with this girl, I saw that she was reading the story of the disciples of the prophet Mohammed, God bless 
him, and his companions (Muslim people bless the name of the prophet when they talk about him). I later met in Algeria a man from this troublesome Adrum (clan). He told me that they did not have the genealogy anymore; however an elder from my clan told me the day before, who in their clan had the story. I spoke to a member of the other clan. He tried to put me into a situation of inferiority, asking me if I knew the story. I showed that I actually knew some of that story and I was looking to write it. When I asked him where his family kept the document, he became more cooperative and said that they did not have it anymore. What they kept was the genealogy. I got referred to the family of another man who had left the village for some time. It seemed obvious that something happened between the two families and I was being sent to go to see the next clan. I thought that they were probably trying to use me to go and see this man and solve some issues they had with that family. I suspect the man's manipulative family could have generated these issues.

This next narrative helps me makes sense of this previous social interaction I have just shared.

Narrative episode 27: A perspective on my family experience from an external informant

"A friend of mine came over for a visit with his girlfriend and took part in the conversations with a family member and informant. After my family member left, we were sat at the kitchen table. He and his girlfriend delicately brought up the subject of psychological manipulation. They explained to me that this type of manipulative behavior is general in Algeria and that engaging with manipulative people is a form of agreeing to play the game, which totally corrupts the mind. There is no way out. It is like poison injected with words that grow in you as soon as you get in touch with it. I 
was amazed by the accuracy of their description. After a few minutes in the company of that informant, the family members understood the pattern of family relationships. It was invaluable in helping me make decisions, as this pattern is difficult to see when one is on the inside."

The tensions were difficult to deal with and every communication in Algeria was a cultural learning experience for me. I needed to have these problems in order to learn how to get over them so I could carry on with my inquiry. Games of honor and demonstrations of memory skills kept us alert. However, they were a source of stress for many of us; they created a social complexity and a tense climate that turned every member of the group into a secluded micro-society. This, I felt, initially created a climate of paranoia rather than one of brotherhood. In this inquiry, I tried to provide my village with an understanding of the good outcomes from reflecting on our education. I illustrate this point with the following narrative.

\section{Narrative episode 28: Long-term grief passed on to the children}

"A scenario that I am familiar with now as it happened to me previously was when one of my relatives on my mother's side from another village, accused the troubling family in my village of holding back the story of the Ancestor and of insulting my father. My mother's family accused them of having said something disrespectful about my father. Using the disagreement between our two clans these members of my mother's village were looking for a way to enter the closed circle of my village and create a conflict that would weaken my father's community. Because they are outsiders, a direct attack would not have worked. It was easier to use me, an insider, to bring the trouble into the family by putting the blame on this other family. This would have reactivated an 
old and unsettled animosity between the clans and divided the village again. If the fight started in my village I would have become weaker. My mother's village would have got revenge on my father and my village for a grief that happened over a generation ago."

This personal example within my family explains a bit why weddings between two different villages are not always well accepted and the bride or the husband, coming from outside the village, is often undermined because they are from the immediate family. With this example, I am showing two different important points in the social dynamic. The first one shows that memory is a necessity, but time is never an issue when it is about gaining back honor. The second shows how the cohesion of the village is kept through its cultural structure. The family is forced to turn inwards on itself and kept together with the duty to protect the heritage of the Ancestor, the same heritage that gave the village its identity and life. An outsider, not being from the Ancestor's lineage, then had another position and a bigger responsibility towards the heritage if they wanted to belong to the community and have the same or more Mana in the village. Above all, respect was given to the one who showed values as I explained earlier. However there Lahnaya status allowed an outsider to come and live in the community. If an outsider came to our village and asked for protection they became the responsibility of the whole community. That person had to follow the rules of the village and respect its values. However, that same individual would not yet become a complete citizen of our community. Their status would be privileged because of the honor they brought to the community by asking for help. At the same time, not aware of the tradition in the community, this individual would remain a guest until they were able to support the community following its values and rules. 


\section{Narrative episode 29: Pride in my inquiry}

"I remember my Informant telling me one day about a fight between villages that would turn into blood crimes. He told me that 50 years ago, people would kill each other to defend their honor. Today we still find distinctions within our village related to weddings respectful of the Marabout tradition or not. The main one is definitely the one that divides the village in two main clans because of the two wives of the Ancestor. There is clearly a war based upon educational status, a competition between clans. My informant from my clan and son of another older informant came to me the second day of the Muslim celebration; it was a holiday for him. He thanked me for the work I was doing and told me that my studies and especially this inquiry on our grandfather were bringing a lot of pride to our Adrum (Clan). When one has an education all the family is carried higher. He confessed himself that he did not know the story but was happy to say that he was leaving today. My research has given an incentive that encouraged my village to look for their heritage. They firmly want it now, not only because they understood that this heritage is important. My uncle said: “...this story belongs to me as much as it belongs to you! We must get it. It is ours and we have to know it!' It was long and difficult but I finally got my family to recognize that it was important to look for this heritage, protect it and pass it to the next generations."

If we, the community, forget about the past, it will vanish. It could probably be kept somewhere by someone else but it would not exist for those who ignore it. Our community relies on memory of and respect for the values inherited from years of history. We teach them in our everyday life but that history is not taught in schools. It is a fact that the stories of the 
village, the historical specifics of the tribes, are not taught anywhere. The climate of political repression silences the diversity. This climate pushing to establish a generalized history for Algeria is inhibiting the retention of micro-histories of communities and clans. This history talks about decolonization and the new Arab-Islamic country born since independence. Of course I am not criticizing independence as I think it is wonderful to be free from oppression but I am pointing out another oppression. This oppression is expressed by silencing the population, their history, language and cultural diversity. My informant, thinking that we should teach our history to our children, came to consciousness about the limits of the actual school curriculum. I consider it a great victory for our community. Freire (1972) argues:

"The central problem is this: how can the oppressed, as divided, unauthentic beings, participate in developing the pedagogy of their liberation? Only as they discover themselves to be host of the oppressor can they contribute to the midwifery of their liberating pedagogy. As long as they live in the duality of to be is to be like, and to be like is to be like the oppressor, this contribution is impossible." (p. 25)

Now that my family had started to realize the importance of their cultural identity and its place in education I was already passing to the next step. "How can we learn from the life story of the Ancestor?" When I talked about learning, I explained that I needed to go to the villages and sit with the grandfathers, the elders. I explained more precisely to my informant that I was not talking about schools; what I was talking about was education. I consider education an act of life, not a training, to take a productive place in society. As such I referred to an education that should be the development of the whole self and not only take place in a governmental institution but one that should also take place in everyday life in the families and houses. I did not want to validate a governmental institution but I supported education as the development of the inner self in the collective cultural location. As I was explaining this to 
my informant, a young man joined us in the living room of my house. He was really interested but appeared to listen discreetly and kept his thoughts for himself. I thought that the context of low self-esteem inherited by those historical abuses created the teaching and learning experience, a very sensitive experience. Raising the community's self esteem would have to be done simultaneously together with the teachings of humility, as they support each other in the learning of knowledge.

\section{Getting to know my young cousin and informant}

In the following narrative, I am getting to know my young informant, my young cousin. I start by presenting him. With the story of his immediate family, father and grandfather, we can understand how the pressures of the family can shape destinies and permeate many generations. I could see how the education system in Algeria was not addressing this type of social justice issue and the old ways of surviving, from before and during France's occupation, were being reproduced even today in the postcolonial Algerian society. At the same time that my informant was sharing with me his personal life story narrative, I tried to find a way to provide him with my understanding and support but my power was limited in this context and often reduced to the vision they have of me as an expatriate from a rich country. What they expected from me was money. They became very disappointed when I showed that I did not have any. However, the fact that I had no monetary privileges helped me to strengthen a relationship based on family heritage rather than financial interest and helped me in my inquiry.

\section{Narrative episode 30: The words of a young man}

"I had a conversation with my informant, Sidi Mulud, (fictional name) a young, 18 year old man. In fact he was not really 18 but his father registered him when he was 
only 2 years old, so on paper he was 18 but in reality he was 20 . He told me that his father, who started working in his early life, around 14 years old, was sick. He had no more back strength. He could no longer work and had given already all he could to provide for the family. His father had a big feeling of injustice. The genesis of this whole situation was the fact that the grandfather had trouble supporting his own children because he was mentally ill. My informant's father had to work to replace the work that his father could not do. But at the age of 40 he was tired and needed support from his son. The young man and I were talking about that and we were trying to understand how this man ended up in this situation. His father did a lot of work but in a situation where there were no rewards, self-esteem or any kind of moral compensation. The father's hard work could not be valued because it was done in compensation for the deficiency of the grandfather. It was a cultural obligation and no special thanks or other reward was due.

When the young man, my informant and cousin, started working he was probably 16 or 17 years old. He just did not have the strength, nor the courage or the heart of the worker and the fighter yet. He had to work. Because three families lived in the same house and as such they were all responsible for bringing wealth to the house. One weak family might bring hardship to all. The young man's family expected him to be strong. The young informant seemed gifted in school. He told me that he was very good in class. However he worked today to participate in providing for the whole family, parents, grandparents, brothers and sisters. Algerian social welfare did not provide more support to them than in the past. They still had to work long hours to provide for the whole family. No emancipation was to be hoped for as the young man had to leave school early. His early responsibilities did not fit with the 
normative education system that asked him to be young when he was already working

like an adult and he could not accept being infantilized by teachers. He was not happy

in that system and needed to be freed from it; however, today he showed the motivation

to think of his education again."

Sidi Mulud has to heal his relationship with the family. Education could be a door for him to enter and find a way to address the issues he has with the people of the village. He needed to find strength in pride and not in grief but there is so much resentment. At 20 years old, he understood a lot already. In our conversations I could see him reacting to some of the things I was saying. He would have his eyes wide open and move his head up and down or showing signs of impatience by moving a lot or have a big smile and saying: "Oh yes that is it!!!” I listened to him a lot. We had many conversations. Sometimes he would feel good, sometimes he would feel frustrated but in general, he would be very open and talkative. He shared a lot about his time in the cyber café's lounge, probably his only socializing times. The following conversation happened the day after we had the conversation in my living room. The young man and I were talked about relationships, work and employment but also religion and education. I found it interesting to see how much this young man, a dropout, was motivated to learn. We were outside on the second floor of my house when this conversation started, facing the mountains from the balcony.

This relationship with my young informant had been very interesting. I share here a conversation I had with him at the beginning of our meeting in Algeria, in November 2011. I want to give insights into my informant's psyche, his concerns and motivations. I place him as an example of the young men's generation. It is important to have an understanding of it from inside. He had a lot of pride and dignity and seemed to have had his dreams crushed more than 
once by controlling social forces. I show these forces in this chapter. Listening to how they operate in the words of a young man is like experiencing them oneself. Appreciating the numbers of unemployed and uneducated young men in Algeria is very important.

It was in my house that a young man, my informant and I talked about how all our village members are spread out in the world. They left to go to other countries, or to cities like Algiers, Bejaia, Tizi Ouzou, or Bouira, or for the Sahara. Today, however the high ratio of youth in the country was proportional to the high unemployment rates. Unemployment was not the main reason that pushed the youth to run away from the country. The insecurity made the population leave in search for any other kind of destiny. The next narrative makes the link between the thought of my young informant and the action of a young man going off to live clandestinely in Europe.

\section{Narrative episode 31: The young clandestine immigrant in Algiers Airport}

$$
\begin{aligned}
& \text { "I remember sitting at the airport one day and a young guy came over to sit with me } \\
& \text { and started talking to me in Arabic. I could not understand anything that he said but } \\
& \text { seeing that he himself could not understand that it was impossible for me to understand } \\
& \text { I gave up and faked an understanding. After a few misunderstandings he got the point } \\
& \text { and we started sharing in a mixed language of French, English and Arabic. He was } \\
& \text { telling me about his plans of illegal immigration... I was wondering if he was an agent } \\
& \text { from the military police, as there are so many everywhere in Algeria. As part of the } \\
& \text { conversation I slowly got him to understand that I had my papers. He said I was lucky, } \\
& \text { went silent and after a bit decided to change seats." }
\end{aligned}
$$


These narrative episodes helped me understand the situation in Algeria. The streets of Tizi-Ouzou changed a few months after my fieldwork when the government opened different bus stops outside the city, closed the minivan stop downtown and added city buses. The operation emptied the streets of the unlicensed businesses on the side of the streets and probably gave more room to quantifiable economic activity. My exposure to the previous public scenery, however, was a great learning experience. I received information from the population of Tizi Ouzou, the House of Culture, my informant, his family and finally two young men who shared bits of their life stories. I had a lot of trouble initially developing a sincere relationship with my family, probably because of cultural challenges but also most likely because of the tense social climate in the country increased the traditional protectionism of my Kabyle relations. With this chapter, I intended to portray Kabylia as viewed from its streets and I organized this chapter as a "zoom" into the inner life of the country provided by the resources of the House of Culture as a reflective analytical place for the future, and the sharing of the thoughts and aspirations of two young men as the doorstep into an insider perspective. Respecting the Kabyle social organization with respect to the world of the outside of the men, and the world of the inside of the women, we move to intimate understanding of the ideological debates in Algeria that participate in the shaping of the philosophies inside the family house. In the next chapter, I focus on the institutions of the Catholic religion, the Muslim religion, and finish with children's and women's rights. I start with a priest of the Catholic Church then I learn more about Islam in Algeria and finally I move to a conversation with the woman in charge of the promotion, safeguarding, and administration of women and children's rights in the country. When I enter the world of the women is when I get to the birthplace of the culture. This next chapter leads me to the kanun (fireplace inside the house) of Kabyle identity. 


\section{CHAPTER SIX:}

\section{IDEOLOGIES}

\section{INTRODUCTION}

Algeria is a place of confusion. The religious complexity does not make it easy for us to live together. Our village today is a large diasporic system spread out all over the world. Since the arrival of the French armies in the early 1800 's, the society has been divided. This country, born after colonization, is suffering in the hands of the colonial heritage that took away our traditions and stories. Gender relations and belief systems are under question. Multiple religious proselytism (Muslim, Catholic, and Protestant) as well as animistic beliefs, and capitalist or socialist ideologies challenge the traditional Kabyle society and shape the Kabyle social landscape. My traditional village was unified around the same faith and values, Kabyle culture and Marabout Muslim heritage, but now is undergoing the same tensions as the rest of the Algerian society. The ideological differences create tension between the Algerians. I illustrate these tensions in Chapter Six.

Algeria is only fifty years old. Independent since 1962, the country is showing a lot of diversity that could be the nest of a democratic country. Part of that diversity is the Kabyle society, made up of small village republics organized together to form a culturally strong and autonomous region in the country. I seek to understand the different ideological aspects that are present in the country today and that influence my Kabyle culture. I start with an overview of the Evangelist cult in Kabylia. I then learn about the Catholic Church, through two of its missionaries, then Islam, from the voice of its daughters, and then move to a debate on secularism with one of the employee of the government involved with women rights in 
Algeria. I will then provide some perspective from that interview regarding the question of culture and feminism.

\section{EVANGELIST CHURCH IN KABYLIA}

Today we, the Kabyle, are very scattered. Economic reasons are often the justification for that division. The ideological pressures are fragmenting the Kabyle psyche. We are caught between Arab and Western countries. For Berber people Western means from the North. We are dealing with a lot of proselytizing forces from Capitalist Imperialism, Salafist Muslims, the Catholic Church, and the very proactive Evangelist movement. As they have done in many countries, Evangelists developed tools of evangelization designed specifically for Berbers. They fuel themselves from our drive for emancipation from political tyranny and Muslim fundamentalism, to get more people into their movement. I use a brief anecdote to illustrate this process.

I was working in Alberta, Edmonton, when one of my colleagues, a German professor, told me that his brother-in-law had asked him to bring a bag to Hawaii. He did, but was questioned at the customs, "Did you pack your bags yourself?" He said, "No" and the custom's officer opened the bag. Inside they found Evangelical tapes. They all appeared to be for the Indian population transiting via Hawaii to India. In Algeria, stories mention a bartering of visas and jobs overseas in exchange for influence in what can be called the Algerian "market for souls". The "business of souls" is orchestrated by neo-colonial Kabyle. The Evangelists' prayers are in the Kabyle language, in the same way they were designed for the population of India. I had a conversation with a Kabyle autonomist about that subject. My informant's argument was that at least the Evangelists were developing religious literature in 
our language, referring for example to the New Testament written in Kabyle in the late 1800s. An official of the Catholic diocese gave this information to me when I went to read the archives of Les Pères Blancs (White Fathers).

I can understand that evangelization is different from Islam as it is transmitted in the language of the people, rather than Islam written in Arabic, but language and culture are interconnected. Indigenous people from all over the world explain that their knowledge and heritage are connected to the land and that it is encoded in a culture that acts like a science in praxis. Amazigh culture, a complex but coherent identity, is one of them. The language is more than a descriptive, linear, succession of words to express ideas and facts; it is a multidimensional, multi layered and interconnected tool, alive and dynamic, evolving and developing, that shapes the minds and life of the Imazighen.

In the evangelism, the Kabyle language is used as a tool of communication. Their objective is to replace the underlying knowledge and belief system embedded in the Amazigh culture by the holy trinity and the whole evangelist belief system. But Kabylia has its own spiritual heritage. There has been a lot of discussion about the place of Islam since the fundamentalist terror. Not so long ago, Muslim fundamentalists in Tizi-Ouzou, a major city of Kabylia, burned down a Kabyle home that was used as a Protestant church. We have a lot of trouble with the fundamentalists already and there is no need for more confusing liturgy. Western proselytism increases the fundamentalists' savagery upon the Imazighen people and the Algerian population in general.

Evangelists do not bring healing and support to our indigenous culture. Instead, such religious proselytism turns our language against our culture and our indigenous spirituality. Evangelism is silencing a culture vital to the survival of the earth and our people. We, the Kabyle, have to protect ourselves in this debate of foreign philosophies on our lands. With the 
control of beliefs systems, Western societies try to control the development of independent and emergent countries. It is important that the population realizes the effects of these influences.

Other long time guests in Algeria are the Christians, who have been here since the Roman Empire. One such example is Saint Augustine, a Berber man, who lived between 340 and 430. Christians settled in Algeria in restricted but significant numbers after our independence. I went to the Catholic archives to look for information on Berber people. I present here one of their priests whom I met in Algiers in an informal meeting in November 2010.

\section{CATHOLICS}

In Algiers, I found "Les Fichiers Berbère." In a conversation with Father Paul, (a pseudonym) one of the priests responsible for the archives of the Algerian diocese, I learned that the diocese had kept archives dating from 1838 until the present day. The priest referred me to two main documents: "Les Fichiers Berbère" (Berber File) and "La Ruche," an initiative of the White Sisters to educate the women of Algeria. An intensive ethnographical work done by Les Pères Blancs (White Fathers) and Les Soeurs Blanches (White Sisters) existed. I found that file in Algiers but could not access it. When I asked the priest for access to the Catholic Archives, he asked me for precise questions in order to narrow down my research. But my research was not only to find an answer to a specific question, but also to experience the research process and meet with the Catholic Church of Algeria. I did not want to enter into the debate about positivism. I also understood that their classification system required precise 
key words for a search. But apart from the documentation itself, I was hoping to experience the Catholic institution in Algeria.

Communication in Algeria is very difficult, with internet, phone lines and cell phones often not working, and it is even difficult to find a phone number as there are no phone books. I had to go to the Archives of the diocese without an appointment where I was lucky and met with a priest involved in the management of the archives.

\section{Interview 1: The Catholic priest}

I started the interview asking about the archives.

-The priest: We are interested in ourselves but for the rest we are not so motivated. We especially do not enter into political issues. Since the independence of Algeria, Cardinal Duval and the Church of Algeria, have established some distance between themselves and the French authorities. That's it. We always maintain a distance from the political issues taking place.

- Will I be able to have a look at the archives?

- Of course, but you will have to ask me precise questions because I have around 600 lockers. So it will be based on your questions and you will need to be guided by me. And I need to find time to do it, time that I will make my best effort to find if (as a joke) you interest me. Intellectually I mean.

- I understand. In fact I am looking for the story of one region, the story of the Mountains of Djur Djura. How were people living? What did they believe? And what was their mode of transmission? Did the church observe anything like that? 
- Okay, listen: "Les Fichiers Berbers" should give you that information on the entire zone. I have been many times because I had a friend who was living there until last year. I have information and I am interested in this area. I have only been a few times recently. I have not taken a lot of time to understand the difference between Kabyle and Arab.

- Are you saying that Arabs don't know the difference between Arabs and Berbers?

- I don't know. I was with Arab students when I went to Tlemcen. Even if we were conversing in French they have another mentality. It has taken me a long time to discover this. In the 1990's I was living in my town, with a population that was half Kabyle, half European. For me Kabyle were like Arabs as they were both speaking a foreign language. I did not realize the difference then, but I discovered it in the 90 's going to Kabylia and meeting people (from the Church) who gave their lives to the church. They gave their lives for the Kabyle but at the same time, they are more critical of the Kabyles. They are the ones who say the worst things about Kabyle, but at the same time are the most passionate about them, passionate with love. (He is red saying this and he moves a lot, takes his head in his hands and shows a sign that means that he does not understand). This is when I understood a lot of things, including things dealing with Kabyles in Algiers. There were behaviors that surprised me but that I was attributing to an individual but not to a culture. (silence) I attributed his behavior to his individuality but then I realize that it was a result of his Kabyle culture.

- Is there behavior or something that stood out? Something that would have talked to you more? 
- No, nothing special. But here is an important example concerning the church. A Father that arrives in Kabylia, is, in general, very welcome. He arrives in a village and he is just a Father. He can even stay in a fundamentalist village and usually he is very welcome. On the other hand, the priest needs to do something useful if he wants to stay in the village. If he does nothing then it will be different. In the 90's I went to live in Bouzmai (disguised city name), in Arab country. He quotes the people, "We look at the guy arriving and we say, "What does he want to do? He wants to convert our children." You are observed for ten years and it is only after those ten years that the kids come to play in your house. They are big thieves, almost unimaginable, but that is another problem. (He has a big smile on his face). My friend that I used to visit used to offer his services as a public writer. A public writer was not there to write love stories only. He wrote to help people, to help them recover their pensions. He needed to know where to send the money. After he had to resign for different reasons, but he had... (He does not finish his sentence.) One day he got invited by one of his friends to go to a celebration. He made some good friends, ones that he liked a lot and so he went to the village celebration. When he was at the celebration his friend was asked, "Why are you inviting a foreigner to our party?" The man answered, "But no, he is not a stranger. He is a Father". My interlocutor lifted up his arms to place emphasis on what he had said then let them fall down. Then everybody went silent and the man was welcomed into the ceremonies. This is not possible in an Arabic country. I give the point of view of the Church but we can verify this characteristic with other situations.

-That's right, on our land people are, even if they consider themselves mainly Muslim, very much attached to the presence of the church. I mean, at least, to the Fathers. It is like a family relationship. Once you are in, you are in. 
-But there is always a past, as I know from the documents that I have, and I have a good part. We can also find that in the White Sisters' work: "La Ruche” (The Bee's Nest). The White Sisters had started a movement for young women inspired by the Scouts, called "La Ruche." And this ruche has had an important influence. I run into people today who tell me that their mother went, or about a grandmother who would say that she was a member of "La Ruche". They tell of the pleasure they took in this educational movement. Yes, you can understand the theme of the diligent bees working for the little girls, with the games, etc.

- It is a movement that really existed in the year 40's to 50's.

-In Kabylia?

-Yes in Kabylia. I remember when the Protestants had more importance [in Kabylia], by the way.

I asked: -Protestants?

-Protestants, yes. I connected to the Protestant church. But now there is this phenomenon of evangelization that creates... I am not against them (Protestants), of course. I remember that the Protestants welcomed us because I was running a workshop for Scouts and there was a protestant pastor's daughter, who was an American, who I was bringing camping, and he gave us the presbytery next to the Methodist church in Tizi Ouzou. We spent four or five days in Les Ouadhias. As it happens, today all of that has disappeared.

-The work of the Nuns from "La Ruche" could be an interesting thing. 
He gave me directions to the next archives. He referred me to the Summer Palace. He excused himself realizing that he used the old colonial name of the place. "I am sorry I am a "Pied Noir" (Black Foot is the name given to the colonizer during the War of Independence). I meant the People's Palace."

"Ironically, Algerians call it The President's Private Garden," I said. He did not comment. He drew me a map. I asked if I could look at documents tomorrow but he refused because he had to do administrative work. That task seemed to be worrying him a bit. He stood up and gave me a phone number of the other archives' location in Algiers.

From the same priest, I was told that Catholics consider the Protestants their brothers but a "Père Blanc" from the Notre Dame d'Afrique (Our Mother of Africa) told me that the Protestant approach was too aggressive. He feared that once the Berbers started finding them too intrusive, it might put the whole Christian agenda in the country in peril. The view of the evangelist church in Algeria was different from that of Notre Dame d'Afrique, but both showed concern over the evangelists' proselytism. The people were looking more and more closely at the evangelist's church as they assumed more importance in the political debates of the country. People can argue that Protestants have been here for a long time, but being in Algeria and being Algerian are different. The few Algerians who decided to convert to this religion lost their place in the Amazigh cultural movement. Instead, they were mixing up messages and diluting their culture, transforming it into another imperialist ideology. Kabyle culture is based on beliefs born from the land and developed in an interconnected system of representations expressed in the Kabyle language. The Kabyle language was not born from evangelist beliefs and as such Kabyle culture cannot be nurtured by this faith. This first meeting gave me a clear insight into the Catholics in Algiers. I found two good sources to look 
at: "Les Fichiers Berbère" and "La Ruche". I decided to continue with my research on the Catholic Church in Algeria.

Two days later, I went back to Kabylia to organize my next visit to the National Archive Library in Constantine. These archives contained a lot of information on the eastern part of Algeria. I experienced another Algeria.

\section{MUSLIMS}

In my village, as I have previously stated before, we have a house that protects the tomb of the Ancestor. I have entered the house many times but the first time I entered a mosque was for this inquiry. It was the great Emir Abdelkader's Mosque in Constantine. A young historian and his brother, who happened to be a colonel in the Algerian army, took me there. I met the young man while I was doing research in the archives of the city. He was unemployed and to stay busy he was doing research on the story of his village. I thought that he could be from the military police, but I did not see any problem in speaking about my inquiry. He actually found it very interesting and was

supportive of my work. He was quiet, working beside me, doing research, taking pictures of documents to print out afterwards. The photocopier was working but it was just cheaper for people to proceed like that.

I had a very interesting conversation with a non-Marabout man in the magnificent Emir Abdelkader Mosque. The man introduced himself as a missionary of Islam. He told me that he was travelling all over the world, working for the promotion of Islam. I looked at his hands and his very strong body and felt shivers all over. He was speaking like an accountant about Islam. For him every action was going to be entered like data and with the introduction of a coefficient, based on the size of the religious investment, one will be approved for entrance into Paradise. During that 
conversation about Islam, I was in Hell. I keep my quantitative skills embryonic, as it was really difficult for me to accept that God would be a quantitative researcher. This man's discourse seemed to be more a means of control, supported by fear and greed, for the promotion of Islam. I was there with a friend, a Kabyle man I met in Canada. My friend, who is fluent in Arabic, French, English and Kabyle was translating the Arabic for me. He is Muslim as well. In his translation, he would add a few critical comments in English making his interpretations obvious. He brought me to the Mosque to help me discover the beauty of Islam. This episode was tough on him and he looked very sad. I told him that I understood what the man was trying to do and he didn't need to worry about my perception of Islam. I reminded him of our long conversation, when I was supporting a qualitative rather than quantitative approach. I reminded my friend that I understand the difference between spirituality and ritual. We had a good laugh about that, thinking of his work in chemistry and mine in social science. However, I understood that we had just had an encounter with a fundamentalist Muslim.

Fundamentalism in Algeria has pushed the Muslim religion far from where it was and where it wanted to be. Fundamentalist Islam is a religion based on the control of the mind, using fear and power to assert the dictatorial power associated with religious fundamentalism. In Algeria, the Imam is a government employee. Some of the Imam's speeches resemble the guidelines of the "Brother of Islam" that organized the GIA (Fundamentalist Army Group). The official story of the birth of GIA says that, after the Islamic Front for Salvation (FIS) won the elections in the early 1990's, the National Front for Liberation (FLN), the party of the presidency since our independence in 1962, saw his power compromised for the first time. The FLN overrode the result of the elections, turning the FIS into an illegal political party and arresting many of its leaders. The FIS parted into the GIA and the Armed Islamic Movement. When the FIS started negotiations with the government, the FIS got attacked by the GIA, 
which disagreed with the negotiations. The FIS had to confront them, as well as the Islamic Army for Salvation, another armed Muslim fundamentalist group. The Islamic terrorist groups, who killed many Algerians, have calmed down since the amnesty was signed between the government and the terrorists, but it has left the country with a history of terror and hatred. There is now a new fundamentalist army group, the Salafiste Group for the Predication and Combat (GSPC), who are linked to Al Qaida.

Of course this linear description of the Algerian Muslim politics has to be looked at in its diversity and as a dynamic movement. We cannot say that the FIS is no longer active in Algeria. Nor is it possible to say that all the people who were trained during the dictatorship, and who experienced the dark times of the religious civil war, have forgotten about their education and experiences. In Algeria, children are dealing with traumatic experiences without any support. There is no real healing policy in the country to help the population in the recovery of a sane lifestyle. In fact, the government is using the ghost of terrorism as means of control. The Berber culture is an oral culture and, as such, memory is important. What happened in the villages will stay forever in the people's minds, hearts, spirits, and bodies. The slogans left on the walls after the events of the Black Spring of 2001, "Ulac Smah Ulac" ("There will be no forgiveness"), are lasting reminders of the horror. Some Kabyle have decided to embrace their pain and carry on the fight.

The divisive policies in the country have been so confusing that there is a general disengagement of the population. In our area of Kabylia, we can see helicopters flying over the city as the army goes to destroy the terrorist camps. The government has been dealing with a lot of terrorism in Algeria, but fundamentalism is an ideology and cannot, as such, be destroyed with arms. However, I must say, during my time in Constantine I only had good 
experiences and all the people I met were very welcoming and made me feel at home.. I was happy to be Muslim and feel connected to them on that level.

\section{The Constantine Archive Library}

The next narrative episode describes the archive library installations in Constantine and the power structure that manages it.

\section{Narrative episode 32: Archives in Constantine.}

"The archives in Constantine cover the region of eastern Algeria, including Bejaia, one of the major cities in eastern Kabylia. I entered the building through a small metal door.

I found it very austere. There was no sign on the outside wall and if a young man had not walked me there I would probably have missed it. I walked in and went to the second floor without meeting anybody. The place looked empty. On the first floor there was a hall. The first thing that I could see was the picture of the President standing beside the Algerian flag. On the right, in the back, there was a little room with a desk for the guard. It was empty when I arrived. I looked around and called out but no-one answered. I then went to the first floor but it was still empty. I saw black and white pictures of cities, people, maps and cover pages of newspapers hanging on the walls. I entered the room. I saw many shelves with books, newspapers and boxes. I found a couple sitting at a table. I asked who was in charge but they did not answer me. I went back to the second floor and I met a woman. She was wearing a veil and spoke to me in Arabic. I explained my research to her. She was very friendly and took me downstairs, showing me around. She explained how to use the resources. A man came over and he did not look very happy. He stopped her from helping me, saying that the legislation had changed and that I could not check the resources. They disagreed. She told him that he 
was wrong. He seemed frustrated. Some internal politics seemed to be at work and I felt uncomfortable being in the middle. Finally, another woman came over, wearing a veil as well. I was surprised because generally in Kabylia just a few women wear veils and here it seemed that all of them did. The man tried to say "No" again but she reminded him of his responsibilities. They asked me for my citizenship and I took out my Algerian ID card. She took it, read it and handed it back to me. Then she started me on my research with a couple of books. She told me that my research was going to be restricted to the data available in the room. I said, "Okay", not really knowing what was in the room, but knowing I could not ask for more. I also understood that she was being diplomatic in order to help me be accepted in the place. The two archive's employees were speaking Arabic most of the time and I could not understand what they were saying. The woman spoke to me in French inviting me to start my research. I sat at a table with some books and started reading.

Later, two young girls came in and after working on something they looked like they were having trouble with their research. They spoke to each other, looked at me and decided to come and see me. Both of them were wearing a veil but seemed very different. One was very calm, and looked naive and warm. The other one was respectful and distant, but seemed to have a more outgoing personality. They worked for a while but did not seem to find the resources they were looking for. They thought I was working there and came to me with a book. They tried to explain something in Arabic. I said I was sorry but I spoke only Kabyle or French. They spoke only Arabic. I was very uncomfortable because I had no background knowledge of Arabic social codes with woman. The two girls came close to me and I felt that they were entering my personal space. Ifound it interesting to feel so powerless. A young man was watching me as well. 
He was taking pictures of resources. He seemed to be very focused. There were also two men in the room smiling discretely. They were watching me trying to make myself understood using French and English. They came close to me with a French book. It was about the story of a city. They could not read it and they explained with difficulty that they were looking for a certain type of information. They wrote a name on a piece of paper. I took the book that they handed me but I could not find what they needed. I looked at the man I had initially interacted with sitting at the desk and went to him, thinking that he could help me to help the girls, but I was still conscious of the difficulties I had with him on my arrival. He was smiling. To my surprise, he reacted very nicely and after that became very helpful. I could ask for anything and he would help me with it. I do not know how this episode with the girls made him change his mind but he did and I was happy with that. I came back during the whole week from 10 am to 5 pm. The young man was there too. He would take out many books and kept taking pictures of the resources. When my turn came to find interesting things I asked him if we were allowed to take photos. He said, "Yes, it was cheaper than photocopying". He explained his situation to me. He was unemployed, having just graduated with a Master's degree in English. Instead of staying in his village with nothing to do, he decided to look for the story of his village and improvise as a historian. He explained that the story of his village had been taken away during colonization. Very humbly and politely he showed me around the city and we slowly became friends. The times for prayers in Constantine were respected scrupulously. The streets were not empty during the prayers but were much less populated. The Mosques seemed to be full all the time. My new friend brought me there and left me his bag and belongings before going inside to pray. I was tempted to go in as well but I thought it was not the right time for a tourist visit." 
This time in Constantine was very interesting. I discovered a city that was clean and active. The old town, the Kasbah, was pleasant, clean and architecturally interesting. An owner of a house there gave us a little tour of his place. He invited us in after I took a picture of the front door. The shop owners were always welcoming and happy to pose for me. I took some pictures of the store, with fresh meat hanging, and pastries. The coal sellers looked like they were from another century. I was still surprised to see that most of the women in the streets were wearing veils. In Kabylia, we have another type of veil that is part of the traditional dress. It is used to protect the hair from the dust, sun, and parasites of the rural lifestyle. I was told that in Algeria the veil was a necessity for Muslim women. Later, another Muslim man told me the contrary. Algeria officially became an Arabic and Muslim country after independence but in fact it was Muslim before that. The Islamophobia in the world after the events in the United States might have generated a reaction from women. Women have developed what Bullock calls the "critical faith-centered perspective", claiming their right to have their religion and as such providing the field of feminist research with another perspective on female emancipation. Bullock in Rethinking Muslim Women (2002) argues that:

"Religious fundamentalisms have also emerged as ideologies and ontologies of resistance to colonial and contemporary modes of imperial intervention and control. However, because of their complicity in the construction of sectarian and gendered oppression, they operate outside of my definition of a "critical faith-centered perspective" (p. 87-88).

As some Muslim women were being subjugated, other Muslim women have taken the decision to veil, to express their religious affiliation. Bullock (2002) explains:

"Veiling was also used as a symbol of political protest and revolutionary struggle in Algeria in the 1950s and in Iran in the 1970s, and the hijab was donned by women who 
did not previously wear the Islamic head scarf, as an act of subversion against colonial powers that sought to eliminate all vestiges of indigenous Muslim societies" (in Jasmin Zine, Fall, 2004, p.185).

Jasmin explains that Muslim women are developing a reactive behavior to the foreign cultural challenges. They are compelled to engage in political activism, exposing their cultural position to the world. In Kabylia, we do not have a majority of veiled women; however, the majority is Muslim. In Kabylia, women struggle to stay Kabyle and refuse to be assimilated to Arab culture because they are Muslims. Clearly Kabyle society is very different from the rest of Algeria. I asked a woman involved with the question of women rights in Algeria to help me understand the place of Kabyle women in Algeria.

\section{A woman and government perspective on Kabyle women's rights in Algeria}

After my stay in Constantine and my cultural immersion in Arab Algeria, I realized that we were from two different cultures, even though most of us are from the same religion. In everyday life we definitely share the same country and the same civil society. However, in Kabylia people complain that the government neglects cities, such as Tizi Ouzou, because we, Kabyle, are asking for a culturally adapted society. The differences between woman in Constantine and Kabylia made me want to know more about women's rights in our country. It is with that goal in mind that I interviewed a government employee involved in the question of women rights in Algeria. I am quoting her here.

Interview 2: An official point of view 
Me: "Do you allow me to use our conversation in my thesis?

Her: Of course. We are at the disposal of the researcher, and we have books that will help them in their research are also available. You will most probably find books that will address your theme. In terms of education, we are in a country where it is assumed that the women educate the children. I don't think this is particular to Algeria or to a Muslim country. However it is clear that this attitude and behavior are in response to a patriarchal family dynamic. It is that divides the roles like that. The man's domain is outside the home, whereas the woman's is inside. When she does not work, and even when she does, she is the one who educates, raises, and takes care of the child's school life, and health. The man is a little bit absent in this education. She has primary custody of the children when there is a divorce, even if the law does not recognize her. The law does not recognize her official rights because the power stays in the father's hands.

Me: Which society are we talking about? It seems to me that there is a division in this society in which we live. Even if we have a government that wants to say that we live in a society that is Arabic and Muslim, it is a society with women and men and children, Berber and non-Berber. So here are you talking to me about a society that would be Arabic and Muslim? Is it in this framework?

Her: Yes, yes because Algeria calls itself Arabic and Muslim regardless of the ethnic group you belong to. You could be Kabyle, or Moabites, but they have the same type of organization, the same type of family. It is based on the division of work between the man and the woman, outside and inside. There is the same relationship of subordination, the same relationship of hierarchy of the sexes, where the man appears to be the agnate. The man dictates everything. That is the model. It could be an Arabic 
society, or a Judeo-Christian society, but it is still the same system. We have extended families but with modernization we are seeing more nuclear families. Today there is a need to review the "Code de la famille" because it portrays the model of a family from the third century of Hegira, with an outdated view of the relationship between man and woman, as well as between grandparents and children.

Me: So you are saying that we are in a society that has changed, that is no more a close-knit society. You speak of extended families versus nuclear families. I am really trying to understand what you are saying. If we are no longer in a society where we live with extended families, do we live in families adapted to a consumerist society?

Her: Yes a nuclear family is the conjugal family, father, mother and children, and to a certain extent the grandparents, but even this tends to disappear. So you will find only this nuclear family in the text. The "Code de la Famille" is the only one that enforces social protection. Everything that is insurance, retirement, capital, in case of death etc... The "Code de la Famille" is the one that reflects a little bit of the social reality but it is not the actual reality, the reflection of a social situation. When they worked on this text it was to concretize the nuclear family: father, mother, and children. There is just a little about social attributes, social allocations. The people who wrote the "Code de la Famille" created it for a nuclear family and not for the extended family.

Me: So where are we with women's_rights in all this?

Her: In all this there is a dichotomy with respect to women's rights. In the public space the woman is a citizen, she has her constitutional and civil rights, she can work, be elected, and vote. In the public space the legality is dedicated to her rights but in her family and private sphere she becomes impotent on a juridical level.. 
Me: What does it mean to be juridically impotent?

Her: She can sign a contract worth billions in the public sector because the contract will concern a society in which she could be the leader, minister or ambassador, but she would not be able to negotiate her own wedding contract because she needs a matrimonial tutor. This is what makes the dichotomy of her status. She is a citizen in the public domain but in a private domain she is powerless.

Me: So, if I understand correctly, the status has changed but it has not been reformed on an essential level, I mean at its roots. Do we see a change happening? Is it starting to change in the families?

Her: I think we need to go back through the historical periods of Algeria, 1962, 1984, 1990 and today, because it is impossible to ignore this. From '62 to '84 the women did not need a tutor to get married. It was written in a text that France was imposing on Algeria. It was kept in the text of Muslim rights concerning the family, but with a clear evolution. It is after 1984 that things became more rigid, after the "Code de la Famille". The FLN, who was leading the country, and that still does lead it, was influenced by the changing times. The modernist current is the one that existed from 1962 to 1984. It was working towards the construction of a modern society. In 1984, the power of the FLN was transferred to the hands of the Conservative Party. There was a radical change and it was then that we reintroduced conservatism. The "Code de la famille" fell apart between '62 and '80 when society was evolving and when the social relationships were evolving towards equality. It is even confirmed by the political discourse. But the current Conservatives made sure that the Health code change in 1985, and the "Code de la Famille" changed in 1984, and we returned to the previous family status, one that existed only in the texts because evolution is 
unavoidable. The code has been superseded because it does not represent the social reality.

Me: How did we go from a traditional society to this government today?

Her: The rights were maintained on paper. France was establishing legislation for the population but it was a tribal model, and Algeria wanted to build a nation. The local systems are nonsensical."

Employed by an institution supported by the government, my interlocutor provided a great description of politics in Algeria. The Algerian government stands against the fundamentalists but at the same time wants to destroy the traditional societies. The Algerian government is considered non-equitable and nonsensical regarding women's rights and economic development. She justified the government policies, using examples of Muslim fundamentalists and French colonization as the common enemies. Within her discourse she built up a demagogic atmosphere for the support of the government. In the rest of the interview, France was always framed as evil in order to turn the actual government into the savior. My interlocutor made a reference to the Arrouch (citizen movement in Kabylia and ancient social organization regrouping different villages) who were associated with the MAK (Movement for the Autonomy of Kabylia) during the Black Spring. They were trying to bring the power back to the community and emancipate from the government and Arabic dictatorship. The "Black Spring", in 2001, started with the assassination of a young high school student, Massinissa Guermah, and turned into a march on Algiers and then into riots that left about one hundred young Kabyle dead, killed by government forces. The government recognized our language as a national language, meaning within the boundaries of the nation, 
but not the official language, because there is no law to make it official. The government started to teach the Amazigh language in the schools. The government employee was quite impatient when she talked about that and referred negatively to Ferhat Melhenni. Ferhat Melhenni was a musician who became a political leader and was arrested thirteen times for his political actions. He was at the head of the Movement for the Autonomy of Kabylia. In 2001, his son, Améziane Melhenni, was assassinated. He created the Provisory Government of Kabylia in France, the first of June 2010. She seemed to be firmly against this movement.

When we talked about schools, she made a brief and vague allusion to multiculturalism. She explained that from 1980 to 1990 schools were becoming Islamized rather than Arabic. She said, "Egypt and Syria sent us their teachers but they were mainly fundamentalist Muslims." She then built up a demagogic spider web as she undermined the traditional Berber education, denouncing as well the Islamist influence, and came back to the FLN policies that she valued for their great progress.

This short interview was very helpful in presenting the laws and gave me more information about the Algerian struggle to create a society. Muslim, Kabyle women have to work out this complex situation in order to adapt to this quickly changing society.

\section{Indigenous and Muslim feminism}

I now enter into a critical discussion about Indigenous feminism. I was expecting to find this information with my previous interview, but instead I found it while looking through literature on Indigenous and Muslim feminist activism in Hawaii and Canada. Most of the Algerian population is actually of Berber heritage but just a few still embrace this culture. The Berber population is mainly located throughout Kabylia, with the Moabites in the south of the country. The Kabyle, as well as the Moabites, were targeted by this government employee as 
nonsensical traditionalists for their promotion of women's rights. Today in Kabylia, women wear jeans and have short hair as a sign of liberation but, at the same time, they are proud to be wearing the traditional Berber dress. These simple actions of women in the province reflect a deeper debate that needs to take place in Algerian society. In Hawaii, the women are addressing the indigenous feminist issues. Haunani-Kay Trask shares her point of view on the situation of Hawaiian women under the diktat of the American representation of women. She argues that:

"The feminism I had studied was just too white, too American. Only issues defined by white women as "feminist" had structured discussions. Their language revolved around First World "rights" talk, that Enlightenment individualism that takes for granted "individual" primacy. Last, but in many ways most troubling, feminist style was aggressively American" (p. 909).

I had this conversation with a Kabyle woman in August 2011 in France. She was telling me that she was organizing a speed dating party. She is a strong Berber activist, defending traditional Berber culture as well as her right to be a Muslim woman. It was happy to see how creative and dynamic she was. I brought up the subject of culture and tradition but she claimed that she was not interested in silly practices. My point was the same as the one that Zine shares here:

“...Some Western feminist articulations of Muslim women's identities have appropriated colonial discourses that construct Muslim women as backward and oppressed. Their redemption, according to this discourse, can come only through emulation of Western norms and conventions of womanhood" (Zine, 2004, p.169). 
I told her that for me, the emancipation of women should come from within the community, with the values and heritage of the community, not from giving in to outside stereotypes of women. This adoption of a foreign representation of a system would not be the emancipation of Berber woman but the adaptation of Berber women to Western standards. Mohanty (2001) argues in her introductory lecture at the Anti-racist Feminist Institute, at the Ontario Institute for Studies in Education, at the University of Toronto, that feminism can be understood as "being conscious of being a woman and doing something about the consequences of being a woman".

From that definition Zine (2004) explains that:

"The corresponding notion of "doing something about the consequences of being a woman" embodies an argument against cultural relativism by claiming for women the agency to act against the negative consequences that often accompany the act of "being a woman" in various cultural milieus that may be located geographically in the global North and South. This notion sees feminist consciousness as being rooted in critical self-examination and political praxis... (p.170).

I tried to explain that every movement of freedom should come from within the individual, within her community and respecting her culture. Such emancipating processes could uplift the whole community and support evolution in a culturally appropriate way. I advocated for what Haunani-Kay Trask (1996) believes:

“... Our indigenous women struggle to create our own history in our own country. Our collective lives lead to a different order of understanding than the praxis of First World individual feminists in the university and elsewhere. For us, it is not theory that gives rise to praxis but the reverse. Indigenous women in struggle fashion indigenous-based 
views of what constitutes women's issues, about how women should lead our indigenous nations, and about the role, if any, of feminism (p. 911).

I also explained, as she was already defending herself from the possible patriarchal attacks she feared I could be attempting, that I had no problem with the party itself and even less with the fact that a Kabyle woman was organizing it. However, what I did not like was that she would generate an image of our culture as silly and was putting Western ideologies on a pedestal unconsciously. Her feminism was another tool of the cultural imperialism that she needed to be aware of. I developed the idea, drawing from the example of the Hawaiian women, quoting again Haunani-Kay Trask:

"The feminist failure of vision here is a result of privilege-an outright insensibility to the vastness of the human world-because they are white Americans. White people's survival does not depend on knowing daily life with a decolonizing mind or sensing reality as a menacing place that must be negotiated with great skill and a discriminating step. We indigenous people occupy two cultural worlds; white people occupy only one. We are the colonized; they are the beneficiaries of colonialism. That some feminists are oblivious to this historical reality does not lessen their power in the colonial equation" (Summer, 1996, p.911).

I agree again with Zine (2004), who says that:

"Egyptian secular feminist Nawal El Saadawi sees contemporary feminists in her country as falling prey to both Western consumerism and religious fundamentalism as they combine their hijabs (head scarves) with designer wear. She is critical of what she regards as their emphasis on fighting patriarchy to the exclusion of other connected forms of oppression, such as global capitalist imperialism... However, by making such 
an essentialized critique, secular Muslim feminists like Saadawi reproduce the Orientalist rhetoric of Western "imperialist feminists" who cast Muslim women in similarly pejorative terms and positioned themselves as the intellectual vanguards of these politically vulnerable women who needed to be guided and schooled in the ways of euro centered cultural feminism" (p. 173-174).

However it is very important to keep in mind that women in Algeria are held hostage by many different sources, from Western imperialism to Muslim fundamentalism. It is going to take a lot of wisdom for Berber women to stay in charge of their own destinies. In the battlefields that are our families, as well as their children, to carry the ideological arms of those imperialisms into the core of our culture, Berber woman have a long way to go before achieving freedom.

\section{SUMMARY}

In this chapter I examined the issue of religion in Algeria. The religious situation is still evolving. Kabyle culture and identity is being eroded more and more for the benefit of a generalized identity, using reductive representations to express beliefs. The Kabyle are reduced to a manifestation of the differences between themselves and their colonizers, Arabs or Western. Western countries influenced the social landscape, as did the Arabic government. Women are forced to discuss their position on the politics of culture and into multiple representation systems. Traditional society is being undermined by the concept of development, whose goal is to silence cultural diversity. I provided an overview of the Catholic Church and introduced us to the projects undertaken by the Catholic Church in the Kabyle region. I then looked closely at the politics of Islam and finally spoke with a person 
responsible for the women and children's rights in the country. Kabylia, as a separate culture, does not seem to be really respected in the country. After my meeting with the women employee of the Algerian government involved with woman rights in Algeria, I became even more worried for my culture. I was able to gather more information for my journey, as I understood the context in which my heritage is developing today. I have made more sense of Algeria's society. I understood my need to go back to my traditional culture to understand the teachings left behind by my grandfather.

In the next chapter, I describe the arrival into my village. I hope to lead readers to an understanding of the organization of my village. It is inside the village that I return to the grave of my Ancestor and it is there that the last part of my inquiry takes place. 


\section{CHAPTER SEVEN:}

\section{THE LIGHTS OF THE KANUN}

\section{INTRODUCTION}

In this chapter, I am one step closer to my village, closer to my family. I start to see the grave of my ancestor coming out of the trees, reminding me of the importance of the rules and values, the qanun. Teachings from my mother are coming back to me as I get closer to the fireplace, the kanun. (The words qanun and kanun are phonetically similar but have a different significance)

I realized that the tamusni, the knowledge from experience that gives wisdom, has changed its meaning in Kabylia to become knowledge for power, to feed the ego. The trees are symbols that remind me of the ancestors and at the same time that they represent the future of my family. In this chapter, I present stories with my father, my mother, and my family, sharing my culture, as I arrive in my village.

The villages in Kabylia are generally located on the hilltops of the region, such as Iril Bouamess (the village of the singer Ait Menguellet), Ait Yenni (the location of a famous traditionnal jewels festival), Taourirt Mimoun (the village of the writer, academic and poet Mulud Mammeri), Agouni Gueghrane (the village of the singer Slimane Azem), and Beni Douala (the village of the singer Matoub Lounes). They appear isolated and are managed like little republics. Every family and village is autonomous. However, the tradition of marriage between villages creates a network that shapes the social landscape of Kabylia like the pearls of the traditional Berber Jewels around the neck of a bride or the lights of the fireplaces, all ignited from one source. The kanun at night reveals the bonds between all the members of the family and designs the landscapes of our society. The fire of a new family kanun being lit in a 
house symbolizes the birthplace of the qanun. In the kanun of the families, the qanun of a whole culture slowly comes to life. I refer also to two gates in the cycle of life of the mountain: the fig tree for life and the olive tree for death.

\section{THE KANUN, THE FIREPLACE OF THE HOUSE, SPEAKS OUT THE QANUN: THE RULES AND REGULATIONS OF THE VILLAGE}

The identity of my village relies not only on the people but also on its trees, animals, wind, rain, and fire. Kabyle culture has a close relationship with the natural world and the spiritual world. In this chapter, I provide a sense of the rules and regulations of our villages and show how the women, the keepers of the fire, participated in the writing of the Kabyle story and in the magical protection of the community. The magical protection is visible on the wall drawings and takes place in ceremonies and rituals where men are often not invited.

The kanun refers to the cooking fire in the traditional Kabyle house. It is a simple hole in the floor, but is the sacred place of the creation of Kabyle culture. Each village and each house has its own qanun and each houses its kanun. Disrespecting the qanun can lead to expulsion from the village. In my village, the qanun stipulates that each member of the village should be present during community meetings. If a member is able to come but chooses not to he will receive a fine of a hundred dinars (Algerian currency). The fines will increase until the individual comes, pays the fine, and participates in the community reunions again. Fines are also given if one uses bad language, such as swearing or insulting, or if the person exhibits threatening behavior in the everyday life of the village or during meetings. Qanun of our village represents the community of the families of our village. 
The kanun in the house used to be kept alive by women. Today, women are trying to manage this essential role in the traditional Kabyle society while maintaining a place in the global world. The image of the liberated woman challenging the traditional woman comes from France, as it is the country that has had the strongest cultural and critical influence on Algeria. To pass down the values, my mother would tell us stories about her village and we would learn from them. My mother would not give formal cultural lectures on values but in the everyday moments with her we would learn to support each other, our land and traditions, respect our elders, and listen to our stories. As well, we would be building our imagination according to the community values. These stories represent a connection between us and ground us in our village.

\section{TAMUSNI: FROM WISDOM TO POWER}

While the qanun is a place for generating traditional values and those values are a source of social strength within the community, today, Algerian society has taken a different course. The important place of women, as keepers of the core and face of our society, with their control and transmission of our value system, is constantly challenged by the ever intrusive value system of Western countries. One main manifestation of this change is the shift in the understanding of the word "tamusni", knowledge. In a lot of the conversations that I have with people in Algeria, I have been constantly reminded of the need for tamusni. The social fragility in Algeria creates a need for support from within the government. The bureaucracy is such that one needs to prepare papers even to request the necessary papers, and it can be quite the ordeal. The word tamusni has even been used to describe the "contact" in the administration, referring to power rather than knowledge. I was fortunately exempted officially from military service by the Algerian consulate in France, but I heard that some 
people were buying their exemption from army representatives in Algeria. This traffic of influence is another of the survival strategies used by the population. This phenomenon is unfortunately frequent in Algeria and is common knowledge. The word Tamusni is even used to describe a "contact" in the administration.

In Algeria, when I return to my village, I often rest in the shade of the trees, though just a few trees are left today. It would be utopian to say that the culture and traditions are strong and healthy in my village. Despite the fact that members of the village are slowly realizing the importance of their cultural heritage, and appreciate the value for future generations, divisions in the village make it an almost impossible task to keep the culture alive. Assimilation is thriving today in Algeria. The politics of assimilation are driving people into mainstream religion, urbanization, and all the effects of the transition into "modernism" have left our gardens dry and houses empty. Capitalism has reached our village and has increased the people's desire to accumulate wealth. From the descriptions of success I understood that the evaluation of life achievement has changed in nature. Success is judged by the car, the size of the house, and the number of kids in school. The topics studied in school are less important than the future paycheck.

Tamusni is a very important word in Kabylia. It used to mean "knowledge," but now it refers to a network of influential people. In the past an individual man or woman with tamusni was wise but now tamusni means powerful, changing it from value based to power based. Now importance is given to the power attained from one's social status and the position within a powerful organization. The level of education is less important than the tamusni as understood today meaning that economic power is now what gives people pride. This relation to power is illustrated in social games that replace humility and responsibility with power struggles. The lack of financial success was mitigated by honour but now undermining the 
success of another person is the chosen path. This to me is an expression of low self-esteem. One social game I have witnessed is the appropriation of one's success by trapping the person in a dependent relationship and then steering them toward a less "successful" route. One of my informants tried to develop this type of relationship with me. He would make sure I could not do anything without him, from grocery shopping to working on my house, creating a dependency so that he would have the monopoly on the market I represent. In Algeria, it is common to develop this type of relationship with expatriates considered to be rich by many in Algeria. Now, even if all the families have relatives living outside the country they are building relationships with expatriates coming back on vacation to try to get some money out of them. There is even a saying for that in Kabyle, "the one closest to you is the one who will hurt you the most".

In Algeria, modernism is a word frequently used by the people. Neo-liberalism, based on the model of Adam Smith or David Ricardo, explains that to be developed and to attain success in the economic market, the Southern countries, including Algeria, need to make their resources available to all on the international market. The Southern countries should align with world production by producing only goods that will be of value on the global market, which means being enslaved to rich countries. Developing institutions will have to obey international laws of competition and capitalism and only have access to their own resources through the international banks. Only then will Southern countries gain access to wealth and social stability as dictated by Western countries. In Algeria development means westernization of traditional society, centralization of population in the main cities, fall of local village economies, social organization, and disappearance of the cultural heritage. The streets of our village are haunted with memories and shadows of the past, kept alive in the fragile families left to inhabit them. However, I have spoken with members of different villages and a lot of 
them talk about initiatives taking place on a microeconomic level to help protect the cultural heritage and the life of the villagers. This heritage starts with the protection of our fig and olive trees.

\section{THE FIG TREE SYMBOL OF LIFE AND FECUNDITY}

The Kabyle people I met, including myself, are trying to find a balance in the world. Culture remains the lifeline of our community. Kabyle people refer to their traditional Indigenous culture as the root for the development of identity. In places like Algiers, Oran or Constantine, those regions of the country that are officially Arabic, I found that Islam was used as the cultural link between people. Islam also offers a guide for development. For us Kabyle however, even if we have been Muslim for centuries, Indigenous beliefs and lifestyles still exist.

"The periodic apparition of fruit on the sacred fig tree similarly reproduces the cycles of a human mother. The perfect cosmic representation of a Kabyle marriage, the fig tree expresses the never-ending chain of human births. In all ancient traditions, including those of Kabylia, the mysteries of a tree express the vertical dimension both of giving birth, which the women do in a standing position, and the continuous chain of the generations" (Makilam, 1999, p. 76).

I would like to repeat here the lyrics of Lounis Ait Mengellet's song, "Idural af Idurar". Ait Menguellet compares the villages on the tops of mountains and hills in Kabylia to the pieces of a traditional Kabyle necklace. Together it is worn by our mother earth and by our women during celebrations. In this tradition, the men have to leave the house early and come back at nightfall. When they come back, the lights are turned on and the family celebrates its unity 
again. In this light, we celebrate the perpetuation of our tradition in the heat of our kanuns. However, in Algeria today, this life circle I just described is about to break. Either silenced by fundamentalism or turned towards consumable goods, women are being dispossessed of their heritage. The kanuns are getting cold and silent.

Traditionally, Berber women are the carriers of water. Water symbolizes life in Indigenous culture. Coming as fountains from the inside of the earth, water is a very important element of the planet, as it is for our body. Women not only carry their babies in water when they are pregnant but they can breastfeed them with milk, and finally ensure that there is always water in the house. With the act of carrying water into the village, they bring life into community. They keep the balance of the village by also being in charge of the fire. The inside of the house, especially the kanun, is the place of magic. Traditionally, the sticks of wood coming out of the fire could only be touched by a trustee knowledgeable in magic, who could manipulate them, as these sticks were considered a sorcerer's wand. The fire was a tool for the alchemy and balance inside of the sacred house. The house that was built and protected by men was brought to life and kept alive by women. The responsibility of the fire was occasionally shared with men. This form of leadership that women represented in society is being totally undermined today. The drawings that women used to do on the inside of houses are disappearing and are being replaced, either by posters of Mecca or random pictures of western singers, actors or actresses. Those earlier drawings expressed not only the imagination of a Kabyle woman but were the encoding of the village stories in a cultural language. The drawings brought the outside world to the world on the inside. The story of the village drawn by women on the walls was encoding the knowledge gathered by the village across time. The women guaranteed coherence of society through the transmission of the story.

Women were shaping the inside of the community, imagination, and psyche. They were working on the spiritual life while they took care of the harvest outside. This responsibility and 
space of expression privileged to women has pretty much disappeared. Women used to have traditional tattoos, in the forms of little dots, lozenges, and waves. Those tattoos were telling stories. They were magic carvings of protection for them and their families. They inscribed their prayers on their bodies, which expressed their desire to keep their homes safe and protected from the magical and spiritual world. But those tattoos are now silenced by mainstream politics. I remember asking my father about having a tattoo but he and my uncle forbade me. My father refused because he considers it to be a sign of delinquency and my uncle because he said it is against Islam. One is supposed to leave his body the way the creator made it. That is what they explained to me. The paintings are also denounced as nonsensical and the magical parts of them are considered evil practices. Traditionally, each act inside the house was rich in meaning and symbols. Today, it has been replaced by the gathering of meaningless objects, to buy into the feeling of being modern and to claim emancipation. Women used to design the stories and beliefs, encoding the knowledge passed in tamusni to the next generation. Berber women, by creating their art on the walls of the house were sharing their imagination and secret thoughts. They were building the mythology and global story of Kabylia. Each time a Berber woman inscribed her story on herself with tattoos or on the walls inside her house with drawings and carvings, she was creating a physical, mental, spiritual, and emotional bond between herself and her loved ones in the community. Kabyle women traditionally gave birth to lots of our beliefs and had an essential role in the education of children. Along with the control of the food and water, imagination, and transmission of the belief system, comes the responsibility of the organization of society, with the responsibility of matchmaking the next generation of the village. The mother was in charge of finding the partner for her children. This last role succeeded in giving them the complete leadership of the heart, body, souls, and mind of the village and shaping the future of the village with the often complicated terms of associations between families. 
It is true that the women of Algeria are being oppressed and silenced. The work of women rights organizations is important if not vital in Algeria. However, as Makilam explains here, the perception of the submissive Berber woman is a mistake, and is based on a misinterpretation of the traditional society.

"The distinction of gender and the separation of tasks and roles between the sexes do not necessarily lead, as has often been thought, to power relations between men and women. It is tiwizi, or helping each other, that dominates amongst the Berber people of Kabylia. This conception of social life implies a notion of responsibility between all the members of ones family and extends to the whole village" (Makilam, 1999, p.4).

In an attempt to emancipate the women in Berber society, one might argue that Kabyle people are actually assisting in a transfer of the dividing colonial forces within Indigenous systems This misrepresentation of the self allows the outsider to enter the community and break the sacred bonds between husband and wives, children and parents, and allows for the fragmentation of the village into a market of souls, minds, bodies, and hearts. The fracture of the unity of our communities and identities facilitates the permeability, management, and exploitation of outsiders. Everywhere in the conversation about culture, the place of women is essential:

"In the description of the different tasks that Kabyle women carry out within the family group one notices that they have never ceased to define their powers in terms of responsibility. From generation to generation, the women transmit power and knowledge from mother to daughter and they help their sons to develop their abilities. The Kabyle woman remains the guardian of traditional language, rituals and values" (Makilam, 1999, p. 4). 
Reading from Makilam's description of Kabyle women I understand my mother, who I describe here in this next narrative.

Narrative episode 33: My mother is an example

"My mother comes into my life in different forms. She comes in the form of the legacy that she left me after she passed away. When she was buried in Algeria on our land, my garden was dark with people. My informant told me that people came from all over the mountain to say goodbye. I was not able to be at the funeral because I did not have the military papers allowing me to enter Algeria without having to go to military service. It was in the peak of terrorism in Algeria. I got those papers only four years after she died and I left immediately to pay my last respects. She was respected because she fed many people during difficult times and also because she was a great support for her husband and family in France. She stayed faithful to her family and her village. My mother gave and received the honor of the whole mountain. Without asking for anything in return she gave with no limit until the creator decided that she needed to come back to him. She was an Angel sent from the heaven to carry us to our destiny.

My mother was a great example of humanity in her devotion to her loved ones. Who can influence you more than the one who holds your heart until you can walk alone? Makilam says:

"The mother transmits not only her milk, but also the maternal care and love destined to foster physical and spiritual growth, and the continuity of the human cycle. It is essential, too, to stress that the role of the woman as nurturer begins much earlier-with 
her pregnancy. She, as a mother, feeds the child growing in her womb and she moulds him or her by offering the physical and biological substance of her human body" (2007, p. 58).

My heart aligned itself to the pulse of my mother. She gave our family the rhythm of a Kabyle harmony. When I am asked today where I was born, I say in the body of a Berber woman; where I grew up, in the body of a Berber woman. There is no country and no paper that can carry and transmit these first teachings of life. She was much more than a simple container of human flesh. She was the bowl that gave me birth and transmitted my genetic heritage. She was the magic bowl (in reference of the Native American sacred pipe) that united two destinies into one. How can I ever thank her enough? My mother was also a funny, beautiful, and unique individual. She was like all of us in Kabyle, expressing herself in the way our traditional society teaches us to. She was devoted to her family and to the transmission of our heritage for the future of our country. Individual success is not success unless everyone can enjoy it. My mother knew how to be herself with us. I remember when she was sick from her cancer just before she died. We were eating together as we always did. She had been away for a long time, but she was back from hospital after chemotherapy. She ate fast, which she never does. She then stood up and went to the bottom drawer of the fridge. She fell on her back and could not stand up by herself. She looked at me, laughed said, "I was too greedy, I could not wait for the end of the meal to eat my grape." I stood up, seeing for the first time my mother asking for help, and giving her my hand. I helped her stand up. She was laughing with her beautiful smile. She took her grapes and came back to the table beside me. She was a wonderful soul until the last minute.

"The child has his dwelling within the secret and hidden shelter of his mother's womb and is bathed in the waters of its garden, nourished by maternal blood and warmth. The 
female body, source of life, is like the earth from which springs fruitfulness. When the baby leaves it, a pregnant woman is said to be like a tomb; because she has to die to give life to the child she formed. The pregnant woman, Tafsa, is considered to be like a grave during the first forty days of mourning; the restrictions surrounding her are the same, they are those of the seeded earth at the time of plowing and in the spring (tafsut)" (JP. Servier, p. 252 in Makilam, 1999, p.71).

A mother until the last minute, she was there for us all. My mother and my father were pulled between two societies: Kabyle, first, with their duty towards the members of our village, and the French society that kept them in the reductionist and oppressively structured place of the immigrant worker. My parents were fighting two separate battles at the same time. Against assimilation into France and at the same time against a country that was being built for us even though my family fought for its independence. It was a struggle to fight against the fragmenting forces and remain a unified family. My parents needed to transmit this strength and unity to their children. My mother was there to make sure my father could go on with his duty as a provider while she was keeping us safe and secure. She would provide a place where he could rebuild his strength for the next day. She kept him and us alive the whole time, never asking for anything in return true to her role as a Kabyle woman.

Makilam explains to us "the cult of the prolongation of life through the mother is evident in every aspect of the daily life environment of the men and women in traditional society and can also be found in the cult of trees" (1999, p.74). Therefore, I cannot limit my story to the time of the fieldwork because there is no limit in the transmission between a mother and her children. It is my mother who nourishes my cultural education. Supported by the love we share, this is how I continue the story of my ancestors. 


\section{THE OLIVE TREE: SYMBOL OF WISDOM OF THE PAST GENERATIONS}

In our way of life, we embedded our knowledge and shaped our societies according to an organic culture. We have seen the place of women and. with a narrative from under the olive trees we carry the metaphor to the land, to understand the place of transmission today, as well as the value of the heritage.

\section{Narrative episode 34: From the bottom of the Olive trees}

"A couple of years ago I attended the funeral of someone who, I thought, was my father's friend in Algeria. He did not tell me much about him but I knew he felt sad. We arrived at this village carved in the mountain. All the men were there silent. There were no activities, just a simple silence. I was surprised by the level of respect that was present at the funeral. I understood later that the man was in fact a long serving member of the liberation army. What exactly was his position? I do not know. All I know is that he fought for his country and was buried with all the honor that he deserved. It was an important time for my father. I sensed that there was something happening there and that there were risks for him. He could not stay home and so I went with him, not really understanding what was happening. Standing outside the house of death with everybody silent, I followed his eyes looking for signs of life. His gaze was looking for something to hold onto and it was following the hard contour of the mountain that his eyes found a fig tree. Standing, growing with no soil for its roots, it was there, alone. Without realizing, he said, "You see, my son, fig trees can even grow on dry rocks in this country". 
In narrative 36, I explain the symbolic place of the fig trees. War has left a heavy weight on my father's generation, giving even more meaning to the fig tree, symbol of life. Even when we experience political oppositions, Kabyle culture survives. In narrative 36, I present both death and life, introducing the place that Makilam (2000) gives of her understanding of the place of the fig tree.

"It is said that he who has misdeeds to reproach himself will try in death to come closer to his family. Only the sacrifice of a fig tree can appease the tormented person and release the soul from his body. The power of the dead is superior to the power of the living. It is believed that it is the source of life and is renewed in the fertility of fields and homes once the dead have reached the realm of invisible life" (p.130).

The tree of life is stronger than the hardship of a life in the Djur Djura Mountains and it brings its teachings and magic. Symbols of life are also symbols of death, and this brings healing. The tree of fecundity was there that day to remind us that life continues. This story takes place under the family tree. If the fig tree is the symbol of fecundity and life, then the symbol of education and wisdom would be the olive tree, which is the tree of death. The graves of the holy Ancestors are often marked with olive trees.

"The association of the woman's creative forces with the invisible forces of the earth results in a variety of pilgrimages to the ancestors, tombs, and more and more often the tombs of the Marabout saints. However, one must consider that the devotion to a Marabout, who is visited in his sanctuary, is in reality aimed at the cult of the earth and of the trees, with the olive tree, the tree of the dead, present in every cemetery" (Makilam, 2007, p.59). 
The olive tree is the tree under which we sit and tell stories. It is a common belief that it is important to respect the place under that tree as it is often a privileged place for the spirits to sit and look at the world of the living. It is an olive tree that transmits the wisdom and protection of my other Ancestor, Sidi Belkacem, in my mother's village. In this dissertation I explain the place of the Ancestor referring to one from my father's village, but I am Marabout on my mother's side as well. Her village also has a venerated Ancestor. The olive harvest gathers the whole family. We collect the fruit that will transform into the precious oil, which is one of the main staples of our nutrition. Narrative 43 shows that family meetings are traditional educational times.

\section{Narrative Episode 35: Harvesting the Olives}

"For this year I had the chance to be there for the gathering of the olives, and this inspired my informant to make me a little gift for his participation in my research and the protection of our culture. After many conversations on the importance of keeping our culture alive, he decided to give me a little surprise. He and all the members of the family, who were available, gathered to pick the olives and make a little movie for me. There were three women, one adolescent girl and ten children. The movie was recorded partly by his youngest daughter. It takes place at the foot of the olive tree. They are all sitting in a circle eating dry figs from the previous year, drinking cow or goat milk and eating the traditional Kabyle bread. It is very touching to see the seriousness with which the young girl is recording the scene. Twice, she asks the other ones to be serious about it. I suppose that her father must have explained to her that she was doing that for me. 
They were sitting in a circle at the bottom of the tree. The weather was a little cold so they were well dressed. The women were all wearing the traditional Berber dress except the youngest one who had put something over her pants to look like a dress, but she was wearing jeans. It reminded me of some of the women I met in Canada during Native ceremonies who had to wear a dress before entering a sacred place. Girls and boys were mixed together but an older man was sitting alone in the back. The women left him there while the kids and the women were having the little feast. Everybody seemed to enjoy his or her time. The camera filmed as they went around and sent good thoughts to the elder of the family who had gone on the pilgrimage to Mecca in the place of his wife who was too sick to go. The olive trees are his.

One woman commented, saying, "He is gone on the pilgrimage for his wife while we are here picking his olives." Another one, his daughter said, "We wish him a safe journey and we hope he comes back soon so we can all gather in happiness." I sensed their emotion watching this video and it made me smile. I felt really touched by this gift and happy that they decided to pursue this tradition together.

They were not actually collecting for him but for themselves on his property. He gives everything that he owns back to his family. When it is time for the olive trees to speak, the population comes from all over the place to go to their land and to pick the olives. I met one man who works in the Sahara. He always takes his vacation during the harvest season to be back and participate in this important ritual. Even if he does not need the money from the oil it is important for him to participate in the tradition. It is hard work but is a source of great pride and happiness to be present during this time. 


\section{REFLEXIONS}

In summary, with the political instability in the country, the qanun of our village has been the protector of local social cohesion and peace for generations. We honor the elders and the past generations when we come back to collect the olives. As I have learned from an elder in the Innu Nation, "When an elder asks you to collect medicine to heal him or her, he actually teaches you where, when, what and how to heal. You should be thankful for the trust he gives you." It is written in the qanun that one should participate in the traditions of the village. In Kabylia, when there is a village reunion in the tadjamait (the gathering house), it is in every kanun of the village that food gets prepared and then shared after the end of the talks. The talks start days before the actual gathering. They start around the kanun. It is a way to settle the debates and it shows again that the talks are taking place for the good of all. The women's contribution to the unity of the village is boundless. The women are also present in the metaphor of the fig tree, the tree of fecundity and symbol of life. On the other side of the life journey stands the olive tree. It is the tree of death and of the wisdom of the past. In this chapter, I have presented these concepts and beliefs in order to explain the roots of the social organization in my village. We understand that traditionally the values were at the center of the community. It is because the Murrabitin in the 1600's, and the Berber Sanhadj missionaries of Islam from Saquiet El Hamra, were bringing peace and knowledge into the village that they very quickly became central figures in the Kabyle cultural landscape. My Ancestor was one of them. In the next chapter, I explain who he was and when he arrived in the village. I show how my village was built according to the Islam of my Ancestor who is the Saint buried in the middle of the village. The village social structure respected a Berber traditional organization. I show how the actual redistribution of power within families is structured and look at the different exchanges in the village that are organized to honour the 
community in a way that always nourishes its roots. In chapter 8, I present the Ancestor and explain using social organization of the village that his heritage is traditional Kabyle as well as Muslim.

In this chapter I explained the metaphors shaping symbolic systems and unifying and women in the cycle of life and death. I understood that the Kabyle society has changed and the culture has taken a turn toward being a power based society rather than value-based society. However throughout my inquiry I am looking for the culture established by my Ancestor. For that purpose, I looked at the stories of the fig and olive trees. Now that I understand the cultural framework of the Kabyle society, in chapter 8, I will explain who my Ancestor is; a Marabout man, in my Kabyle village. 


\section{CHAPTER 8:}

\section{THE FOUNDER AND FOUNDATION OF MY VILLAGE}

\section{INTRODUCTION}

In this final chapter I focus on the story of the Marabout people. Marabout people's lives are challenged in the contemporaneous Algeria; however Kabyle and Arabs still show respect to that heritage today. The graves of these Saints are still places of worship. I understand who the first Marabout were and how they are perceived today. "Agourram", medicine man in the Amazigh tradition and religious model, the Marabout are still, in many places, considered Saints and part of the Kabyle traditional society. Their graves are still places of pilgrimage. In this last chapter, I put together the last piece of my cultural heritage with the history of my Ancestor. In the first part, I present the history of the Murrabitin (Marabouts) a heritage that explains the spiritual gift that gave Marabouts such charisma in the Djur Djura Mountains. I explain that they are the blending of Kabyle animistic beliefs and Islam. I then reflect on the perception of Marabouts in Kabylia today with the critical perspective of non-marabout Kabyle. I continue this chapter describing the clan system of my village that is recognizable in the theory of segmentarity from Durkheim (1893-1922) and Gellner's (1969-1972-1976), a theory developed on a study of the social organization of the Berber people. 


\section{WHO WAS MY ANCESTOR? (History, teachings and gifts)}

To answer this question we look at the history of the Murrabitin and the spiritual and/or religious place and responsibilities that they had in the Kabyle belief system and society. We understand from Makilam (1999) the presence of the Ancestor:

"Highlighted by the passing down of names to their descendants, the worship of the Ancestor, which sacralizes life after death, is not an isolated cult. It is lived out and is evident in all aspects of daily life, and is expressed in the seasonal renewal of the cycle of plant life. The fertility that links the woman-mother to the earth mother, and extends through plant life to the cult of trees, demonstrates the unity of human life within its cosmic whole" (p.75-76).

Sitting in the middle of my village, I look at this big green building and I wonder about its meaning. My ancestor is buried inside. I have seen and experienced 'the cult of the ancestors' many times in indigenous communities. Finding a similar cult back home definitely reminded me of the sign of a pre-Islamic belief system; however my village is also a Muslim village. I am looking for the origin of my family, the reason for this strong indigenous voice inside of me as well as the origin of my Muslim faith.

My Ancestor is a holy man partly because he is a descendant of the prophet Mohamed or a descendant of one of his companions. Augustin Bernard (1932) somewhat corroborates this story:

"The XVIth century sees the pogroms of their (Sanhadj Berber's) rebirth with the great Marabout movements started from the tradition of the Saquiet el Hamra, the "Land of the Saints". In the XVI and XVII centuries the Berbers of Sanhadj of Atlas and the Veiled Sanhadj group into a big confederation and stretch their influence to the 
Sahara's Oasis. In the XVIII century they come to possess the Ziz and hunt the Arabs out. They are masters of the South Atlas between the Dra and Algeria" (personal translation, p.93).

The spiritual duty of the Marabout is to serve the people and make sure that they have a place to pray and open themselves to God. The spiritual gifts that Marabouts have are accompanied by a responsibility that inspires us to a greater respect for the teachings and a devotion to the good of mankind. If we are supposed to have "Baraka", which means being protected by God, and are gifted by God, then these gifts are for God and for the service of the population. It is known that those gifts were given to my Ancestor because of the strength of his faith and because he lived the life of a Saint. In this chapter to understand who are the Marabouts, we look closely at all these different aspects of the existence of the Marabouts. I start by presenting the epistemology of the word Marabout itself.

\section{Epistemology of the word Marabout in Kabylia}

I went back to "La Maison de la culture de Tizi Ouzou" to find copies of the Berber files. I was looking for stories referring to possible animistic activities and found something interesting: Poyto's text (1967) “Contribution à l'étude des sites préhistoriques en pays Kabyle: Notes d'explorations (Contribution to the study of prehistoric sites in Kabyle country, Exploratory notes)" written in the Berber Documentation Files of Fort National (Fort National is the colonial name for Larbaâ Nath Iraten, a city part of the Tizi Ouzou Willaya prefecture):

"Cautious searching of the special and spiritual places of the animistic cult: caves, rocks, sacred trees, streams, residences of the beneficial genies called "Iassassen" in Kabyle... reveals that some of them have kept their rustic, archaic cachet, and probably their shape and structure from pre-historical times. Others have been 
Islamized. Local legends turned them into graves of Ouali (saints), raised Koubas there and even mosques or real Zaouias. But if we look closely we quickly realize that, under an Islamic label, ancient ancestral cults have retained a lot of their vitality. The rituals seem primarily focused upon the mysteries of life and the personal experience of these, but also their dissemination and propagation" (p.17).

In the same document, I found a short paragraph that connected my intuitions with the ethnographical research that had come to hand. Edmond Doutté, in Poyto (1967) says:

“...After my research I realized that in these «Iassassen», of the 99 stations I spotted, 67 were localized in proximity to a high place. This percentage proves the ancient age of human implantation in those places and the degree to which the vitality of the cults relied upon the spirits" (p.18).

I went to the le Centre National de Recherche Préhistorique, Anthropologique et Historique (CNRPAH) previously called CRAPE, in Algiers. A Touareg and researcher for the center brought me into the library and introduced me to the employees, lending his credentials to allow me access to the resources. He gave me a couple of texts, recommending that I read the last books from Rachid Bellil, a disciple of Mouloud Mammeri. Mouloud Mammeri was a great poet, an ethnographer and the manager, in 1969, of the CRAPE (Centre de Recherches Anthropologiques Préhistoriques et Ethnographiques, Centre for Anthropologic Prehistoric and Ethnographic research). Mammeri (1990) wrote in his book Inna- Yas Ccix Muhend (translation: Cheikh Mohand said) that the word Marabout is actually Agourram, designating an individual gifted with a power more magical than religious. Agourram would be the shaman in Kabyle traditional society. This individual would not manage the sacred but the supernatural forces." 
Rachid Bellil's academic path tackles the research on Berbers in Algeria. He wrote two major books in 2006: The Oasis of Gourara (Algerian Sahara): The time of the Saints and The Zenetes text from Gourara (In French: Les Oasis du Gourara (Sahara Algérien): Le temps des Saints (The time of the Saints) and Textes Zénètes du Gourara) published by the CNRPAH. In the first book he provides his understanding of what he considers a Marabout to be:

"It is not necessary to remind us that it is in memory of the Almoravides Ribats, where one used to learn the Koran, the science of the Hadith, the precepts of Islam as well as the handling of weapons, that the word M'rabet was formed, a word that French people call improperly and pejoratively Marabout." (p.97)

Bellil's version in some ways confirmed the one of Mouloud Mammeri (1990) who said in his book Cheikh Mohand "the name Marabout is the Berber form of the Arab word, itself a synonym of the popular classic Murrabit where the word Almoravide came from". Tassadit Yacine also explains that for some authors, the Marabout are all Chorfa, descendants of the Idriss, himself son of Hassan, son of Fatima. For others, they are people of the country who were educated and knew the rules to access to the role of spiritual leader in their society. They knew how to use them for their own profit" (p.33).

When Mouloud Mammeri (1984) explains that "the original, pre Islamic meaning of the word Marabout is Agurram, designating mainly a character gifted with powers more magical than religious, Tassadit Yacine (1988) analyses this situation in these terms: "The Marabout realized in their ways the Weberian design of the opposition between the prophet and the sorcerer. Mutatis mutantis, the Agurram was the sorcerer in the old Berber society. The Marabout is going to intervene against him as a prophet" (p.53). Clearly stated here is the relationship between the Marabouts and Islam. The next part explains to us in in detail the Islamic origins of the Marabouts. 


\section{A Muslim leader from the Saquiet El Hamra (the Red source)}

Abu-Bakr Adesselam Ben Choaib (1907) describes ritual practices that do not seem very Islamic. I see more the residual traces of the old animistic beliefs rather than the Islam of the Murrabitin (same word for Marabout). I am concerned that the author misleads us to a personal opinion on the Murrabitin who had their time of glory but then got pushed down by another Islamic movement, the Almohades who took over the population of Northern Africa, possibly slightly changing history. In this section I present this part of the history of the Murrabitin.

Islam arrived from the East of Africa and, with a very long story, settled in Saquiet El Hamra (the Red Source) with the lineage of the Prophet. Saquiet is a water source and Hamra means red in Arabic - the colour of the sand in the desert. The family of the prophet had to go away after some battles for the succession of the Prophet. It is Idriss II who settled there, the great, great son of the Prophet from his daughter Fatima, mother of Idriss, himself married to a Berber woman, Kenza. "He was shown in public only when he was old enough. For security reasons, he was taken to Sekiet-El Hamra (another spelling for Saquiet el Hamra) in 188/810 (The Muslim Calendar starts after the departure of the prophet from Medina in 622 of Gregorian calendar), where he was proclaimed Sultan by the tribes true to his father" (Gaid, 2000, p.60).

Later down the road we find the Murrabitin movement starting from the Red sands of the Sahara desert. The Murrabitin were known for their war against the Animist tribes all over Northern Africa and in the desert of the Sahara. It is actually very interesting to see that the author of this article carries the name of one of the greatest Murrain Abu-Bakr-Ben OmarLemtouna (part of the Berber tribes' coalition of the Sanhadj), himself descendant of the fateful Abdallah-Ben Yassine Mekkouk-El Djazouli. 
Abdallah Ben Yassine on his journey back from the Mecca stopped in Kerouan, Libya and realized that his people, even if they were true Muslims, did not practice the real Islam. He was then given a guide to bring with him to teach his people. The resistance of the local populations was strong and he finally decided to retreat to an island with his teacher and a small group of men to learn the Murrabitin ways. It is there that he built the first ribat (arab word for fortress). The good reputation of this fortress and religious school brought it over a thousand men who were trained and became the army that started changing the face of Islam in the region. This story is recovered in part from Mouloud Gaid's book, The Berbers in History, The Morabitines from yesterday and the Marabout of today (p.10-14, 2000). He explains that: "The Morabitines choose Abou-Bakr-Ben Omar Lemtouna. Abdallah-ben Yassine died the Sunday the 24 of Djoumad al Oued of the year 451(1073) and was buried in Kerifa, where a mausoleum was built on his grave" (p. 14).

However, when Emir Abu-Bakr who was considered a saint, went to protect his people who were being attacked by the inhabitants of the sub-Saharan region, his cousin, Youcef ben Techfin (whom he had left in power before he went and who took his army away) "stole" his place. Married with Zeyneb the ex-wife of Emir Abu-Bakr, Youcef ben Techfin received the advice from her to not give back the place to his cousin. Youcef who had enlarged the whole empire made clear that his cousin had the choice between war and receiving all he would need to settle in the Sahara desert. Emir Abu-Bakr accepted his cousin's terms to avoid a conflict that would have destroyed the original mission of the creation of a strong Islamic empire.

Zeyneb knew that the man had the faith of a Saint and would not fight. "He went back to Sahara to pursue the fight against the animists. He got touched by a poisoned arrow during a fight and died in the month of Chaabane year 480 (1087)" (Gaid, 2000, p.17). 
The Islam that has been embraced and blessed by the Berber peoples all over the north of Africa kept going until political divisions formed and the Islam world started fighting for the heritage of the Prophet Mahomet (God bless him). We currently find ourselves in confusion between culture, religious power and greed. Becoming a Marabout is, in part, supposed to be a heritage transmitted from the father only. A man who has been faithful and who strictly followed the principles of Islam can be given the status of Saint after his death. However, his children will become Marabout even if the man was not a Marabout during his lifetime. This explanation of the Marabout culture is extracted from the Marabouts and Khouans: Study of Islam made by Louis Rinn (1884), explaining the word Marabout as coming from the Arabic word for link or connected; this explanation seems to be in agreement with Alain Mahé (1998) again. Continuing on his study of the Kabyle justice system he explains that:

"When a non Chorfa (descendant of the prophet) wants to reach the status of Holiness the individual must have conformed to a local model of sanctity (exile, retreat, initiation, ostentary manifestation of generosity and of pacifism, or miracles, etc...); we have to be reminded that those secular individuals also have ways of accumulating wealth and power. The Marabout movement alone does not drain, as suggests Gellner, the unequal potential of communities. In fact, the mediation of the Marabout in the resolving of conflicts was held back by the modes that the secular leaders imposed on the Marabout interventions. And it is, in particular, the previous agreement of the parties involved in the opportunity of soliciting them that restrained considerably their influence as scribe on everything” (p.56).

The Marabout heritage and transmission is under question today. Marabout people seem to have, unfortunately, lost their political place. But they keep the reputation and 
sometimes still are asked to intervene as healers with shamanistic and/or spiritual and mystical religious gifts that I propose to present here after.

\section{Baraka (supernatural gifts)}

This story told by my informant in this next narrative, provides insight into the religious and philosophical stands of my Ancestor in relation to the actual Islam now promoted but in the same time it is showing the miracle associated with the teachings of the Ancestor.

Narrative Episode 36: The Imam and my Ancestor have different opinions toward the place of women in everyday life.

"An Imam was sent to our village. He was married, had a son and a daughter. His wife and daughter were kept at home all the time and only he and his son could mix with the population. One day the son got sick and after going to many doctors the Imam was desperate. It is then that he dreamed of our Ancestor recommending him to let his daughter go to the fountains like the other woman of the village. He refused but seeing his son dying he decided to let his daughter participate to the life of the people. His son healed miraculously after that."

This narrative explains the Kabyle root in Marabout organization as well as it helps in understanding the respect for the Kabyle culture. This narrative gives insights about the Islam of my Ancestor. However, if the place of burial of my Ancestor is still a place of pilgrimage and cult, the risk to see his grave disappearing today is real. The Ancestor is not a prophet. He is an intercessor to God and a model of good values and culture. It is only as an intercessor 
that his memory can survive today. As my informant explained, and as I witnessed as well during a religious celebration in the mountains, the cult of the ancestor still gathers a lot of people. Men and women come for multiple reasons. The pilgrimage can be a simple act of faith. Some Saints are more venerated than others and have their specialties. Stories of miracles and healings are keeping the myth alive and the sacred identity of the descendants stays as a heritage passed on to the next generations.

The inherited magical gifts and blessings are called Baraka. Baraka constitutes a blessing and protection that cover the Murrabit. It is considered a gift from God to a family. Baraka is also described as the gift given to the descendants of the prophet Mahomet. Kabyle people could ask to be under the protection of the Baraka of a Murrabit. My father always says before I leave: "May God give you Baraka and bless your journey”. Mammeri (1984) again explains that:

“...The Baraka of the Murrabit is a supernatural power; it realizes miracles and, for that, it is a place of hope and of all the fears: we wait (or we fear) from him as much as from God, because, even if as Murrabit he is not less human, he is closer to our needs and our miseries and our wishes..." (p.167)

Today, the entire existence of Murrabit in the Berber villages is criticized extensively in Kabylia. Assimilated to the main stream Muslim people, the Murrabit have to cope with the decisions that they made in order to survive the events of history. Responsible for the liberation from the Turkish invasion in Algeria, and strong opposition to the French government, this tribal government faced many of waves of destruction. France uprooted villages, deporting residents into camps, where their government would be free to conduct research and develop an education system to promote its ideology in the displaced population. It was the main location for Pierre Bourdieu's fieldwork when he was in the French army. It is 
how he gained access to a lot of the knowledge of the Kabyle cultural heritage. After the independence, the Algerian army dictatorship was dreadful for the Kabyle village republics of the past. The Algerian central government worked on centralizing the power into the hands of their people in Algiers. They developed other tools of manipulation such as internalized oppression, destruction of self-esteem and cultural imperialism with the promotion of the Arab culture and language. The Kabyle traditional society went into an even stronger decline because of cultural genocide.

\section{The gift of healing}

It is in an article from the Revue Africaine (1907) that I found in the National Archives of Constantine, an Arab city in the East of Algeria, that Abu-Bakr Abdesselam Ben Choaib (1907) explains that:

"Muslim religion does not oppose itself to this practice as long as the sick person believes only that the Marabout to whom he/her is talking has no influence on the sickness that touches him/her and that his role cannot go further that the one of the intercessor. If at the contrary, he/she thinks that the Marabout himself is capable of healing the sickness that he has, as it is the case for a good part of the people who are practicing the moral medicine, the Muslim Orthodoxy considers it absolutely like a simple apostolate, because those attributions and powers can only be given to Allah the unique God" (p.250).

Abu-Bakr Adesselam Ben Choaib (1907) explains that:

"This belief in the unity of God that constitutes the basis of the Muslim religion shows in a sufficient manner that even if the religion would be one that would venerate and 
treat saints with honour, it is not less true that religion takes back all absolute power and considers the Saints on this point as simple mortals" (p. 251).

Ben Choaib (1907) talks about an extravagant Marabout practice and says that: "people of the city themselves, to some rare exceptions, are gifted with an extraordinary tendency to give faith to incredible stories. And for the Muslim of the countryside, their credulity has no limit” (p. 251). Then Ben Choaib (1907) distinguishes two types of sicknesses: the physical that can be explained by natural effects, and moral sicknesses like neuralgias or hysteria. For physical illnesses, there is a Saint to pray to and a pilgrimage destination. For example, sterility: "The sterile woman must, to become fertile, do a pilgrimage for seven consecutive weeks to Sidi Ed Dâoûdi Ben-Nâceur, old Saint Protector of Tlemcen. The visits had to happen on a Wednesday" (Ben Choaib, 1907, p. 252). However, if the person suffers from moral sickness, he/she has to refer to a Taleb who will make prognostics that will help find the name of the spirit that possessed the person.

"When the Djinn (spirit) is black, the sick person has to celebrate a Ouada (offering) to honour the black people. At a fixed date these men would gather in the house of the sick person and after executing some of their dances called khebèt, the chief will take an animal that needs to be sacrificed (generally a male goat or a rooster in this circumstance), turn it seven times around the sick person sited in the centre of the black people and then cremate it. With the blood coming from this stick, the chief of this kind of conference will trace a vertical line on the forehead of the sick person and will draw bracelets on each feet and hands" (Ben Choaib, 1907, p. 254).

Ben Choaib (1907) finishes his article by explaining that the responsibility of the success of the pilgrimage or the rituals is on the shoulders of the person realizing them. If it fails, if the person is not healed, it is because they did not do accomplish the rituals properly. I 
must confess that even if I have heard of such practices in my village, I have never practiced nor witnessed them myself. However, I did experience people telling me about them. I have personally observed practices, like writing quotes from the Koran on pieces of paper, then putting some salt on and it folding it in a wallet size. These practices were more integrating religious practices based on the Koran into animistic beliefs. It shows that Marabout heritage is the harmony of a Kabyle as well as a Muslim heritage.

\section{THE MARABOUTS’ HERITAGE UNDER CRITICISM}

The heritage of the Saints of Islam, the Murrabitin (also called Marabout), coming from Saquiet el Hamra, (the Red Source also called the Land of the Saints), is still very important in Kabylia. It is deeply rooted in the indigenous tradition. The Murrabitin shared and even sometimes took the place of the Agurram (the medicine man or woman). The Murrabitin brought with them Arabic literacy and the old and modern sciences. Their Islam was considered a benefit to the population. It complemented the local cultures. The Murrabitin were counselors, advisors and spiritual guides. The Saints stayed out of conflicts within the population though they took a place of leadership during the war for independence against the French invaders. Many of the Murrabitin were killed or deported. Remains of that story can be found in Bourai, a little city on the west coast of New Caledonia. The French colonials deported Marabouts and Kabyle tribal chiefs to Bourai, in 1873. In Algeria, since the arrival of the French, colonial propaganda focused on changing the population's view of the Murrabitin. They were transformed from saints into abusers in the minds of the population. The Saints developed a lot of social influence from the gratitude of the communities. They received many blessings from the Kabyle population. The Murrabitin's influence in the community was eventually turned against them. It was a colonial strategy that helped to weaken the Kabyle 
society. It brought confusion and division into the Kabyle population. The Kabyle spiritual landscape fragmented into different religious demagogies. A few years after independence, Muslim fundamentalism and terrorism enveloped Algeria and this pushed Islam even further away from the Islam that had been accepted into Amazigh society. In spite of this history, the Saint's graves and their teachings remain for those who wish to learn.

\section{The debate on Marabout legitimacy in Kabyle culture today}

Even if history is presented in a linear way showing relations of causalities between events and defining some definitive periods in the history, it is clear in the history of Kabyle people that this linear way of knowing cannot be used. Every influence that shaped the Kabyle landscape is still present today. The social organization continues to carry the resentment and divisions that all those wars generated. As such, we cannot say that one era is finished or starting; history repeats itself. In the middle of a socio-cultural turmoil Marabout people are being assaulted from all sides. In this following section, when Tassadit Yacine refers to the pre-Islamic roots of the Marabout, Iassassen, I detect a touch of confusion in her words.

"Marabaoutism has been, througout history, confronted with new situations, which it tried to face with the means that it had, showing an admirable faculty of adaptation, that allowed it to go through the four centuries, without losing its temporal or symbolical power. This success took the place of domination over secular groups, with a will to model permanently, on the image of a sclerozing Puritanism, individual behaviours as much as cultural expressions" (1988, p.55).

Tassadit Yacine (1988) puts secular culture and Marabout beliefs in opposition to one another. However, if Marabout people were converting to Islam, they were also taking from pagan traditions and never opposed to the Catholic Church. Marabout never imposed their beliefs upon 
the population; one was free to go ask for spiritual guidance if one wanted. Many of the Zaouia were the places of ceremony where teachings were being passed on. The Zaouias were open to all spiritual traditions. Marabouts are, still today, respectful of the diversity of beliefs.

Kabyle people ask for a "secular" society, meaning a society independent of religion. Some Kabyle ask for a non-religious country in reaction to the Islamic fundamentalism. The foundations of the Kabyle social claims for "secular" society are not coming from the philosophical or cultural history of the population. We can probably recognize here, with confidence, the effects of French cultural imperialism in Algeria. The public debates are invaded with foreign philosophy, and the population, fragile regarding its own philosophical foundations, turns to outsider solutions for insider problems. But again the main problem here remains that the Kabyle population is confusing secularism with agnosticism and atheism.

Tassadit Yacine (1998) supports the idea that Murrabit have been strongly imposing their religious views upon people. She describes Marabout people as very oppressive and accuses them of imposing their proselytism upon the population.

"Marabout received material benefits for the paiement of diverse interventions and from symbolic capital that confers their conditions. The secular people from neighbours tribes were supposed to give them a certain number of advantages fixed by traditions. They had to pay an annual tax (achour) that consisted most of the time in cereals (usually ten per cent of the harvest). Outside of its economical value, the achour also had a sociological value which constituted for some people a way to get protection and for others, to be recognized. However the people not paying the achour were not punished, but were free to attract to themselves the curse of the Saint. At the origin, this tax was presented as only a support for the keeping of the mosque and a donation for the Tolba" (Tolba is the Cheikh or priest, p.6). 
During my first visit in the "Maison de la Culture de Tizi Ouzou", my first informant there, told me a couple of stories about Marabouts that are in line with what T. Yacine is saying. My informant also told me a story to explain the situation.

Narrative episode 37: My informant from the House of Culture tells me about Marabout

"Kabyle say that to decide the repartition of the land between people, we take a sieve that is used to filter the big pieces of the couscous and we let it roll down the hill... Where it stops goes to the Marabout." This is a critical story to say that Marabout keep the best part of the land for them and the parts that are hard to work and live on, meaning the slopes of the mountain, are for the Kabyle... We laughed at that story but then he added on a more respectful tune that Marabout used to be noble people and he added that many of his friends are Marabout but he doesn't want to charge them for the abuses that their parents might have committed."

This young man is a devoted Muslim. He prays five times a day and goes to the mosque on Fridays. I know, having been in his village and having spent a lot of time with him in different locations like Tizi Ouzou or my village, that he is definitely attached to his Kabyle identity, and he does not see any problem in being Berber and Muslim. In fact, he never told me about his faith until I saw him praying. He is a Muslim but like many Kabyle, he denounces the abuses and oppression of the fundamentalists. At the same time, if he does not directly stand against the Marabout and their Zaouias, he does not want to go in a Zaouia anymore. The mysticism of the Zaouias is denounced in the Mosques of today. The public opinion of the believers is shaped in the Mosques, and again the public opinion is the tool used to discredit the Marabout heritage. One day my 
informant, referring to the incense that he saw burning at a Zaouia, told me that the people of the Zaouia were using drugs to get people hooked on their remedy. My informant is not a Marabout but I am from Marabout lineage. I have never been taught any Muslim practices other than the Ramadan, the fasting month. What I know about my spiritual heritage, I received from my mother's stories and from the respect my father gives to the Ancestor.

\section{Narrative Episode 38: Friday, the Prayer day}

"I was working every day even on Friday and I was reminded that Friday was a praying day. I realized that my housemates and informant were very serious every time they came back from the Mosque. This is not how I see praying. In my mind, praying is supposed to make the heart lighter and not make you upset. One day I even told them to not go to the mosque if it was to feel like they feel after. I noticed it because most of the time they would engage with me but on Friday afternoons their faces were closed. Most of the time they did not want to tell me. My housemates avoided conversations about my spiritual heritage, the story of the family, my ancestor and my village. But one day however my older uncle came to my house. He was frustrated. He told me that the Imam had made bad comments about the Marabout. It made me very upset and even more upset that a Marabout could accept to hear those insults without moving. He said that they could not do anything because it was dangerous to speak against the Imam. My informant said: "If you speak up people can come and take you during the night". If it was an imaginary or real I am not sure but I am sure that the man does not think that he has freedom of speech. I spoke to another Marabout man in the city. I knew he was there during the sermon. When I met him he was with other members of the village. They were not happy with the word of the Imam. The week after they decided to go back to the Mosque on the Mountain rather than the one closer in the city for their prayers. The next week I heard that the Imam had withdrawn his words. A little later I 
got given another version about the words of the Imam. My informant told me that what the Imam was saying was not exactly directed against the Marabout. I felt that time that someone was trying to water down my wine, if I can say so in a Muslim context. They were undermining the situation for me. A little bit later I got the message that all the roads were blocked because of a maraboutic celebration in one of the villages in the Mountain. The old man who brought me that information was proud to have evidence to show me of the respect for the Marabout traditions. He said that the mountain was full of people and he went on and on showing great happiness and he was moving his cane with force in the air showing a great pride."

This narrative illustrates the debate about Marabout legitimacy today. With this narrative, I explain that there are differences in the official Islam of the mosque and the traditional Islam of the villages. One critique of the Marabout Islam is the presence and role of the Saint. The Saint is an intercessor because with his or her life, the Saint has become closer to God. He or she, because they are also Murrabitin women, helps in carrying the prayers to the Creator. Actual religious people are accusing Marabout of not being Muslim because, according to Islam, there should not be anyone standing between God and men. At the same time, some Kabyle people also accuse the Marabout of being charlatans and hypocrites. Stories are numerous about abuses committed by one Saint or another. As Rachid Bellil (2001) explains here:

“On a religious level still, one can note the relation of Mawali (newly convert to Islam) imposed on non-Arabic populations who were adopting Islam. The converted were linked to an Arab tribe. This link would allow some to access some advantages. It seems that at the beginning of the propagation of Islam by the Arabs, the non-Arabs (called âdjami) were not becoming totally free with their conversion but were supposed 
to surrender to Arab protectors. We have then here a double submission: to the religion of the prophet Muhammad first and to the Arabs, because this religion appeared between them and they were the first to surrender to Islam. We would notice that in the collective unconscious of North African populations (Berbers), this double submission seems anchored because while calling themselves Muslim, these populations attributed to the Arabs a superior quality: it was between them that the prophet of Islam appeared. But if this relationship, with the payment of a symbolic or real tribute, was imposed on the Berber populations in the first time of their conversion to Islam, they have disenfranchised themselves from the statutes of Mawali" (Personal translation, p.98).

In the time of a cultural renewal of Tamazight as a national culture and language in Algeria, the Murrabitin heritage is undergoing increased threat from every direction. Kabyle desire to be emancipated and want to push away any religious ties to become part of the Western developed world. Muslim religion has moved to a more dogmatic and less spiritual religion. Yet my village still stands as a Marabout village while expressing its Kabyle culture. The social organization that I describe in the next section shows the articulation of that double heritage.

\section{BERBER SOCIOLOGY: Clan System and Theory of Segmentarity}

As we just saw, the place of the Marabout in Kabyle society is challenged today. However, I explain in the next section that the organization of the Marabout society is a Kabyle indigenous social organization with a Muslim belief. Geertz (1968) defines Islamic history as a structural tension between two necessities: "The one of adapting a universal religion to the diversity of the society in which this religion is implanted, and the one of preserving the Islam 
of the origins, as revealed to the prophet" (personal translation, p.35). I understand the history of my village in the theory of segmentarity and the Kabyle clan organization of my community.

When the unity of my village was strong, the village was expanding and the fruits (experience, knowledge, economic wealth) gathered by the families were coming back strengthening the community and maintaining the energy of attraction alive among us. Now after the colonization, the Algerian military dictatorship, and with the religious proselytism, we leave our village. The transmission of the cultural heritage usually organized within the village was lived as a community learning experience. This transmission does not happen so often any more. Only a couple of rituals, like gathering for the birthdates of the prophet, are surviving. With the disappearance of that traditional education disappears the tradition and the Kabyle/Marabout society. Fortunately the Ancestor has left behind a society that can be understood from his genealogy.

\section{Clan system}

Married to two women, the Ancestor had four sons who created four Idrumen (plural for Adrum or clan). From the four clans more families were created and from these families, we have the diasporas all around the world. The original wives were from two different places. The first wife did not have Maraboutic ancestry. She was from another village. The second wife was Marabout coming from my village, where the Ancestor lived most of his life and where he is buried today. The holiness of the Ancestor comes form his genealogical connection to the prophet Muhammad. This blood heritage created differences between people in the decision making authority in the community. However, that difference in genealogy is used as a system of emulation between the members of the village. The people from the half non-maraboutic heritage compensate in the decision making process with more knowledge of 
the qanun of the village, a better understanding of the story of the Ancestor and also from their physical proximity to the sacred place. This half non-maraboutic part of the village also has more men in their group and as such has more power during executive meetings.

The second family has a stronger spiritual influence as they come from a sacred lineage from both parents; however they have fewer men in their families and most of them are living away from the village or were killed during the war for independence. Their authority in the decisions taken in the village is not as strong anymore. For the first time, and to such an extent that my father was surprised, a member of the first family associated itself with the last man living in the village of an opposite clan. This decision was taken so the man would not be left alone. He benefits from the solidarity between families. The circle will therefore not be broken by an excessive weakness of one family and an imbalance in the political forces. The unity of the village depends on the strength of each and every one of its members.

The power relationship from members of the four different clans of the same generation designs horizontal forces that create a circle around the ancestral heritage. A division like the clan system in the village creates an initial competition that is turned into energy of solidarity. Each family is competing for honour, pride, faith, economical wealth and education. Everything seems to be a reason for a competition. At the end it all comes back to the strengthening of the value system: qanun. The energy- the plus (communitarian culture) and the minus (clan competition) generate a spiral that zooms in and out, from the inside, the place of the Ancestor, to the outside, the place of adversity. The adversity of the out side world gives the impulsion back towards the group as a unified community. The dynamic of the group can be seen during village assemblies where rhetorical challenges take place. The winner is the one who shows the most human values: spiritual, physical, emotional and mental strength. 
However, these must be demonstrated in doing well for the village. All changes in the village occur after long talks and the reaching of a consensus.

In the village, if everyone seems to be challenging each other, nobody wants to be stronger than the other one. Instead every clan devotes his strength to protect the village and our spiritual heritage. Victory gives responsibility not power. The responsibility is always shared by the village. What is created is a closed place where there is no place (in theory) for mistakes and no place for an outsider. However, from the outside, if these social games could be seen as a strong gate keeping others away, it does not mean that the blessings of the Ancestor are kept only for the village. The outsider can worship, be a Khouan (brother or sister) and become respected for his or her faith. The outsider can become a member of the family. The descendant of this outsider can become Marabout as well. From the ancestor's faith God's blessings will come.

\section{Kabyle Society, the segmentarity theory}

The clan system seems to be ruled by endemic competition and perpetual rhetorical games for honour. From outside, it seems to be a force of division but seen through the segmentarity theory, it is in fact energy of social cohesion. It was confusing for me to witness division and competition in Kabyle indigenous culture. I understand indigenous cultures as motivated by principle of inclusion and sharing. Reflecting on the segmentarity theory helped me make sense of the social relationships in this Kabyle and Murrabit micro-society. During my time in Algeria, I regularly heard people undermining each other or referring to disputes and arguments. I thought that there was no village unity anymore and that those divisions were the expression of colonial fragmentation. I still believe that there is a social post-traumatic disorder generated by the colonial history of Algeria, but when I found Emile Durkheim's theory of segmental social organization (1893) based on Kabyle society, I started uncovering a 
very interesting analysis. Gellner also provided his understanding of the segmentarity theory. From both authors, I understand that Kabyle society is organized in concentric circles moving from the centre out. Mahé explains this organization here.

"On the topic of segmentarity, in fact, tribes and confederations are ruled by principles of virtue from which every unity of parenthood (tribal lineage, segment of lineage, families etc...) is susceptible of either splitting itself in equivalent unities more restricted (fission of segment), or oppose to each other the unity of each segment, or to ally with them inside of a larger entity that can be globalized (fusion of segments). Since the end of the sixties, this theoretical definition of segmentarity has constituted a principal paradigm of theoretical questions in Maghreb anthropology” (Mahé, p. 52).

In the village the families are organized in circles according to the generations. Each family forms an Adrum (clan). There are four of them in my village. The village is composed from the cohesion between the Idrumen (plural of Adrum). Each circle is a place for competition. The circles are described as essentially hermetic to the outsider. It is in fact difficult even for the next generation to enter the circle of the previous generation because of the hierarchy of age. However, as Mahé draws the society using the concept of solidarities what creates the society is the solidarity between its members. It is important to note that these boundaries unify the group.

"In his book on social education Durkheim reinforces the theory of segments of society in the example of Kabylia like Hanoteau and Letourneau had just described. The founder of French sociology had, for a main objective, to find an illustration of two types of solidarities. According to him, solidarities distinguish societies where specialization and heterogeneity of social roles implicate complementing individuals (organic solidarities). Societies, like in Kabylia, which interchange ability of 
individuals; for one role to another one allows the development of a mechanical society” (Mahé, 1998, p.53).

From inside the group, I see that the battle is hard between families but from the outside, the picture is one of unity and oneness against outsiders. The next narrative shows that the ancestor himself was experiencing social pressures during his lifetime.

\section{Narrative episode 39: Competition between Marabout}

"Another man calling himself Marabout came to the same mountain and developed an influence between our people. It came to the point that the argument between the two Marabouts divided the population into two groups. The new man was accused of lying but he had support from a part of the population. The presence of a holy man in a village gives the believers a superior social status. It could be one reason why the new man found himself supported. It was helping the undermined part of the population to rise up to the same social level. It brought division in the mountain and the two men had to face each other and settle the argument. A war was about to start but to avoid it my ancestor decided to leave. He offered to everyone who believed he was right to follow him. When he left the mountain broke in two. People saw that the Mountain was following him and decided to stay with him."

This narrative explains that even if the legitimacy of the Saints comes from their spiritual strength, it does not keep them from sharing the social and political organization of the Kabyle society. Mahé (1998) explains, from the segmentarity theory, that the Kabyle society is not yet a place of equality and can be rather harsh to its population.

"The basis of the Gellnerian argumentation put in front first the egalitarianism of a segmented society. I have to remark that from those known inequalities of fortune 
and rank: some individual, playing games of honor, can even build positions of power. Gellner supported then, according to the vulgar segmentarist, that the balanced opposition between segments, is regulated by their fusion and their scission. However, local history attests that some conflicts particularly difficult between lineages can be solved with the extermination of male individuals, or by their exodus" (Mahé, 1998, p.54).

The fact that the ancestor himself has to deal with political problems shows that his place was democratic and depended on the choices of the population. It shows how he made his place in the Kabyle village republics. It is with his faith and pacifistic ideas that he was adopted. Mahé (1998), explaining Gellner's work and locating himself against Durkheim's vision of segmentarity based on a static organization and a principle of mechanic solidarity, states:

"Gellner wants to show how, in the social segmented system of the rural Maghreb, the lineages taken in a real tornado of exchanges of violence, welcomed within them the Marabout pacificators in order that their mediations could cool down the conflicts: this function cannot be assumed only by religious lineages to the exclusion of the others. The pacifying Marabouts are gathered in the lineages beneficial of some kind of spatial extraterritoriality a structural in connection to the segmented system. Indeed, not only they are for most of them regrouped in an agglomeration located at the outskirts of neighboring tribal territories but as well in order to keep their functions and preserve their status they must not enter in the divisions and in the conflicts that oppose permanently the seculars" (p.54).

Presenting the clan of my village connecting to the theory of segmentarity that was developed from studies of Berber social organization, I demonstrated that my Ancestor was not only 
Muslim but also respectful of the Kabyle society. The Muslim beliefs of my Ancestor enriched the Kabyle traditional society and contributed to the keeping of its cohesion.

\section{CONCLUSION}

The dissension between the different Islams and the Kabyle society, politics of the government and Western cultural imperialism are jeopardizing the future of my heritage. It is for that reason that I wanted to learn it before it totally disappears. In this chapter I explained where the Ancestor comes from, and how he settled in the village, building his own village in respect of the Kabyle culture. I now understand that many Kabyle people do not understand this belief anymore, considering it feudal and abusive. I understand as well that the fragmentation of the social organization in the Djur Djura/Atlas Mountains during the colonial era has had repercussions on the Kabyle society. Even today the Eurocentric philosophies affect the cultural landscape increasing the mistrust toward religions or any kind of spirituality for the profit of a secular society with the face of consumerism. The Western consumerist life style is another option taken by members of the population in the mountains in reaction to the religious proselytism. However, my village rests as an example of the traditional Berber organization. I demonstrated with the work of Durkheim (1863-1922) viewed by Mahé (1998) and Gellner (1969-1972-1976) that my village organization respects the segmentarity of the indigenous Kabyle society. With this final chapter, I have entered the last circle of the village and now understand the roots and origins of my cultural heritage. I now know that I am a descendant of a Saint from Saquiet El Hamra, a Sanhadj Berber in the Kabyle Mountains bringing Islam and adopting the Kabyle life style. The traditional Berber beliefs integrated the Islam of the Marabout. The Marabouts and indigenous culture are the ones that brought me back my history, guiding me through the story that I have unfolded here. 


\section{EPILOGUE}

\section{SUMMARY}

It is after I encountered other indigenous cultures that I understood the voice inside of me, speaking of cultural recovery. I travelled in developing countries like India, Nepal, Thailand and many others, but never did I truly understand the call for the recovery of my culture more than when I lived in indigenous communities in Canada and New Zealand, especially in Maliotenam in Northern Quebec, where I received spiritual teachings. I grew up in France as an Algerian and a Kabyle. I knew about my heritage vaguely thanks to the stories my mother told me, but the colonial and Cartesian thinking of the French society always undermined them. This is why I had to break free from this reductive approach, seeking a more intoned and in-depth methodology that connected with the spiritual part of my identity as well. Story telling appeared to be the best way for me to share my experience. Of course, being a member of the community, I couldn't just go to my village and simply inquire about stories of the past. I also needed to contextualize my inquiry in the present time with a methodology that brought something back to my village: involving my participants into the inquiry raising questions in groups and bringing elders to reflect on the story of our Ancestor.

This inquiry has been important for me and my participants/relatives because it helped awaken many who were sleeping and it uncovered many memories of my community. It has been a difficult experience to reconnect myself to my people because I had to learn from the field to deal with what I took at the beginning for a generalized fight between individuals. I had to step back and reflect on relationship patterns to understand that this generalization of the hardship between, and inside of, families has in fact had a positive outcome. In fact the winner of these games is always the qanun, system and rules and regulations of the society. qanun brings us together for the good of us all. I had to understand the place of women in the 
society to understand a very important layer of my identity. It took my father's reputation and great patience to break the walls that were developed around me by French education and to enter back into the heart of my identity. I understand how the story of my ancestor is a Kabyle spiritual story, as well as being a story of a Muslim religious man to whom I am proud to be a descendant.

\section{GENERAL OUTLINE ON MARABOUT IDENTITY}

Edmond Doutté (1900) remarks pertinently that spirituality is a big part of Berber identity and that Islam seems to be very specific in the Atlas Mountains. "Hooker and Ball, exploring Morocco especially as geologists and botanists, realized however that the cult of the saint seemed to be the only form under which religion manifests itself to the eyes of Berber of the Atlas" (p.6). Later in his article, Marabouts (1900), Doutté refers to "M.Goldzihers who emitted a probable opinion and that new research could probably support with facts telling that Maraboutism of North of Africa is nothing more than a form that manifested itself in Islam from a taste that ancient Berber had for witchcraft and the veneration from which they would surround their sorcerers and witches, who were in reality prophets, prophetesses and priests" (Goldziher, Almohades, p.48-51). Doutté highlights the fact that "one will need to take into account the fact that, to retrace the origins of Maraboutism, in the first place, the cult of the Maure Kings is signaled by Tertullian, Minusciux Felix, Cyprian, Lactance.”_Cpr. Duveyrier (1864) refers to in Touareg du Nord, p.415. Extract from the document used for the study of North of Africa by the General Governor of Algeria (p.261). 


\section{KABYLE SOCIO-POLITICAL POSITIONING}

It is important again to insist on the fact that an increasing number of Berber people have decided to abandon all kinds of beliefs. They get into what they call a secular projection of society denouncing Islam as an invader because it is in Arabic. The faithful and peaceful Muslims are now often hiding their faith to avoid being accused of betrayal to the Kabyle culture. The claims for secularism become claims for atheism and are accompanied with a call for western institutions and western social organization in the Kabyle regions. The socio-economical position is a bit confusing but the call for freedom is loud and clear. There are dissensions between the partisans of the independent and autonomous Kabylia who are Muslim, and the others who are not. We know that belief and knowledge are coming together to shape a culture that creates its society and it seems clear that the influence of religion and/or beliefs on culture is not really understood in Algeria. The actual call for secularism is actually more a call for the end of the oppression, terrorism and fundamentalism, and a call for a cultural recognition, rather than a call to finish with spirituality.

The Kabyle movement of the Arrouch tried to bring back the power to the village with the empowerment of the Tadjmaith or Djemha (meeting in the community house of the village); it was born from a citizen movement. However, the bloody repression of the two Berber springs that shocked the province of Kabylia left the population claims for heritage in mourning. The movement was silenced by an appeasing political decision that silenced the true claim for the recognition of the Tamazight language and the Berber culture as official in the country. It leaves time for the Arabic Islamic state to develop itself in the communities with the support of the religious proselytism and the politics of terror as tools of control. 


\section{POLITICS OF CULTURE}

A major tool of control in the world today is the generalization of culture. Generalization of culture is the creation of a global culture from bits and pieces of other cultures giving it a general taste of everything, while silencing the individual heart or essence of each and every one of them. It is a way of silencing diversity, drowning it in the limits of itself, and using the masses to silence the individual. Another more direct way of destroying culture is enculturation. It is much more direct but equally violent as a force in the generalization of culture. The process of enculturation is not only cutting the roots. Enculturation means utterly uprooting someone, removing all the connection to the land and leaving behind a "tabula rasa", a dead land, open to all foreign aggressions. Using the process of enculturation, one wants to become the master of an assimilated group and in control of the lands left behind. I agree with Edward Said in Politics, Power and Culture (2001) who explains the power games that are shaping cultural landscapes of the planet. Kabyles have to be prepared to understand the discourse of culture in education to face the challenges of building an Amazigh education system. The Berber Spring of 1980 left 126 students dead and 500 injured due to Algerian government repression. Since then, a Kabyle government has been created in France, and Tamazight has become a national language and is taught in school. Much must be done in order to support the development of a Kabyle education system. The Arabic revolution in 2011 has shown a great need for cultural and social discourses amongst the populations of Northern Africa. If Kabylia starts to speak of political autonomy, Kabyle still consider themselves part of the Imazighen cultural family. If, culturally, they challenge the idea of cultural borders, then the national borders continue to be important. Among all the Kabyles I met during my inquiry, only one of them wanted to have a Kabyle independent state. 
Another final example of the destruction of cultural diversity is the presence of religious fundamentalism and dogmatism. For a long time religious people have understood the need to train locals, to create leaders within the communities, spreading the religion within a population. This is a kind of neo-colonialism that can be illustrated as a outside seed that fixes itself on existing beliefs in order to feed from the faith of the population and eat away its body, soul, mind and heart. I remember speaking with my Ojibwa grandfather (who passed away in April 2009) and I recall him telling me that he believed that if Native people gave so much attention to the cross, it was not because of its connection with Jesus but more with the fact that they would see in the cross the representation of the four directions. This misunderstanding between the cross and the four directions is another example of the diversion of the representation system that increased impact of acculturation from dominant societies. Exploitation and/or cultural assimilation works the same way as religious proselytism. I heard many stories of rape by missionaries in residential schools in Canada; some of them were even shared in the news. My Innu friends in Canada use to tell me: "We got in trouble when the Hudson Bay company arrived with the Good News." The good news refers to Christianity and the birth of the Christ. It is with this image in my head that I describe acculturation: A religious man or woman carrying a weapon comes on a land and deports the population to another mental, physical, emotional and spiritual place away from their ancestor's territories. The ideas of the missionary grow within the population's culture, and using positivist methods, described earlier in the thesis, empower the abuser. These abusers reprogram the population until this population does not fully comprehend who they are anymore. These abuses continue long enough to be disempowered and suppress any liberated consciousness. This is what happens when education becomes exploitative, manipulative and oppressive. 
Acculturation works that way. You take a human being and develop a relationship supported on different levels of intimacy, trust, power and/or dependency (legitimate or not), then you build up around that person a demagogic world that narrows down his/her system of representation into the one you wish that individual to adhere to, then you work on getting closer and closer to the child within until that person sees only you in a illegitimate paternalistic or even a maternalistic relationship. The relationship is illegitimate because it is the result of manipulation. Then, from that isolation and loneliness, you offer choices that will indefinitely chain the individual to you. In the dark corner of the self where the child within each and every one of us is kept silent, the soul of the child gets abused and its innocence and freedom are taken away. You overpowered him/her and dried out his/her cultural land to the point of leaving a cracking soul/soil. Finally, this new dependent individual becomes trained to work in a society of slavery. I talk about the child within us in reference to an Innu elder who told me one day that he could only trust the individuals in whom I can see the child in their eyes. In my culture it translates again with Nyia, that is generosity but also naivety and trust, values that are held by the child and that tend to disappear with a difficult life.

Of course what I describe is the process of cultural enslavement and destruction, but individuals are not passive. This is why we still have Kabyle, Berber and indigenous people here today. Our resilience is in our nature. We cannot be changed because this is who we are. It is not knowledge. It is not power. Our identity is holistic and non-dissociable. Some systems promote cultural destruction. Education is the Trojan horse of these colonial and/or imperialistic ideologies. So when teaching today, one might want to ask oneself the question: “Am I manipulating for my profit or am I supporting a child in its personal, natural, cultural, equitable and ecological development of the self?" 
It is a very difficult question. Many people on this planet, living in a democratic and/or non-democratic society, facing the questions of multiculturalism, gender, sexuality, race, class issues, are being asked to speak for someone else. These people, when questioned, take decisions for someone else whether or not they know the child, the family and/or the population. But can we speak for someone we don't know? Can we decide for a country we have never seen? Because families make populations, can we educators decide to erase or not, one's cultural heritage in order to support ethnocentric, materialistic, imperialistic, destructive and reductionist perspectives of a socio-economical order? Can we, in the name of democracy, support the instrumentation of our institutions in promoting a narrow idea of the self, in the sense of an elitist minority and its abusive ideas of what a good culture might be?

\section{CONCLUSION}

My aim is to address the issues regarding the assimilation of Berber people into ethnocentric states by reflecting on a philosophy of education that promotes peace and understanding rather than abuses and manipulation. I stand against exploitative systems of education. I share my personal experience of the struggles of acculturation. I draw from a Berber/indigenous philosophy, a principle of sharing with an open heart rather than taking with a positivist's mind. With the example of the trees that grow up stretching their roots deep in the earth, and their branches all over the planet, I wish to work on bringing back a sense of belonging to mankind rather than to limit it to members of a geopolitical system one is a part of. I wish to bring back a sense of culture as seen by indigenous people, a sense connected to the strong belief of belonging to the earth rather than a sense of coming from somewhere else and abusing the earth like an everlasting resource of wealth. In the realization of the need for an ecological relationship between and among individuals, I see how a fruit that does not grow 
in a political or demagogical "container/structure", like the fruits exported before they mature to financially rich countries, stays connected to the roots of its original tree. It is from this connection that the tree can be of a great contribution to a human society. We understand with the example of Berber people that societies gain a lot from holding onto their cultural roots. Respecting the freedom of the souls, I shared my story as a reader, a participant, a researcher and a member of the family of the IMAZIGHEN (translation: FREE MAN). (This word in our language honors both women and men.)

Even though I am an indigenous man writing this dissertation in which I speak of an indigenous culture, this inquiry is not an indigenous dissertation. The imaginary reader to whom this dissertation is addressed is not Kabyle but a mainstream Anglophone who may know little or nothing about Kabyle people. The language, English, makes it impossible for most Kabyle to read it because the culture of the language is foreign to Kabyle. Most of the metaphors I have used in previous drafts have been changed from metaphor to explanation; I used metaphors and images of my country and culture, but had to replace them with something more accessible to the non-Kabyle reader. Even if it has a rational depth, I wish for the text to be understood in many different ways, and unfortunately it has lost some of the depth that the Kabyle language carries. These explanations do not fully carry our culture. In fact, at many times, I thought I was showing times and places to foreigners when what I wanted to do was not to open our sacred places to outsiders but to enter these places myself to learn about my land and heritage. Many times I have felt like I had a camera implanted on my shoulder and that double presence made my people and family uncomfortable at times. In hindsight, I find that this inquiry only draws a multi-dimensional picture of my people and, to a certain point, I am happy about it. After writing this dissertation, I have learned a lot about relational, social and political Kabylia but I still think that Kabyle academia does not exist. Yet what I have is 
inquiries, research about Kabyle, but nothing that is Kabyle. In some ways it is a good thing because I do not want to put us all in a western library; it would be more legitimate to do this research in a Kabyle institution. Doing research in a Kabyle institution would help find ways to strengthen and revitalize our culture from within. Research shall leave us with our resources on our lands rather than objectify us and expropriate us from our knowledge.

This inquiry has been a great experience for me; it has been a wonderful excuse to go back home. Using my third language, English, to do this work has been very interesting because English and French cultures are similar, even though they are not embedded in the same historical relationships. As such, I continue to distance myself from the colonial power and visions that could have been mine growing up in France and reflecting on my identity as Kabyle Marabout.

I am, therefore, grateful to Victoria University in Wellington New Zealand, especially to Te Kura Maori, for the time and space that their institution has given me. I am most grateful to the Maori people, especially my Whanau (family) from Te Herenga Waka Marae, who supported me on this journey. I am positive that this journey is only beginning. Now, it will take another form, time and space, and will be the journey of a Kabyle academic. 


\section{REFERENCE LIST}

Abdelfettah. L.N. (2003/4). Du mythe de l'isolat kabyle, [The myth of Kabyle Isolation], Cahiers d'études africaines, $n^{\circ}$ 175, p.507-531.

Aith Mansour, A. F. (2000). Histoire de ma vie [Story of my Life]. Paris, France: La Découverte Edition.

Agger, B. (1988). Marcuse's “One dimensionality": socio-historical and ideological context, Dialectical Anthropology, Volume 13, Number 4. MA, USA: Kluwer Academic Publisher, p.315-329.

Alfred, T. (1999). Peace, power, righteousness: An indigenous manifesto, Oxford, UK: Oxford University Press

Anderson, K. \& Lawrence, B. (2005). Strong women voices: Native vision and community survival. Toronto, ON, Canada: Sumach Press, p.37-54.

Atkinson, P. (1997). Narrative turn or blind alley?, Qualitative Health Research, vol. 7, No. 3, p.325-344.

Atkinson, P. (2001). Handbook of Ethnography, The ethics of Ethnography, Sage Research Methods, ISBN 978184608337, p.2-20.

Atkinson, Robert (2007). The life story interview as a bridge in narrative inquiry, Handbook of narrative inquiry. D. Jean Clandinin (Ed.) Thousand Oaks, CA, USA: Sage, p.224-245. Attarian, H. (2009). Lifelines: Matrilineal autobiographical narratives, memory and identity. Unpublished PhD dissertation, McGill University, Montreal, Qc, Canada. 
Azem S, (1982). Algérie mon beau pays [Algeria my beautiful country]. Paris, France: Pathe Marconi.

Bamberg, M. (2006). Stories: Big or small. Why do we care? Narrative Inquiry, 16(1), p.139147.

Barnes, D. (1976). From communication to curriculum. Harmondsworth, UK: Penguin.

Battiste, M. (2009). Research ethics for protecting indigenous knowledge and heritage. Institutional and researcher responsibilities. Handbook of critical and indigenous methodologies. California, USA: Sage publication Inc., p.497-509.

Bellil, R. (2006). Les Oasis du Gourara II [Oasis of Gourara], Sahara Algérien [Algerian Sahara]. Fondation des Ksour, Paris, France: Éditions Peter, Louvain.

Ben Choaib, A.A.B. (1905). La Tébia ou les mauvais genies [Tebia or the bad spirits], Sociological and Geographic Bulletin, [Bulletin géographique et sociologique], Oran, Algeria, p.295-298.

Ben Choaib, A.A.B. (1906). Croyances populaires chez les indigènes Algériens [popular Beliefs within Algerian Indigenous Peoples], Sociological and Geographic Bulletin [Bulletin géographique et sociologique], Oran, Algeria, p.170-174.

Ben Choaib, A.A.B. (1907). Notes sur les amulettes chez les indigenes Algériens [Notes on the amulets for the Algerian Indigenous], Revue Africaine [African Revue], Oran, Algeria, p.250-257.

Benham, K.P. M., (2007). On Culturally Relevant Story Making From an Indigenous Perspective. Handbook of narrative inquiry : Mapping a methodology. Sage Publications, p. 513-533. 
Bernard A., (1932). Le Sahara Occidental [Occiental Sahara], Annales de géographie, T41, n.229, as retrieved from www.persee.fr/web/revues/home/prescrpt/article/geo_0003$\underline{4010 \_1932 \_41229 \_11075}$, p.91-94.

Bernstein, B. (1990). The structuring pedagogy of the discourse: Class, codes and control. Volume IV. London, UK: Routledge.

Berry, Keith (2007). Embracing the catastrophe: Gay body seeks acceptance. Qualitative Inquiry, 13 (2), p.259-281.

Bishop R., (2005). Freeing ourselves from neocolonial domination in research, A Kaupapa Maori Approach to creating knowledge. In Norman K. Denzin, Yvona S. Lincoln, (Eds.). The Third Handbook of Qualitative Research, Third Edition. Thousand Oaks, CA, USA: Sage publications.

Bouamara, R. (2009). Le Silence Tiraillé [Silence torn apart]. Ville Houdlemont, France: Cœur d'Occident Ed, p.156.

Bourdieu, P. (1961). Sociologie de l'Algérie [Algerian Sociology]. Paris, France: Quadrige/PUF Ed.

Bourdieu, P. (1972). Esquisse d'une théorie de la pratique [Outline of a theory of practice]. Paris, France: Seuil Ed. .

Bourdieu Pierre. (dec.2003) The Participatory Objectification [L'objectivation participante]. Actes de la recherche en sciences sociales. Regards croisés sur l'anthropologie de Pierre Bourdieu. Vol. 150, As retrieved from: http://www.persee.fr/web/revues/home/prescript/article/arss_03355322_2003_num_150_1_2770, p. 43-58. 
Bourdieu, P. (1980). Le Sens pratique [The Practical Sense]. Paris, France: Minuit Ed.

Bourdieu, P., \& Sayad, A. (Jan. - Mar., 1964). Paysans déracinés, Bouleversements morphologiques et changements culturels en Algérie, [Uprooted peasants, morphological upheavals and cultural changes in Algeria], Études rurales [Rural Studies]. Paris, France: Publisher EHESS, No. 12, p. 56-94.

Bower, C. A. (1998, Spring/Summer). An open letter on the double binds in educational reform. Wild Duck Review, 4, p.7.

Bruner, J. (Autumn 1991). The narrative construction of reality, Critical Inquiry. Chicago, USA: University of Chicago Press, Vol. 18, Number 1, p.1-21.

Bullock, K.H. (2002). Rethinking Muslim Women and the Veil. Herndon, VA, USA: International Institute of Islamic Thought.

Chachoua, K. (2002). L'Islam kabyle : XVIIIe -XXe siècles : religion, État et société en Algérie [Kabyle Islam: XVIIIe- XXe century: Religion, State and Society in Algeria], Civilisations arabe et islamique [Arab and Islamic Civilizations]. Paris : Maisonneuve et Larose.

Chaker, S. (1989). Berbères d'aujourd'hui, [Berber of today], Paris, France: L'Harmattan edition.

Connelly, F. M. \& Clandinin, J. (1990). Story of experience and Narrative Inquiry, Educational researcher, as retrieved from http: www.er.aera.net, p.7

Costandi, S. (2007). Between Middle East and West: Exploring the Life and Work of a Palestinian Canadian Teacher through Narrative Inquiry. Unpublished PhD dissertation, McGill University, Montreal. 
Dauphinee, E. (2010). The ethics of auto-ethnography. Review of international studies, 36, p.799-818.

Denzin, N. K. (1997). Interpretive ethnography: Ethnographic practices for the 21st century. London: Sage.

Denzin N.K. (2003). Performance Ethnography, Critical Performance Pedagogy. Sage Research Methods, p.2-22.

Derry, S. J. (1999). A fish called peer learning: Searching for common themes. In A. O’Donnell \& A. King (Eds.), Cognitive perspectives on peer learning. Mahwah, NJ, USA: Lawrence Erlbaum, p.197-211.

Durkheim, E. (1893). De la division du travail social [The division of work in society]. Paris, France: PUF Ed.

Durkheim, E. (1922). Éducation et sociologie [Education and Sociology]. Paris, France: Quadrige/PUF Edition.

Doloriert, C. and Sambrook, S. (2009), Ethical confession of the "I" of auto-ethnography: the student's dilemma, Qualitative Research in Organizations and Management: An International Journal, Vol. 4 (1), p.27-45.

Doutté, E. (1900) Notes sur l'Islâm maghribins : Marabouts [Notes on Magrib's Islâm: Marabouts], Revue de l'histoire des religions [History of Religion Revue], Tome XL and XLI, Paris, Ernest Leroux ed.

Doutté, E. (1909) Magie et religion dans l'Afrique du Nord [Magic and religion in North Africa], Algiers, Algeria: Ed. Adolph Jourdan. 
Duveyrier, H. (1864), Touaregs du Nord [Touaregs of the North]. Paris, France: Ed. Challanel Ainé.

Ellis, C. \& Bochner, A. P. (2010). Auto-ethnography, personal narrative, reflexivity: Researcher as subject. Handbook of qualitative research. Thousand Oaks, CA, USA: Sage. p.733-768.

Fanon, F. (1963). The Wretched of the Earth, trans. Constance Farrington. New York, USA: Grove Press.

Fanon, F. (1986). Black skin, white masks, trans. C. L. Markmann. 1967. London, UK: Pluto Press.

Foucault, M. (1980). Power/Knowledge: Selected interviews and other writings 1972-1977. London, UK: Harvester Press.

Foucault, M. (1994). Genealogy of social criticism. The postmodern turn: New perspective on social theory. Cambridge, UK: Cambridge University Press, p.39-45.

Frank, A.W. (1995). The wounded storyteller: Body, illness, and ethics. Chicago, USA: The University of Chicago Press.

Freire, P. (1972). Pedagogy of the oppressed. New York, USA: Seabury Press.

Freire, P. (1975). Cultural action for freedom. Cambridge, USA: Harvard Educational Review Monography.

Freire, P. (1985). The politics of education: Culture, power, and liberation. South Hadley, MA, USA: Bergin \& Garvey. 
Freire, P., \& Macedo, D. (1987). Literacy: Regarding the word and the world. South Hadley, MA, USA: Bergin \& Garvey Publishers.

Frow, J. and Morris, M. (1997), Australian Cultural Studies: a reader, Manufactured in Singapore. p.XVIII.

Gaid, M. (2000), Les berbères dans l'histoire : Les Morabitines d'hier et les Marabouts d'aujourd'hui. [Yesterday's Morabitins and today's Marabouts]. Tome VII, Alger, Algeria: Mimouni Hichem Ed.

Garcia-Arenal, M. \& Moreno, M. E. (1995). Idrīssisme et villes idrīssides, Studia Islamica. Publisher Maisonneuve et Larose, No. 82, as retrieved from: http://www.jstor.org/stable/1595579

Ghazarian, C. (2002). On the way to reflective ethnography, From ethnography to reflective anthropology. New practices, new stakes. Paris, France: Armand Colin, p.5-33.

Geertz, C. (1974). "From the Native point of view": On the nature of anthropological understanding, Bulletin of American Academy of Arts and Science, Vol. 18, No1, p.26.45.

Geertz C. (1986). Making experiences, authoring selves. Anthropology of experience, edited by V. Tumer and E. Bruner, Urbana, USA: University of Illinois Press, p.373-380.

Geertz C. (1995). After the fact: two countries, Four decades, One anthropologist. President and Fellows of Harvard College, USA.

Geertz, C. (1993). Islam Observed, New York, 1968; " Preface," in H. Elboudrari (ed.): Modes de transmission de la culture religieuse en Islam [Transmission modes in religious culture in Islam].Cairo, Egypt. p.V-XI.

Gellner, E. (1969). Saint of the Atlas. London, UK: Weidenfeld and Nicolson. 
Gellner, E. (1972). Arabs and Berbers. Worcester and London, UK: The Trinity Press.

Gellner, E. (1976). Comment devenir Marabout? [How to become Marabout?], B.E.S.M., double number, 128-129, appeared during the 1st trimester, p.1-43.

Grande, S. (1964). Red Pedagogy: Native American social and political thought. New York, USA: Rowman and Littlefield Publishers Inc.

Griffin, L. J. (1992). Temporality, Events and Explanation in Historical Sociology: an introduction. Sociology Methods and Research, p.403-427.

Goldziher, (1887). Materialien zur Kenniniss der Almohadenbewegung, in Doutté, E. (1900) Notes sur l'Islâm maghribins : Marabouts [Notes on Magrib's Islâm: Marabouts], Revue de l'histoire des religions [History of Religion Revue], Tome XL and XLI, Paris, Ernest Leroux ed., p.2.

Goodall, Bud H.L. (2006). A need to know: The clandestine history of a CIA family. Walnut Creek, CA, USA: Left Coast Press.

Hall, S. (2005). Cultural Identity and Diaspora, Theorizing Diaspora. J. Braziel \& M. A. Malden (Eds.). (check) USA: Blackwell Publishing.

Hanson, R. (2006). Identity and Memory. Transcribing Oral Histories of Plant Animism in the Upper Amazon, Master's degree thesis, USA: University of Kansas, p.14-15.

Hanoteau, A. \& Letourneux, A. (1893). La Kabylie et les coutumes Kabyles, [Kabylia and Kabyles' costumes]. Paris, France: Challamel Ed.

Holman Jones, S. (2005). Auto-ethnography: Making the personal political. Handbook of qualitative research, Norman K. Denzin \& Yvonna S. Lincoln (Eds.). Thousand Oaks, CA, USA: Sage, p.763-791. 
How, A. (2003). Critical Theory. Tradition in Social Theory, series editor Ian Craib. New York, USA: Palgrave Macmillan.

Jardin, Y. \& Rekacewicz, P. (1994). Les Berbères en Afrique du nord [Berbers in North of Africa], as retrieved from http://www.monde-diplomatique.fr/cartes/berberes1994

Josselson, R. (2007). Ethical attitude in Narrative Research, Principles and Practicalities, Handbook of narrative Inquiry: Mapping a methodology, Sage Publications Ltd., p.537566.

Kim, B. (2001). Social constructivism. In M. Orey (Ed.), Emerging perspectives on learning, teaching, and technology, as retrieved from:

http://www.coe.uga.edu/epltt/SocialConstructivism.htm.

Lacoste-Dujardin, C. (1970). Le conte Kabyle: Étude ethnologique [The Kabyle tale: Ethnological study]. Paris, France: François Maspero Edition.

Lacoste-Dujardin, C. (1984). Genèse et évolution d'une représentation géopolitique:

L'imagerie Kabyle à travers la production bibliographique de 1840 à 1891, [Genesis and evolution of a geopolitical representation: The imagery Kabyle through the bibliographical production of 1840 to 1891]. Connaissances du Maghreb, Paris, France: CNRS Edition, p. 257-277.

Lacoste-Dujardin, C. (1999). Une intelligentsia Kabyle en France: Des artisans d'un “pont transméditerranéen" [A Kabyle intelligentsia in France: Craftsmen of a transmediterranean bridge]. Paris, France: Hérodote, 94 (3), p.37-45.

Lacoste-Dujardin, C. (2001). Géographie culturelle et géopolitique en Kabylie. La révolte de la jeunesse kabyle pour une Algérie démocratique [Cultural geography and geopolitics in Kabyle: The revolt of Kabyle youth for a democratic Algeria]. Paris, 
France: Hérodote, 103 (4), p.57-91.

Liu, C. H. and Matthew, R. (2005). Vygotsky's philosophy: constructivism and its criticism examined, International education journal, Shannon Research Press, p.386-399.

Maguire, M. (2006). Auto-ethnography: Answerability/Responsibility in Authoring Self and Others in Social Sciences/Humanities, Forum: Qualitative Social Research, vol. 7, no.2, Art. 16, as retrieved from: http://www.qualitativeresearch.net/index.php/fqs/article/view/106/221.

Mahé, A. (1998). Violence et médiation. Théorie de la segmentarité ou pratiques juridiques en Kabylie [Violence and Mediation. Segmentarity Theory or juridical practices in Kabylia], Genèses, 32, as retrieved from:

http://www.persee.fr/web/revues/home/prescript/article/genes_11553219_1998_num_32_1_1523, p.51-65.

Makareti, (1986). The Old-Time Māori, New Women's Classics. Auckland, New Zealand.

Makilam, (2000). Magie des femmes Kabyle et l'unité de la société traditionnelle [Magic of Kabyle Woman and Unity of the Traditional Society]. Paris, France: Edisud.

Makilam (2007), Symbols and Magic in the Art of Kabyle Woman, translated from French by Elysabeth Corp. Francophone Culture and Literatures; V. 52, New York, USA: Peter Lang Publishing, Inc.

Mammeri, M. (1990). Tajerrumt N Tmazight (Tantala Taqbaylit). Algiers, Algeria : Bouchene Edition.

Mammeri, M. (1984). L'ahellil du Gourara [The Ahellil from Gourara]. Paris, Fondation des sciences de l'Homme Ed. 
Mammeri, M. (1996). Contes Berbères de Kabylie [Berber tales from Kabylia], Paris, France: Pocket junior Edition.

Marcuse, (1973 [1941]). Reason and Revolution: Hegel and the Rise of Social Theory. London, UK: Routledge and Kegan Paul Ltd.

McCabe, B. (2009, September 23). The storytellers: 27 writers on 27 short stories from 27 authors. Baltimore City Paper. Retrieved from: http://www2.citypaper.com/arts/story.asp?id=19001

Mead, H.M. (2003). Tikanga Māori: Living by Māori Values. Wellington, New Zealand: Huia Publishers.

McLaren, P., Giroux, H (1997). Writing from the margins: Geographies of Identity, pedagogy and power. Revolutionary multiculturalism, Pedagogy of dissents from the new millennium, Boulder, CO, USA: Westview Press, p.16-41.

McLeer, A. (Winter 1998). Saving the Victim: Recuperating the Language of the Victim. Reassessing Global Feminism, Hypuatia vol. 13, no. 1.

McMahon, M. (1997, December). Social Constructivism and the World Wide Web - A Paradigm for Learning, Paper presented at the ASCILITE conference, Perth, Australia.

McNiff, J. (2007). My story is my living educational theory, Handbook of Narrative Inquiry, Mapping a methodology. Sage publication Inc. chap 12, p. 315.

McPeck, J.E. (1981). Critical Thinking and Education. Oxford, UK: Martin Robertson.

Melhenni, F. (2004). Algérie: la question Kabyle [Algeria: The Kabyle question], Essai. Paris, France: Édition Michalon. 
Meynier, G., (2007). L'Algérie des origines. De la préhistoire à l'avénement de l'islam [The original Algeria, From prehistoric times to the advent of Islam]. Paris, France: Edition La Découverte.

Mohanty, C.T. (1991). Under Western eyes: Feminist scholarship and colonial discourses, Third world women and the politics of feminism. Bloomington, USA: Indiana University Press.

Mohanty, C. T. (2001). Introductory lecture at the Anti-racist Feminist Institute, Ontario Institute for Studies in Education. University of Toronto, ON, Canada.

Mohia-Navet, N. (2008). L'expérience de terrain, Pour une approche relationnelle dans les sciences sociales [Field experience, For a relational approach to social sciences], Terrains anthropologiques, Paris, France: La Découverte Edition.

Mohia-Navet, N. (1993). Les thérapies traditionnelles dans la société Kabyle, pour une anthropologie [Traditional therapy in Kabyle society, for an psychoanalytical anthropology]. Paris, France: L’Harmattan Edition.

Neuman, L. (2005). Social research methods: quantitative and qualitative approach. Boston, Mass; London, UK: Allyn and Bacon, $6^{\text {th }}$ Edition.

O'Reilly, S. (2000). She's still on my mind: Teachers' memory-work and self-study. Unpublished Doctoral Dissertation, Department of Integrated Studies in Education, McGill University, Montreal, Canada.

Ouellet, F. (2006, Spring). Socioconstructivisme et enseignement collegial [Socioconstructivism and Collegial education], Pédagogie collégiale [Collegial pedagogy], vol. 19, $n^{\circ}$, Quebec, Canada: Sherbrooke University Press. Péguy, C. (1993). Notre jeunesse [Our Youth]. Folio Essai, Paris, Editions Gallimard. 
Penetito, W. (2002). Research and context for a theory of Maori schooling, McGill Journal of Education, vol.37, (1), Montréal, Canada, p.89-110.

Phoenix, A. (2008). Analyzing narrative contexts, Doing narrative research, in Molly Andrews, Corinne Squire \& Maria Tamboukou (Eds.)London, UK: Sage Publications. p. 64-77.

Polanyi, M. (1961). “Knowing and being”, Mind, Vol. 70 (280), Oxford, UK: Oxford University Press, p.458-70.

Polkinghorne, D.E. (1988). Narrative knowing and the human science. New York, USA: State University of New York Press.

Poulos, C.N. (2008). Accidental ethnography: An inquiry into family secrecy. Walnut Creek, CA, USA: Left Coast Press.

Poyto, R. (1967). Contribution à létude des sites préhistoriques en pays Kabyle: notes d'exploration (1963-1967) (Contributions to the study of Prehistorical sites in Kabyle Country: Notes of exploration (1963-1967)), Fort National, Algeria: Ed. F.D.B.

Pratt, M.L. (1992). Imperial eyes: Travel writing and transculturation. London: Routledge.

Price, J. (1996). Snakes in the swamp: Ethical issues in qualitative research. Ethics process in the narrative study of lives, Edition, Thousand Oaks, CA, USA: Sage. p.207-215.

Punch, M. (1994). Politics and Ethics in Qualitative Research, Handbook of qualitative research, N. Denzin \& Y. Lincoln (Eds.). Thousand Oaks, CA, USA: Sage. p.83-98. Rigney, L-R. (1999). Internationalization of an Indigenous Anticolonial Cultural Critique of Research Methodologies: A Guide to Indigenist Research Methodology and Its Principles. Wicazo Sa Review, Minneapolis, USA: Univ ersity of Minnesota Press, p.109-121. 
Rinn, L. (1884). Marabouts et Khouans: Étude de l'Islam Algérien [Marabouts and Khouans: Study of Islam in Algeria], Algiers, Algeria: Adolphe Jourdain Ed.

Roof, W.C. (1993). Religion and Narrative. Review of religious research 34, Religious research association Inc, p.297-310.

Roth, W.M. (2009). Auto/Ethnography and the question of ethics. [22 paragraphs]. Forum Qualitative Sozialforschung/Forum : Qualitative Social Research, 10(1). Art. 38. As retrieved from: http://nbn-resolving.de/urn:nbn:de:0114-fqs0901381

Said, E.W. (2000). Out of Place: A Memoir. New York, USA: Knopf Edition.

Said, E.W. (2004). Power, Politics and Culture: Interviews with Edward W. Said and Gauri Viswanathan. London, UK: Bloomsbury.

Sayad, A. (1991). L'immigration ou les paradoxes de l'altérité [Immigration or the paradoxes of alterity]. Bruxelles, Belgium: Editions Universitaires [Academic editions] De BoeckWesmael.

Shirinian, I. (2000). Writing and memory: The search for home in Armenian diaspora literature as cultural practice. Kingston, Ontario, Canada: Blue Heron Press.

Silverstein, P. (Dec. 2003). De l'enracinement et du déracinement [From rooting to uprooting], Act de la Recherche en Science Sociales [Act of the research in Social Sciences]. Vol. 150, N1, p.27-42.

Smith, G. H. (1992). Research Issues Related to Maori Education, Research Unit for Maori Education, University of Auckland.

Smith, L.T. (1999) Decolonising Methodologies: Research and Indigenous Peoples. Dunedin, New Zealand: Zed Books, New York, and Otago University Press. 
Stora, B. (2010). Le nationalisme Algérien avant 1954 [Algerian nationalism before 1954]. Paris, France: CNRS Edition.

Taylor, C. (1994). 'The Politics of Recognition', Re-examining the Politics of Recognition., Princeton, USA: Princeton University Press, p.25-73.

Tillmann, L. M. (2009). Body and bulimia revisited: Reflections on "A Secret Life." Journal of Applied Communication Research, 37(1), p.98-112.

Tolish, M. (2010). A critique of current practice: Ten foundational guidelines for autoethnographers, as retrieved from: http://qhr.sagepub.com/content/20/12/1599.

Toyosaki, S.; Pensoneau-Conway, S. L.; Wendt, Nathan A. \& Leathers, Kyle. (2009). Community auto-ethnography: Compiling the personal and resituating whiteness. Cultural Studies - Critical Methodologies, 9(1), p.56-83.

Trask, H.K. (1996, Summer). Feminism and Indigenous Hawaiian Nationalism, Feminist Theory and Practice, Signs, Vol. 21, No. 4. Chicago, USA: The University of Chicago Press, p.906-916.

Shaw, G.B. (1946). Saint Joan: A Chronicle Play in Six Scenes and an Epilogue. London, UK: Penguin Books.

Spry, T. (2011). Performing Auto- ethnography: An Embodied Methodological Praxis, Qualitative Inquiry, St. Uichol, K. (2000). Indigenous, cultural, and cross-cultural psychology: A theoretical, conceptual, and epistemological analysis, Asian Journal of Social Psychology, p 265-287.

Weber, M. (1978 [1972]). Economy and Society: An outline of interpretive sociology. Los Angeles, USA: University of California Press. 
Wertsch, J.V. (1991). Voices of the mind: A socio-cultural approach to mediated action. Cambridge, MA, USA: Harvard University Press.

Whariki Research Group, (2005). Collaborative research with Maori on sensitive issues: the application of Tikanga and Kaupapa in research on Maori Sudden Infant Death Syndrome, Special Policy Journal of New Zealand te Puna Whakaaro, Retrieved from http://www.msd.govt.nz/about-msd-and-our-work/publications-resources/journals-andmagazines/social-policy-journal/spj25/collaborative-research-with-maori-on-sensitiveissues-25-pages88-104.html

Whitehead, (1929). The Aims of Education. New York, USA: MacMillan.

Yacine, T. (1988). Poésie Berbère et Identité [Berber poetics and Identity], Qasi Udifella, Hérault des At Sidi Braham [Qasi Udifella hero of the Sidi Braham]. Paris, France: Maison des sciences de l'Homme, [House of Human Sciences].

Yacine, T. (1989). Ait Menguellet chante [Ait Menguellet sings]. Paris, France: La Découverte Edition.

Yaghejian, A. (2002). From both sides of a border, writing home: The auto-ethnography of an Armenian-Canadian. Unpublished Master's Thesis, Department of Integrated Studies in Education, McGill University, Montreal, Canada.

Yanchar S.C. and Williams D.D. (2006). Reconsidering the compatibility thesis and electicism: Five proposed guidelines for method use, Educational researcher, vol. 35, No. 9, p.3-12.

Young, S.L. (2009). 'Half and Half: An (Auto) ethnography of Hybrid Identities in a Korean American Mother-Daughter Relationship', Journal of International and Intercultural Communication, 2: 2, p.139-167. 
Zine, J. (2004, Fall). Creating a Critical Faith-Centered Space for Antiracist Feminism: Reflections of a Muslim Scholar, Journal of Feminist Studies in Religion, 20, (2), Bloomington, IN, USA: Indiana University Press on behalf of FSR Inc., p. 167-187. 


\section{MEMORANDUM \\ Phone $\quad$ 0-4-463 5676 \\ Fax 0-4-463 5209 \\ Email_Allison.kirkman@vuw.ac.nz}

\begin{tabular}{l|l}
\hline TO & Belkacem Taieb \\
\hline COPY TO & Wally Penetito, Robin Averil \\
\hline FROM & Dr Allison Kirkman, Convener, Human Ethics Committee \\
\hline
\end{tabular}

\begin{tabular}{l|l}
\hline DATE & 20 October 2010 \\
\hline PAGES & 1 \\
\hline
\end{tabular}

SUBJECT Ethics Approval: No 17972 An auto-ethnography of cultural recovery through a healing pedagogy: The story of an Indigenous man from the DjurDjura mountains of Kabylie

Thank you for your application for ethical approval, which have now been considered by the Standing Committee of the Human Ethics Committee.

Your application has been approved from the above date and this approval continues until 1 October 2011. If your data collection is not completed by this date you should apply to the Human Ethics Committee for an extension to this approval.

Best wishes with the research.

Allison Kirkman

Human Ethics Committee 


\section{Information sheet for Participants}

Research Project: An auto-ethnography of cultural recovery through a healing pedagogy: The story of an Indigenous man from the DjurDjura mountains in Kabylie.

Salam Aleikum, Azul fellawen,

This consent letter asks for your participation in the study described below.

My name is Si Belkacem TAIEB. I grew up in France where I was socialized in French and received my early education in French schools. However I got taught our Berber traditions as well, first in my family but also living in a Kabyle Diaspora and going to Algeria every summer from my birth and for more than 35 years.

I have worked in education in Canada for the past 10 years. I am currently working on my doctoral studies at the Victoria University in Wellington, New Zealand. My proposed inquiry involves exploring the place of our ancestors, Ou L'Hadj and our Kabyle heritage to think of an appropriate education for us today.

I aim to explore, in my own Berber auto-ethnography through a participatory action research, my specific case of cultural recovery. That culture is mine; it is the culture of Berber people from the Djur Djura mountains in Algeria. I aim to reflect on the possibility of developing emancipating teaching practices and philosophy inspired by indigenous cultures, indigenous teachings, and, particularly, on a Kabyle way of life. I invite your participation in my project. 
1. To engage in informal conversations about the story of our ancestor.

2. To explain to me the social organization of our village.

3. To allow me to participate in moments of the village's everyday life.

4. To share family stories with me.

5. To help me understand our place in the global Kabyle landscape today

I will respect the protocols as well as the social traditions of our community. This research does not seek to modify the traditions but to create a context for reconnecting me by speaking directly to you.

In everyday activities, I would like to understand our heritage with people from the village but living in or outside the village. I would like to experience Kabyle culture today. From informal communication I invite you to share your perceptions, views, and stories about your personal educational experience of our ancestor and our culture.

I would like to videotape and or audio taped some of our conversations.

Your participation is voluntary. If you don't want to be audio taped or video taped I will respect your wishes.

You will be able to check for accuracy and choose to add or delete any information. I am doing that research with approval of the ethics committee of Victoria University in Wellington. From that research I will be writing a $\mathrm{PhD}$ thesis and it will be available to you on your request. We will be able to find the origins of the beliefs in our village and their connection with the society today. We will as well be able to position ourselves in the debate around the legitimacy of the Marabout in Kabylie. An extended outcome of that research will be to allow us to understand our history and context and work for the protection and transmission of our cultural heritage.

It would be an honor and a privilege to work with you in this research endeavor. Respectfully, Tanmirth, 
Si Belkacem TAIEB

Work: (00 64) 02102675092

Email: belkacemtaieb@gmail.com
Signature:

in Algeria: (00 213) 557260197

Supervisors:

- Wally Penetito (PhD), Professor of Maori Education, Faculty of Education, Victoria University of Wellington, Wellington, New Zealand. Email: wally.penetito@vuw.ac.nz - Dr. Mary H. Maguire, Faculty of Education, McGill University, Montréal, Québec, Canada. E-mail: mary.maguire@mcgill.ca

Statement of informed consent

I, the participant, understand my participation in this research project is voluntary and I can withdraw at any time without consequence.

I understand that my participation involves answering questions, or being audio or video taped

I understand that my anonymity will be respected.

Participant

Name:

Signature: 


\section{Consent form for Participants}

Research Project: An auto-ethnography of cultural recovery through a healing pedagogy: The story of an Indigenous man from the DjurDjura mountains in Kabylie.

I have read Belkacem TAIEB introductory letter, which explains this research project, and I agree to participate in the project. I understand that:

- Names of the participants will remain confidential to the researcher.

- Participant can ask for their name to be given but the researcher will do his best to keep the document anonymous.

\section{$\mathrm{O}$}

- Participants can choose to withdraw consent for their participation in this research without having to give a reason, up to and including the final point of data collection .

- The interviews will be audiotaped, videotaped and then written-up. Following the Interviews, participants will be offered the opportunity to view transcripts of the conversations to enable them to check for accuracy.

- Data collected will be seen only by the researcher, the PhD supervisors and a typist, and will be stored securely in a locked cabinet in a locked room at Victoria University of Wellington.

- Research findings may be published and will be shared with the Berber and academic community and other interested people, but individuals will not be identifiable.

- Useful information from the study will be shared on request with participants in the form of a thesis.

- The method and place to send a copy of the thesis will have to be discussed specifically with interested participants because of mail delivery issues. 
- I understand my participation in this research project is voluntary and I can withdraw at any time without consequence before the $1^{\text {st }}$ of September 2011.

Name (please print):

Signature:

Date $(\mathrm{d} / \mathrm{m} / \mathrm{y})$ :

PhD student:

Si Belkacem TAIEB

Work: (00 64) 02102675092

Email: belkacemtaieb@gmail.com

Supervisors:

- Wally Penetito (PhD), Professor of Maori Education, Faculty of Education, Victoria University of Wellington, Wellington, New Zealand. Email: wally.penetito@vuw.ac.nz - Dr. Mary H. Maguire, Faculty of Education, McGill University, Montréal, Québec, Canada. E-mail: mary.maguire@mcgill.ca in Algeria: (00 213) 557260197 


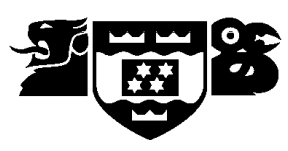

\section{HUMAN ETHICS COMMITTEE}

\section{Application for Approval of Research Projects}

Please write legibly or type if possible. Applications must be signed by supervisor (for student projects) and Head of School

Note: The Human Ethics Committee attempts to have all applications approved within three weeks but a longer period may be necessary if applications require substantial revision.

\section{NATURE OF PROPOSED RESEARCH:}
(a) Staff Research
Student Research $\bigotimes \quad$ (tick one)
(b) If Student Research
Degree PHD
Course Code
(c) Project Title: An auto-ethnography of cultural recovery through a healing pedagogy: The story of an Indigenous man from the DjurDjura mountains in Kabylie.

\section{INVESTIGATORS:}

(a) Principal Investigator

\begin{tabular}{|l|l|}
\hline Name & BELKACEM TAIEB \\
\hline e-mail address & belkacemtaieb@gmail.com \\
\hline School/Dept/Group & $\begin{array}{l}\text { Faculty of Education, te Kura Maori, Victoria university } \\
\text { Wellington }\end{array}$ \\
\hline
\end{tabular}

(b) Other Researchers

Name

Position

(c) Supervisor (in the case of student research projects)

Wally Penetito

te Kura Maori

\section{DURATION OF RESEARCH}

(a) Proposed starting date for data collection September $1^{\text {st }} 2010$

(Note: that NO part of the research requiring ethical approval may commence prior to approval being given)

(b) Proposed date of completion of project as a whole October 1 ${ }^{\text {st }}, 2011$ 

CONSIDERATIONS

(a) Sources of funding for the project

Please indicate any ethical issues or conflicts of interest that may arise because of sources of funding

e.g. restrictions on publication of results

Phd scholarship and personal investments

(b) Is any professional code of ethics to be followed

$\mathrm{Y} \bigotimes \mathbf{N}$

If yes, name Local general code of ethics decided in Tadjmait (meeting) by the elders but no reference to international professional code of ethic as none have been decided on that topic with the people of the village.

(c) Is ethical approval required from any other body

If yes, name and indicate when/if approval will be given

\section{DETAILS OF PROJECT}

Briefly Outline:

(a) The objectives of the project

I aim to explore, in a Berber auto-ethnography done through participatory action research, a specific case of cultural recovery. That culture is mine; it is the culture of Berber people from the Djur Djura mountains in Algeria. Based on work already completed in my masters degree "Education as a healing process", the objectiveS of tha project are:

- To reflect on the possibility of a feasible and transformative pedagogy that is based on indigenous cultures, indigenous teachings, and, particularly, on a Kabyle way of life.

- To write this research as an auto-ethnography in order to inscribe my self into my culture.

- To highlight the path of recovery I am taking to support future work by indigenous scholars.

- To serve as a document of reference that will help understand the context, the mechanism, the political and sociological issues of such a project.

- To write a personal experience that is a pedagogical instrument that will contribute to the larger discussion of appropriate Indigenous pedagogies.

- To support the development of a pedagogy for indigenous people that develops a self awareness.

-To develop a consciousness of the processes of identity that will support the learning of a metacognitive indigenous identity-building in an indigenous world. 
b) Method of data collection

The actual "auto" part of the research is a set of writings of my own experience in the context of my culture. I am not going to be conducting any direct interviews but I will be looking at answers to some guiding questions to explore the knowledge and experience of my family and community on the topic of my research.

For example I expect to be working with one male elder of one of the 4 families that represent the village.

Here are some of the questions that will form the basis of the interview:

What do you know about your ancestor?

What values form your inherited family story is still important for you?

Living in cities today how did tradition change or adapt?

How important is your heritage for you today?

What do you wish to pass on?

How do you wish to pass it on to the coming generations?

What do you think of the place of your heritage in the world today?

Those questions taking place in an indigenous culture indicate the general outline of questions that will be asked but for different reasons cultural as well as political they can not be asked directly like that. I will more look for the answers in the story being told. Asking direct questions taking a position of authority would not be seen as respectful of the elders and would raise a sensibility that might alter the relationship and level of trust and openess with the researcher.

In my master's, I used Narrative Inquiry as a method for my research. Located in an oral tradition, a research project within Berber culture means conversations, field work, exchanges with elders and a lot of informal communication. In that regard, Narrative Inquiry seems to be the best appropriate way to undertake research work in my community. It is a story based research methodology and it will stay in the cultural location of the study. It will be situated within the berber local culture.

My cultural location also needs a holistic method to acknowledge the individuals, the knowledge, and the relationship in the same time as the spirit of the situation. Narrative inquiry is driven by the idea that things are interconnected and they are to be considered as a whole to be understood completely.

In this type of research I will keep coming back to the processes, the knowledge and the relationship, keeping a reflective approach to the experience . It is a spiral approach to research. This can be accomplished through the careful use of both computer and paper based records, a field and reflective log, careful organization of the material and respect for the confidentiality of the knowledge gathered as well as the relationship and bounds created with the community. The research will be conducted with culturally appropriate informed consent.

(c) The benefits and scientific value of the project

As a Berber researcher I want to reconnect myself to my heritage. This program of research looks at formal and informal Berber education in order to address questions of citizenship, cultural exchange, language and culture teaching, and on a larger scale Indigenous cultures and values. I plan to approach intercultural relations, looking for aspects that allow intercontextuality respectful of the diversity of Algeria. In the practical frame of the rhetoric of diversity, I plan to move from a philosophy of cultural denial and oppression to a philosophy of diversity and equity. This will contribue in the 
development of educational policies of equity and will support the development of pedagogy of diversity and human ecological integrity.

Praxis of the research:

This indigenous research engages an indigenous person in the protection of his own identity and dignity by taking on the responsibility for his own evolution and the values that belong to him and that he inherited from his ancestors.

\section{Practically speaking:}

This pedagogy is not a pedagogy of decolonization that confuses the struggle for identity with an identity in itself. I intend to write an applied pedagogy of independence, one that breaks free from colonial and/or postcolonial pedagogies and the rhetoric of industrialization and globalization, and that does not use critical pedagogy to replace indigenous claims and identity. It works in ways that are outside of critical pedagogy and development philosophy, and it teaches spiritual awakening as a way to sense the world and to learn.

\section{(d) Characteristics of the participants}

This is an auto-ethnography centered on research in my family village. The village is built around the grave of its founder, my ancestor, a spiritual leader. This is where the research starts. From that we move to the first circle of people who are directly related to him. They are my close relatives and I am part of that first circle, all descendants of one of his four sons.

Even if the village seems physically empty at certain times of the year we are still connected and it is from that connection that I will learn.

Then we move on to the next circle that includes the mountains and the people living there, most of them not related to the same ancestor but living in the language and culture. Going all the way down the mountain we move to the valley and get involved with other people but also with more public administration, like government, public libraries, foreign scholars etc... On a specific level I will deal with 4 families in the village, starting with mine, with my father and my uncle, who are both directly involved in my education, but I will also learn through my mother's family, from my mother and grand mother who have gone into the other world. I will, as well, get involved with active members of Berber associations and research from different background and countries, mainly in France and Algeria. Participants will be aged from 21 to 80 years old.

(e) Method of recruitment

This is my own ancestor's village and the key participants, my close family, have already agreed to participate. I will gain access to them sharing their everyday life but also special gathering moments. I will work with the people according to their connection with our main sacred ancestor, the founder of the village, and with the role they play in my education. My recruitment will also be informed by the role people play in keeping the traditions alive in the village. I will be looking for the paticipants in village meetings. Further interviews will result from the previous ones like a snow ball effect. I will also work with people I met, going to previous community work, like the building of a cemetery, bringing water into the houses, etc... I will contact them by word of mouth on the mountain, by phone or personal invitation but I will mainly work with the people who still live in the village.

(f) Payments that are to be made/expenses to be reimbursed to participants 
In general this work does not involve payment. However as my father is the key to the knowledge being looked at I might need to support him in coming back to the traditional places with me. In the village gatherings are moments of celebration also, so this means providing for the village to support the workers and participants... At appropriate times I may provide gifts to show respect to the tradition.

(g) Other assistance (e.g. meals, transport) that is to be given to participants

My contribution will include volunteer work and offerings to the village and ancestor, like the sacrifice of a sheep, money or flour. Eventhough my research is essentially based on Berber it is done on other indigenous lands like turtle Island (North of America) or Aotearoa (New Zealand). LEAVE THE MAORI PART OUT OF ETHICS I will give a Koha (donation) in Maori locations to recognize and honor their support to do my research and the use of the land. My experience of native American culture is much deeper and is today a part of my personal phlosopohy as such it will be present in my reseach. I will honor these teachings by respecting the protocols of transmissions and teaching with offering of tobacco. I will also before the sharing, smudge with sage, cedar, sweet grass before attempting to native american meetings...

(h) Any special hazards and/or inconvenience (including deception) that participants will encounter

There will be no use of deception in this work.

The research will probably raise psychological tensions due to difficult memories coming back to participants, but as the work will be done with the community it will be supported in community healing systems. The participants may fear that they are being asked to betray their people and give away family stories but they will be informed that their sharing will stay with the researcher a paticipating member of the family and they will always have the choice to share or not.

The ideas/informations might be shared but people will stay anymous.

Consent will mainly be obtained orally. When recorded it will appear on tape or camera.

A consent form will be handed to them to sign as a choice if they consider it appropriate.

However the reasearch is very positive for the community. It will actually bring back members of the community and in fact would possibly support the coming to consciousness of cultural heritage. It might be difficult for some participants to understand what is happening as there are not many academics in the village but I will be as transparent and clear as possible within the limits of the ethical implications of the project.

(i) State whether consent is for:

\begin{tabular}{|ll|ll|}
\hline (i) & the collection of data & $\mathbf{Y}$ & $\mathbf{N} \square$ \\
\hline (ii) & attribution of opinions or information & $\mathbf{Y}$ & $\mathbf{N}$ \\
\hline (iii) & release of data to others & $\mathbf{Y}$ & $\mathbf{N} \square$ \\
\hline (iv) & use for a conference report or a publication & $\mathbf{Y} \square$ & $\mathbf{N} \square$ \\
\hline (v) & use for some particular purpose (specify) & $\mathbf{Y} \square$ & $\mathbf{N}$ \\
\hline
\end{tabular}

The result of the research will be a source of information restoring the origins of the village and the real story of the ancestor and it will be passed on to the population as a booklet, a movie, an exhibit, or maybe as a seminar or conference during gatherings like "Tachourt" (gathering with offerings to the village), or participation in diverse ways like conferences or meetings in France organised by "La 
Federation des Berbères de France" per example, or conferences on the Kabyle situation in Uquam (Université du Québec à Montréal). Written notes will be available all year long but kept by a trustee chosen in the community.

Another way of sharing is to facilitate the meeting of all the different participants concerned by the research, allowing them to be involved in all the dimensions of the study.

The release of data to the Other is for the use of the data for analysis but not the divulgation of any name.

Attach a copy of any questionnaire or interview schedule to the application

(j) How is informed consent to be obtained (see sections 4.1, 4.5(d) and 4.8(g) of the Human Ethics Policy)

(i) the research is strictly anonymous, an information sheet is supplied and informed consent is implied by voluntary participation in filling out a questionnaire for example (include a copy of the information sheet) $\quad \mathrm{Y} \square \mathrm{N} \bigotimes$

(ii) the research is not anonymous but is confidential and informed consent will be obtained through a signed consent form (include a copy of the consent form and information sheet) $\quad Y \square N \triangle$

(iii) the research is neither anonymous or confidential and informed consent will be obtained through a signed consent form (include a copy of the consent form and information sheet) $\quad \mathrm{Y} \square \mathrm{N}$ \

(iv) informed consent will be obtained by some other method (please specify and provide details)

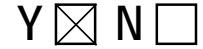

This research is not anonymous to me for reasons given above. First because I am the participant and I am sharing my own story. It is conducted in my own family and community.

However I will take the greatest care to insure that information received from one participant will not be shared with anybody during the research process. I will not communicate the name of any participants in the research and the outcomes will be presented in the form of a PhD dissertation relating the experience as a result.

The informed consent will be received from participant in culturally appropriate forms, such as audio tape recording of response. The investigator will not be giving names unless asked by the participants. A written consent form will be signed by participants who wish to have their names published.

I will be using a qualitative method of interviews therefore there will not be any premade sets of questions but I will write a description of the main line of inquiry on the top of the consent form. I will share that information also with people who don't want to sign consent form.

With the exception of anonymous research as in (i), if it is proposed that written consent will not be obtained, please explain why

Sharing stories will be appropriate but any political/religious conversations and/or other that will inform the research will have to be anonymous as it could have negative repercussion on participants, including myself in Algeria.

I will respect the context of the indigenous society where the knowledge comes from. 
(k) If the research will not be conducted on a strictly anonymous basis state how issues of confidentiality of participants are to be ensured if this is intended. (See section 4..1(e) of the Human Ethics Policy). (e.g. who will listen to tapes, see questionnaires or have access to data). Please ensure that you distinguish clearly between anonymity and confidentiality. Indicate which of these are applicable.

(i) access to the research data will be restricted to the investigator

$$
\mathrm{Y} \bigotimes \mathbf{N} \square
$$

(ii) access to the research data will be restricted to the investigator and their supervisor (student research)

(iii) all opinions and data will be reported in aggregated form in such a way that individual persons or organisations are not identifiable $\quad \mathrm{Y} \square \mathrm{N}$ \

(iv) Other (please specify)

Unless required by the participant him or herself and regarding his/her own participation, research data will be restricted to the investigator during the time of research but then given back to the participant concerned after research is done. In some locations it might be difficult or sensitive to share data collection as it might influence further interviews. All this will be made clear to the participant plus I will receive their approval through the appropriate form of consent.

(I) Procedure for the storage of, access to and disposal of data, both during and at the conclusion of the research. (see section 4.12 of the Human Ethics Policy). Indicate which are applicable:

(i) all written material (questionnaires, interview notes, etc) will be kept in a locked file and access is restricted to the investigator $\quad Y \bigotimes N \square$

(ii) all electronic information will be kept in a password-protected file and access will be restricted to the investigator

(iii) all questionnaires, interview notes and similar materials will be destroyed:
(a) at the conclusion of the research
$\mathrm{Y} \square \mathrm{N}$ Х

or (b) years after the conclusion of the research

$Y \square N \bigotimes$

(iv) any audio or video recordings will be returned to participants and/or electronically wiped

$\mathrm{Y} \square \mathrm{N} \bigotimes$

(v) other procedures (please specify):

If data and material are not to be destroyed please indicate why and the procedures envisaged for ongoing storage and security

All material not destroyed will be kept safely by the investigator. Because it is an auto-ethnography I will keep it as part of my on going reflection.

(m) Feedback procedures (See section 7 of Appendix 1 of the Human Ethics Policy). You should indicate whether feedback will be provided to participants and in what form. If feedback will not be given, indicate the reasons why. 
As it will be a participatory action research, feedback will be actually in the participation itself in all kind of forms according to the type of work done with and by the participants. It could be meeting minutes or pictures or even movies and/or songs or simply informal conversations.

(n) Reporting and publication of results. Please indicate which of the following are appropriate. The proposed form of publications should be indicated on the information sheet and/or consent form.
(i) publication in academic or professional journals
$Y \bigotimes N$
(ii) dissemination at academic or professional conferences
$\mathrm{Y} \bigotimes \mathrm{N}$
(iii) deposit of the research paper or thesis in the University Library (student research)
Y $\mathrm{N}$

(iv) other (please specify) 
Signature of investigators as listed on page 1 (including supervisors) and Head of School.

NB: All investigators and the Head of School must sign before an application is submitted for approval

\begin{tabular}{|l|l|}
\hline & Date \\
\hline Date \\
\hline Date \\
\hline
\end{tabular}

Head of School:

Date 


\section{APPLICATIONS FOR HUMAN ETHICS APPROVAL}

\section{CHECKLIST}

- Have you read the Human Ethics Policy?

- Is ethical approval required for your project?

- Have you established whether informed consent needs to be obtained for your project?

- In the case of student projects, have you consulted your supervisor about any human ethics implications of your research?

- Has your supervisor read and signed the application?

- Have you included an information sheet for participants which explains the nature and purpose of your research, the proposed use of the material collected, who will have access to it, whether the data will be kept confidential to you, how anonymity or confidentiality is to be guaranteed?

- Have you included a written consent form?

- If not, have you explained on the application form why you do not need to get written consent?

- Are you asking participants to give consent to:

- collect data from them

- attribute information to them

- release that information to others

- use the data for particular purposes

- Have you indicated clearly to participants on the information sheet or consent form how they will be able to get feedback on the research from you (e.g. they may tick a box on the consent form indicating that they would like to be sent a summary), and how the data will be stored or disposed of at the conclusion of the research?

- Have you included a copy of any questionnaire or interview checklist you propose using?

- Has your application been seen by the head of your school or department (or the person given responsibility to consider applications on behalf of the head (see section 4.5(b) of the Human Ethics Policy).

PLEASE FORWARD YOUR COMPLETED APPLICATION FORM TO THE SECRETARY, HUMAN ETHICS COMMITTEE OR, IN THE CASE OF APPLICATIONS FROM SCHOOLS OR DEPARTMENTS WITH AN APPROVED ETHICS SUB-COMMITTEE, TO THE CONVENER OF THAT SUBCOMMITTEE 